Aus dem Department für Endokrinologie

(Prof. Dr. med. W. Wuttke)

der Medizinischen Fakultät der Universität Göttingen

\title{
Analyse des Effekts von $\beta$-Ecdyson auf die histologische Struktur der proximalen Tibia von gonadektomierten Sprague-Dawley-Ratten
}

\author{
INAUGURAL - DISSERTATION \\ zur Erlangung des Doktorgrades \\ der Medizinischen Fakultät \\ der Georg-August-Universität zu Göttingen \\ vorgelegt von \\ Nanne Carolin Coors \\ aus \\ Walsrode
}

Göttingen 2010 
Dekan: Prof. Dr. med. C. Frömmel

I. Berichterstatter: Prof. Dr. med. W. Wuttke

II. Berichterstatter: Prof. Dr. med. Hüfner

III. Berichterstatter/in:

Tag der mündlichen Prüfung: 16.11.2010 


\section{Inhaltsverzeichnis}

Inhaltsverzeichnis

\section{I.1) Knochen}

I.1.1) Anatomie des langen Röhrenknochens

I.1.2) Physiologie des Knochens

I.1.3) Bedeutung der Geschlechtshormone für den Knochen

I.2) Pathologie des Knochens am Beispiel der Osteoporose

I.2.1) Osteoporose der Frau

I.2.2) Osteoporose des Mannes

I.2.3) Bedeutung des Knochenmarks für die Osteoporose

I.2.4) Therapie der Osteoporose

I.3) Die gonadektomierte Ratte als tierexperimentelles Modell der Osteoporose

I.3.1) Die weibliche ovariektomierte Ratte

I.3.2) Die männliche orchidektomierte Ratte

I.3.3) Lokalisations-abhängige Knochenveränderung in der Rattentibia nach Gonadektomie

I.4) Die Testsubstanz $\beta$-Ecdvson als ein Hauptvertreter der Ecdvsteroide

I.4.1) Ecdysteroide im Allgemeinen

I.4.2) $\beta$-Ecdyson im Speziellen

I.5) Fragestellung und Studienziel

II.1) Allgemeines zur Haltung und Versorgung der Versuchstiere

II.2.1) Identische Vorbedingungen für alle Tiere

II.2.2) Analyse der Knochenstruktur vor $\beta$-Ecdyson-Applikation mittels pQCT- 
II.2.3) Randomisierte Zuteilung zu den Futtergruppen und Gonadektomie $\quad 27$

$\begin{array}{ll}\text { II.2.4) Körpergewichtsanalyse während des Versuchszeitraums } & \mathbf{2 8}\end{array}$

II.2.5) Abschließende pQCT-Messung und Versuchsende 29

II.3) Vermessung der intakten Rattentibiae $\quad 29$

II.4) Verarbeitung der Knochen zu mikroskopischen Hartschnittpräparaten $\quad 30$

II.4.1) Kürzen der Tibiae auf vorgesehene Präparatlänge und Fixierung $\quad 30$

II.4.2) Vorbehandlung des Knochengewebes und Einbettung mit Hilfe von

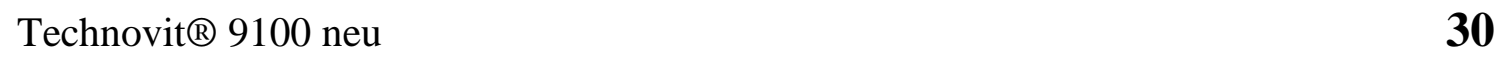

II.4.3) Verarbeitung der Polymerisate zu Hartschnittpräparaten mittels Mikrotomie 31

II.4.4) Entplastung und Goldner-Färbung der Hartschnittpräparate 31

II.5) Histologische Auswertung der Tibiapräparate 32

II.5.1) Mikroskop und Computersoftware $\quad 32$

II.5.2) Messung der Kortikalisdicke in diaphysären und metaphysären Bereichen $\quad 33$

II.5.3) Bestimmung der Fläche und der prozentualen Anteile an Trabekeln $\begin{array}{ll}\text { und Knochenmark } & 34\end{array}$

II.6) Graphische Darstellung und Analvse der gemessenen Werte 36

III.) Ergebnisse $\quad 37$

III.1) Vergleich der beiden angewandten morphometrischen Analyseverfahren 37

III.1.1) Auswertung der Trabekelfläche in der tibialen Metaphyse männlicher S.D.Ratten

III.1.2) Auswertung des prozentualen Trabekelanteils in der tibialen Metaphyse männlicher S.D.-Ratten

III.1.3) Auswertung der Fläche gelben Knochenmarks in der tibialen Metaphyse männlicher S.D.-Ratten

III.1.4) Auswertung des prozentualen Anteils gelben Knochenmarks in der tibialen Metaphyse männlicher S.D.-Ratten

III.1.5) Auswertung der Fläche roten Knochenmarks in der tibialen Metaphyse männlicher S.D.-Ratten

III.1.6) Auswertung des prozentualen Anteils roten Knochenmarks in der tibialen Metaphyse männlicher S.D.-Ratten 
III.1.7) Auswertung der Trabekelfläche in der tibialen Metaphyse weiblicher S.D.Ratten

III.1.8) Auswertung des prozentualen Trabekelanteils in der tibialen Metaphyse weiblicher S.D.-Ratten

III.1.9) Auswertung der Fläche gelben Knochenmarks in der tibialen Metaphyse weiblicher S.D.-Ratten

III.1.10) Auswertung des prozentualen Anteils gelben Knochenmarks in der tibialen Metaphyse weiblicher S.D.-Ratten

III.1.11) Auswertung der Fläche roten Knochenmarks in der tibialen Metaphyse weiblicher S.D.-Ratten

III.1.12) Auswertung des prozentualen Anteils roten Knochenmarks in der tibialen Metaphyse weiblicher S.D.-Ratten

III.2) Nahrungsaufnahme im Rahmen der Futterstudie mit ß-Ecdyson

III.2.1 Futteraufnahme der männlichen S.D.-Ratten

III.2.2) Futteraufnahme der weiblichen S.D.-Ratten

III.3) Körpergewichtsverlauf im Rahmen der Futterstudie mit ß-Ecdyson

III.3.1) Körpergewichtsverlauf der männlichen S.D.-Ratten

III.3.2) Körpergewichtsverlauf der weiblichen S.D.-Ratten

III.4) Effekt von ß-Ecdvson auf Tibialänge und Tibiakopfdurchmesser

III.4.1) Tibialänge und Tibiakopfdurchmesser der männlichen S.D.-Ratten

III.4.2) Tibialänge und Tibiakopfdurchmesser der weiblichen S.D.-Ratten

III.5) Effekt von $\beta$-Ecdyson auf die diaphysäre und metaphysäre Kortikalisdicke

III.5.1) Diaphysäre und metaphysäre Kortikalisdicke der männlichen S.D.-Ratten

III.5.2) Diaphysäre und metaphysäre Kortikalisdicke der weiblichen S.D.-Ratten

III.6) Effekt von $\beta$-Ecdyson auf weitere mikroskopische Aspekte der tibialen Metaphvse von männlichen S.D.-Ratten

III.6.1) Trabekelfläche und prozentualer Trabekelanteil in der tibialen Metaphyse

III.6.2) Fläche und prozentualer Anteil gelben Knochenmarks in der tibialen Metaphyse

III.6.3) Fläche und prozentualer Anteil roten Knochenmarks in der tibialen Metaphyse 
III.7) Effekt von $\beta$-Ecdyson auf weitere mikroskopische Aspekte der tibialen Metaphyse von weiblichen S.D.-Ratten

III.7.1) Trabekelfläche und prozentualer Trabekelanteil in der tibialen Metaphyse

III.7.2) Fläche und prozentualer Anteil gelben Knochenmarks in der tibialen Metaphyse

III.7.3) Fläche und prozentualer Anteil roten Knochenmarks in der tibialen Metaphyse

III.8) Effekt von $\beta$-Ecdyson auf weitere mikroskopische Aspekte der tibialen Epiphvse von männlichen S.D.-Ratten

III.8.1) Trabekelfläche und prozentualer Trabekelanteil in der tibialen Epiphyse

III.8.2) Fläche und prozentualer Anteil gelben Knochenmarks in der tibialen Epiphyse

III.8.3) Fläche und prozentualer Anteil roten Knochenmarks in der tibialen Epiphyse

III.9) Effekt von B-Ecdyson auf weitere mikroskopische Aspekte der tibialen Epiphyse von weiblichen S.D.-Ratten

III.9.1) Trabekelfläche und prozentualer Trabekelanteil in der tibialen Epiphyse

III.9.2) Fläche und prozentualer Anteil gelben Knochenmarks in der tibialen Epiphyse

III.9.3)Fläche und prozentualer Anteil roten Knochenmarks in der tibialen Epiphyse

IV.1) Studienziel

IV.2) Vergleich zweier Computer-assistierter Fotoanalyseverfahren im Hinblick auf die Untersuchung von Trabekel- und Knochenmarkstruktur in der tibialen Metaphyse

IV.3) Futteraufnahme und Körpergewichtsverlauf im Rahmen der Futterstudie mit $\beta$-Ecdyson

IV.3.1) Futteraufnahme und Körpergewicht der männlichen S.D.-Ratten

IV.3.2) Futteraufnahme und Körpergewicht der weiblichen S.D.-Ratten

IV.4) Die Tibia der gonadektomierten Ratte als Osteoporosemodell

IV.5.1) Auswirkungen auf Tibialänge und Tibiakopfdurchmesser der männlichen S.D.-Ratten 
IV.5.2) Auswirkungen auf Tibialänge und Tibiakopfdurchmesser der weiblichen S.D.-Ratten

IV.6) Effekt von $\beta$-Ecdyson auf mikroskopische Aspekte der Tibia

IV.6.1) Auswirkungen auf die diaphysäre und metaphysäre Kortikalisdicke

IV.6.1.1) Auswirkungen auf die Kortikalisdicke männlicher S.D.-Ratten

IV.6.1.2) Auswirkungen auf die Kortikalisdicke weiblicher S.D.-Ratten

IV.6.2) Auswirkungen auf das Trabekelsystem in der proximalen Tibia

IV.6.2.1) Auswirkungen auf das Trabekelsystem männlicher S.D.-Ratten

IV.6.2.2) Auswirkungen auf das Trabekelsystem weiblicher S.D.-Ratten

IV.6.3) Auswirkungen auf das gelbe Knochenmark in der proximalen Tibia

IV.6.3.1) Auswirkungen auf das gelbe Knochenmark männlicher S.D.-Ratten

IV.6.3.2) Auswirkungen auf das gelbe Knochenmark weiblicher S.D.-Ratten

IV.6.4) Auswirkungen auf das rote Knochenmark in der proximalen Tibia

IV.6.4.1) Auswirkungen auf das rote Knochenmark männlicher S.D.-Ratten

IV.6.4.2) Auswirkungen auf das rote Knochenmark weiblicher S.D.-Ratten

IV.7) Kritische Auseinandersetzung mit der angewandten Methodik 


\section{Abkürzungsverzeichnis}

$\mathrm{AR}=$ Androgenrezeptor

$\mathrm{BMD}=$ Bone Mineral Density $=$ Knochendichte

$\mathrm{BMU}=$ Bone Multicellular Units

D-Methode $=$ Schwellenwertbildung am 8-Bit-Grauwertbild

$\mathrm{E}_{2}=17 \beta$-Östradiol

$\operatorname{Ecd}=\beta$-Ecdyson

$\mathrm{ER}=$ Östrogenrezeptor

F-Methode $=$ Schwellenwertbildung am Negativbild im roten Farbauszug

i. p. $=$ intraperitoneal

$\mathrm{KG}=$ Körpergewicht

$\mathrm{kg}=$ Kilogramm

LD50 $=$ mittlere letale Dosis bezogen auf 50\% der Population

M-CSF = Makrophagen-Kolonie-stimulierender Faktor

$\mathrm{mg}=$ Milligramm

$\mathrm{OPG}=$ Osteoprotegerin

orx / ORX = orchidektomiert / Orchidektomie

ovx / OVX = ovariektomiert / Ovariektomie

p.o. $=$ per os

PPAR $\gamma 2=$ Peroxisom-Proliferator-Aktivator Gamma 2

pQCT $=$ periphere quantitative Computer-Tomographie

PTH $=$ Parathormon

RANK $=$ Receptor activator of nuclear factor NFאB

RANKL $=$ Receptor activator of nuclear factor NF $\kappa B$ Ligand

Runx2 = Runt-related Transcription Factor 2

RXR = Retinoid-X-Rezeptor

$\mathrm{SD}=$ Standard Deviation $=$ Standardabweichung

S.D. - Ratten $=$ Sprague-Dawley-Ratten

SERM = Selektiver Östrogen-Rezeptor-Modulator

sf = sojafrei / phytoöstrogenarm 
$\mathrm{T}=$ Testosteron

$\mathrm{TNF}=$ Tumor-Nekrose-Faktor

UAW = Unerwünschte Arzneimittelwirkungen

UsP = Ultraspiracle Protein

$\mathrm{WHO}=$ Weltgesundheitsorganisation 


\section{I.) Einleitung}

\section{I.1) Knochen}

Der Knochen ist ein Organ mit einer Vielzahl unterschiedlicher Funktionen. Offensichtlich erscheint zum einen die Aufgabe als skelettales Grundgerüst für Haltung, Bewegung und Schutz der inneren Organe. Zum anderen stellt er mit dem in ihm enthaltenen roten Knochenmark jedoch auch ein Kompartiment für die Blutbildung dar. Nicht zuletzt gilt der Knochen mit einem Anteil von $99 \%$ des im Körper vorkommenden Calciums außerdem als Speichermedium für dieses Elektrolyt, welches im Bedarfsfall vergleichsweise schnell mobilisiert werden kann. Das Calcium ist in Verbindung mit Phosphat in Form von Hydroxylapatitkristallen in das Knochengerüst eingelagert. Gemeinsam mit einigen anderen Mineralien ist es verantwortlich für die Festigkeit des Knochens. Das Knochengerüst selbst hingegen besteht vor allem aus Typ-1-Kollagenfibrillen, welche durch unterschiedliche Ausrichtung die Biegsamkeit des Knochens ermöglichen. Diese zwei essenziellen Knochenbestandteile müssen somit in einem ausgewogenen Gleichgewicht zueinander stehen, um eine optimale Biegefestigkeit des Knochens zu gewährleisten (Chavassieux et al. 2007).

\section{I.1.1) Anatomie des langen Röhrenknochens}

Der lange Röhrenknochen wird häufig exemplarisch als anatomisches Knochenmodell für Erläuterungszwecke herangezogen. Diese Tatsache basiert unter anderem auf der anschaulichen Abgrenzbarkeit der einzelnen Strukturelemente des Knochens. So setzt sich dieser aus jeweils einer proximalen und einer distalen Epiphyse zusammen, welche durch einen Schaft, die sogenannte Diaphyse, verbunden sind. Die Epiphysen beteiligen sich als Knochenendstücke funktionell an der Gelenkbildung und sind somit anteilig mit Gelenkknorpel überzogen. Der sich verdickende Übergang zwischen Diaphyse und Epiphyse wird Metaphyse genannt. Zwischen Epiphyse und Metaphyse liegt außerdem die Epiphysenfuge aus hyalinen Knorpelanteilen. Dieser, auch als Wachstumszone bezeichnete Knochenabschnitt, ist bis zur endgültigen Verknöcherung Ausgangspunkt des Längenwachstums.

Außen besteht das Knochengewebe, vor allem diaphysär, aus der sogenannten Kortikalis. Dieser kortikale Lamellenknochen setzt sich aus einer Vielzahl lamellenartig aufgebauter Osteone und Schaltlamellen zusammen. Die Kortikalis bildet somit eine äußere Hülle um die innen gelegene Markhöhle, welche neben einem Netzwerk aus trabekulären Knochenbälkchen auch das Knochenmark enthält. Die jeweilige individuelle Knochenqualität wird maßgeblich von den Eigenschaften der Kortikalis und der Trabekel, sowie deren Verhältnis zueinander 
bestimmt. Bei der Kortikalis kommt es dabei unter anderem auf die Dicke und auf den optimalen Abstand zur Knochenlängsachse an. Bezüglich des trabekulären Systems zählen vor allem die Zahl, die Dicke, die räumliche Ausrichtung und die Verbindung der einzelnen Knochenbälkchen untereinander. Nicht zuletzt spielen aber auch das Maß an Mineralisation, die Güte des Kollagens und der ausgeglichene Knochenstoffwechsel eine wichtige Rolle. (Audran et al. 2001, Chavassieux et al. 2007)

\section{I.1.2) Physiologie des Knochens}

Der Knochen ist ein stoffwechselaktives Organ, das sich fortwährend in einem dynamischen Wandel befindet. So wird vermutet, dass fünf bis zehn Prozent des bestehenden Knochens jährlich durch Umbau ersetzt werden (Martin TJ und Seeman 2007). Dies bedeutet also, dass das menschliche ausgewachsene Skelett alle zehn Jahre vollständig regeneriert ist (Manolagas 2000). Vor allem in Abhängigkeit von mechanischen Belastungen und funktionellen Ansprüchen befindet es sich in einem flexiblen Gleichgewicht zwischen Knochenaufbau und Knochenabbau. Unter dem in dieser Hinsicht bedeutenden Begriff „Remodeling“ versteht man die Knochenumbauprozesse, die nach Abschluss des Wachstums zum Erhalt der Knochenmasse und Reparatur von Mikroschäden beitragen. Diese Umgestaltungsmechanismen umfassen eine vorangehende Knochenresoprtion durch Osteoklasten und anschließende, zeitlich verzögerte Knochenneubildung durch Osteoblasten. Während die Osteoklasten für den Knochenabbau etwa zwei bis vier Wochen benötigen, dauert die Neubildung durch die Osteoblasten und die anschließende Mineralisierung circa vier bis sechs Monate (Pietschmann et al. 2009). Osteoklasten bauen den Knochen mittels Säuren und lysosomalen Enzymen, wie Cathepsin K, ab und hinterlassen dabei beim Menschen, im Gegensatz zur Ratte, kortikal sogenannte Havers-Kanäle und trabekulär dem entsprechende Howship-Lakunen (Raisz 1999).

Die Knochenresorption und die Neusynthese im Rahmen des Remodeling finden an umschriebenen, lokalisierten Bereichen des Knochens, den sogenannten „,bone multicellular units“ (BMU) statt (Chavassieux et al. 2007). Die Anzahl der vorhandenen BMUs im menschlichen Skelett wird auf ein bis zwei Millionen geschätzt (Martin TJ und Seeman 2007). Während die Bilanz zwischen Resorption von Knochensubstanz und deren anschließender Neubildung im Wachstumsalter meist noch ausgeglichen ist, kommt es etwa ab einem Alter von 30 Jahren bei Männern und Frauen gleichermaßen zu einer Gleichgewichtsverschiebung zugunsten einer überwiegenden Resorption, das heißt zu einem negativen BMU-Gleichgewicht (Seeman 2004). Dieser altersbedingte Prozess führt zu einem langsamen, aber stetigen Verlust an Knochenmasse, der zunächst jedoch noch nicht als 
pathologisch einzustufen ist (Seeman 2003). Diese physiologische Abnahme von Knochenmasse beträgt dabei etwa ein Prozent pro Jahr (Riede et al. 2004). In Abhängigkeit von der Größe der während des Wachstums maximal erreichten Knochenmasse, der sogenannten „Peak bone mass“, kann der Knochenverlust somit unterschiedlich gut toleriert werden. Je größer also die ursprüngliche maximale Knochenmasse ausgeprägt war, desto besser kann ein altersbedingter Knochenabbau kompensiert werden (Seeman 2003). Die Homöostase zwischen Resorption und Formation im Remodelingprozess wird dabei durch eine Vielzahl lokal und systemisch interagierender Mediatoren und Zytokine reguliert, deren genaue Aktivität und Zusammenspiel noch aufzuklären sind.

\section{I.1.3) Bedeutung der Geschlechtshormone für den Knochen}

Ein Großteil der hormonellen Einflussnahme auf den Knochen wird durch Geschlechtshormone ausgeübt. Diesbezüglich wird heutzutage von einer mehr oder weniger geschlechtsunabhängigen, komplexen Interaktion der gonadalen Steroide innerhalb des Knochenstoffwechsel ausgegangen (Venken et al. 2008). Androgene und Östrogene spielen sowohl für die Knochenentwicklung während des Wachstums, das sogenannte Modeling, als auch für den Knochenerhalt im erwachsenen Skelett durch Remodeling eine bedeutende Rolle. Vor allem durch Studien über die Auswirkungen von Östrogenmangel auf den Knochen konnte die herausragende Bedeutung von Östrogenen für das Skelettsystem evaluiert werden. Dabei werden die Knocheneffekte vor allem über den Östrogenrezeptor $\alpha$ $(E R \alpha)$ und weniger über den $E R \beta$ vermittelt (Riggs et al. 2002, Seidlová-Wuttke et al. 2008b). So ist $17 \beta$-Östradiol $\left(E_{2}\right)$ zum Ende der Wachstumsphase beispielsweise für den Epiphysenfugenschluss bei beiden Geschlechtern verantwortlich (Juul 2001). Ferner bewahrt $E_{2}$ im erwachsenen Skelett Knochenmasse und Struktur. Dies geschieht unter anderem über die Aufrechterhaltung eines ausgewogenen Gleichgewichts zwischen Knochenaufbau und Abbau durch Einflussnahme auf die am Knochenstoffwechsel beteiligten Mediatoren und Zytokine, wie IL-6, TNF, M-CSF und OPG (Manolagas 2000).

Testosteron (T) gilt als Hauptvertreter der Androgene. Beim Mann findet die Testosteronsynthese zu einem Großteil von etwa 95\% in den Testes statt (Venken et al. 2008). Der verbleibende Rest und weitere weniger aktive Androgene werden durch die Nebennierenrinde zur Verfügung gestellt. Bei der prämenopausalen Frau erfolgt die Testosteronproduktion zu 25\% in den Ovarien, zu 25\% in den Nebennierenrinden und zu 50\% im peripheren Gewebe durch enzymatische Umsetzung (Riggs et al. 2002). Die Testosteronwirkung kann entweder direkt über den entsprechenden Androgenrezeptor (AR) oder indirekt nach enzymatischer Umsetzung erfolgen. Letzteres umfasst neben der 
Umwandlung in den aktiven Metaboliten 5 $\alpha$-Dihydrotestosteron mittels $5 \alpha$-Reduktase, die Aromatisierung $\mathrm{zu} \mathrm{E}_{2}$ (Vanderschueren et al. 2004). Durch Aromatisierung $\mathrm{zu} \mathrm{E}_{2}$ wird die Voraussetzung für eine potenzielle Wirkung über den ER $\alpha$ geschaffen (Callewaert et al. 2009). Diese Umwandlungsprozesse können durch entsprechende Enzympräsenz auch lokal im Knochen stattfinden und dort die von Osteoblasten und Osteoklasten exprimierten AR und ER aktivieren (Venken et al. 2008). So gibt es bezüglich der Wirkung am AR beispielsweise Hinweise auf eine entscheidende Bedeutung bei der männlichen skelettalen Phänotypentwicklung durch das darüber stimulierte periostale Knochenwachstum (Reim et al. 2008). Des Weiteren scheinen Androgene gemeinsam mit den Östrogenen über den AR und den ER $\alpha$ zur Aufrechterhaltung der Trabekelmasse beizutragen (Vanderschueren et al. 2004).

\section{I.2) Pathologie des Knochens am Beispiel der Osteoporose}

Die Consensus Development Conference zum Thema "Prophylaxis and Treatment of Osteoporosis“ (Consensus Development Conference 1991) definierte die Osteoporose als eine systemische Skeletterkrankung, die mit einer erniedrigten Knochenmasse einhergeht. Innerhalb des Knochens komme es dabei morphologisch zu einer Störung der Mikroarchitektur, die mit einem erhöhten Frakturrisiko assoziiert sei.

In der klinischen Diagnostik finden derzeit Osteoporosekriterien der Weltgesundheitsorganisation (WHO) anhand von Knochendichtemesswerten (BMD) Anwendung (WHO Study Group 1994). Die WHO-Kriterien werden dabei geschlechtsunabhängig verwendet (Pietschmann et al. 2009), da sich das absolute Frakturrisiko für Männer und Frauen gleichen Alters und gleicher BMD zu entsprechen scheinen (Seeman et al. 2006). Insgesamt stellt die Osteoporose trotz Assoziation mit verschiedenen ätiologischen Faktoren eine typische multifaktoriell bedingte Skeletterkrankung dar. So spielen Risikofaktoren wie die individuell erreichte Peak bone mass, der allgemeine Lebensstil, Bewegung, Ernährung und nicht zuletzt die genetische Erbanlage eine entscheidende Rolle für die Pathophysiologie der Osteoporose (Pietschmann et al. 2009).

\section{I.2.1) Osteoporose der Frau}

Bei der Frau kommt es im Rahmen des postmenopausal zunehmenden Östrogenmangels durch Abnahme der ovariellen Produktion zunächst zu einer schnellen Phase erhöhten Knochenstoffwechsels. Jener beruht vor allem auf dem Wegfall der knochenprotektiven Hormoneigenschaften. Dies ließ sich unter anderem mit Hilfe von Studien belegen, die eine prophylaktische Wirkung der Östrogensubstitution gegen den Knochenverlust zeigen konnten (Delmas 1997). Diese erste Phase ist vorübergehend und umfasst ungefähr die ersten vier bis 
acht postmenopausalen Jahre. Angriffsort des beschleunigten Knochenstoffwechsels ist dabei überwiegend der trabekuläre Knochen, sodass der dortige Knochenverlust etwa drei bis fünf Mal größer ist als beim kortikalen Knochen (Riggs et al. 1998). So gehen im Rahmen dieses beschleunigten Knochenumsatzes etwa 20-30\% des trabekulären und 5-10\% des kortikalen Knochens verloren (Riggs et al. 2002). Auf diese frühe schnelle Knochenverlustepisode folgt eine altersbedingte Phase mit langsamerem, kontinuierlichem Knochenabbau, der neben den trabekulären nun auch den kortikalen Knochen betrifft. Die Tatsache, dass Frauen naturgemäß eine niedrigere Peak bone mass und somit weniger starke Knochen als Männer aufweisen, ist einer der Gründe, warum Frauen durch die beiden Knochenverlustphasen tendenziell auch stärker zu osteoporotischen Frakturen neigen (Ohlsson und Vandenput 2009). Was den pathophysiologischen Mechanismus des Knochenverlusts betrifft, wird bei einem Großteil der postmenopausalen Frauen heutzutage ursächlich von einer Erhöhung der Remodeling-Rate ausgegangen, die wiederum mit einer Störung des Gleichgewichts zwischen Knochenresorption und Knochenwiederaufbau assoziiert ist (Seeman 2003). Dies macht sich durch eine größere Anzahl an BMUs bemerkbar, welche an den jeweiligen Knochenstrukturen $\mathrm{zu}$ weitreichenden strukturellen Veränderungen bis hin zum schwerwiegenden Knochenverlust führen können. Dabei wird der trabekuläre Knochen insgesamt schneller umgesetzt als jener der Kortikalis, da erstgenannter infolge einer größeren Oberfläche auch mehr Angriffspunkte für die Entstehung von BMUs und dem zellulären Remodeling bietet. Im Verlauf kann es somit zur Ausdünnung von Kortikalis und Trabekel kommen. Ferner resultieren eine Störung des Trabekelsystems und dessen Vernetzung aus der erhöhten BMU-Zahl und den tieferen Resorptionslakunen (Seeman 2002). Das trabekuläre System verliert bei Frauen somit vor allem durch den Verlust seiner netzartigen Verbindung und der Kommunikation untereinander eine wichtige Grundlage für seine Stabilität (Martin TJ und Seeman 2007).

\section{I.2.2) Osteoporose des Mannes}

Die Osteoporose beim Mann stand lange Zeit im Abseits des Interesses, da diese Erkrankung vorrangig mit dem weiblichen Geschlecht in Verbindung gebracht wurde. Mittlerweile jedoch beschäftigen sich zunehmend Studien auch mit der männlichen Osteoporose, da auch diese einen nicht unerheblichen Einfluss auf Morbidität und Mortalität von Männern hat.

Bei Männern existiert neben der seltenen idiopathischen Osteoporose bei Jüngeren nur eine primäre Osteoporose vom Typ 2, das heißt der senilen Osteoporose (Khosla et al. 2008). Diese ist im Gegensatz zur postmenopausalen Osteoporose, das heißt der primären Osteoporose vom Typ 1, nur durch einen langsamen, aber stetigen Knochenverlust 
gekennzeichnet. Da es beim Mann keinen physiologischen, mit der Menopause vergleichbaren, abrupt auftretenden Geschlechtshormonmangel gibt, fehlt somit auch ein Äquivalent zur weiblichen schnellen Knochenabbauphase mit erhöhter Remodeling-Rate im mittleren Lebensalter (Seeman et al. 2006). Im Vergleich zur Frau nimmt der GesamtTestosteronspiegel beim Mann mit zunehmendem Alter nur maximal $1 \%$ pro Jahr ab (Venken et al. 2008). Die altersassoziierten Veränderungen am Trabekelsystem zeigen sich beim Mann vor allem in Form einer kontinuierlichen Ausdünnung und weniger in einem Konnektivitätsverlust (Venken et al. 2008, Seeman et al. 2006, Seeman 2004). Dabei kommt es zu einem trabekulären und kortikalen Knochenverlust von etwa 20-25\% (Riggs et al. 2002). Nichtsdestotrotz spielen hormonelle Faktoren auch bei der männlichen Osteoporose eine entscheidende Rolle. Wider Erwarten dominieren hier jedoch nicht, wie lange vermutet, die Androgene, obgleich ein entsprechender Mangel auch mit Auswirkungen auf das Skelettsystem assoziiert ist (Pietschmann et al. 2009). Vielmehr stellen Östrogene scheinbar auch beim Mann einen Haupteinflussfaktor dar. Diesbezüglich legen Studien nahe, dass die Abhängigkeit des männlichen Knochenstoffwechsels von „,weiblichen“ Hormonen auf der enzymatischen Aromatisierung von $\mathrm{T} \mathrm{zu} \mathrm{E}_{2}$ im peripheren Gewebe basiert (Gennari et al. 2003). Letzteres macht etwa $85 \%$ des männlichen Östrogenspiegels aus, wohingegen die verbleibenden $15 \%$ direkt testikulär synthetisiert werden (Gennari et al. 2004). Studienergebnisse bezüglich des Effekts einer experimentell induzierten Hemmung der Aromatisierung von $\mathrm{T} \mathrm{zu} \mathrm{E}_{2}$ legten unter anderem die Vermutung einer entscheidenden Rolle von $\mathrm{E}_{2}$ im männlichen Knochensystem nahe. Unter diesen Voraussetzungen konnte trotz eines normalen Testosteronspiegels, ein verstärkter Knochenumsatz und damit assoziierter Knochenverlust beobachtet werden, der mit jenem unter Androgenmangel vergleichbar war (Vanderschueren et al. 1996). Als zusätzlichen Hinweis für die Bedeutung von Östrogenen im männlichen Knochenmetabolismus konnten tierexperimentelle Studien an Ratten außerdem zeigen, dass eine Testosteronsubstitution den trabekulären Knochen nach ORX zwar vor einem gesteigerten Abbau schützt, dabei allerdings nicht das Niveau der östrogenen Knochenprotektion erreicht (Stürmer et al. 2009).

\section{I.2.3) Bedeutung des Knochenmarks für die Osteoporose}

Das Knochenmark ist innerhalb der Markhöhle zwischen den Maschen des Trabekelnetzwerks lokalisiert. Es setzt sich zusammen aus dem roten, hämatopoetisch aktiven Mark, sowie dem gelben Knochenmark. Die beiden Knochenmarkstypen zeigen dabei ein altersabhängiges Verteilungsmuster. Tendenziell wird das beim Kind ursprünglich ubiquitär vorkommende rote Knochenmark innerhalb der Diaphyse mit zunehmendem Alter durch das 
gelbe Knochenmark verdrängt, sodass sich beim Erwachsenen das rote Mark letztlich vor allem auf platte Knochen und einzelne epiphysäre Bereiche langer Röhrenknochen beschränkt (Vahlensieck und Schmidt 2000). Zellulär besteht das rote Knochenmark aus Erythrozyten, Leukozyten, Thrombozyten und ihren jeweiligen Vorläuferzellen. Schon um den Zeitpunkt des Erreichens der individuellen Peak Bone Mass herum, beginnt bereits der Wandel der Verteilungsmusters von rotem zu gelbem Knochenmark innerhalb der Markhöhle (Rosen et al. 2009). Dabei wird jedoch nicht nur das hämatopoetische rote Knochenmark durch gelbes Mark ersetzt, sondern auch das trabekuläre Knochengewebe (Justesen et al. 2001). Die Adipozyten des gelben Knochenmarks besitzen als Vorläufer dieselbe pluripotente mesenchymale Stammzelle wie Osteoblasten. Durch verschiedene regulierende Faktoren kann der jeweilige Differenzierungsweg bevorzugt eingeschlagen werden. Adipogenese-fördernd wirkt beispielsweise der Transkriptionsfaktor Peroxisom-Proliferator-Aktivator Gamma 2 (PPAR $\gamma 2), \quad$ Osteoblastogenese-fördernd hingegen unter anderem der Runt-related Transcription Factor 2 (Runx2) (Duque 2008, Moerman et al. 2004, Rosen und Klibanski 2009). Der wachsende Anteil gelben Fettmarks mit Alterszunahme wird unter anderem durch Bevorzugung des erstgenannten Differenzierungswegs zum Adipozyten begründet (Kawai und Rosen 2009). Auch im Rahmen der Osteoporose konnten Studien einen erhöhten Fettmarkanteil im Vergleich zu Knochengesunden nachweisen (Kawai und Rosen 2009). Diesbezüglich scheint der postmenopausale $\mathrm{E}_{2}$-Mangel für die gesteigerte Adipogenese innerhalb des Knochenmarks in gewissem Maße mitverantwortlich zu sein, sodass ein entsprechender Hormonersatz diesem Prozess vorbeugen kann (Syed et al. 2008). Ferner wird dem Fettmark nach neueren Studien eine ausgeprägte endokrine Aktivität zugeschrieben, mittels derer es durch Sekretion unterschiedlicher Faktoren selbst Einfluss auf den Zellstoffwechsel innerhalb der Markhöhle nehmen kann (Kawai und Rosen 2009). Bei den durch Adipozyten sezernierten Stoffen handelt es sich zum Beispiel um bestimmte Fettsäuren und Zytokine, wie TNF und IL-6, die das benachbarte zelluläre Milieu beeinflussen können (Rosen et al. 2009). Den freigesetzten Fettsäuren wird dabei ein lipotoxischer Effekt auf Osteoblasten zugeschrieben (Duque 2008), der durch Einfluss auf deren Funktion und Lebensdauer möglicherweise einen weiteren relevanten Beitrag zur Pathogenese der Osteoporose leistet. Den sezernierten proinflammatorischen Zytokinen wird durch die Wirkung auf Osteoklasten und deren Vorläufer ein stimulierender Effekt auf die Knochenresorption zugeschrieben (Pfeilschifter et al. 2002). Aufgrund der steigenden Adipozytenzahl mit Alterszunahme oder im Rahmen osteoporotischer Veränderungen wird entsprechend durch vermehrte Sekretion auch die Lipotoxizität verstärkt. 


\section{I.2.4) Therapie der Osteoporose}

In der Osteoporosetherapie gibt es derzeit verschiedene Wirkstoffe mit unterschiedlichen Ansatzpunkten im Knochenstoffwechsel. $\mathrm{Zu}$ nennende Beispiele sind unter anderem Bisphosphonate, Selektive Östrogen-Rezeptor-Modulatoren (SERMs), Parathormon (PTH) und Strontiumranelat (Pietschmann et al. 2009, Kanis et al. 2008). Die Pathophysiologie der Osteoporose und die Abhängigkeit des Knochenstoffwechsels von den Geschlechtshormonen $\mathrm{E}_{2}$ und $\mathrm{T}$ legen eine Therapie mit entsprechender Substitution nahe. Die Indikation für einen Hormonersatz mit Östrogenen wird aufgrund schwerwiegender Nebenwirkungen, wie eines erhöhten Risikos für KHK/Myokardinfarkt, Mamma-Ca, Apoplex und Thrombembolien, jedoch sehr eng gestellt. Die Testosteronsubstitution beim hypogonadalen, osteoporotischen Mann ist bisweilen noch kein etabliertes Therapieverfahren. Zwar wurden diesbezüglich bereits einige Studien durchgeführt, jedoch konnte trotz verbesserter trabekulärer Knochenstruktur (Stürmer et al. 2009) und BMD im Tierversuch bislang noch keine eindeutige Senkung des Frakturrisikos bei manifester Osteoporose belegt werden (Bassil et al. 2009). Unter dem Aspekt der steigenden Prävalenz bei zum Teil begrenzten Therapiemöglichkeiten wäre somit die Entwicklung nicht-östrogener Substanzen mit weniger ausgeprägtem Nebenwirkungsprofil als zukünftige Therapieoption der männlichen und weiblichen Osteoporose erstrebenswert. Die hierfür gesteckten Therapieziele umfassen neben der Prophylaxe des Knochenverlusts unter anderem auch die Hemmung des medullären Fettzellaufbaus, da sich dieser durch Bildung lipotoxischer Substanzen zusätzlich schädigend auf die Knochenstruktur auswirken kann.

\section{I.3) Die gonadektomierte Ratte als tierexperimentelles Modell der Osteoporose}

\section{I.3.1) Die weibliche ovariektomierte Ratte}

Die ovariektomierte (ovx) weibliche Ratte gilt seit langem als anerkanntes und etabliertes Tiermodell für die postmenopausale Osteoporose der Frau. Neben allgemeinen Vorteilen, wie verhältnismäßig günstigen Erwerbs- und Haltungskosten, überschaubarer Entwicklungs- und Lebensdauer, sowie dem gut untersuchten Knochensystem (Turner et al. 2001), entsprechen die Knochenverhältnisse nach Ovariektomie (OVX) in etwa denen der postmenopausalen Frau (Wronski et al. 1989). Diese sind gekennzeichnet durch einen erhöhten Knochenumsatz mit ungleicher Steigerung von Resorption und Bildung, der folglich in einem NettoKnochenverlust resultiert (Wronski et al. 1989). Dabei ist vor allem der trabekuläre Knochen durch seine größere Oberfläche Angriffsort des beschleunigten und intensivierten 
Knochenstoffwechsels (Wronski et al. 1985). Auf lange Sicht und mit zunehmendem Lebensalter kann auch der kortikale Knochen, jedoch in meist geringerer Ausprägung, in entsprechende Veränderungen involviert sein (Danielsen et al. 1993). Die dominierende Entstehungsursache des Knochenverlusts ist dabei vor allem der durch OVX bedingte Östrogenmangel und der damit verbundene Wegfall der knochenprotektiven Hormoneigenschaften. Dies ist vergleichbar mit dem Erlöschen der ovariellen Funktion in der Hormonproduktion und deren Folgen bei der postmenopausalen Frau (Kalu 1991).

\section{I.3.2) Die männliche orchidektomierte Ratte}

Mit Zunahme des wissenschaftlichen Interesses an der Osteoporose beim Mann wurde die männliche orchidektomierte (orx) Ratte aufgrund der guten Erfahrung mit der Anwendung bei weiblichen Ratten als Tiermodell für die Osteoporose eingeführt. Als Hintergrundidee fungierte dabei ursprünglich die Entdeckung, dass der männliche Hypogonadismus ein Risikofaktor für die männliche Osteoporose darstellt. Diese basiert neben klinischen Beobachtungen vor allem darauf, dass in tierexperimentellen Untersuchungen der sinkende bzw. nahezu supprimierte Testosteronspiegel nach Orchidektomie (ORX) mit einer erhöhten Knochenresorptionsrate assoziiert war (Vanderschueren et al. 1996). Weitere anschließende Studien ließen jedoch beobachten, dass Östrogene bei Männern scheinbar ebenfalls eine dominierende Rolle im Knochenstoffwechsel spielen. Daraus entwickelte sich die Hypothese, dass die Abnahme der Testosteronproduktion nach Gonadektomie gleichzeitig auch dessen Umwandlungsmöglichkeit zu Östrogen via Aromatase herab setzt und folglich auch der Knochenverlust in erster Linie aus dem Mangel am knochenprotektiven Östrogen resultiert. ORX induziert somit wie OVX artifiziell einen Geschlechtshormonmangelzustand, indem sowohl der Östrogen- als auch der Testosteronspiegel im Blut stark reduziert werden (Vanderschueren et al. 2004).

\section{I.3.3) Lokalisations-abhängige Knochenveränderung in der Rattentibia nach Gonadektomie}

Die trabekulären Knochenveränderungen nach Gonadektomie zeigen in Abhängigkeit von der anatomischen Lokalisation unterschiedliche Ausprägungen. So konnte in Studien gezeigt werden, dass die tibiale Metaphyse stärker vom Trabekelverlust betroffen ist als zum Beispiel ein lumbaler Wirbelköper (Yamaura et al. 1996, Wronski et al. 1986). Auch Analysen mittels pQCT, sowie biomechanische Tests, konnten belegen, dass die Tibiametaphyse eine geeignete Lokalisation für die Effektstudie von Testsubstanzen im Hinblick auf eine mögliche knochenprotektive Wirkung bei postmenopausaler Osteoporose darstellt (Zhang et al. 2007). Die tibiale Epiphyse gilt als ein Knochenabschnitt, der keine oder nur eine geringe 
Manifestation eines Knochenverlusts durch Hormonmangel aufweist. Trotz wenig ausgeprägter Veränderungen in Form von Knochenverlust in der Epiphyse, erwies diese sich in einigen Studien dennoch als empfindlich für den Mangel an gonadalen Hormonen und reagierte auf diesen mit einem erhöhten Knochenstoffwechsel. Diese Beobachtungen implizierten die Schlussfolgerung, dass ein gesteigerter Knochenumsatz nicht zwangsläufig zu einem Knochenverlust führen muss (Westerlind et al. 1997).

Aufgrund der ausgeprägten Sensibilität und der raschen Reaktion der proximalen Tibiametaphyse auf hormonelle Veränderungen nach Gonadektomie eignet diese sich besonders für die Analyse von Effekten applizierter Substanzen in tierexperimentellen Studien.

\section{I.4) Die Testsubstanz $\beta$-Ecdyson als ein Hauptvertreter der Ecdysteroide}

\section{I.4.1) Ecdysteroide im Allgemeinen}

Hinter dem Oberbegriff der Ecdysteroide verbirgt sich eine zunehmend große Zahl strukturverwandter Substanzen, die zur Gruppe der Steroide gehören. Ihr Vorkommen konnte bislang bei Arthropoden, Wirbellosen, Pilzen und Pflanzen, wie Gymnospermen und Angiospermen, nachgewiesen werden (Dinan et al. 2009). Der chemische Aufbau zeigt ein polyhydroxyliertes steroidales Grundgerüst (Cyclopentanoperhydrophenanthrene) mit cisA/B-Ring bestehend aus 27 bis 29 C-Atomen. Zusätzlich befinden sich typischerweise an der 17ß-Position eine Alkylseitenkette, am B-Ring eine 7-en-6-one Chromophor-Gruppe sowie an der 14a-Position eine Hydroxylgruppe (Báthori et al. 2008, Báthori und Pongrácz 2005, Lafont und Horn 1989).

Bei Arthropoden, das heißt Gliederfüßer wie Insekten, Spinnen, Krebsen oder Tausendfüßer, repräsentieren Ecdysteroide die Gruppe der Steroidhormone. Dieser Tierstamm ist bisher der einzige, für den ein hormoneller Effekt im streng genommenen Sinne der Definition nachgewiesen werden konnte (Báthori et al. 2008). Diese Hormonwirkung wird bei Insekten über nukleäre Rezeptoren ausgeübt, die wiederum Einfluss auf die Genexpression nehmen. Der Ecdysteroidrezeptor agiert bei seiner Bindung als Heterodimerkomplex mit dem Ultraspiracle (UsP) oder dem Retinoid-X-Rezeptor (RXR) als dessen homologes Äquivalent in Wirbeltieren (Yao et al. 1993, Oro et al. 1990). Der Wirkmechanismus bei Säugern konnte bislang noch nicht endgültig aufgeklärt werden. Eine Wirkung über einen nukleären Ecdysteroidrezeptor, wie bei Arthropoden, wird jedoch weitgehend ausgeschlossen.

Bei Insekten übernehmen Ecdysteroide beispielsweise Funktionen im Bereich der Häutung, der Entwicklung, der Metamorphose, der Reproduktion und der Diapause, das heißt in nahezu allen relevanten Lebensabschnitten (Dinan 2001, Dinan 1995, Horn 1989). 
Im Jahre 1954 konnte $\alpha$-Ecdyson als erstes Ecdysteroid aus der Seidenraupenpuppe Bombyx mori durch Peter Karlson isoliert werden. Für diesen ersten Isolationsprozess von $25 \mathrm{mg}$ $\alpha$-Ecdyson waren $500 \mathrm{~kg}$ Seidenraupenpuppen erforderlich (Karlson 1996). Die Dimension des Verhältnisses zwischen Menge notwendigen Materials und der daraus isolierten Menge an $\alpha$-Ecdyson verdeutlicht die eingeschränkte Verfügbarkeit an Ecdysteroiden in den frühen Anfängen dieses Forschungsbereichs. Zwölf Jahre später, im Jahre 1966, konnten Ecdysteroide auch aus pflanzlichem Material gewonnen werden (Lafont und Dinan 2003). Aus dieser Entdeckung heraus wurden daraufhin zur Differenzierung der Quelle die Begriffe Zoo- bzw. Phytoecdysteroide geprägt. Seit dieser ersten Isolation konnten im Verlauf bislang über 250 Phytoecdysteroide isoliert werden, sodass deren Vielfalt jene der Zooecdysteoride mittlerweile überwiegt (Báthori et al. 2000, Báthori und Pongrácz 2005). Diese einzigartige strukturelle Auswahl bei Pflanzen beruht vor allem auf unterschiedlichen Kombinationsmöglichkeiten bezüglich Anzahl, Stellung und Lokalisation substituierter Hydroxylgruppen am Ecdysteroidgrundgerüst (Báthori und Pongrácz 2005). Insgesamt lassen sich in geschätzten fünf bis sechs Prozent der Pflanzenspezies Phytoecdysteroide in signifikanten Konzentrationen nachweisen (Dinan 1995). Ein vielzitiertes Beispiel einer allbekannten ecdysteroidhaltigen Pflanze stellt der Spinat dar.

Obwohl genauere Daten noch zu evaluieren sind, vermutet man, dass Ecdysteroide bei Pflanzen unter anderem die Funktion des Schädlingschutzes innehaben. Darauf deutet beispielsweise die Beobachtung hin, dass einige dieser pflanzenfressenden Spezies nach Aufnahme geringer Ecdysteroidmengen eine Unterbrechung ihrer regulären Entwicklung erfahren (Lafont und Dinan 2009).

Durch eine zum Teil zwei- bis fünf-fach höhere Ecdysteroidkonzentration in Pflanzen im Vergleich zu Insekten (Báthori et al. 2008) stellen erstere heutzutage somit auch die Hauptisolationsquelle dar. Dank der auf diese Weise erweiterten Verfügbarkeit der Ecdysteroide und Fortentwicklung effizienterer Extraktionsverfahren, sind die Voraussetzungen für pharmakologische Effektstudien im Lauf der Zeit wesentlich verbessert worden. Motiviert durch die Beobachtung diverser positiver pharmakologischer Eigenschaften und dem vielfältigen, nebenwirkungsarmen Gebrauch Ecdysteroid-haltiger Präparate in der traditionellen chinesischen Medizin, haben Ecdysteroide und deren Wirkung auf Tier und Mensch in den vergangenen Jahren zunehmend das wissenschaftliche Interesse geweckt (Dinan und Lafont 2006). Ein wesentliches Forschungsziel ist dabei der wissenschaftliche Wirkungsnachweis der in Anwendungen beobachteten Effekte durch adäquate Studien. Zwar sind seit Entdeckung der Ecdysteroide und vor allem seit erleichterter 
Verfügbarkeit einige Effektstudien an Wirbeltieren und Säugern durchgeführt worden, allerdings wurden die erhaltenen Resultate oftmals nicht in englischer Sprache veröffentlicht und der Studienrahmen war somit auch nicht immer hinreichend nachvollziehbar. So erwiesen sich einige der Studien aufgrund von zu geringer Probandenanzahl oder extrem niedrigen applizierten Ecdysteroidmengen als eher zweifelhaft (Sláma und Lafont 1995). Neben einer möglichen Verwendung als Insektizide in der Landwirtschaft, erhofft man sich von der Forschung und Entwicklung vor allem eine etwaige medizinische Nutzung der mannigfaltigen Wirkungen. Die bislang beobachteten Effekte werden im folgenden, speziellen Abschnitt über $\beta$-Ecdyson beschrieben, da der überwiegende Teil ecdysteroidaler Studien mit Hilfe der Testsubstanz $\beta$-Ecdyson als stellvertretendes Hauptecdysteroid durchgeführt wurde.

\section{I.4.2) $\beta$-Ecdyson im Speziellen}

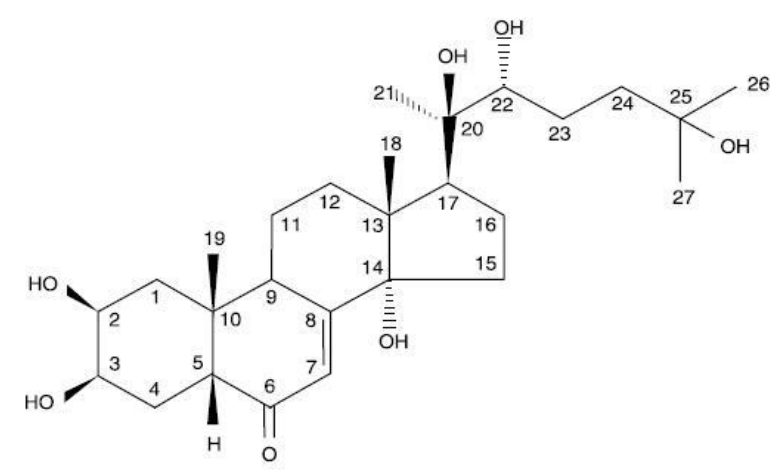

Abb.1: Strukturformel des $\beta$-Ecdysons $\left(\mathrm{C}_{27} \mathrm{H}_{44} \mathrm{O}_{7}\right)$ (aus Dinan und Lafont 2006, S. 2)

Nachdem auch $\beta$-Ecdyson 1956 erstmals durch Peter Karlson aus der Seidenraupenpuppe isoliert wurde, konnte es nach späterer Isolation aus der Languste Jasus lalandei 1966 durch Hampshire und Horn genauer charakterisiert und veröffentlicht werden (Thompson und Lusby 1989). Später ließ es sich sowohl aus Pflanzen als auch Tieren extrahieren und zählt durch sein weit verbreitetes und reichliches Vorkommen heute zum Hauptvertreter der Ecdysteroide. Aufgrund seiner jedoch nahezu gleichzeitigen Entdeckung durch verschiedene Wissenschaftler, entwickelte sich in der Literatur ein Nebeneinander verschiedener Bezeichnungen für $\beta$-Ecdyson. $\mathrm{Zu}$ nennende Beispiele hierfür sind 20-Hydroxyecdyson, Crustecdyson, Ecdysteron, Polypodine A und Isoinokosteron (Báthori et al. 2000). Im Rahmen dieser Arbeit wird im Folgenden $\beta$-Ecdyson synonym für die genannten Begriffe verwendet.

In den Jahren nach Entdeckung des $\beta$-Ecdysons wurde eine Vielzahl an Studien durchgeführt, die eine mögliche Wirkung von Ecdysteroiden auf den Säugetierorganismus nachweisen bzw. 
ausschließen sollten. Im Verlauf konnte eine Fülle unterschiedlicher Wirkungen erfasst werden, die nahezu alle zentralen physiologischen Prozesse des Organismus mehr oder weniger betreffen. Dabei muss jedoch betont werden, dass die nicht-spezifischen pharmakologischen Effekte bei Wirbeltieren und Menschen nicht mit einer Hormonaktivität gleichgesetzt werden dürfen (Báthori und Pongrácz 2005, Sláma und Lafont 1995).

Eine der frühen intensiv behandelten Ergebnisse stellt die Beobachtung dar, dass $\beta$-Ecdyson die Proteinsynthese stimuliert und somit den Gesamtproteingehalt von Geweben und Organen steigert (Syrov 2000). Durch verstärkte Proteinsynthese und anabole Wirkung auf Muskelgewebe, nimmt dieses und somit auch die fettfreie Körpermasse, vor allem bei effektivem Training und adäquater Proteinzufuhr über die Nahrung, zu (Lafont und Dinan 2009, Báthori et al. 2008). Die steigernde Wirkung auf die Muskelmasse und die verbesserte Ausdauer begründen das besondere Interesse von Sportlern und Bodybuildern an Ecdysteroiden. Die entsprechende Nachfrage spiegelt sich an einem Angebot von mittlerweile etwa 300 ecdysteroidhaltigen Produkten auf dem Markt wider (Dinan und Lafont 2006). Desgleichen findet der steigernde Effekt auf die fettfreie Masse bei gleichzeitiger Senkung des Futterverbrauchs auch in der landwirtschaftlichen Tierzucht, insbesondere aufgrund ökonomischer Gesichtspunkte, besondere Beachtung (Báthori et al. 2008). Aus diesem Grund gilt es gleichermaßen Verfahren zur Aufdeckung einer solchen strittigen Ecdysteroidnutzung zu entwickeln (Le Bizec et al. 2002).

In beiden möglichen Anwendungsbereichen werden neben der anabolen Aktivität vor allem die fehlenden androgenen und anti-gonadotropen Nebenwirkungen der Produkte beworben, $\mathrm{da}$ dies einen entscheidenden Unterschied $\mathrm{zu}$ beispielsweise Androgen-haltigen Dopingpräparaten darstellt (Báthori et al. 2008). An Tiermodellen durchgeführte Studien konnten tatsächlich belegen, dass $\beta$-Ecdyson und andere Ecdysteroide trotz Wirkung auf viele physiologische Prozesse keine androgenen Nebeneffekte erzeugen. Diese Schlussfolgerung wurde aus dem Fehlen einer Gewichtszunahme von Prostata und Samenblase als Vertreter Androgen-sensibler Organe abgeleitet (Báthori et al. 2008, Ogawa et al. 1974). Auch Prabhu und Nayar schlossen 1974 eine östrogene oder antiöstrogene Wirkung von $\beta$-Ecdyson nach intravaginaler Applikation mittels Vaginalzytologie aus. Báthori et al. (2008) schlussfolgerten ferner nach Durchführung von entsprechenden Radioligand-binding assays, dass Ecdysteroide allgemein nicht an nukleäre Steroidrezeptoren von Wirbeltieren binden und somit folglich auch keine östrogenen, glukokortikoiden oder androgenen Nebeneffekte ausüben.

Durch fehlende Interaktion mit humanen Steroidrezeptoren, kein endogenes Vorkommen von Ecdysteroiden und deren Rezeptoren beim Menschen sowie gleichzeitige spezifische Bindung 
an Ecdysteroidrezeptoren der Arthropoden wird zurzeit besonders an der Entwicklung von Gen-Switch Systemen für zukünftige potenzielle Anwendung in der Gentherapie geforscht (Lafont und Dinan 2003 und 2009).

Zusätzlich zum gering ausgeprägten Nebenwirkungsprofil, weisen Ecdysteroide ferner eine geringe akute Toxizität bei der Applikation in Säugern auf. Demgemäß konnte für $\beta$-Ecdyson bei Anwendung in Mäusen eine mittlere letale Dosis von LD50: > 6,4g/kg KG bei intraperitonealer (i.p.) und eine LD50: > 9 g/kg KG bei oraler Applikation evaluiert werden (Ogawa et al.1974). Unter Berücksichtigung der verfügbaren Studienergebnisse präsentieren sich Ecdysteroide auch bei anderen Säugetieren, inklusive des Menschen, als nicht toxische Substanzen, wobei jedoch ergänzende Langzeitstudien mit einer regelmäßigen bzw. kontinuierlichen Applikation noch ausstehen (Lafont und Dinan 2009). Überdies hinaus werden Ecdysteroiden oder Ecdysteroid-haltigen pflanzlichen Präparaten allgemein eine stärkende und widerstandserhöhende Wirkung gegen Stress und damit assoziierte Erkrankungen zugeschrieben (Báthori et al. 2008, Lafont und Dinan 2009). Dabei beschränkt sich die Wirkung im Regelfall jedoch nur auf die Prävention, das heißt, dass die Substanzen nach Krankheitsausbruch nicht notwendigerweise einen heilenden Effekt ausüben können (Lafont und Dinan 2009). 
Aufgrund des besonderen Umfangs ist eine Auswahl weiterer wichtiger bislang bekannter Effekte von $\beta$-Ecdyson im Folgenden lediglich in einer stichpunktartigen Übersicht dargestellt:

Tabelle 1: Übersicht über eine Auswahl bislang untersuchter Effekte von $\beta$-Ecdyson in Säugetieren, Wachteln und Menschen

\begin{tabular}{|c|c|c|}
\hline B-Ecdyson-Effekt & $\begin{array}{l}\text { untersuchte Gruppe / } \\
\text { Applikationsform : }\end{array}$ & Literaturquelle: \\
\hline \multicolumn{3}{|l|}{ A: in vitro: } \\
\hline $\begin{array}{l}\text { Abnahme der Glukoseproduktion in } \\
\text { Leberzellkultur }\end{array}$ & Ratten & Kizelsztein et al. 2009 \\
\hline $\begin{array}{ll}\text { Förderung } & \text { der } \\
\text { Keratinozytendifferenzierung } & \end{array}$ & Mensch & $\begin{array}{l}\text { Detmar et al. } 1994 \\
\text { (Abstract) }\end{array}$ \\
\hline \multicolumn{3}{|l|}{ B: in vivo: } \\
\hline $\begin{array}{l}\text { Blutzucker-senkend bei experimentell } \\
\text { induzierter Hyperglykämie }\end{array}$ & $\begin{array}{l}\text { Ratten/Mäuse } \\
\text { i. p. }\end{array}$ & Yoshida et al. 1971 \\
\hline $\begin{array}{l}\text { Abnahme der Fettgewebsmasse und } \\
\text { bessere Vorbeugung von Ernährungs- } \\
\text { bedingtem Übergewicht }\end{array}$ & $\begin{array}{l}\text { Mäuse } \\
\text { p. o. }\end{array}$ & Kizelsztein et al. 2009 \\
\hline $\begin{array}{l}\text { Abnahme des Cholesterinspiegels durch } \\
\text { vermehrte Ausscheidung via Galle }\end{array}$ & & Lupien et al. 1969 \\
\hline$>$ Wachstums-fördernd & $\begin{array}{l}\text { Japanische Wachteln } \\
\text { p. o. }\end{array}$ & Koudela et al. 1995 \\
\hline $\begin{array}{l}>\text { Förderung der chemotherapeutischen } \\
\text { Antitumor-Wirkung von Cisplatin und } \\
\text { Adriamycin }\end{array}$ & Mäuse & Konovalova et al. 2002 \\
\hline $\begin{array}{l}\text { Hypoazotämisch, das heißt Senkung } \\
\text { stickstoffhaltiger } \\
\text { Proteinstoffwechselprodukte } \\
\text { (z.B. Harnstoff) im Blut }\end{array}$ & $\begin{array}{l}\text { Ratten } \\
\text { p. o. /Magensonde }\end{array}$ & Saatov et al. 1999 \\
\hline 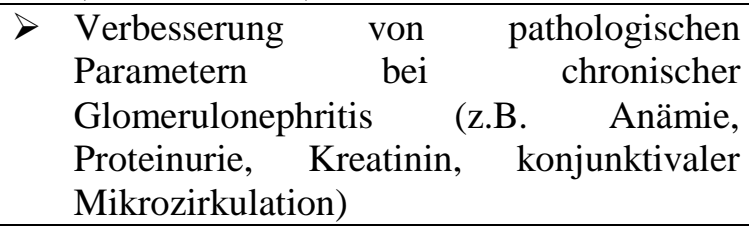 & $\begin{array}{l}\text { Mensch } \\
\text { p. o. }\end{array}$ & Saatov et al. 1999 \\
\hline $\begin{array}{l}>\text { Steigerung der Erythrozytenzahl und des } \\
\text { Hämoglobingehalts im Blut }\end{array}$ & Ratten & $\begin{array}{l}\text { Syrov et al. } 1997 \\
\text { (Abstract) }\end{array}$ \\
\hline
\end{tabular}

Im Rahmen der vorliegenden Studie sind die bisher untersuchten Effekte von $\beta$-Ecdyson auf den Knochen und dessen Stoffwechsel von besonderem Interesse. So konnten Syrov et al. 1986 einen begünstigenden Effekt von $5 \mathrm{mg} / \mathrm{kg}$ oral appliziertem $\beta$-Ecdyson auf die Knochenheilung nach experimentell induzierten Frakturen beobachten (Syrov et al. 1986, Lafont und Dinan 2003). Außerdem erwies sich $\beta$-Ecdyson in einer weiteren Studie als 
stimulierend auf die proliferative Aktivität von Osteoblasten-ähnlichen UMR106 Zellen (Gao XY et al. 2000, Lafont und Dinan 2003). Problematisch an diesen beiden Effektstudien ist die Gegebenheit, dass die Ergebnisse nicht in Englisch oder lediglich in Form von Abstracts veröffentlicht wurden und somit schwer zu bewerten sind. Unlängst wurden jedoch auch Studienergebnisse in englischer Sprache publiziert, die zeigen konnten, dass $\beta$-Ecdyson bei Mäusen stimulierend auf die Differenzierung von Mesenchymzellen zu Osteoblasten wirken (Gao L et al. 2008). Diese stimulierenden Effekte von $\beta$-Ecdyson auf die knochenbildenden Zellen stellen eine wichtige Voraussetzung für eine geförderte Synthese von Knochengewebe dar. Möglicherweise ergibt sich aus dieser Beobachtung heraus demzufolge ein möglicher Therapieansatz zur Prävention von Knochenverlust durch altersassoziierten Geschlechtshormonmangel und zur nebenwirkungsarmen Behandlung des osteopenisch bzw. osteoporotisch veränderten Knochens.

Durch verbesserte quantitative und qualitative Isolationsmöglichkeiten von $\beta$-Ecdyson, konnten inzwischen auch die Kosten für die Substanz gesenkt werden, sodass es zunächst für pharmakologische Untersuchungen und im Verlauf für eine mögliche pharmazeutische Produktion leichter verfügbar geworden ist (Lafont und Dinan 2009). Nicht zuletzt wäre daraus folgend, auch aus ökonomischer Sicht, eine Entwicklung von preisgünstigen Behandlungsalternativen für häufige Erkrankungen wie der Osteoporose in der zunehmend alternden Gesellschaft von Interesse.

\section{Fragestellung und Studienziel}

In diesem Sinne ist es das Ziel der vorliegenden Studie, einen möglichen Effekt von $\beta$-Ecdyson auf Knochen mit erhöhtem Osteopenierisiko im Vergleich zum physiologisch normalen Knochen zu analysieren. Mit Hilfe eines dreimonatigen Futterversuchs soll eine potenzielle osteoprotektive Wirkung des $\beta$-Ecdysons gegenüber dem durch Geschlechtshormonmangel induzierten Knochenverlust nach Gonadektomie bei männlichen und weiblichen Ratten untersucht werden. Die Analyse fokussiert sich somit auf die Histologie der Tibia von ovx bzw. orx S.D.-Ratten, da sich diese, wie eingangs beschrieben, vor allem im Metaphysenbereich besonders sensibel und reaktiv gegenüber hormonellen Veränderungen sowie Substanzapplikation, beispielsweise nach Gonadektomie, zeigt. Im Rahmen der vorliegenden Arbeit soll des Weiteren die kritische Auseinandersetzung mit den zwei angewandten morphometrischen Verfahren in der Trabekel- und Knochenmarksanalyse durch einen Methodenvergleich erfolgen. 


\section{II.) Material und Methoden}

\section{II.1) Allgemeines zur Haltung und Versorgung der Versuchstiere}

Die vorliegende Studie wurde mit der Zielsetzung konzipiert, die Auswirkungen der Substanz $\beta$-Ecdyson auf unterschiedliche Organsysteme der Ratte $\mathrm{zu}$ untersuchen. Zur Induktion potenzieller Effekte wurde eine knapp dreimonatige Applikation des $\beta$-Ecdysons per os (p.o.) über das Futter vorgesehen.

Vor Studienbeginn wurde zunächst eine entsprechende Tierversuchsgenehmigung bei der Bezirksregierung Braunschweig beantragt. Jene genehmigte den Versuch am 3.08.2006 unter der folgenden Genehmigungsnummer: AZ: 33.42502-082-06.

Während des Versuchszeitraums vom 17.10.2007 bis 5.03.2008 wurde daraufhin ein Kollektiv von insgesamt 96 Sprague-Dawley-Ratten (S.D.-Ratten) (Harlan Winkelmann, Borchen) beobachtet und betreut. Die vorgenommene, scheinbar unausgewogene Geschlechterverteilung von 60 Männchen im Vergleich zu 36 Weibchen deutet bereits auf die Tatsache hin, dass das Experiment schwerpunktmäßig auf Beobachtungen am Tiermodell der männlichen Ratte ausgerichtet war.

Bei Ankunft, das heißt am 17.10.2007, waren die Tiere etwa sieben Wochen alt, was bei der Ratte ungefähr dem Entwicklungsstand des Eintritts in die Geschlechtsreife entspricht.

Alle Tiere wurden ab dem Moment ihres Eintreffens während des gesamten Zeitraums unter konstanten, definierten Umweltbedingungen in konventioneller, offener Haltung versorgt, das heißt es wurden keine besonderen Einschleusungsmaßnahmen der betreuenden Personen vorgenommen. Somit wurden beim Umgang mit den Tieren lediglich Kittel und Schuhüberzieher getragen. Umwelteinflüsse, wie Licht und Temperatur, wurden standardisiert. Demnach gab es täglich ein 12-stündiges Beleuchtungsintervall von 7-19 Uhr bzw. von 6-18 Uhr, gefolgt von einem entsprechend langen Dunkelheitszyklus. Die Luftfeuchtigkeit im Tierstall betrug 40-50 \% bei einer Durchschnittsraumtemperatur von ungefähr $21^{\circ} \mathrm{C}$. Weiterhin wurde eine größenabhängige Haltung von vier bis sechs Tieren pro Käfig der Marke Makrolon® Typ 4 mit einer Fläche von $1800 \mathrm{~cm}^{2}$ festgelegt. Diese wurden mit Streu (Lignocel®, Rosenberg) ausgelegt und zweimal wöchentlich zu fixen Zeiten gegen gereinigte Käfige durch Umsetzen der Tiere ausgetauscht.

Weiterhin hatten die Ratten während der gesamten Versuchsdauer einen ad-libitum-Zugang zu Wasser und Futter. Letzteres verfügte über eine gruppenabhängige individuelle Dosis der $\mathrm{zu}$ untersuchenden Substanz $\beta$-Ecdyson. Der somit beliebige Futterverbrauch und indirekt auch die damit variable Aufnahme an $\beta$-Ecdyson wurden jedoch einmal wöchentlich zu möglichst gleicher Uhrzeit durch Wiegen der Restfuttermenge bilanziert. Diese wurde von der 
ursprünglich zugeführten Menge von 1500g Futter pro Woche subtrahiert. Mittels Division durch die Anzahl der im jeweiligen Käfig befindlichen Ratten konnte schließlich der entsprechende Futterverbrauch pro Tier berechnet werden.

\section{II.2) Spezieller Versuchsablauf}

\section{II.2.1) Identische Vorbedingungen für alle Tiere}

Zu Beginn des Versuchs galten im Rahmen einer Eingewöhnungs- und Adaptationsphase für alle Tiere zunächst dieselben Vorbedingungen hinsichtlich des Futters und der Intaktheit der geschlechtlichen/hormonellen Funktionen. Dementsprechend wurden alle 96 Tiere, unabhängig von ihrer späteren Futtergruppe, zunächst für knapp einen Monat (17.10.07 bis 14.11.07) mit dem phytoöstrogenarmen Futter V1354-000 R-Z (10mm) der Firma ssniff® Spezialdiäten $\mathrm{GmbH}$, Soest ernährt (Zusammensetzung siehe methodischer Anhang).

\section{II.2.2) Analyse der Knochenstruktur vor $\beta$-Ecdyson-Applikation mittels pQCT-Messung}

Zur Evaluation der Knochenstruktur unter ebendiesen Vorbedingungen und vor der erstmaligen $\beta$-Ecdyson-Applikation über das Futter, wurde vom 28.11.07 bis 7.12.07 die erste periphere quantitative Computer-Tomographie-Messung (pQCT) der mittlerweile 3 Monate alten, also deutlich post-pubertären, Ratten durchgeführt. Für die Messung wurde das pQCTGerät Stratec XCT 4.50 (Stratec Inc., Pforzheim) verwendet. Dabei wurden die Knochen der mit Isofluran narkotisierten Tiere sowohl im Bereich der linken Tibia, als teilweise auch in der Lendenwirbelregion dargestellt. Die Auswertung der dabei erhaltenen Daten hinsichtlich Knochenbeschaffenheit und umgebenden Fettanteil erfolgte im Rahmen anderer Dissertationen.

\section{II.2.3) Randomisierte Zuteilung zu den Futtergruppen und Gonadektomie}

Nach der zunächst identischen Vorbehandlung aller 96 S.D.-Ratten, erfolgte daraufhin die Einteilung in acht gleich große Gruppen à 12 Tiere. Dabei wurden die geschlechtlichen Unterschiede berücksichtigt. Die folgende Tabelle 2 liefert eine Übersicht über die Gruppenverteilung. Weiterhin sind die entsprechend damit verbundenen Parameter bezüglich Futter und gonadalem Status gruppenabhängig dargestellt. 
Tabelle 2: Tabellarische Übersicht über die Zuteilung der S.D.-Ratten zu den jeweiligen Futtergruppen

\begin{tabular}{|c|c|}
\hline Gruppe 1 (Nr. 1-12) & Männlich, orx, sojafrei $\rightarrow$ Kontrollgruppe \\
\hline Gruppe 2 (Nr. 13-24) & Männlich, intakt, sojafrei $\rightarrow$ Kontrollgruppe \\
\hline Gruppe 3 (Nr. 25-36) & Männlich, orx, $\beta$-Ecdyson 0,5 ( $\triangleq$ Ecd 11) \\
\hline Gruppe 4 (Nr.37-48) & Männlich, orx, $\beta$-Ecdyson 1,0 ( $\triangleq$ Ecd 22) \\
\hline Gruppe 5 (Nr.49-60) & Männlich, orx, $\beta$-Ecdyson 3,0 (스 Ecd 67) \\
\hline Gruppe 6 (Nr.61-72) & Weiblich, ovx, sojafrei \\
\hline Gruppe 7 (Nr.73-84) & Weiblich, ovx, $\beta$-Ecdyson 0,2 (^ Ecd 4) \\
\hline Gruppe 8 (Nr.85-96) & Weiblich, ovx, $\beta$-Ecdyson 0,5 ( $\triangleq$ Ecd 10) \\
\hline
\end{tabular}

Vom 10.12.07 bis 14.12.07 wurde, wie aus der Tabelle ersichtlich, bei den Tieren je nach Gruppenzugehörigkeit und Geschlecht eine ORX bzw. OVX durchgeführt. Die Operation erfolgte unter Vollnarkose mit Isofluran. Gleichzeitig erfolgte eine analgetische Therapie mit Rimadyl®, einem nicht-steroidalen Antiphlogistikum mit dem Wirkstoff Carprofen. Ausgenommen von der Operation blieben die zur intakten Kontrollgruppe erklärten 12 Tiere aus Gruppe 2. Ab dem Zeitpunkt der ORX bzw. OVX erhielten die Tiere ihrer Gruppe entsprechend Futter mit der jeweiligen $\beta$-Ecdyson-Konzentration über einen Zeitraum von fast 5 Monaten. Das Futter wurde nach Anforderung von der Firma ssniff® Spezialdiäten $\mathrm{GmbH}$, Soest hergestellt und mit entsprechenden Mengen der Testsubstanz $\beta$-Ecdyson versetzt. Wie aus Tabelle 1 ersichtlich, erhielten die männlichen Ratten der Gruppe 3 Futter mit $0,5 \mathrm{~g} / \mathrm{kg}$, der Gruppe $41,0 \mathrm{mg} / \mathrm{kg}$ und der Gruppe $53,0 \mathrm{mg} / \mathrm{kg} \quad \beta$-Ecdyson. Bei den Weibchen konnten aufgrund von bereits erfolgten Studien feiner differenzierte Konzentrationen von $0,2 \mathrm{mg} / \mathrm{kg}$ bei Gruppe 7 und $0,5 \mathrm{mg} / \mathrm{kg} \quad \beta$-Ecdyson bei Gruppe 8 eingesetzt werden. Die Ratten der Gruppen 1, 2 und 6 erhielten als Kontrollgruppen weiterhin sojafreies Futter.

\section{II.2.4) Körpergewichtsanalyse während des Versuchszeitraums}

Während der vorliegenden Studie wurde der Verlauf des Körpergewichts durch wiederholtes Wiegen verfolgt. Mit den erhaltenen Werten ließ sich bei Studienende der Futterverbrauch bzw. die $\beta$-Ecdysonaufnahme in Bezug auf das Körpergewicht berechnen. Zur Vermeidung einer zusätzlichen Stressbelastung für die Tiere, wurde das Wiegen möglichst mit den grundsätzlich vorgesehenen Maßnahmen, wie zum Beispiel den pQCT-Messungen bzw. der o.g. Operation, kombiniert. Über den gesamten Versuchszeitraum hinweg konnten somit pro Tier jeweils fünf Werte für die Körpergewichte protokolliert werden. 


\section{II.2.5) Abschließende pQCT-Messung und Versuchsende}

Eine Woche vor Versuchsende, das heißt vom 25.02.08 bis 27.02.08, erfolgte, wie oben beschrieben, eine erneute Evaluation des Knochenaufbaus der Tiere mit Hilfe des pQCTGeräts. In der darauffolgenden Woche vom 3.03.08 bis 5.03.2008 endete die Studie. Die S.D.Ratten wurden zunächst in $\mathrm{C}_{2}$-Narkose versetzt und daraufhin durch Decapitation getötet. In der direkt anschließenden Obduktion wurden eine Blutprobe, Herz, Leber, Uterus, Prostata und Samenblase entnommen und auf makroskopisch sichtbare Auffälligkeiten überprüft. Die dadurch erhaltenen Präparate wurden anschließend gewogen und zunächst bis zur Weiterverarbeitung in flüssigem Stickstoff konserviert. Zusätzlich zu den entfernten Organen, wurden die jeweils linken Tibiae frei präpariert und separat von Musculus gastrocnemius und paratibialem Fettgewebe ebenfalls in flüssigem Stickstoff aufbewahrt. Im Anschluss an die Obduktion wurden die entnommenen Organe und Gewebe in der Kühltruhe bis zur weiteren Verarbeitung gelagert.

\section{II.3) Vermessung der intakten Rattentibiae}

Vor der Weiterverarbeitung der noch intakten Knochen zu Hartschnittpräparaten, wurden diese mit Hilfe einer Schieblehre (Digitaler Messschieber, TCM, Hamburg) vermessen. So wurden sowohl die Länge der Tibiae, als auch die Tibiakopfdurchmesser auf Metaphysenhöhe von anterior nach posterior bzw. von medial nach lateral bestimmt und protokolliert.

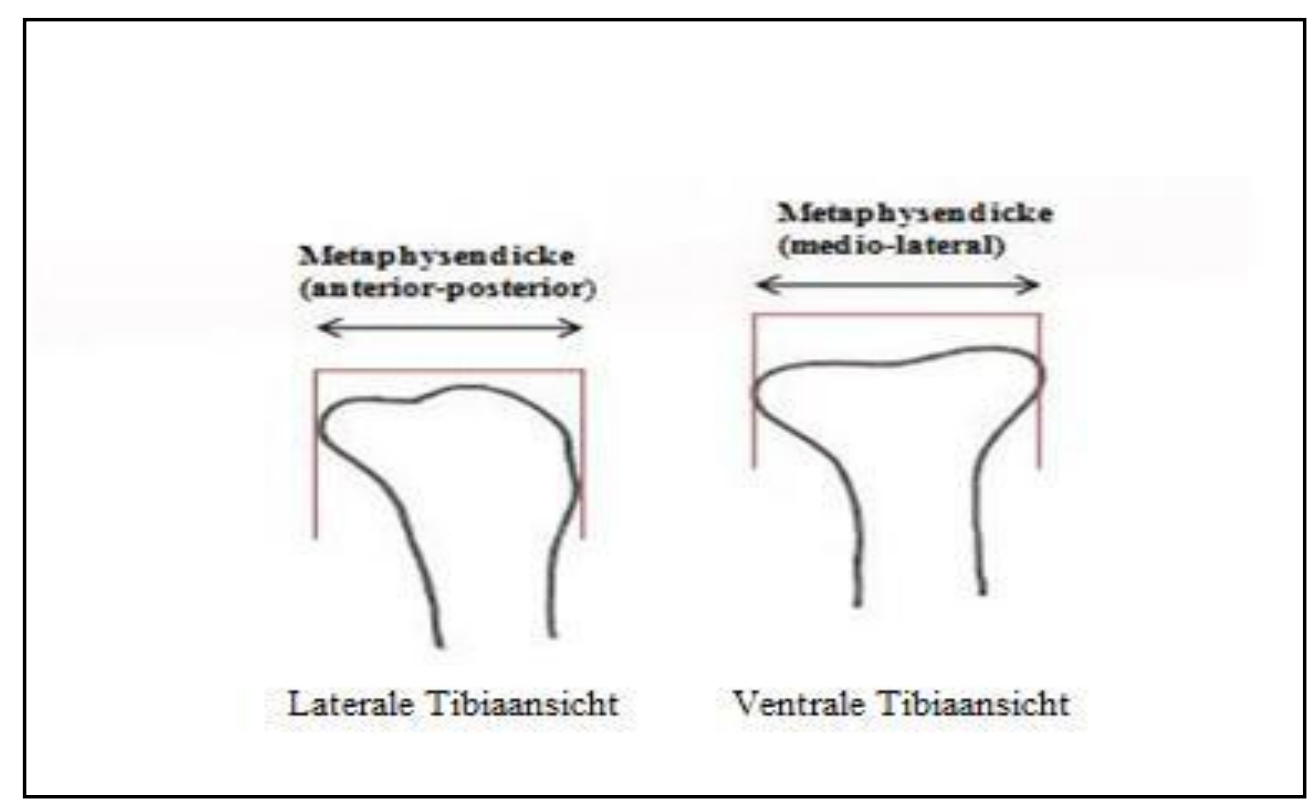

Abb.2: Schematische Darstellung der Messung des Tibiakopfdurchmessers bzw. der Metaphysendicke in anterior-posteriorer und medio-lateraler Richtung mittels Schieblehre. 


\section{II.4) Verarbeitung der Knochen zu mikroskopischen Hartschnittpräparaten}

\section{II.4.1) Kürzen der Tibiae auf vorgesehene Präparatlänge und Fixierung}

Vor Weiterverarbeitung der Knochen wurden diese etwa 20 Minuten zuvor aus der Tiefkühltruhe genommen. Das Antauen sollte die Splittergefahr durch den gefrorenen Flüssigkeitsanteil senken. Im Folgenden wurden die Knochen mit Hilfe einer Zange auf 2/3 der proximalen Diaphyse gekürzt. Um einen glatten, splitterfreien Schnitt zu erzielen, wurde in einem Knochenmarkarmen, also optisch helleren Bereich angesetzt. Das gekürzte Knochenstück wurde anschließend zur Fixierung für 36 Stunden in $4 \%$ gepufferte Formalinlösung (0,1 M bzw. 0,02 M Phosphatpuffer) gegeben.

\section{II.4.2) Vorbehandlung des Knochengewebes und Einbettung mit Hilfe von Technovit ${ }^{\circledR} 9100$ neu}

$\mathrm{Zu}$ allererst galt es die Knochen zu dehydrieren, um die Bildung von „Lunkerstellen“ aus weißen Perlpolymerisaten zu verhindern. Zur stufenweisen Entwässerung wurden die Knochen somit für jeweils 24 Stunden in einer aufsteigenden Alkoholreihe positioniert. Die folgende Abbildung zeigt unter anderem das dafür verwendete Entwässerungsprotokoll, das bei Raumtemperatur durchgeführt wurde.
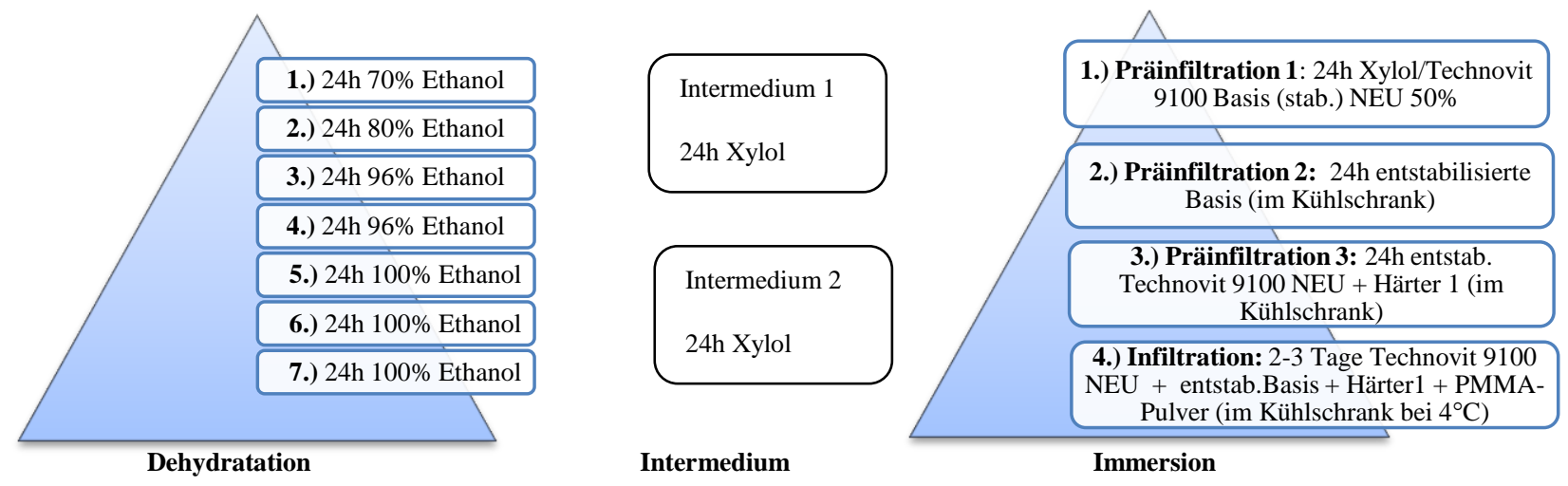

Abb. 3: Dehydratation, Intermedium und Immersion

Technovit ${ }^{\circledR} 9100 \mathrm{NEU} /$ Basis $\rightarrow$ Monomer aus reaktionsfähigen Kohlenstoffketten Härter $1 \rightarrow$ Peroxidverbindung, die die Polymerisation einleitet PMMA-Pulver $\rightarrow$ zusätzlicher innerer Füllstoff

Auf den nächsten zwei Stufen der Vorbehandlung wurden die entwässerten Knochenstücke für wieder jeweils 24 Stunden in zwei aufeinanderfolgende Intermedien aus Xylol gegeben. 
Als letzter Schritt für die Einbettung der Knochen folgte die Immersion, die sich aus den Stufen der Präinfiltration 1-3 und der endgültigen Infiltration der Tibiae zusammensetzte. Verwendet dafür wurde das Einbettungssystem Technovit ${ }^{\circledR} 9100$ NEU der Firma Heraeus, das auf der Polymerisation von Methylmethacrylat in Kälte basiert. So wurde im letzten Schritt der Immersion das unmittelbar vor Verwendung angesetzte Polymerisationsgemisch vorsichtig randvoll in die Einbettungsform mit den darin positionierten Knochen gegossen. Anschließend erfolgte eine etwa 10-minütige Evakuation im Exsikkator, um potenzielle Lufteinschlüsse im zukünftigen Präparat $\mathrm{zu}$ reduzieren. Danach wurden die Einbettungsgefäße für den Polymerisationsprozess unter Sauerstoffausschluss mit einem Deckel verschlossen. Es folgte eine 2- bis 3-tägige Aushärtung im Kühlschrank bei minus 7 bis minus $8{ }^{\circ} \mathrm{C}$. Anschließend wurden die polymerisierten Blöcke aus den Einbettungsformen gelöst und vorübergehend noch für kurze Zeit im Kühlschrank aufbewahrt. Eine detailliertere Beschreibung der für den Polymerisationsablauf verwendeten Komponenten und Reagenzien erfolgt aus Gründen der Übersichtlichkeit im methodischen Anhang.

\section{II.4.3) Verarbeitung der Polymerisate zu Hartschnittpräparaten mittels Mikrotomie}

Nach dem vollständigen Aushärten der Polymerisate konnten diese mit Hilfe eines Hartschnittmikrotoms zu lichtmikroskopischen Präparaten weiterverarbeitet werden. Es folgte somit das Anfertigen von $4 \mu \mathrm{m}$ dicken Schnitten entlang der Knochenlängsachse. Verwendet wurde hierfür das Tischrotationsmikrotom Leica RM 2165 mit einem 16-cmHartmetallmesser mit D-Schliff. Als Schneideflüssigkeit wurde 30\%iges Ethanol mit einem Pinsel auf die entsprechende Schnittfläche aufgetragen. Bei Erhalt eines angemessenen Schnitts, wurde dieser mit Hilfe eines Tropfens 30\%igen Ethanols auf den Objektträger aufgezogen. Als Objektträger wurden Menzel Gläser SuperFrost Ultra Plus® verwendet. Zum Strecken des positionierten Schnittpräparats wurde ein Tropfen 50\%iges Ethanol aufgebracht. Abschließend wurde das Präparat mit Kisol-Folie der Firma Kettenbach abgedeckt und in einer Presse über Nacht bei $57^{\circ} \mathrm{C}$ im Trockenschrank getrocknet.

\section{II.4.4) Entplastung und Goldner-Färbung der Hartschnittpräparate}

Vor dem Färben der Hartschnittpräparate mit Hilfe der Goldner-Färbung, mussten diese durch Entfernen des Einbettungsmaterials, das heißt des Acrylats, zunächst vorbehandelt werden. Das folgende Schema zeigt die schrittweise Entplastung der Schnitte durch Eintauchen in folgende Reagenzien: 

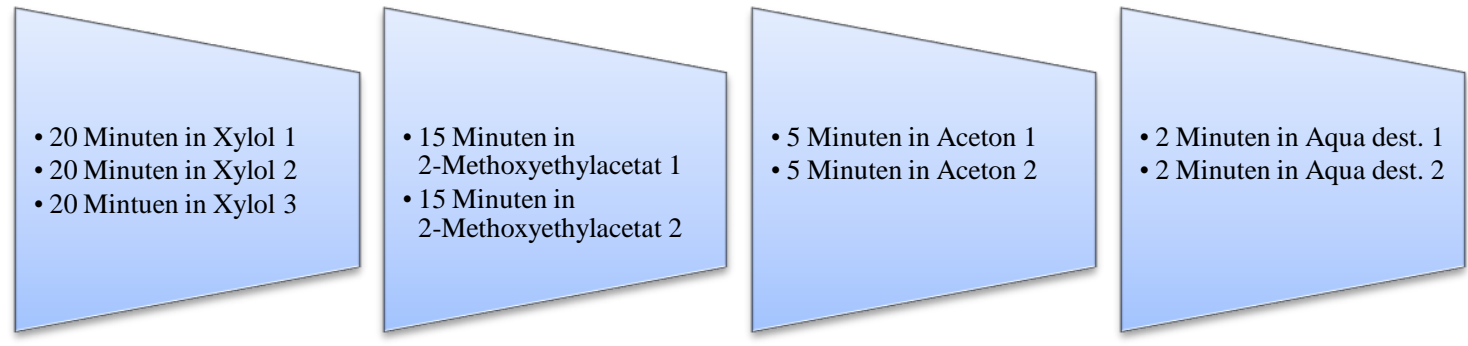

Abb.4: Schrittweise Entplastung der in Technovit ${ }^{\circledR} 9100$ neu eingebetteten Hartschnittpräparate

Nach der Entplastung konnten die Gewebeschnitte mittels Goldner-Färbung zu lichtmikroskopischen Präparaten fertig gestellt werden. Die Färbung umfasste insgesamt 10 Einzelschritte, bei denen die Präparate in vorgegebener Reihenfolge und Dauer in die entsprechenden Reagenzien eingestellt wurden. In der folgenden Übersicht ist die Abfolge der Schritte während der Goldner-Färbung dargestellt.

-10 Minuten in Weigerts Hämatoxylin

-10 Minuten in Leitungswasser Bläuen

- 45 Minuten in 2g Ponceau de Xylidine $+1 \mathrm{~g}$ Säurefuchsin $+0,4 \mathrm{ml} 1 \%$ ige Essigsäure $+200 \mathrm{ml}$ destilliertes Wasser

-1 Minute in 1\%iger Essigsäure spülen

-Kurzes Abspülen in destilliertem Wasser

-7 Minuten in 2g Wolframatophosphorsäure + 1g Orange G + 200ml destilliertes Wasser

- 1 Minute in 1\%iger Essigsäure spülen

-10 Minuten in 0,4g Lichtgrün + 0,4ml Essigsäure $+200 \mathrm{ml}$ destilliertes Wasser

- mit 1\%iger Essigsäure auswaschen

-Entwässern : 5 Minuten in 96\%igem Ethanol, dann 3 mal je 5 Minuten in 100\%igem Ethanol

-3 mal je 10 Minuten in Xylol

Abb.5: Ablauf der Goldner-Färbung

Zum Abschluss der Goldner-Färbung wurden die Präparate auf dem Objektträger noch mit einem Deckglas versehen. Dies wurde mit Hilfe eines Tropfens Eukitt aufgeklebt.

\section{II.5) Histologische Auswertung der Tibiapräparate}

\section{II.5.1) Mikroskop und Computersoftware}

Für die lichtmikroskopische Auswertung der Tibiapräparate wurde ein Zeiss Axiophot Mikroskop ${ }^{\circledR}$ verwendet. Die fotogestützten Auswertungen wurden durch die integrierte CCDKamera ermöglicht. Dabei wurden die aufgenommenen Präparatfotos mit Hilfe der Software analySIS® 3.0 (Soft Imaging System GmbH / Olympus, Hamburg) analysiert und ausgewertet. 


\section{II.5.2) Messung der Kortikalisdicke in diaphysären und metaphysären Bereichen}

Für die Messung der Kortikalisdicke wurde eine Vergrößerung von 3,125 (1,25 × 2,5) gewählt. In einem ersten Schritt wurde zunächst ein intakter Kortikalisabschnitt im diaphysären Bereich ausgewählt und in einem Foto fixiert. Daraufhin wurden zehn beliebige Abstände zwischen äußerer und innerer Kortikalsseite gemessen, indem diese möglichst parallel zueinander im etwa $90^{\circ}$-Winkel zum Kortikalisverlauf eingezeichnet wurden. Aus den zehn erhaltenen Einzelwerten wurde im Folgenden ein Mittelwert berechnet. Diese beschriebene Arbeitsabfolge wurde anschließend für den metaphysären Bereich wiederholt und sowohl für die mediale, als auch die laterale Tibiaseite durchgeführt.

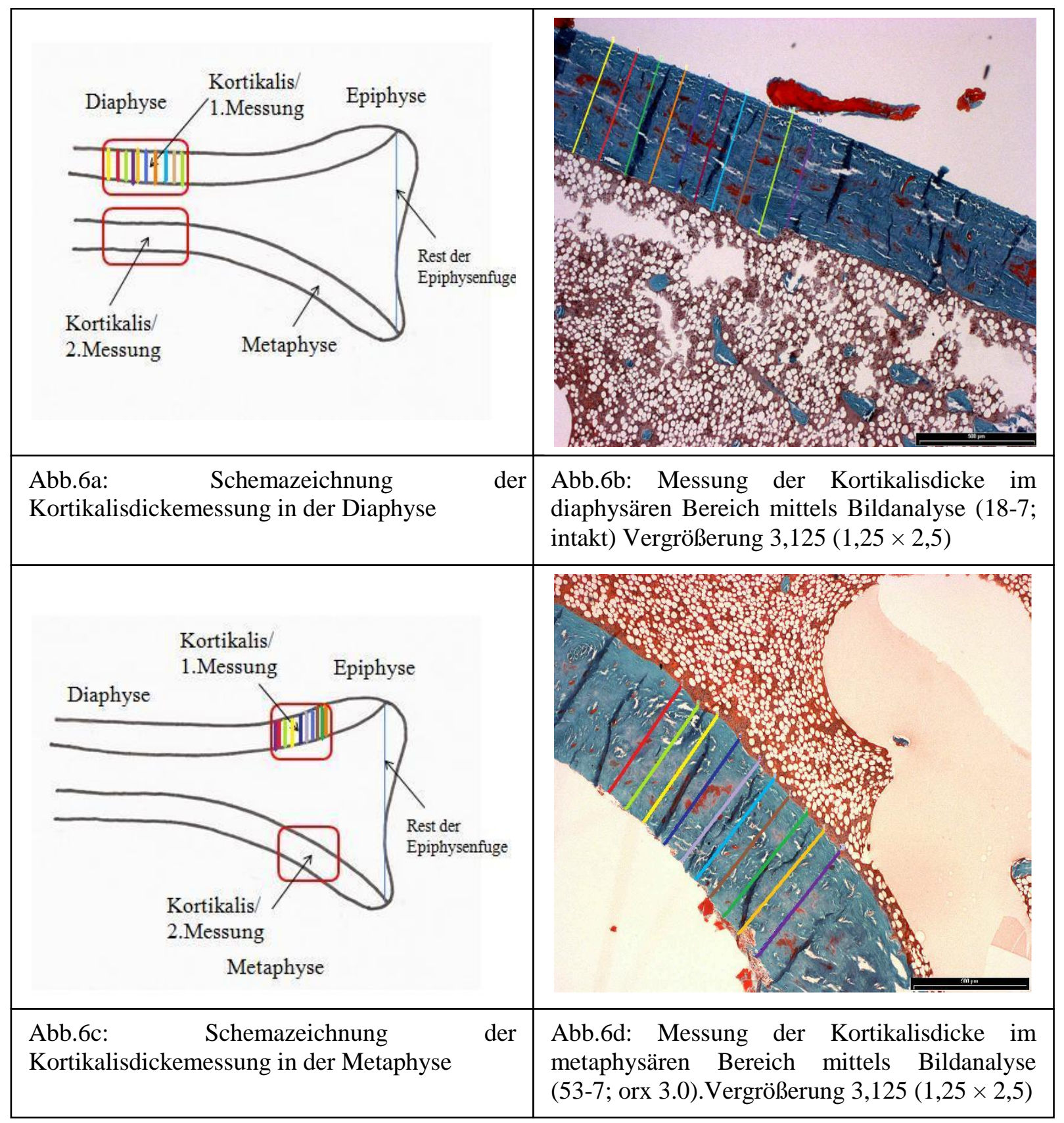




\section{II.5.3) Bestimmung der Fläche und der prozentualen Anteile an Trabekeln und Knochenmark}

Zur Messung der relativen Anteile an Trabekeln, rotem Knochenmark und gelbem Fettmark in der Tibia wurden mittels Fotoanalyse Schwellenwerte an identischen Bildausschnitten mit Hilfe zweier unterschiedlicher, im Folgenden beschriebenen, Verfahren gebildet und anschließend eine Phasenanalyse durchgeführt. Dies erfolgte bei einer Vergrößerung von 12,5 (1,25 × 10). Dabei wurden zwei unterschiedliche Tibiaregionen ausgewählt: Zum Einen ein $1 \mathrm{~mm}$ unter der Knorpelgrenze zentral liegender Bereich der Metaphyse, zum Anderen ein direkt an den Knorpel angrenzender Abschnitt der Epiphyse. Letzteres wurde sowohl auf der medialen, als auch der lateralen Seite des Tibiakopfes durchgeführt. Für die Auswertung der Präparate im Metaphysenbereich wurden zwei verschiedene Verfahren der Fotoanalyse parallel angewandt und die erhaltenen Ergebnisse gemittelt. Die Epiphyse wurde nur mittels Verfahren 2, das heißt der Schwellenwertbildung am Negativbild im roten Farbauszug, analysiert. Im Folgenden sind die dafür im analySIS-Programm durchgeführten Arbeitsschritte mit den entsprechenden Beispielfotos dargestellt:

Verfahren 1: 1.) Fixierung des auszuwertenden Präparatabschnitts im Foto

„D-Methode“ 2.) Änderung der Bit-Tiefe in 8 Bit durch Farbreduktion

3.) Umsetzung des Nativbildes in einen Grauabzug

4.) Definition der Schwellenwerte durch Zuordnung zu den im 8-Bit-Grauwertbild auszuwertenden Tibiaanteilen

5.) Phasenanalyse anhand der zugewiesenen Schwellenwerte

\begin{tabular}{|l|l|l|}
\hline Riaphyse \\
rotem/gelbemKM
\end{tabular}




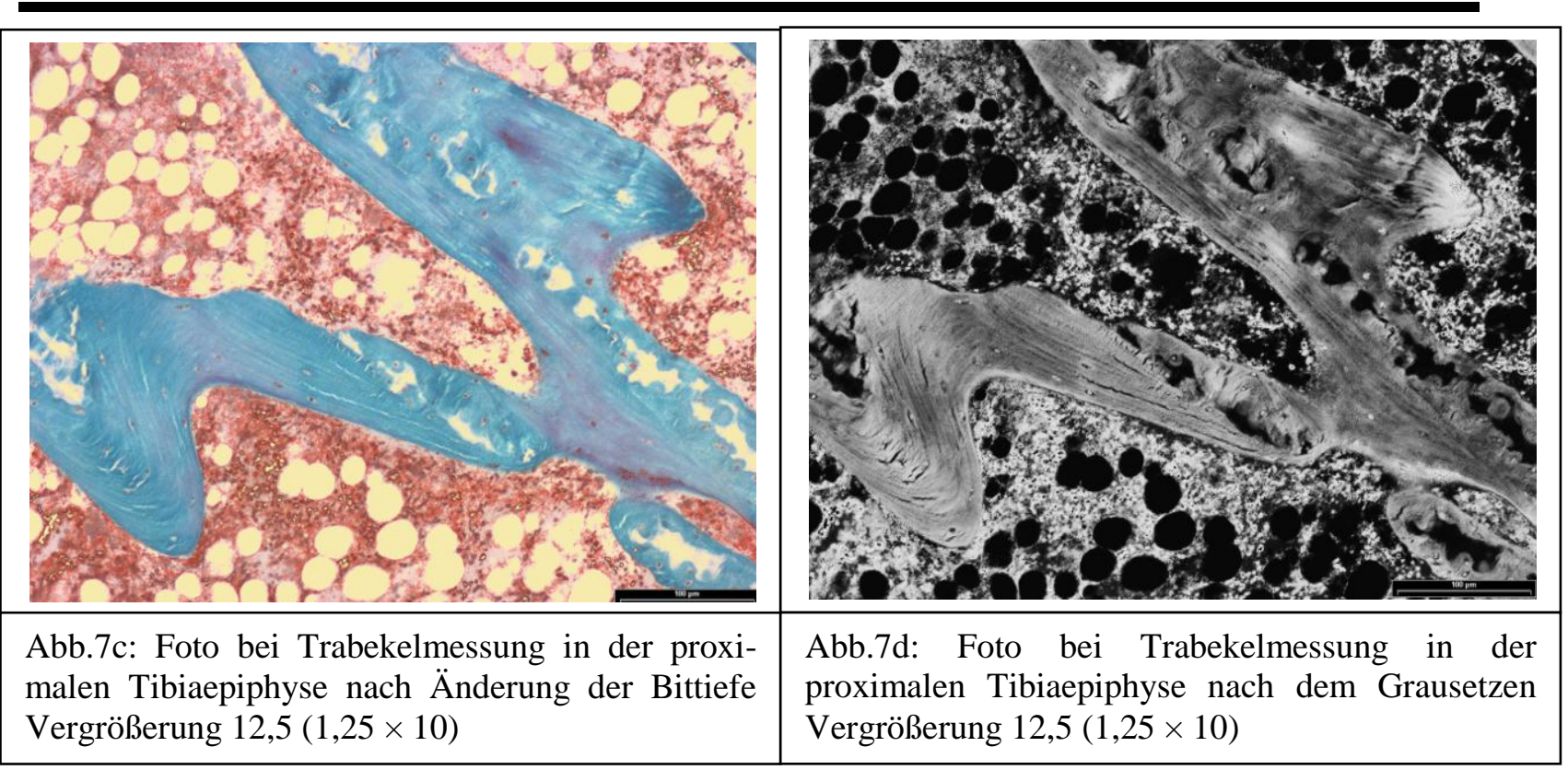

Die im letzten Schritt durchgeführte Phasenanalyse lieferte schließlich die berechneten absoluten und relativen Anteile an Trabekeln, rotem und gelbem Knochenmark in der jeweiligen Tibiaregion.

Die Abbildungen 7a-d zeigen Beispielfotos für das Verfahren 2 / F-Methode:

Verfahren 2: 1.) Fixierung des auszuwertenden Präparatabschnitts im Foto

„F-Methode““ 2.) Inversion der Bildintensität ins entsprechende Negativbild

3.) Auswahl des roten Farbauszugs

4.) Definition der Schwellenwerte durch Zuordnung zu den im Bildabzug auszuwertenden Knochenstrukturen

5.) Phasenanalyse anhand der zugewiesenen Schwellenwerte

\begin{tabular}{|l|l|}
\hline $\begin{array}{l}\text { Spongiosa mit } \\
\text { rotem/gelbemKM Epiphyse }\end{array}$ \\
\hline $\begin{array}{l}\text { Abb.8a: Schemazeichnung der Trabekelmessung in } \\
\text { der proximalen Tibiaepiphyse }\end{array}$
\end{tabular} \begin{tabular}{l}
$\begin{array}{l}\text { Abb.8b: Nativbild bei Trabekelmessung in der } \\
\text { proximalen Tibiaepiphyse (34-10; orx } \\
\text { Vergrößerung 12,5 (1,25 } 0.5)\end{array}$ \\
\hline
\end{tabular}




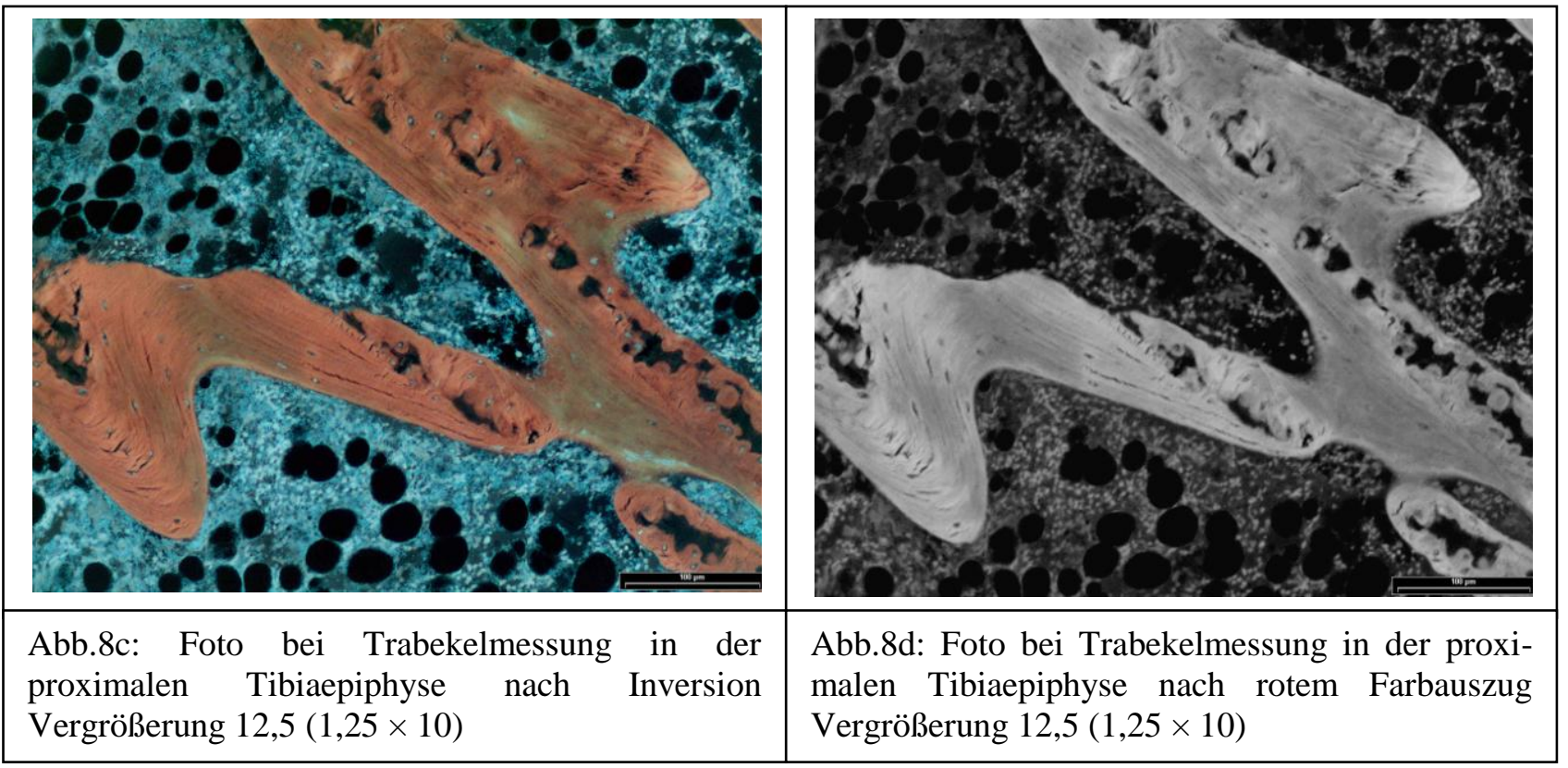

\section{Graphische Darstellung und Analyse der gemessenen Werte}

Für die graphische Darstellung und die Analyse der durch die histologische Auswertung erhaltenen Messwerte wurde das Software-Programm GraphPad Prism 4® verwendet und jeweils ein unverbundener t-Test durchgeführt. Für die Ergebnisanalyse wurde ein Niveau von $\mathrm{p}<0,05$ als signifikant definiert. 


\section{III.) Ergebnisse}

\section{III.1) Vergleich der beiden angewandten morphometrischen Analyseverfahren}

Im Rahmen der vorliegenden Studie erfolgte die parallele Anwendung zweier Computerassistierter Auswertungsverfahren zur morphometrischen Fotoanalyse von Knochenstrukturen hinsichtlich Fläche und prozentualen Anteilen an Trabekeln, rotem Knochenmark sowie gelbem Fettmark in der tibialen Metaphyse gonadektomierter S.D.-Ratten. Dabei lag jeweils ein identisches Nativbild des zu analysierenden Tibiabereichs zu Grunde. Das hier mit „D-Methode“ bezeichnete Verfahren basiert auf der Schwellenwertbestimmung am 8-BitGrauwertbild. Die „F-Methode“ umfasst die Schwellenwertbildung am entsprechenden Negativbild mit rotem Farbauszug. Zur Bewertung einer Eignung der Methoden bezüglich ihrer Anwendbarkeit in lichtmikroskopischen Effektstudien von Substanzen, wurden die jeweiligen Ergebnisse der Methoden im Folgenden miteinander verglichen.

\section{III.1.1) Auswertung der Trabekelfläche in der tibialen Metaphyse männlicher S.D.-Ratten}

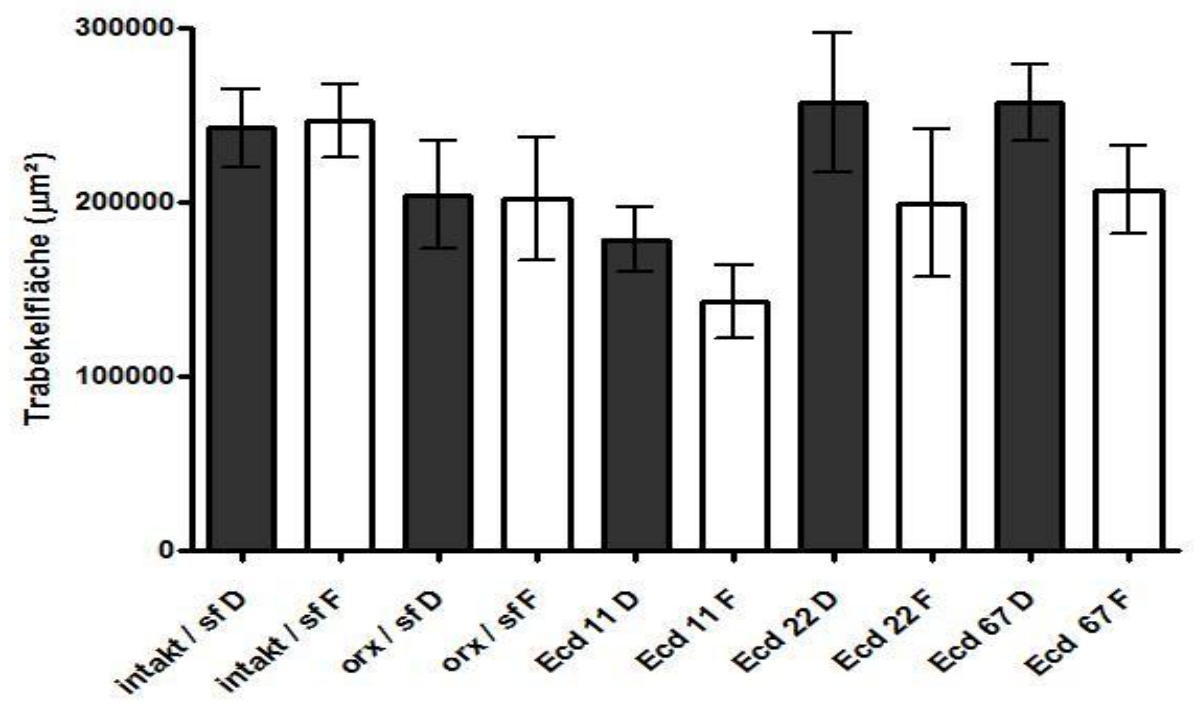

Abb.9: Vergleich und Gegenüberstellung der mittels Schwellenwertbildung am 8-BitGrauwertbild (D-Methode/grau) ermittelten Ergebnisse mit jenen am Negativbild im roten Farbauszug (F-Methode/weiß). Gegenstand der Methodenanwendung war hier die Analyse des Effekts von $\beta$-Ecdyson (Ecd $11 \mathrm{mg} / \mathrm{kg} \mathrm{KG;} \mathrm{Ecd} 22 \mathrm{mg} / \mathrm{kg} \mathrm{KG}$; Ecd $67 \mathrm{mg} / \mathrm{kg} \mathrm{KG}$ ) auf die Trabekelfläche (in Mikrometer ${ }^{2}$ ) in der tibialen Metaphyse im Bereich von einem Millimeter distal der proximalen Epiphysenfuge nach dreimonatigem Futterversuch an männlichen orx S.D.-Ratten im Vergleich zur intakten bzw. orx Kontrollgruppe unter sf Futter. ( $\mathrm{D}=\mathrm{D}$-Methode; $\mathrm{F}=$ F-Methode $)$ 
Mit der angewandten Statistik konnte im Bereich der tibialen Metaphyse von männlichen S.D.-Ratten kein signifikanter Unterschied in den Ergebnissen der beiden angewandten Auswertungsmethoden bezüglich der Trabekelfläche nachgewiesen werden (Abb.9).

\section{III.1.2) Auswertung des prozentualen Trabekelanteils in der tibialen Metaphyse männlicher S.D.-Ratten}

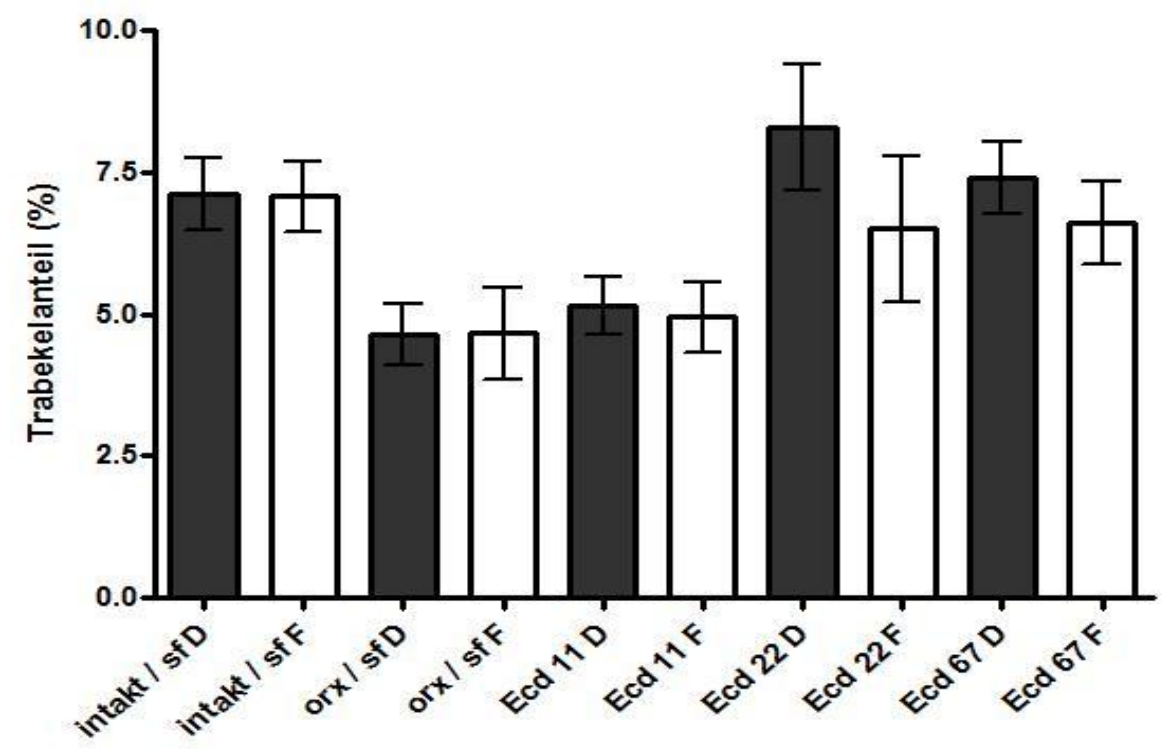

Abb.10: Vergleich und Gegenüberstellung der mittels Schwellenwertbildung am 8-BitGrauwertbild (D-Methode/grau) ermittelten Ergebnisse mit jenen am Negativbild im roten Farbauszug (F-Methode/weiß). Gegenstand der Methodenanwendung war hier die Analyse des Effekts von $\beta$-Ecdyson (Ecd $11 \mathrm{mg} / \mathrm{kg} \mathrm{KG;} \mathrm{Ecd} 22 \mathrm{mg} / \mathrm{kg} \mathrm{KG;} \mathrm{Ecd} 67 \mathrm{mg} / \mathrm{kg} \mathrm{KG}$ ) auf den prozentualen Trabekelanteil in der tibialen Metaphyse im Bereich von einem Millimeter distal der proximalen Epiphysenfuge nach dreimonatigem Futterversuch an männlichen orx S.D.-Ratten im Vergleich zur intakten bzw. orx Kontrollgruppe unter sf Futter. (D = DMethode; F-Methode).

Der Methodenvergleich in Bezug auf die Messergebnisse für den prozentualen Trabekelanteil in der tibialen Metaphyse ergab mit der angewandten Statistik keine signifikanten Unterschiede (Abb.10). 


\section{III.1.3) Auswertung der Fläche gelben Knochenmarks in der tibialen Metaphyse männlicher S.D.-Ratten}

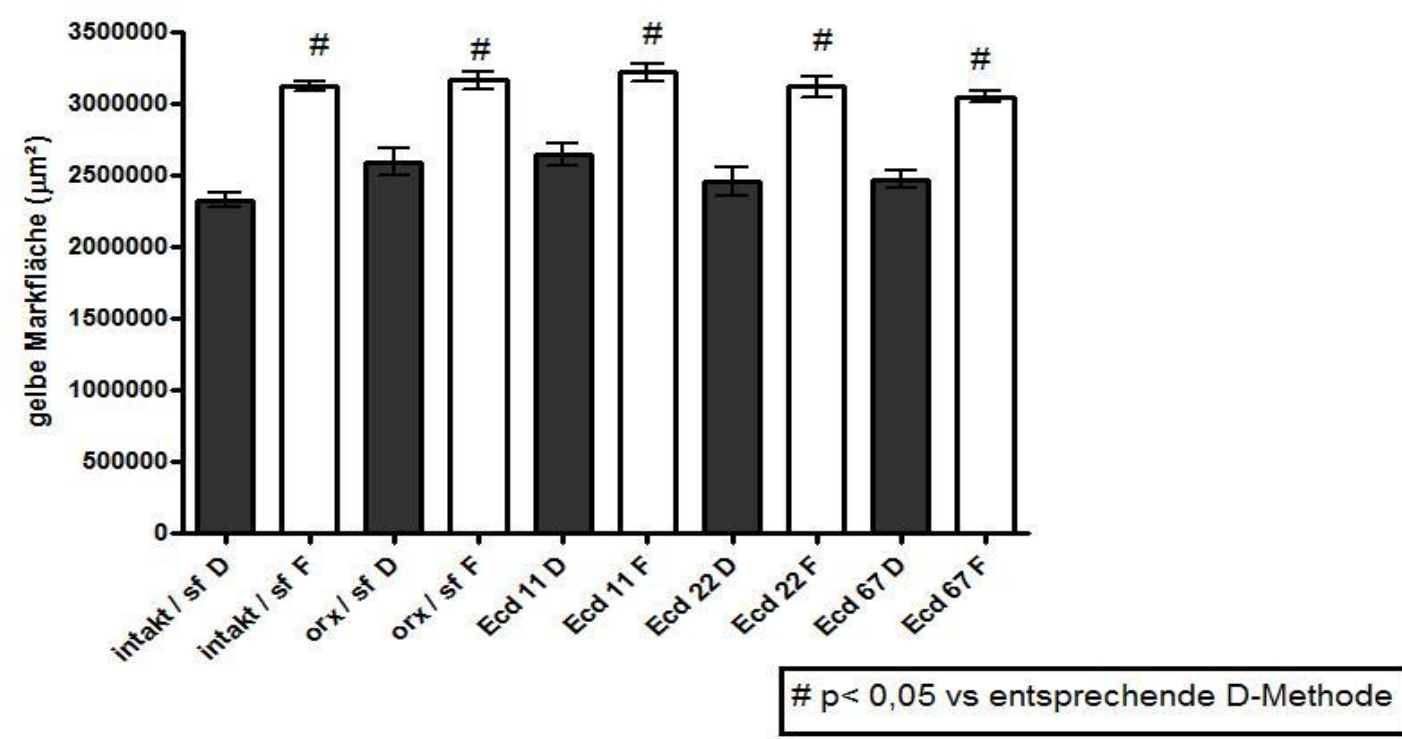

Abb.11: Vergleich und Gegenüberstellung der mittels Schwellenwertbildung am 8-BitGrauwertbild (D-Methode/grau) ermittelten Ergebnisse mit jenen am Negativbild im roten Farbauszug (F-Methode/weiß). Gegenstand der Methodenanwendung war hier die Analyse des Effekts von $\beta$-Ecdyson (Ecd $11 \mathrm{mg} / \mathrm{kg} \mathrm{KG;} \mathrm{Ecd} 22 \mathrm{mg} / \mathrm{kg} \mathrm{KG;} \mathrm{Ecd} 67 \mathrm{mg} / \mathrm{kg} \mathrm{KG}$ ) auf die Fläche gelben Knochenmarks (in Mikrometer ${ }^{2}$ ) in der tibialen Metaphyse im Bereich von einem Millimeter distal der proximalen Epiphysenfuge nach dreimonatigem Futterversuch an männlichen orx S.D.-Ratten im Vergleich zur intakten bzw. orx Kontrollgruppe unter sf Futter. ( $\mathrm{D}=\mathrm{D}-\mathrm{Methode} ; \mathrm{F}=$ F-Methode)

Der Vergleich der beiden Auswertungsmethoden zeigte hier im Vergleich zu der Trabekelauswertung in jeder der untersuchten Gruppen deutlich signifikante Unterschiede zwischen den Messergebnissen bezüglich der Fläche gelben Marks (Abb.11). Dabei fielen die mit Hilfe der Schwellenwertbestimmung am Negativbild im roten Farbauszug ermittelten Ergebnisse (F-Methode) stets signifikant größer aus als jene, die mittels Schwellenwertbildung am 8-Bit-Grauwertbild (D-Methode) ausgewertet wurden.

\section{III.1.4) Auswertung des prozentualen Anteils gelben Knochenmarks in der tibialen Metaphyse männlicher S.D.-Ratten}

Die Durchführung des Vergleichs zwischen den zwei unterschiedlichen Auswertungsmethoden zeigte hier erneut in jeder der untersuchten Gruppen signifikante Unterschiede zwischen den Messergebnissen bezüglich des prozentualen Anteils gelben Marks (Abb.12). Dabei ergaben die mit der F-Methode ermittelten gelben Markanteile stets signifikant höhere Werte als jene, die mittels D-Methode ausgewertet wurden. 


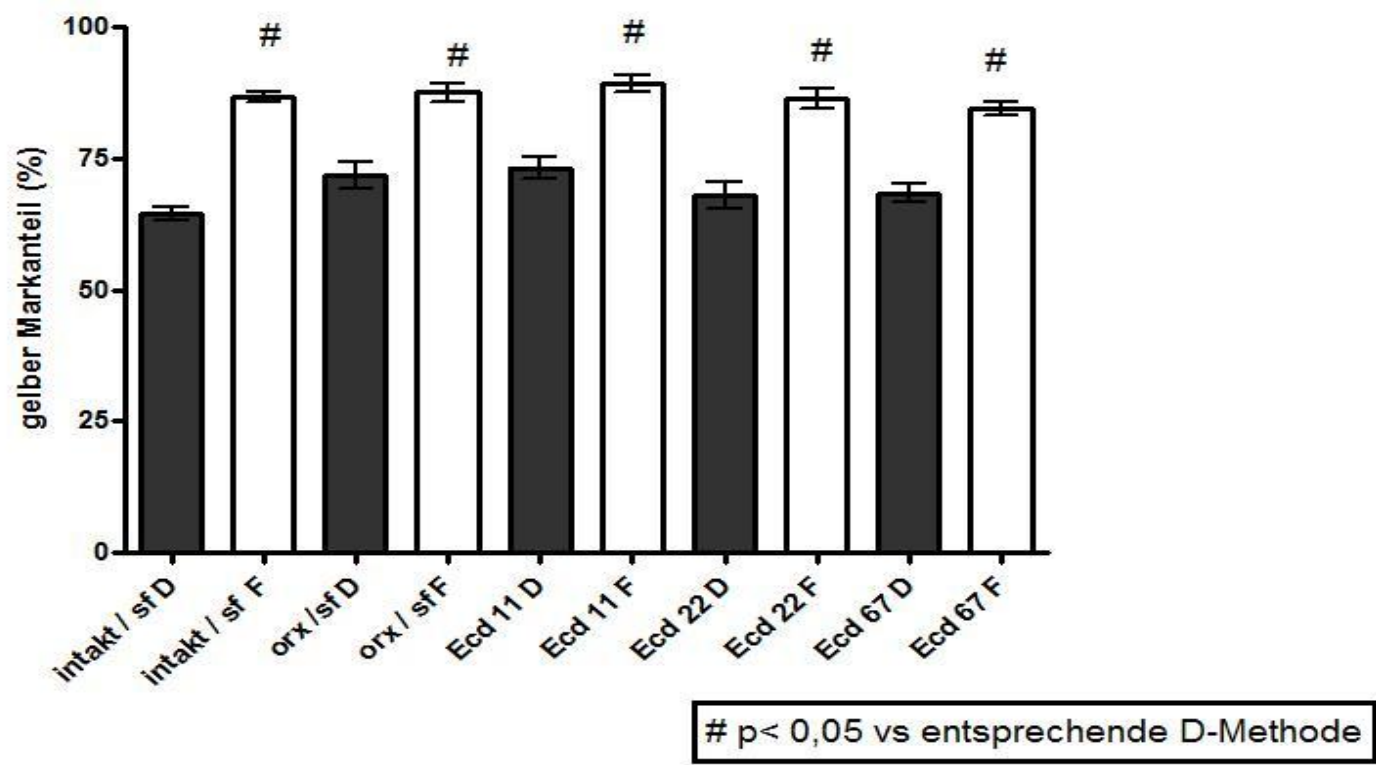

Abb.12: Vergleich und Gegenüberstellung der mittels Schwellenwertbildung am 8-BitGrauwertbild (D-Methode/grau) ermittelten Ergebnisse mit jenen am Negativbild im roten Farbauszug (F-Methode/weiß). Gegenstand der Methodenanwendung war hier die Analyse des Effekts von $\beta$-Ecdyson (Ecd $11 \mathrm{mg} / \mathrm{kg} \mathrm{KG;} \mathrm{Ecd} 22 \mathrm{mg} / \mathrm{kg} \mathrm{KG;} \mathrm{Ecd} 67 \mathrm{mg} / \mathrm{kg} \mathrm{KG}$ ) auf den prozentualen Anteil gelben Knochenmarks in der tibialen Metaphyse im Bereich von einem Millimeter distal der proximalen Epiphysenfuge nach dreimonatigem Futterversuch an männlichen orx S.D.-Ratten im Vergleich zur intakten bzw. orx Kontrollgruppe unter sf Futter. (D = D-Methode; F = F-Methode)

\section{III.1.5) Auswertung der Fläche roten Knochenmarks in der tibialen Metaphyse männlicher S.D.-Ratten}

Durch den Vergleich der angewandten Auswertungsmethoden konnten auch für den Parameter der roten Knochenmarkfläche signifikante Unterschiede zwischen den erhaltenen Messergebnissen dargelegt werden (Abb.13). Dabei fielen die mittels Schwellenwertbildung am 8-Bit-Grauwertbild erhaltenen Ergebnisse (D-Methode) signifikant größer aus als jene, die anhand der Schwellenwertbestimmung am Negativbild im roten Farbauszug (F-Methode) ermittelt wurden. 


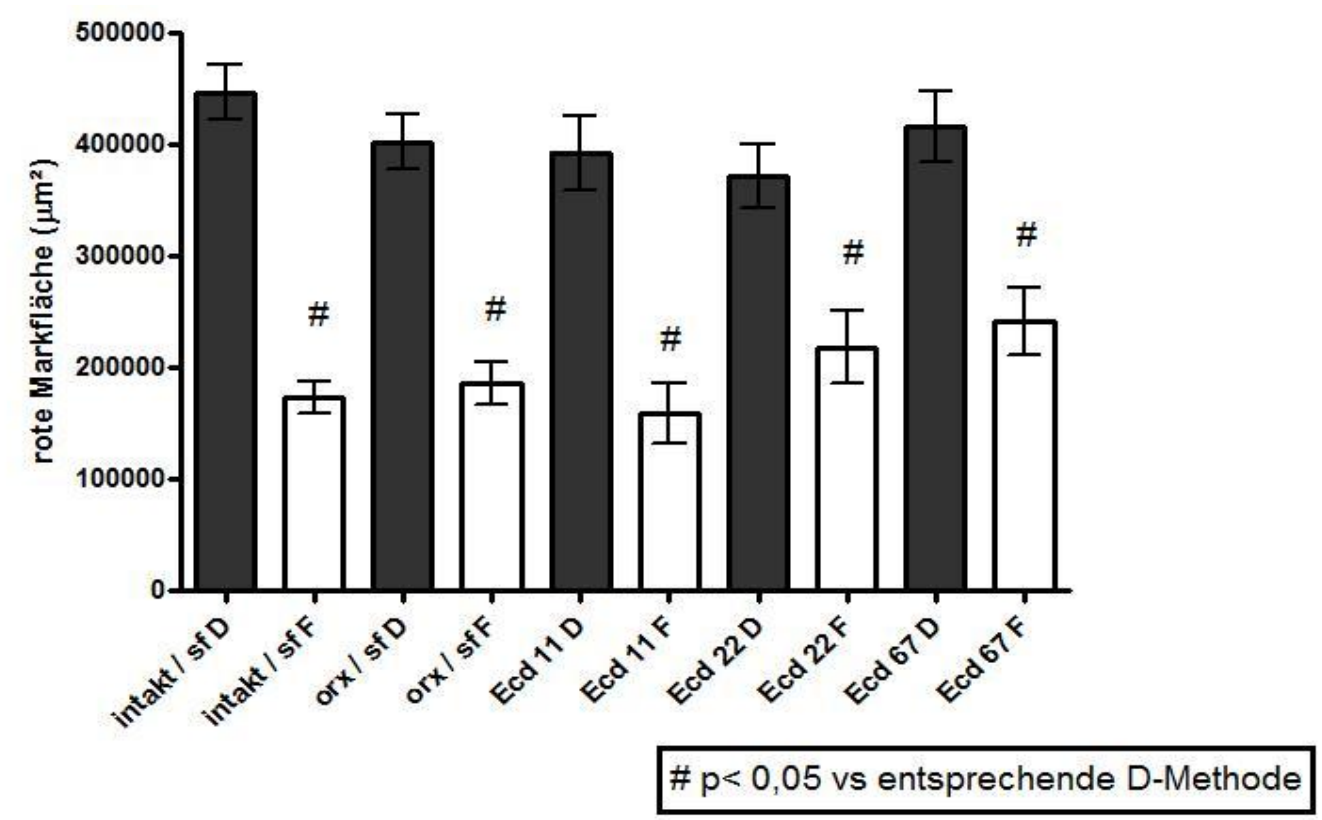

Abb.13: Vergleich und Gegenüberstellung der mittels Schwellenwertbildung am 8-BitGrauwertbild (D-Methode/grau) ermittelten Ergebnisse mit jenen am Negativbild im roten Farbauszug (F-Methode/weiß). Gegenstand der Methodenanwendung war hier die Analyse des Effekts von $\beta$-Ecdyson (Ecd $11 \mathrm{mg} / \mathrm{kg} \mathrm{KG;} \mathrm{Ecd} 22 \mathrm{mg} / \mathrm{kg} \mathrm{KG;} \mathrm{Ecd} 67 \mathrm{mg} / \mathrm{kg} \mathrm{KG}$ ) auf die Fläche roten Knochenmarks (in Mikrometer ${ }^{2}$ ) in der tibialen Metaphyse im Bereich von einem Millimeter distal der proximalen Epiphysenfuge nach dreimonatigem Futterversuch an männlichen orx S.D.-Ratten im Vergleich zur intakten bzw. orx Kontrollgruppe unter sf Futter. $(\mathrm{D}=\mathrm{D}-$ Methode; $\mathrm{F}=\mathrm{F}-$ Methode $)$

\section{III.1.6) Auswertung des prozentualen Anteils roten Knochenmarks in der tibialen Metaphyse männlicher S.D.-Ratten}

Der Methodenvergleich hinsichtlich der Messergebnisse für den prozentualen Anteil roten Knochenmarks in der tibialen Metaphyse ergab bei den männlichen S.D.-Ratten ebenfalls einen signifikanten Unterschied zwischen den beiden Analyseverfahren (Abb.14). Dabei fielen die mittels Schwellenwertbildung am 8-Bit-Grauwertbild erhaltenen Ergebnisse (DMethode), wie schon bei der roten Knochenmarkfläche, signifikant größer aus als jene, die anhand der Schwellenwertbestimmung am Negativbild im roten Farbauszug (F-Methode) ermittelt wurden. 


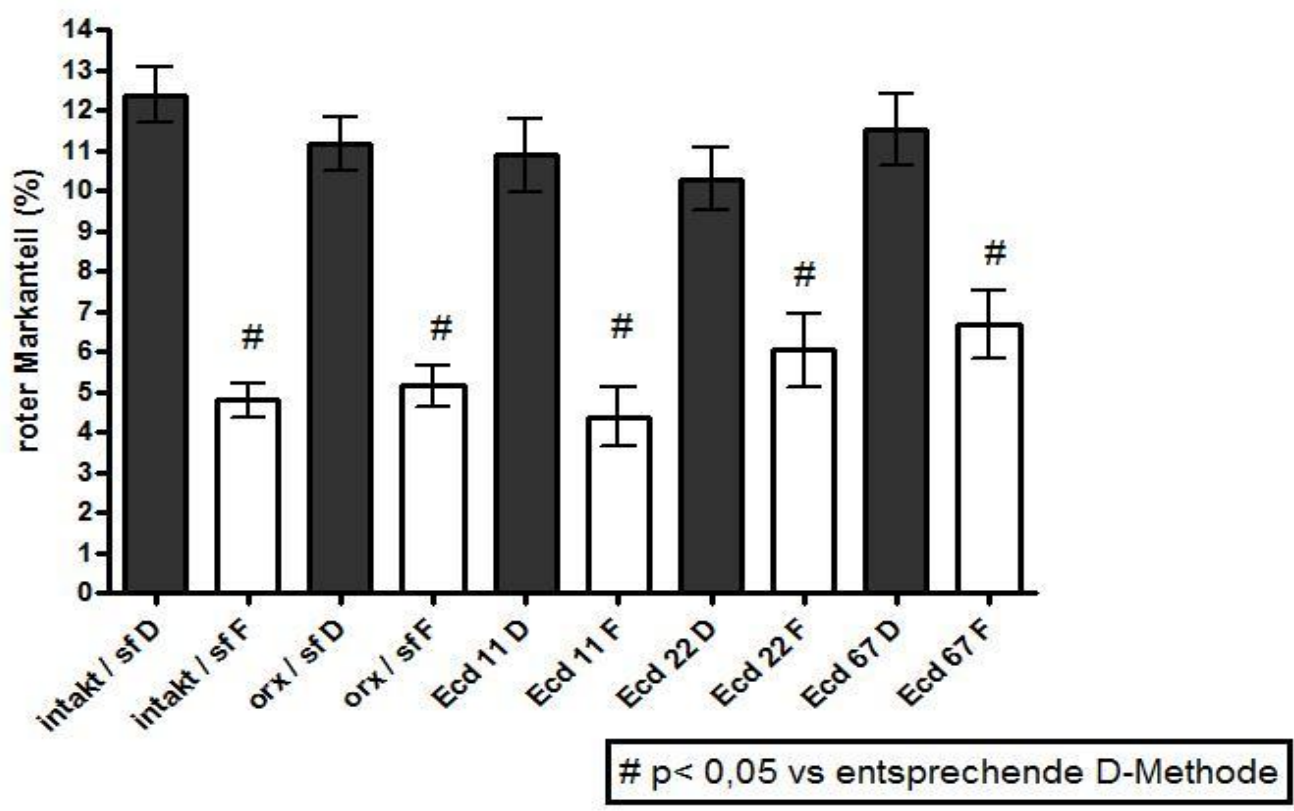

Abb.14: Vergleich und Gegenüberstellung der mittels Schwellenwertbildung am 8-BitGrauwertbild (D-Methode/grau) ermittelten Ergebnisse mit jenen am Negativbild im roten Farbauszug (F-Methode/weiß). Gegenstand der Methodenanwendung war hier die Analyse des Effekts von $\beta$-Ecdyson (Ecd $11 \mathrm{mg} / \mathrm{kg} \mathrm{KG}$; Ecd $22 \mathrm{mg} / \mathrm{kg} \mathrm{KG}$; Ecd $67 \mathrm{mg} / \mathrm{kg} \mathrm{KG}$ ) auf den prozentualen Anteil roten Knochenmarks in der tibialen Metaphyse im Bereich von einem Millimeter distal der proximalen Epiphysenfuge nach dreimonatigem Futterversuch an männlichen orx S.D.-Ratten im Vergleich zur intakten bzw. orx Kontrollgruppe unter sf Futter. $(\mathrm{D}=\mathrm{D}-$ Methode; $\mathrm{F}=$ F-Methode $)$

\section{III.1.7) Auswertung der Trabekelfläche in der tibialen Metaphyse weiblicher S.D.-Ratten}

Der wie bei den männlichen S.D.-Ratten durchgeführte Methodenvergleich zwischen den beiden verwendeten Auswertungsverfahren wies bei den weiblichen Tieren einen signifikanten Unterschied der Ergebnisse für die Trabekelfläche bei den mit einer $\beta$ Ecdysondosis von $10 \mathrm{mg} / \mathrm{kg}$ KG behandelten Tieren nach. Dabei wurden durch Schwellenwertbildung am 8-Bit-Grauwertbild (D-Methode) im Vergleich zur jenen am Negativbild im roten Farbauszug (F-Methode) signifikant größere Werte für die Trabekelfläche ermittelt. Es handelte sich bei dem Unterschied um eine Mittelwertdifferenz von $\bar{x} \pm s=(67580 \pm 30420) \mu \mathrm{m}^{2}$ (Abb.15). Für die beiden anderen untersuchten Gruppen konnte mit der angewandten Statistik kein Unterschied zwischen den Analyseverfahren nachgewiesen werden. 


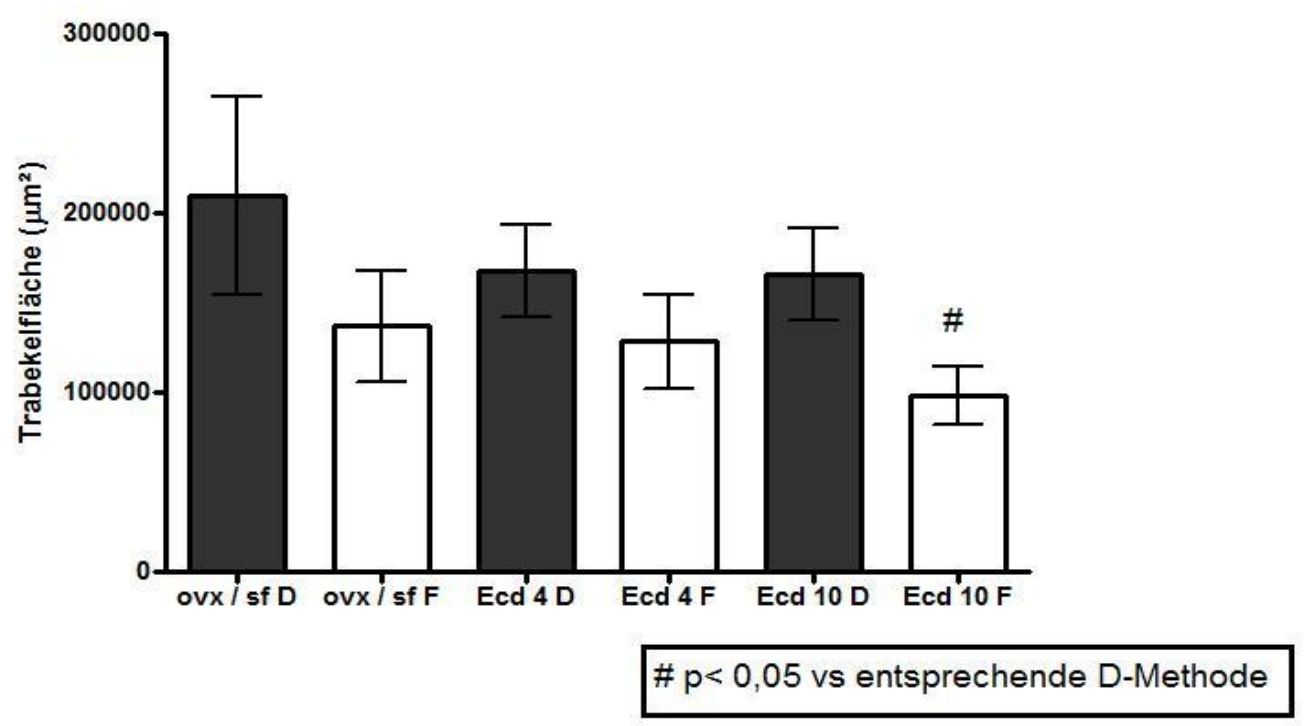

Abb.15: Vergleich und Gegenüberstellung der mittels Schwellenwertbildung am 8-BitGrauwertbild (D-Methode/grau) ermittelten Ergebnisse mit jenen am Negativbild im roten Farbauszug (F-Methode/weiß). Gegenstand der Methodenanwendung war hier die Analyse des Effekts von $\beta$-Ecdyson (Ecd 4 mg/kg KG; Ecd $10 \mathrm{mg} / \mathrm{kg} \mathrm{KG)} \mathrm{auf} \mathrm{die} \mathrm{Trabekelfläche} \mathrm{(in}$ Mikrometer $^{2}$ ) in der tibialen Metaphyse im Bereich von einem Millimeter distal der proximalen Epiphysenfuge nach dreimonatigem Futterversuch weiblichen ovx S.D.-Ratten im Vergleich zur ovx Kontrollgruppe unter sf Futter. ( $\mathrm{D}=\mathrm{D}-$ Methode; F = F-Methode)

\section{III.1.8) Auswertung des prozentualen Trabekelanteils in der tibialen Metaphyse weiblicher S.D.-Ratten}

Der Methodenvergleich zeigte, wie bei der Trabekelfläche, einen signifikanten Unterschied zwischen den Messergebnissen für den prozentualen Trabekelanteil der Gruppe mit einer $\beta$ Ecdyson-Aufnahme von $10 \mathrm{mg} / \mathrm{kg} \mathrm{KG}$. Auch hier waren die erhaltenen Messwerte unter Verwendung der Schwellenwertbestimmung am 8-Bit-Grauwertbild (D-Methode) signifikant größer als jene am Negativbild im roten Farbauszug (F-Methode). Die Ergebnisse zeigten dabei eine Mittelwertabweichung zwischen D- und F-Methode von $\bar{x} \pm s=(2.36 \pm 0.94)$ Prozentpunkten (Abb.16). 


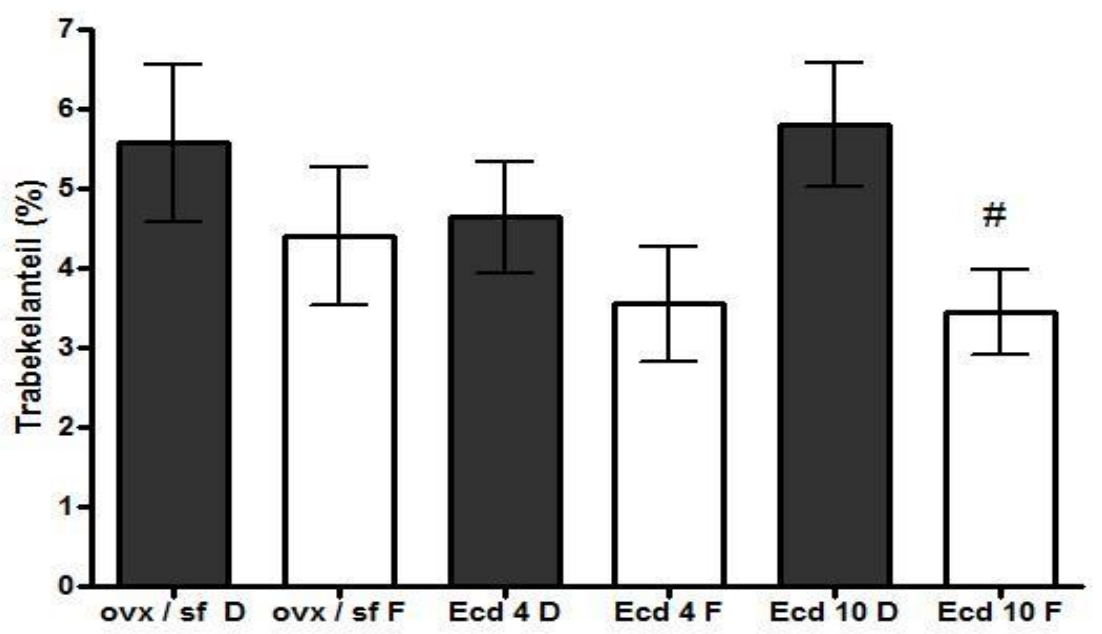

$\# p<0,05$ vs entsprechende $D-M e t h o d e$

Abb.16: Vergleich und Gegenüberstellung der mittels Schwellenwertbildung am 8-BitGrauwertbild (D-Methode/grau) ermittelten Ergebnisse mit jenen am Negativbild im roten Farbauszug (F-Methode/weiß). Gegenstand der Methodenanwendung war hier die Analyse des Effekts von $\beta$-Ecdyson (Ecd $4 \mathrm{mg} / \mathrm{kg} \mathrm{KG;} \mathrm{Ecd} 10 \mathrm{mg} / \mathrm{kg} \mathrm{KG}$ ) auf den prozentualen Trabekelanteil in der tibialen Metaphyse im Bereich von einem Millimeter distal der proximalen Epiphysenfuge nach dreimonatigem Futterversuch an weiblichen ovx S.D.-Ratten im Vergleich zur ovx Kontrollgruppe unter sf Futter. (D = D-Methode; F-Methode)

\section{III.1.9) Auswertung der Fläche gelben Knochenmarks in der tibialen Metaphyse weiblicher S.D.-Ratten}

Der Vergleich zwischen den beiden Auswertungsmethoden zeigte auch bei den weiblichen Tieren einen signifikanten Unterschied zwischen den ermittelten Flächenwerten für den Parameter des gelben Knochenmarks. Dabei fielen, wie auch bei den männlichen S.D.-Ratten, die mittels Schwellenwertbildung am Negativbild im roten Farbauszug (F-Methode) ermittelten Flächen signifikant größer aus als jene, die am 8-Bit-Grauwertbild (D-Methode) ermittelt wurden. Die Differenzen zwischen den einzelnen Mittelwerten betrugen dabei für die Kontrollgruppe $\bar{x} \pm s=(-680200 \pm 128100) \mu \mathrm{m}^{2}$, für die $\beta$-Ecdysondosis von $4 \mathrm{mg} / \mathrm{kg} \mathrm{KG}$ $\bar{x} \pm s=(-719700 \pm 74390) \mu \mathrm{m}^{2}$ und für die Dosis von $10 \mathrm{mg} / \mathrm{kg} \mathrm{KG} \bar{x} \pm s=(-433000 \pm$ 79100) $\mu \mathrm{m}^{2}$ (Abb.17). 


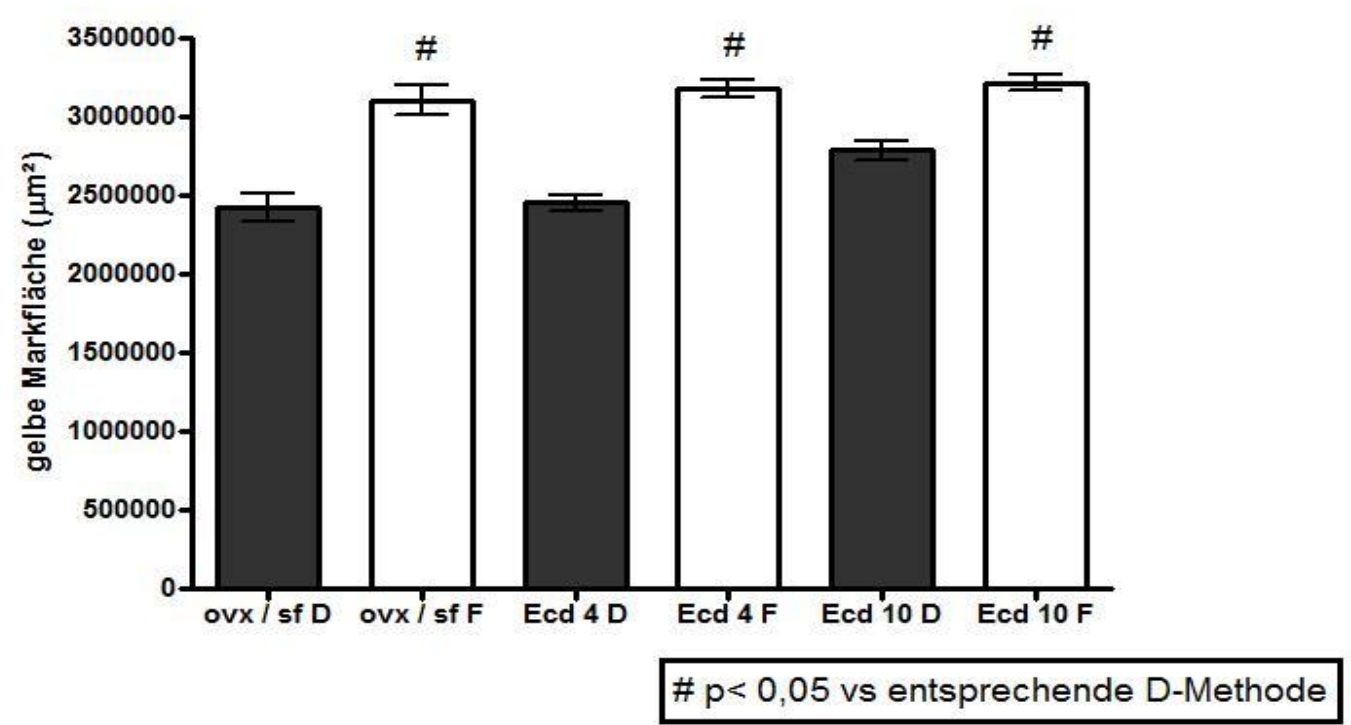

Abb.17: Vergleich und Gegenüberstellung der mittels Schwellenwertbildung am 8-BitGrauwertbild (D-Methode/grau) ermittelten Ergebnisse mit jenen am Negativbild im roten Farbauszug (F-Methode/weiß). Gegenstand der Methodenanwendung war hier die Analyse des Effekts von $\beta$-Ecdyson (Ecd $4 \mathrm{mg} / \mathrm{kg} \mathrm{KG;} \mathrm{Ecd} 10 \mathrm{mg} / \mathrm{kg} \mathrm{KG}$ ) auf die Fläche gelben Knochenmarks (in Mikrometer ${ }^{2}$ ) in der tibialen Metaphyse im Bereich von einem Millimeter distal der proximalen Epiphysenfuge nach dreimonatigem Futterversuch an weiblichen ovx S.D.Ratten im Vergleich zur ovx Kontrollgruppe unter sf Futter. ( $\mathrm{D}=\mathrm{D}$-Methode; F = F-Methode)

\section{III.1.10) Auswertung des prozentualen Anteils gelben Knochenmarks in der tibialen Metaphyse weiblicher S.D.-Ratten}

Der Vergleich zwischen den zwei angewandten Auswertungsmethoden hinsichtlich des prozentualen gelben Knochenmarkanteils ergab, wie bei der Flächenbestimmung, signifikante Unterschiede zwischen den erhaltenen Messergebnissen. Die F-Methode mit Schwellenwertbildung am Negativbild im roten Farbauszug ermittelte dabei signifikant höhere prozentuale Anteile gelben Marks als die D-Methode mit Schwellenwertbestimmung am 8-Bit-Grauwertbild. Die Unterschiede zwischen den errechneten Mittelwerten beliefen sich bei den ovx Kontrolltieren auf $\bar{x} \pm s=(-18.84 \pm 3.546)$ Prozentpunkte, bei der $\beta$ Ecdyson-Dosis von $4 \mathrm{mg} / \mathrm{kg} \mathrm{KG}$ auf $\bar{x} \pm s=(-19.93 \pm 2.060)$ Prozentpunkte und bei 10 $\mathrm{mg} / \mathrm{kg} \mathrm{KG}$ auf $\bar{x} \pm s=(-11.99 \pm 2.190)$ Prozentpunkte (Abb.18). 


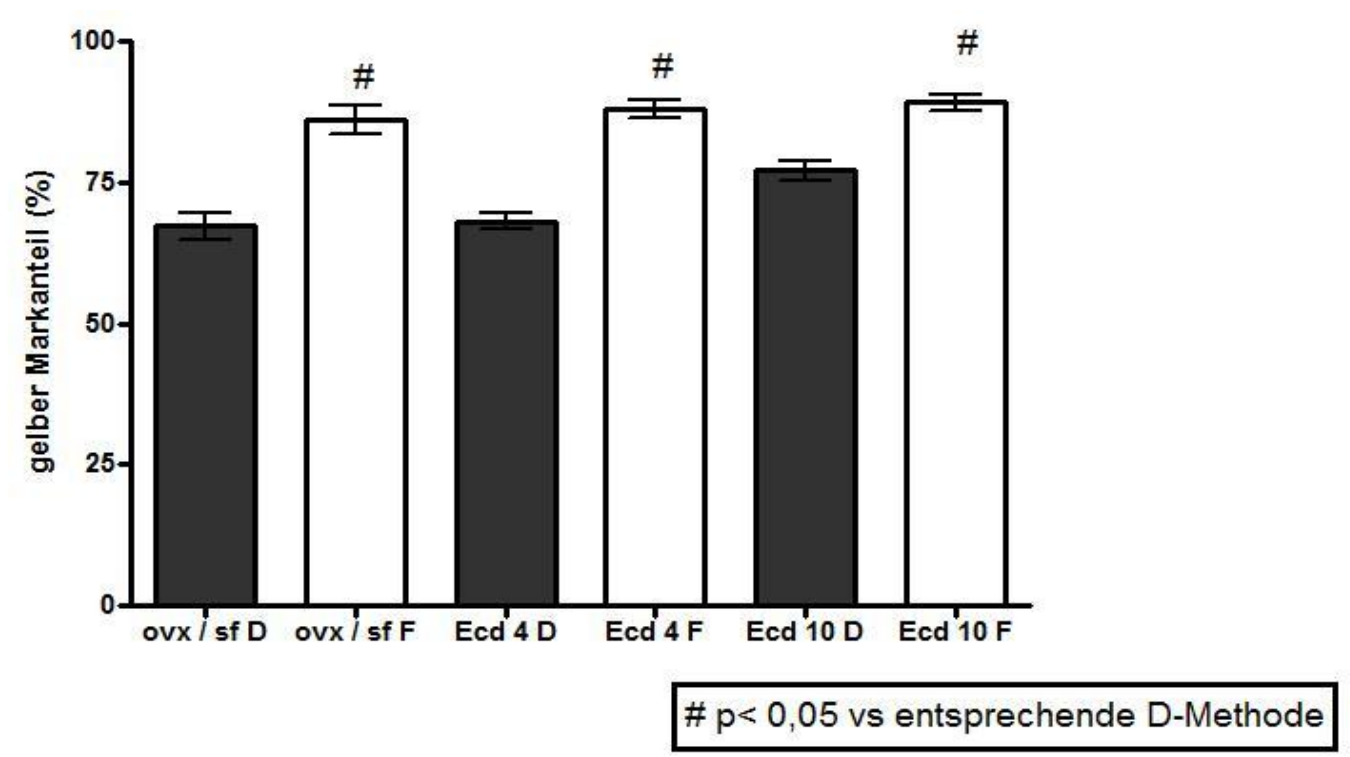

Abb.18: Vergleich und Gegenüberstellung der mittels Schwellenwertbildung am 8-BitGrauwertbild (D-Methode/grau) ermittelten Ergebnisse mit jenen am Negativbild im roten Farbauszug (F-Methode/weiß). Gegenstand der Methodenanwendung war hier die Analyse des Effekts von $\beta$-Ecdyson (Ecd $4 \mathrm{mg} / \mathrm{kg} \mathrm{KG;} \mathrm{Ecd} 10 \mathrm{mg} / \mathrm{kg} \mathrm{KG}$ ) auf den prozentualen Anteil gelben Knochenmarks in der tibialen Metaphyse im Bereich von einem Millimeter distal der proximalen Epiphysenfuge nach dreimonatigem Futterversuch an weiblichen ovx S.D.-Ratten im Vergleich zur ovx Kontrollgruppe unter sf Futter. ( $\mathrm{D}=\mathrm{D}-$ Methode; F = F-Methode)

\section{III.1.11) Auswertung der Fläche roten Knochenmarks in der tibialen Metaphyse weiblicher S.D.-Ratten}

Der Methodenvergleich bezüglich der Auswertungsergebnisse für die Fläche roten Knochenmarks innerhalb der tibialen Metaphyse ergaben bei den weiblichen Tieren, wie bei den männlichen S.D.-Ratten, signifikante Unterschiede zwischen der D-Methode und der FMethode (Abb.19). Dabei fielen die gemessenen Flächen für das rote Mark durch die Auswertung mittels Schwellenwertbildung am 8-Bit-Grauwertbild (D-Methode) signifikant größer aus als jene, die am Negativbild im roten Farbauszug (F-Methode) ermittelt wurden. 


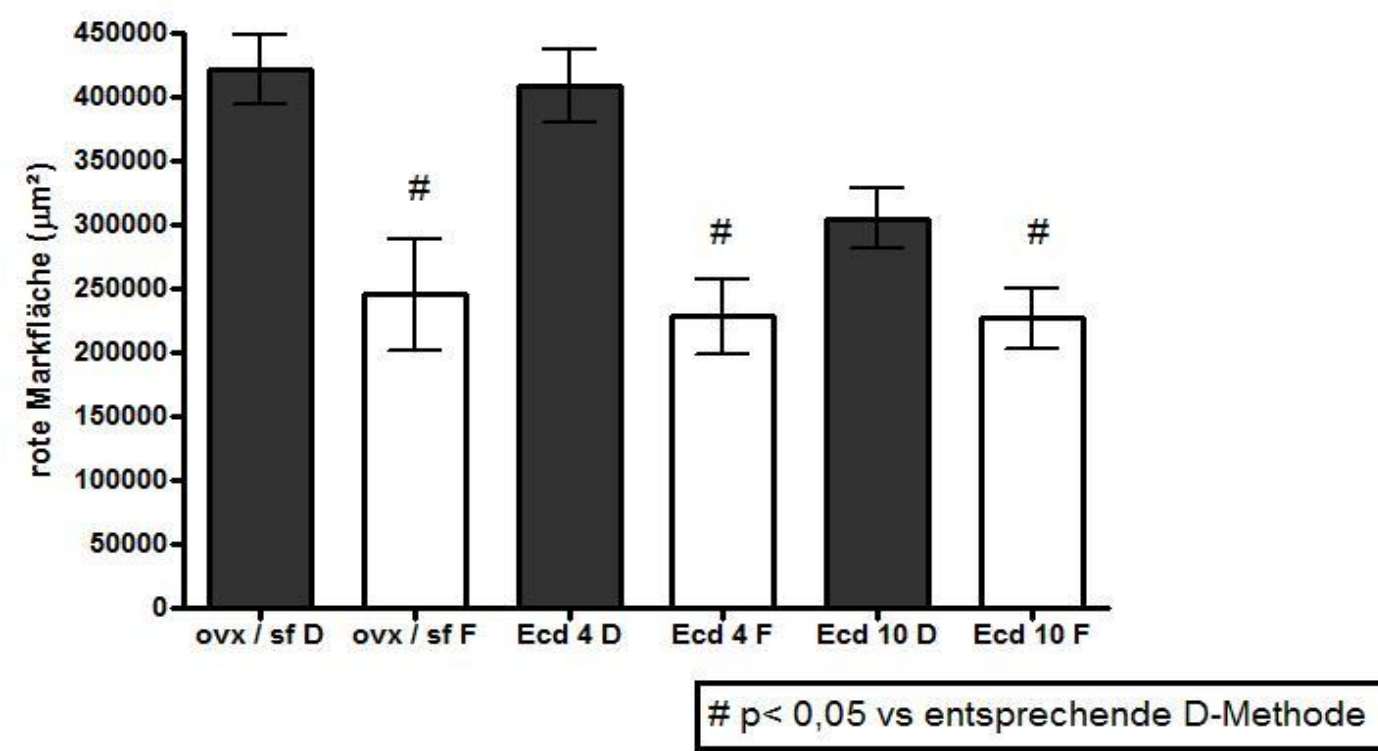

Abb.19: Vergleich und Gegenüberstellung der mittels Schwellenwertbildung am 8-BitGrauwertbild (D-Methode/grau) ermittelten Ergebnisse mit jenen am Negativbild im roten Farbauszug (F-Methode/weiß). Gegenstand der Methodenanwendung war hier die Analyse des Effekts von $\beta$-Ecdyson (Ecd $4 \mathrm{mg} / \mathrm{kg} \mathrm{KG;} \mathrm{Ecd} 10 \mathrm{mg} / \mathrm{kg} \mathrm{KG}$ ) auf die Fläche roten Knochenmarks (in Mikrometer ${ }^{2}$ ) in der tibialen Metaphyse im Bereich von einem Millimeter distal der proximalen Epiphysenfuge nach dreimonatigem Futterversuch an weiblichen ovx S.D.-Ratten im Vergleich zur ovx Kontrollgruppe unter sf Futter. ( $\mathrm{D}=\mathrm{D}$-Methode; F= F-Methode)

\section{III.1.12) Auswertung des prozentualen Anteils roten Knochenmarks in der tibialen Metaphyse weiblicher S.D.-Ratten}

Der Methodenvergleich in Bezug auf die Messergebnisse für den prozentualen Anteil roten Knochenmarks in der tibialen Metaphyse ergab bei den weiblichen S.D.-Ratten ebenfalls einen signifikanten Unterschied zwischen den beiden Analyseverfahren (Abb.20). Dabei fielen die mittels Schwellenwertbildung am 8-Bit-Grauwertbild erhaltenen Ergebnisse (D-Methode), wie schon bei der roten Knochenmarkfläche, signifikant größer aus als jene, die anhand der Schwellenwertbestimmung am Negativbild im roten Farbauszug (F-Methode) ermittelt wurden. 


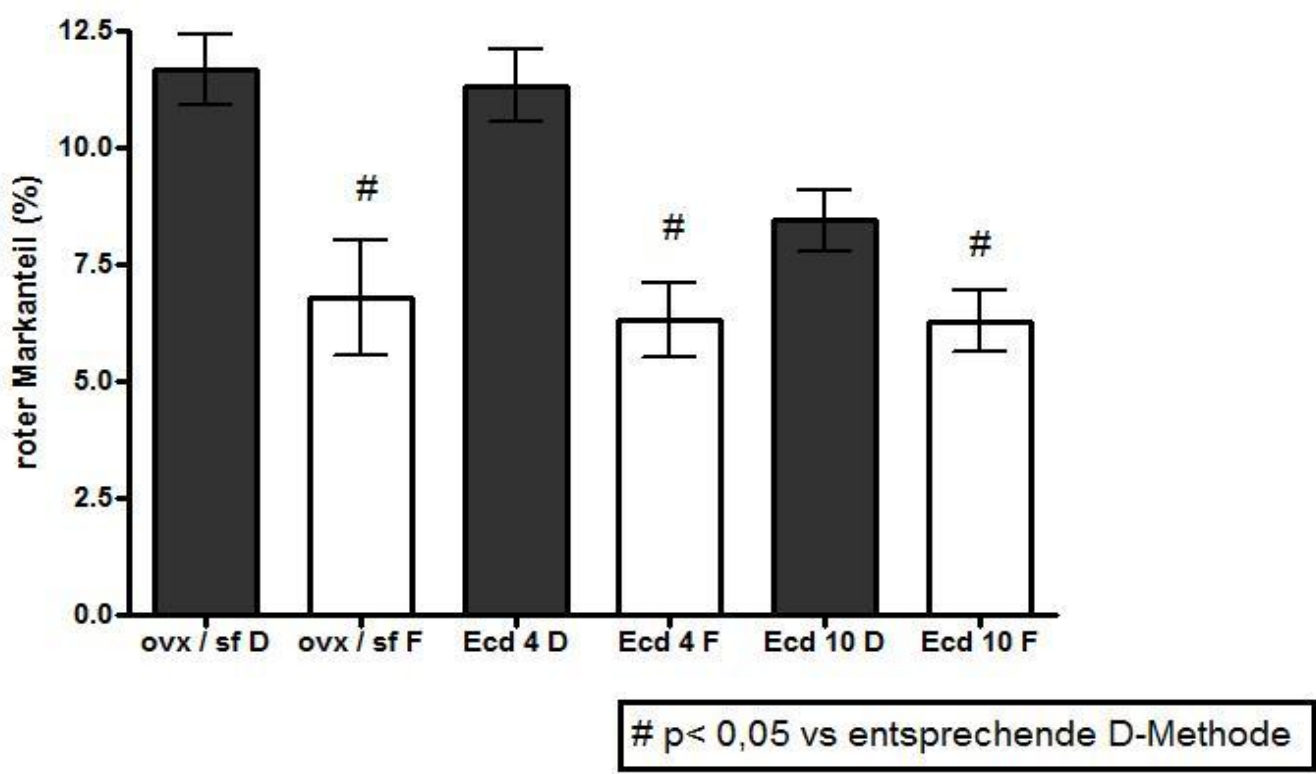

Abb.20: Vergleich und Gegenüberstellung der mittels Schwellenwertbildung am 8-BitGrauwertbild (D-Methode/grau) ermittelten Ergebnisse mit jenen am Negativbild im roten Farbauszug (F-Methode/weiß). Gegenstand der Methodenanwendung war hier die Analyse des Effekts von $\beta$-Ecdyson (Ecd $4 \mathrm{mg} / \mathrm{kg} \mathrm{KG}$; Ecd $10 \mathrm{mg} / \mathrm{kg} \mathrm{KG}$ ) auf den prozentualen Anteil roten Knochenmarks in der tibialen Metaphyse im Bereich von einem Millimeter distal der proximalen Epiphysenfuge nach dreimonatigem Futterversuch an weiblichen ovx S.D.-Ratten im Vergleich zur ovx Kontrollgruppe unter sf Futter. ( $\mathrm{D}=\mathrm{D}$-Methode; F = F-Methode) 


\section{III.2) Nahrungsaufnahme im Rahmen der Futterstudie mit $\beta$-Ecdyson}

\section{III.2.1) Futteraufnahme der männlichen S.D.-Ratten}

Die wochenweise kontrollierte Futteraufnahme der männlichen Tiere im post-orx Verlauf ist in der Abbildung 21 dargestellt. Ein anfänglicher Peak in den ersten zwei Wochen nach ORX fiel zeitlich mit einem starken Abfall der Außentemperaturen auf minus $10{ }^{\circ} \mathrm{C}$ mit einem potentiellen Einfluss auf die Klimatisierung des Tierstalls zusammen. Etwa ab der vierten Woche nach ORX erreichte die Futteraufnahme individuell für jede Gruppe ein relativ konstantes Niveau (Abb.21).

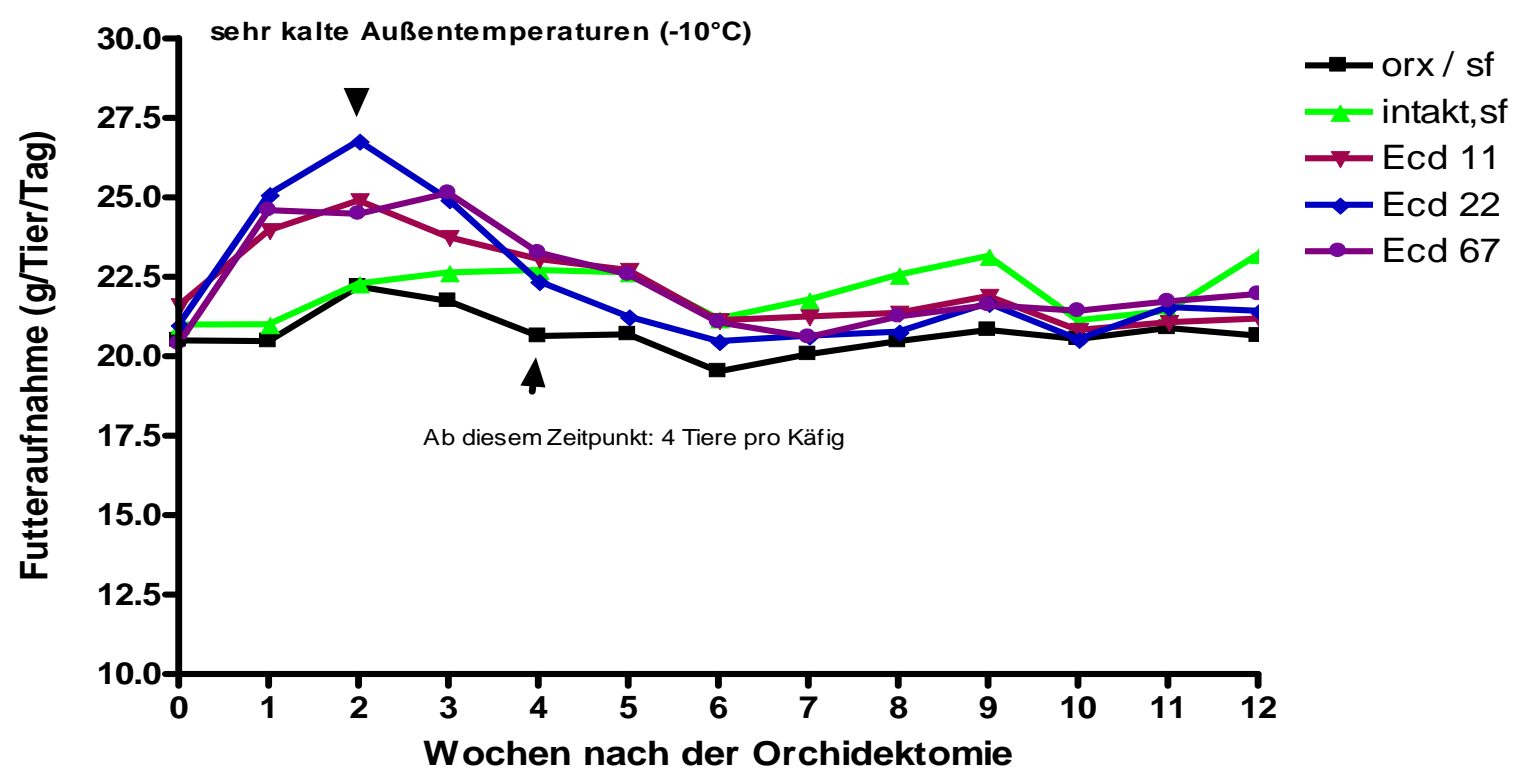

Abb.21: Übersicht über den post-orx Verlauf der Futteraufnahme (in Gramm pro Tier pro Tag) von männlichen S.D.-Ratten während eines dreimonatigen Futterversuchs mit $\beta$-Ecdyson (Ecd 11 $\mathrm{mg} / \mathrm{kg} \mathrm{KG}$; Ecd 22 mg/kg KG; 67 mg/kg KG) im Vergleich zur intakten bzw. orx Kontrollgruppe unter sf Futter.

Der Vergleich der Futteraufnahme (Abb.22) zwischen den beiden Kontrollgruppen zeigte eine signifikant höhere aufgenommene Futtermenge bei den intakten Tieren. Auch in der Gegenüberstellung der orx Kontrolltiere und der mit $\beta$-Ecdyson substituierten Tiere fraßen letztere signifikant mehr Futter. Somit nahmen die orx Kontrolltiere mit täglich durchschnittlich $(20.71 \pm 0.18) \mathrm{g}$ am wenigsten Nahrung zu sich. Die intakten Tiere fraßen im gesamten Zeitraum täglich durchschnittlich $(22.06 \pm 0.23) \mathrm{g}$, die Tiere mit einer $\beta$-EcdysonDosis von $11 \mathrm{mg} / \mathrm{kg} \mathrm{KG}(22.21 \pm 0.37) \mathrm{g}$, mit $22 \mathrm{mg} / \mathrm{kg} \mathrm{KG}(22.19 \pm 0.57) \mathrm{g}$ und mit $67 \mathrm{mg} / \mathrm{kg}$ KG $(22.31 \pm 0.44) g$. 


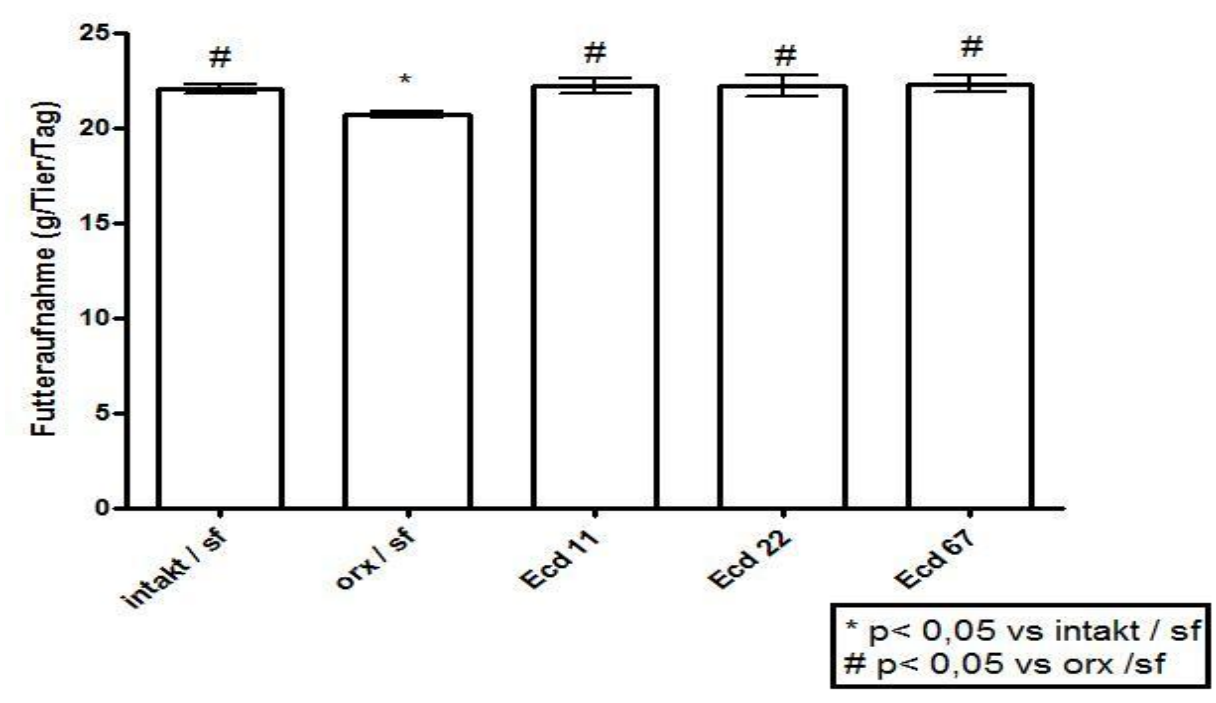

Abb. 22: Der Effekt von $\beta$-Ecdyson (Ecd $11 \mathrm{mg} / \mathrm{kg} \mathrm{KG;} \mathrm{Ecd} 22 \mathrm{mg} / \mathrm{kg} \mathrm{KG;} \mathrm{Ecd} 67$ $\mathrm{mg} / \mathrm{kg} \mathrm{KG}$ ) auf die Futteraufnahme (in Gramm pro Tier pro Tag) von männlichen orx S.D.-Ratten nach dreimonatigem Futterversuch im Vergleich zur intakten bzw. orx Kontrollgruppe unter sf Futter.

\section{III.2.2) Futteraufnahme der weiblichen S.D.-Ratten}

Bei den weiblichen S.D.-Ratten ergab die wöchentliche Kontrolle der Futteraufnahme den in Abbildung 23 dargestellten Verlauf. Wie bei den männlichen Tieren fällt auch hier der Peak in den ersten zwei Wochen nach der OVX zeitlich mit einem Abfall der Außentemperatur auf minus $10{ }^{\circ} \mathrm{C}$ zusammen. Der anschließende Abfall der aufgenommenen Futtermenge in der Folgewoche geschah parallel zu einer kurzfristigen räumlichen Umstellung der Käfige. Nach Korrektur des veränderten Stellplatzes in der fünften Woche nach OVX erreichte die Futteraufnahme, wie bei den Männchen, ein etwa gleich bleibendes Niveau.

Der Vergleich der aufgenommenen Futtermengen zwischen den Futtergruppen der weiblichen S.D.-Ratten brachte mit der angewandten statistischen Methode keinen signifikanten Unterschied hervor (Abb.24). Die ovx Kontrolltiere nahmen täglich durchschnittlich (18.79 \pm 0.43)g Futter zu sich. Bei den mit einer $\beta$-Ecdyson-Dosis von $4 \mathrm{mg} / \mathrm{kg} \mathrm{KG}$ substituierten Tieren betrug die tägliche Futtermenge durchschnittlich $(19.32 \pm 0.41) \mathrm{g}$, bei denen mit 10 $\mathrm{mg} / \mathrm{kg} \mathrm{KG}(19.34 \pm 0.40) \mathrm{g}$. 


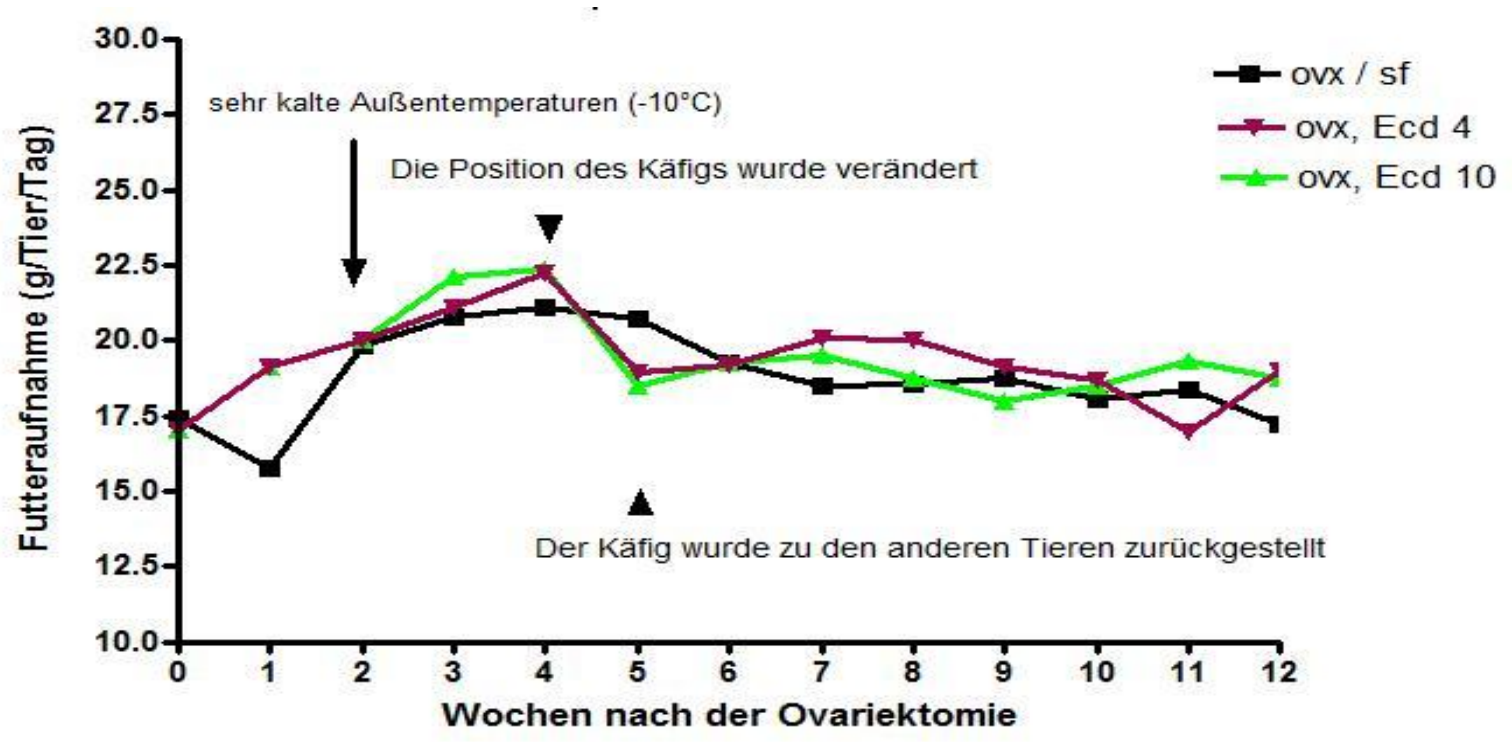

Abb.23: Übersicht über den post-ovx Verlauf der Futteraufnahme (in Gramm pro Tier pro Tag) von weiblichen S.D.-Ratten während eines dreimonatigen Futterversuchs mit $\beta$-Ecdyson (Ecd 4 $\mathrm{mg} / \mathrm{kg} \mathrm{KG}$; Ecd 10 mg/kg KG) im Vergleich zur ovx Kontrollgruppe unter sf Futter.

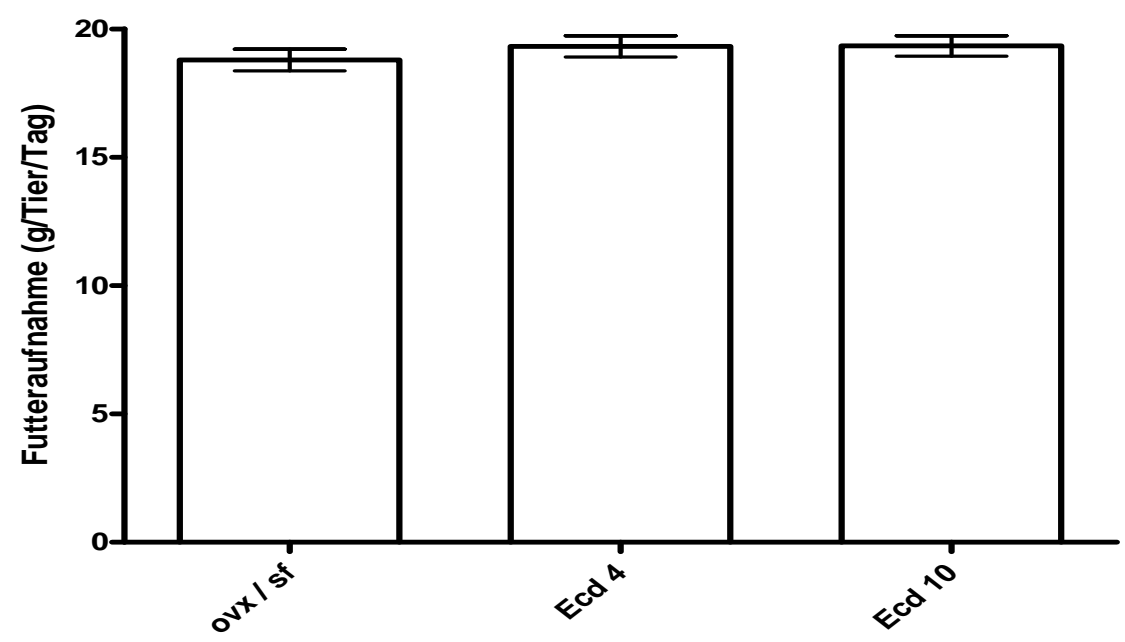

Abb.24: Der Effekt von $\beta$-Ecdyson (Ecd $4 \mathrm{mg} / \mathrm{kg} \mathrm{KG;} \mathrm{Ecd} 10 \mathrm{mg} / \mathrm{kg} \mathrm{KG}$ ) auf die Futteraufnahme (in Gramm pro Tier pro Tag) von weiblichen ovx S.D.-Ratten nach dreimonatigem Futterversuch im Vergleich zur ovx Kontrollgruppe unter sf Futter. 


\section{III.3) Körpergewichtsverlauf im Rahmen der Futterstudie mit $\beta$-Ecdyson}

\section{III.3.1) Körpergewichtsverlauf der männlichen S.D.-Ratten}

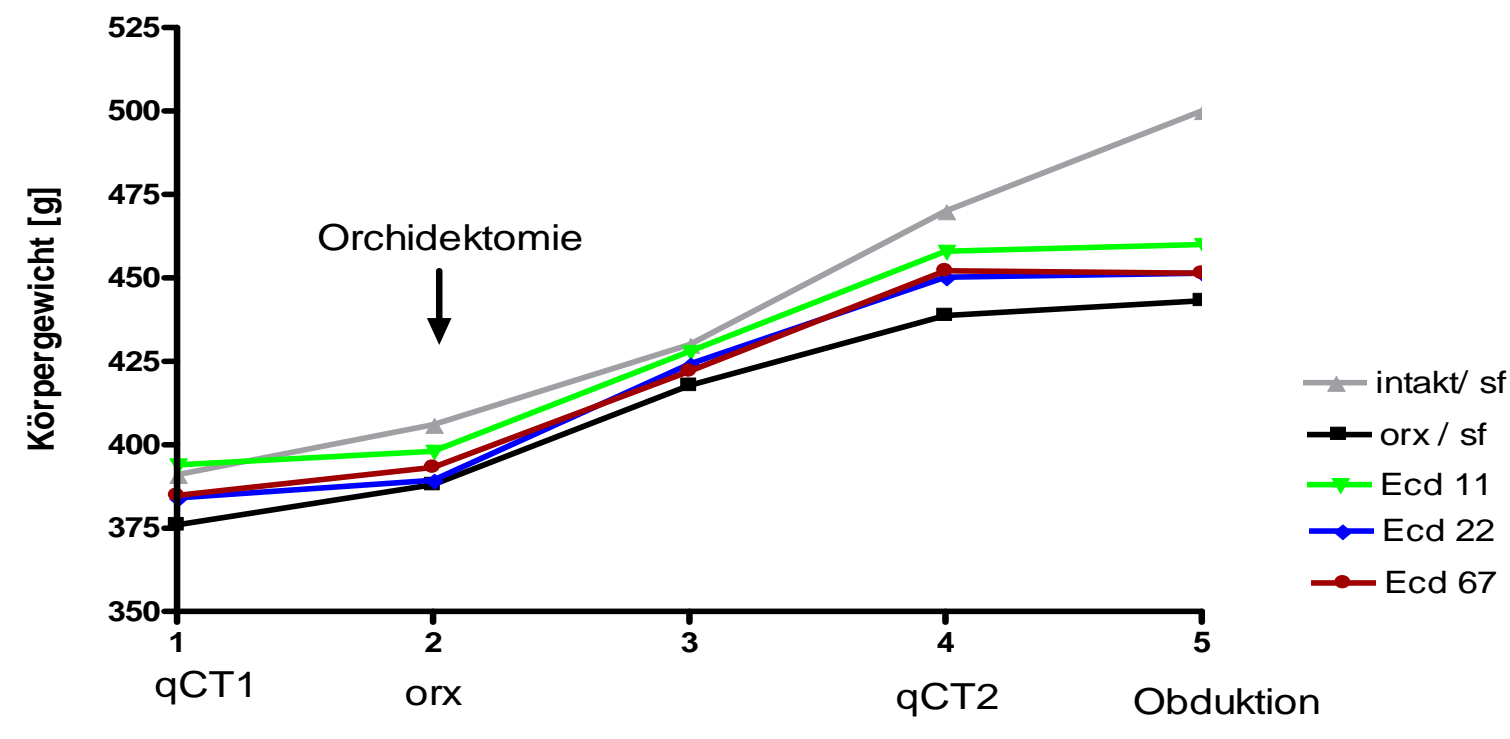

Monate nach Ankunft

Abb.25: Der Effekt von $\beta$-Ecdyson (Ecd $11 \mathrm{mg} / \mathrm{kg} \mathrm{KG;} \mathrm{Ecd} 22 \mathrm{mg} / \mathrm{kg} \mathrm{KG}$; Ecd $67 \mathrm{mg} / \mathrm{kg} \mathrm{KG}$ ) auf den Körpergewichtsverlauf von männlichen orx S.D.-Ratten nach dreimonatigem Futterversuch im Vergleich zur intakten bzw. orx Kontrollgruppe unter sf Futter.

Die Abbildung 25 gibt eine Übersicht über den Verlauf des Körpergewichts der männlichen S.D.-Ratten während der vorliegenden Futterstudie. Alle fünf Futtergruppen zeigen eine kontinuierliche Zunahme des Körpergewichts über den gesamten Zeitraum. Die intakten Tiere weisen, mit Ausnahme der ersten Gewichtsmessung, das höchste Körpergewicht auf. Ab dem Zeitpunkt der ORX verstärkte sich jedoch die Steigung der Körpergewichtszunahme bei den orx Tieren ohne jedoch das Niveau der intakten Kontrollgruppe zu erreichen. Die orx Kontrollgruppe zeigte während des gesamten Versuchszeitraums das niedrigste Körpergewicht. Somit lagen die mit $\beta$-Ecdyson behandelten Tieren mit ihrem Gewicht zwischen den beiden Kontrollgruppen. Durch die Berechnung des Delta-Körpergewichts ließ sich anschließend die Veränderung des Körpergewichts vom Zeitpunkt der ersten pQCTMessung bis zum Tag der Obduktion beurteilen (Abb.26). Die intakten Tiere nahmen ab der ersten pQCT-Messung durchschnittlich $(109.0 \pm 16.23) \mathrm{g}$ zu. Bei den orx Kontrolltieren belief sich dich Gewichtszunahme auf $(67.14 \pm 4.02) \mathrm{g}$. Die mit $\beta$-Ecdyson behandelten Tiere nahmen bei der Dosis von $11 \mathrm{mg} / \mathrm{kg} \mathrm{KG}(66.28 \pm 4.56) \mathrm{g}$, von $22 \mathrm{mg} / \mathrm{kg} \mathrm{KG}(67.41 \pm 4.44) \mathrm{g}$ und von $67 \mathrm{mg} / \mathrm{kg} \mathrm{KG}(66.65 \pm 2.99) \mathrm{g}$ zu. Somit wiesen alle orx S.D.-Ratten im Vergleich zu den intakten Tieren eine signifikant geringere Zunahme an Körpergewicht über den 
Versuchszeitraum hinweg auf. Der Unterschied des Delta-Körpergewichts betrug zwischen orx und intakter Kontrollgruppe $(-41.89 \pm 16.72)$ g. Bei den mit $\beta$-Ecdyson behandelten Tieren im Vergleich zur intakten Kontrolle belief sich die Mittelwertdifferenz für die Dosis von 11 $\mathrm{mg} / \mathrm{kg} \mathrm{KG}$ auf $(42.75 \pm 16.85) \mathrm{g}$, von $22 \mathrm{mg} / \mathrm{kg} \mathrm{KG}$ auf $(41.63 \pm 16.82) \mathrm{g}$ und von $67 \mathrm{mg} / \mathrm{kg}$ KG auf $(42.38 \pm 16.50)$ g. Es konnte hingegen kein signifikanter Unterschied hinsichtlich der Delta-Körpergewichte zwischen der orx Kontrollgruppe und den mit $\beta$-Ecdyson substituierten Tieren nachgewiesen werden.

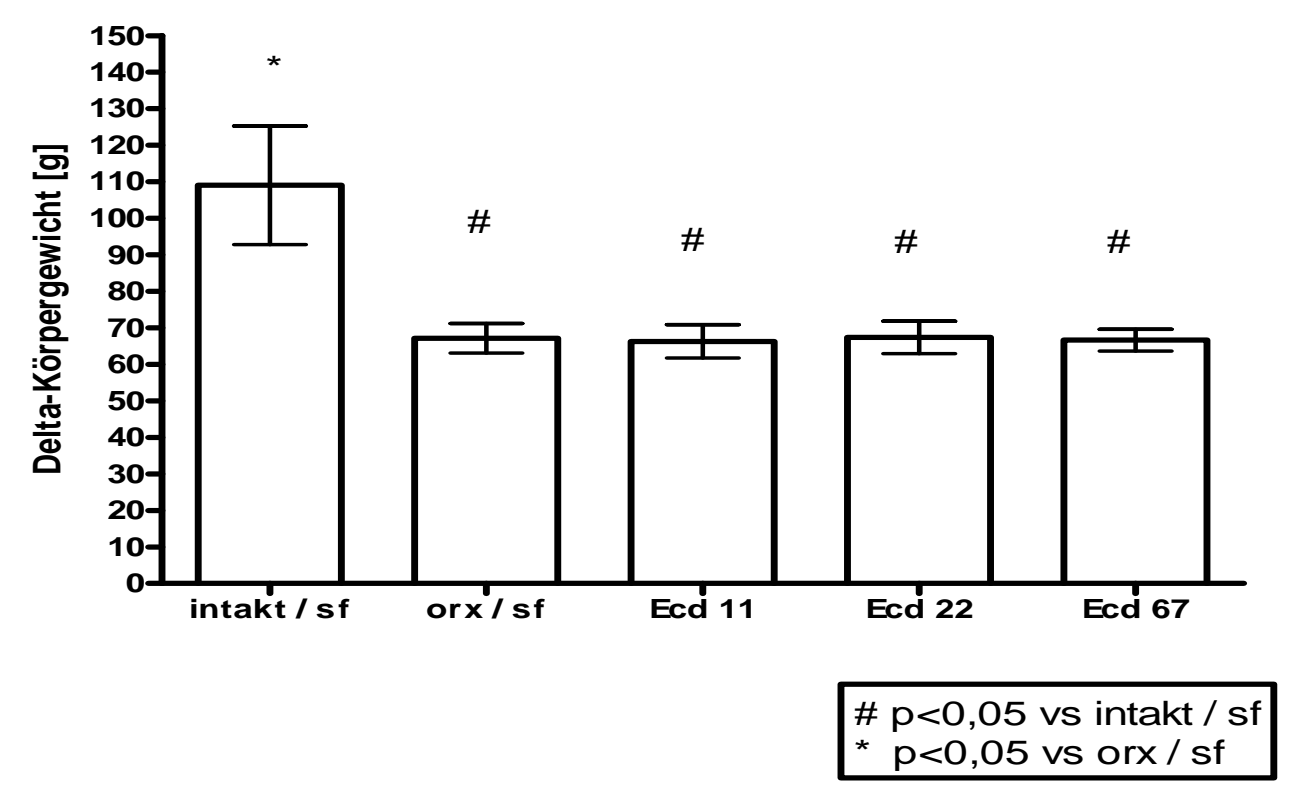

Abb.26: Der Effekt von $\beta$-Ecdyson (Ecd 11 mg/kg KG; Ecd 22 mg/kg KG; Ecd 67 $\mathrm{mg} / \mathrm{kg} \mathrm{KG)} \mathrm{auf} \mathrm{die} \mathrm{Differenz} \mathrm{des} \mathrm{Körpergewichts} \mathrm{zwischen} \mathrm{dem} \mathrm{Zeitpunkt} \mathrm{der} \mathrm{ersten}$ pQCT-Messung bis zum Moment der Obduktion bei männlichen orx S.D.-Ratten nach dreimonatigem Futterversuch im Vergleich zur intakten bzw. orx Kontrollgruppe unter sf Futter.

\section{III.3.2) Körpergewichtsverlauf der weiblichen S.D.-Ratten}

Auch die weiblichen Tiere nahmen über den gesamten Versuchszeitraum kontinuierlich an Körpergewicht zu. Ein steiler Anstieg der Gewichtszunahme erfolgte im ersten Monat nach OVX (Abb.27).

Mit der verwendeten Statistik konnte bei den weiblichen ovx S.D.-Ratten hingegen kein signifikanter Unterschied bezüglich der Delta-Körpergewichte zwischen den Kontrolltieren und den mit $\beta$-Ecdyson-substituierten Tieren nachgewiesen werden (Abb.28). Ab dem Zeitpunkt der ersten pQCT-Messung nahmen die ovx Kontrolltiere durchschnittlich $(94.64 \pm 4.70) \mathrm{g}$ zu. Bei der $\beta$-Ecdyson-Aufnahme von $4 \mathrm{mg} / \mathrm{kg} \mathrm{KG}$ betrug der Gewichtszuwachs $(99.43 \pm 4.66) \mathrm{g}$ und von $10 \mathrm{mg} / \mathrm{kg} \mathrm{KG}(96.90 \pm 5.37) \mathrm{g}$. 


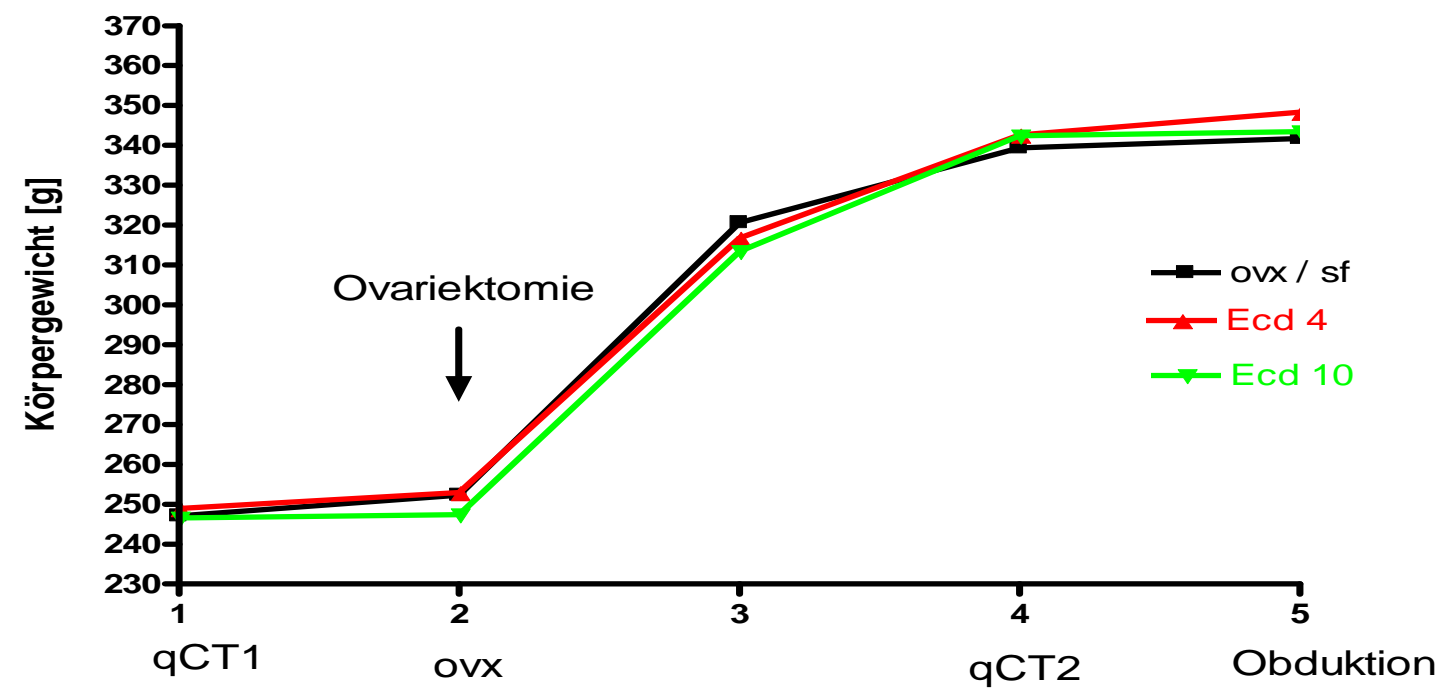

Monate nach Ankunft

Abb.27: Der Effekt von $\beta$-Ecdyson (Ecd $4 \mathrm{mg} / \mathrm{kg} \mathrm{KG}$; Ecd $10 \mathrm{mg} / \mathrm{kg} \mathrm{KG}$ ) auf den Körpergewichtsverlauf von weiblichen ovx S.D.-Ratten nach dreimonatigem Futterversuch im Vergleich zur ovx Kontrollgruppe unter sf Futter.

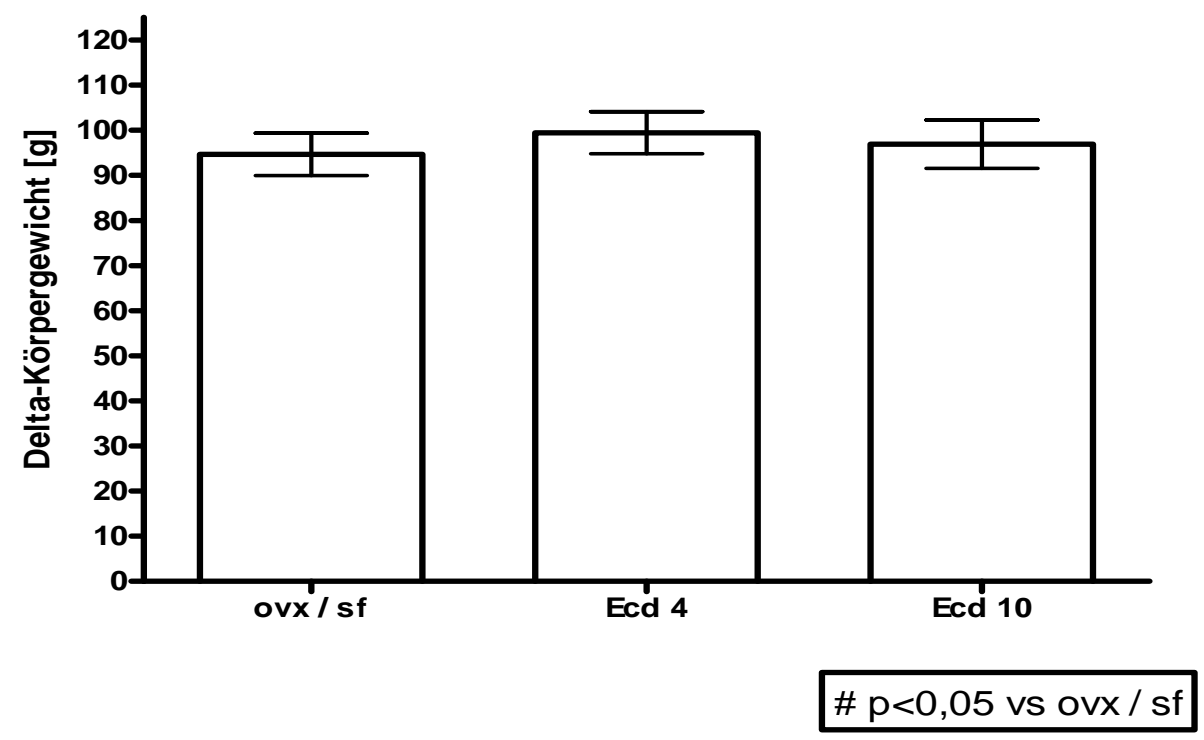

Abb.28: Der Effekt von $\beta$-Ecdyson (Ecd $4 \mathrm{mg} / \mathrm{kg} \mathrm{KG;} \mathrm{Ecd} 10 \mathrm{mg} / \mathrm{kg} \mathrm{KG)} \mathrm{auf} \mathrm{die}$ Differenz des Körpergewichts zwischen dem Zeitpunkt der ersten pQCT-Messung bis zum Moment der Obduktion bei weiblichen ovx S.D.-Ratten nach dreimonatigem Futterversuch im Vergleich zur ovx Kontrollgruppe unter sf Futter. 


\section{III.4) Effekt von $\beta$-Ecdyson auf Tibialänge und Tibiakopfdurchmesser}

\section{III.4.1) Tibialänge und Tibiakopfdurchmesser der männlichen S.D.-Ratten}

Bei der makroskopischen Vermessung der intakten, unbehandelten Tibiae mittels Schieblehre hinsichtlich Länge und Tibiakopfdurchmesser (Abb.2) konnten signifikante Unterschiede zwischen den einzelnen Gruppen festgestellt werden.

Bei den männlichen Tieren waren die Tibialängen nach $\beta$-Ecdyson-Behandlung ab einer Dosis von $11 \mathrm{mg} / \mathrm{kg} \mathrm{KG}$ im Vergleich zu den intakten und den orx Tieren signifikant reduziert (Abb.29), wobei die Knochen bei den intakten Tieren mit einer durchschnittlichen Größe von $(42,7 \pm 0,4) \mathrm{mm}$ am längsten waren. Die Metaphysendicke, sowohl in medio-lateraler als auch in anterior-posteriorer Messung, zeigten mit der verwendeten Statistik keine signifikanten Veränderungen durch die $\beta$-Ecdyson-Aufnahme (Abb.30).

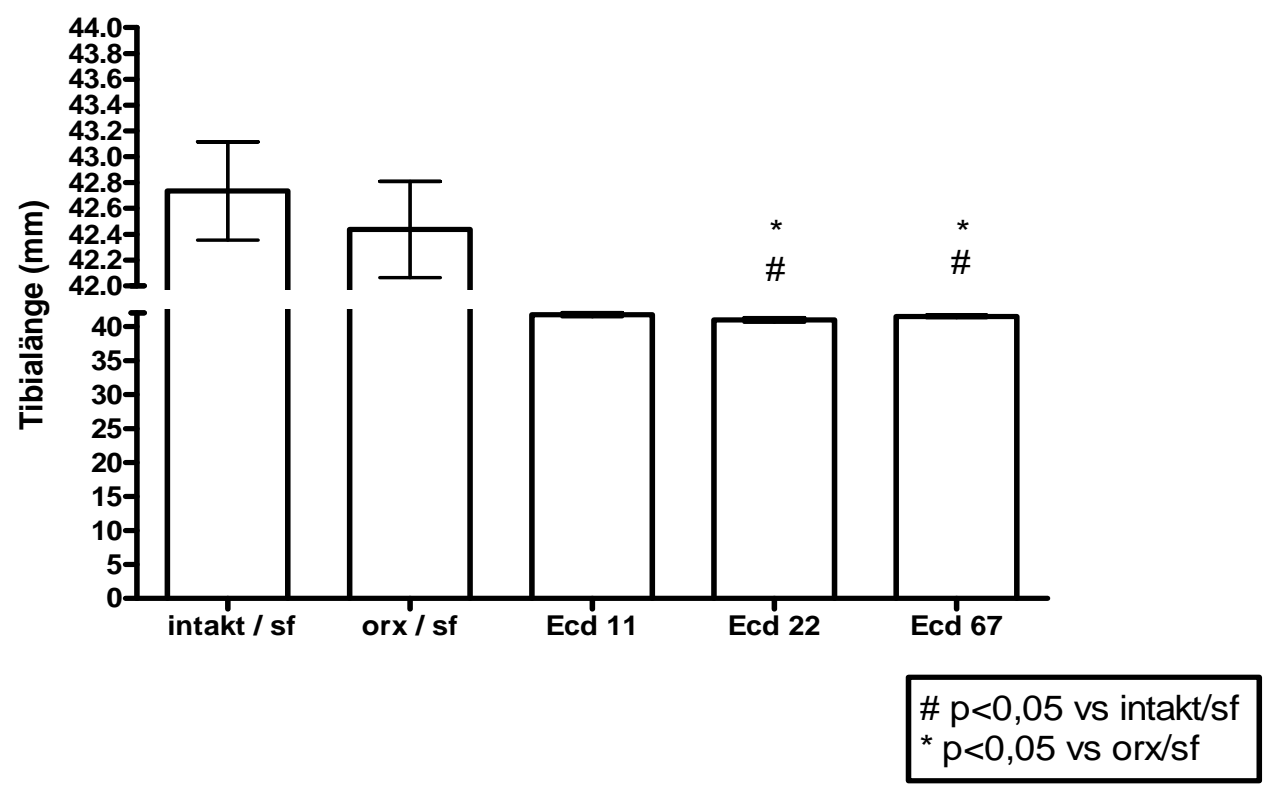

Abb.29: Der Effekt von $\beta$-Ecdyson (Ecd $11 \mathrm{mg} / \mathrm{kg} \mathrm{KG;} \mathrm{Ecd} 22 \mathrm{mg} / \mathrm{kg} \mathrm{KG}$; Ecd 67 $\mathrm{mg} / \mathrm{kg} \mathrm{KG}$ ) auf die Tibialänge (in Millimeter) nach dreimonatigem Futterversuch an männlichen orx S.D.-Ratten im Vergleich zur Kontrollgruppe mit intakten bzw. orx S.D.-Ratten unter sf Futter. 


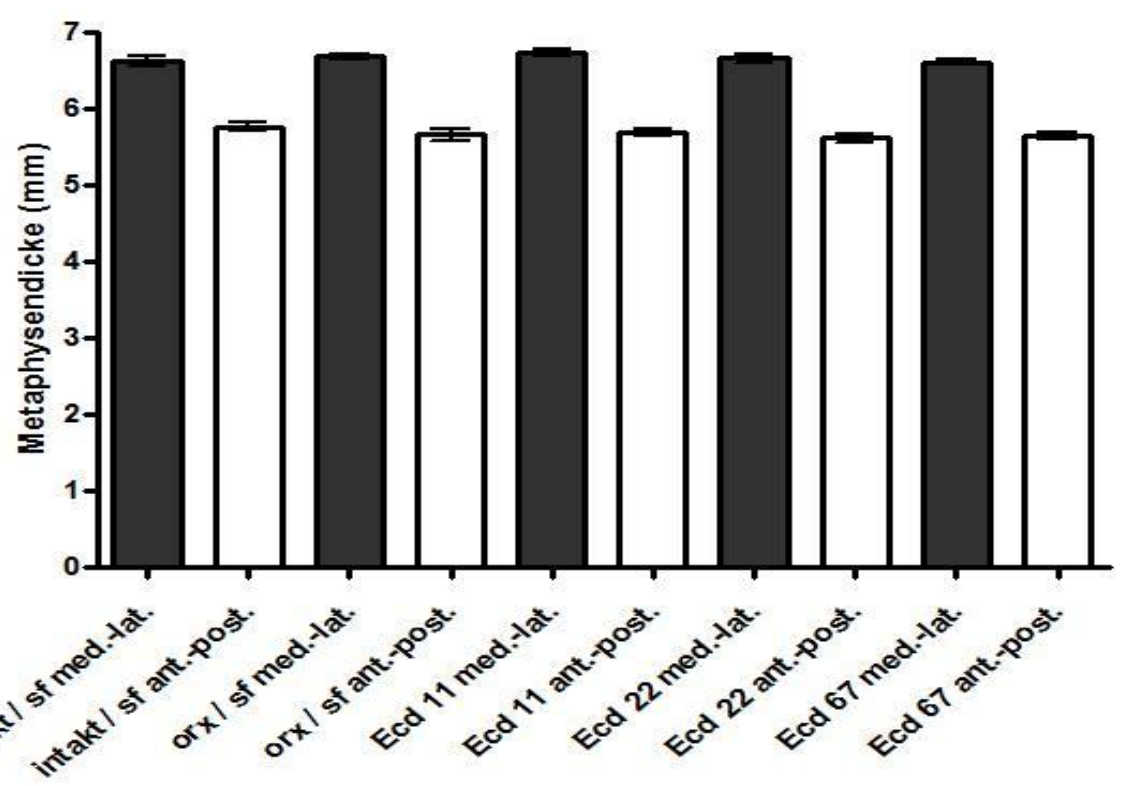

Abb.30: Der Effekt von $\beta$-Ecdyson (Ecd $11 \mathrm{mg} / \mathrm{kg} \mathrm{KG;} \mathrm{Ecd} 22 \mathrm{mg} / \mathrm{kg} \mathrm{KG}$; Ecd 67 $\mathrm{mg} / \mathrm{kg} \mathrm{KG}$ ) auf die Metaphysendicke in medio-lateraler (grau) und anteriorposteriorer (weiß) Messung (in Millimeter) nach dreimonatigem Futterversuch an männlichen orx S.D.-Ratten im Vergleich zur intakten bzw. orx Kontrollgruppe unter sf Futter.

\section{III.4.2) Tibialänge und Tibiakopfdurchmesser der weiblichen S.D.-Ratten}

Die weiblichen ovx Ratten wiesen bei einer $\beta$-Ecdyson-Aufnahme von $10 \mathrm{mg} / \mathrm{kg} \mathrm{KG}$ eine schwach signifikante Abnahme des Tibiakopfdurchmessers in der medio-lateralen und anterior-posterioren Dimension im Vergleich zur ovx Kontrollgruppe unter sojafreiem Futter auf (Abb.32). Die Knochenlänge wurde durch $\beta$-Ecdyson jedoch nicht signifikant verändert (Abb.31).

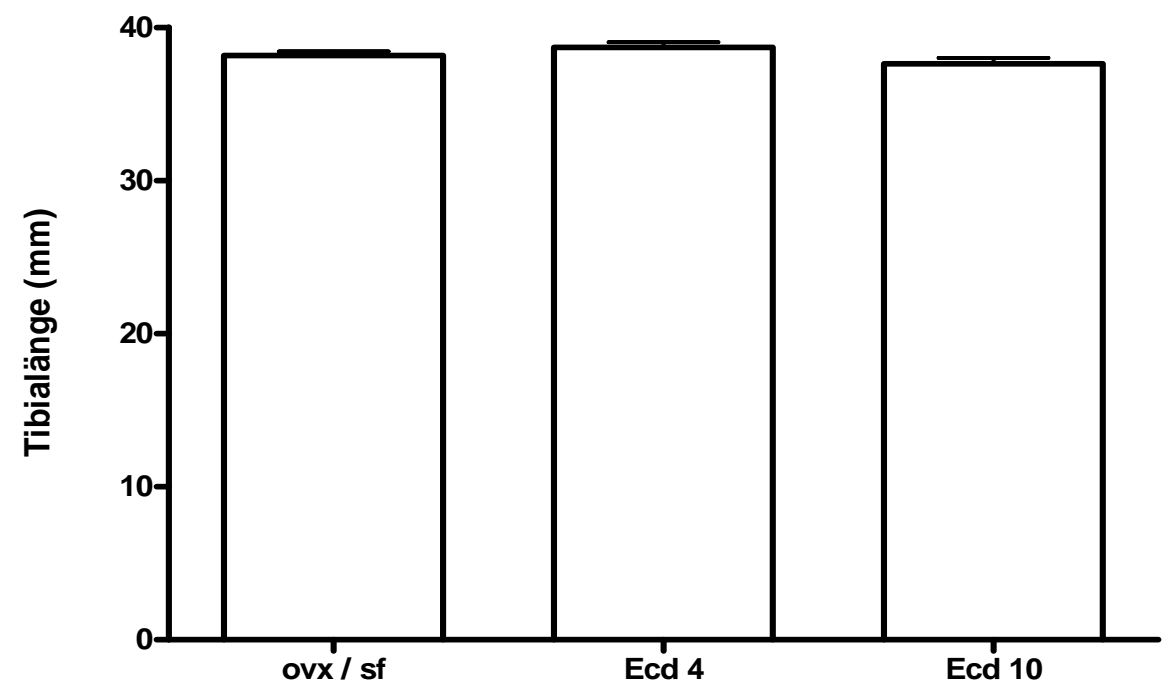

Abb.31: Der Effekt von $\beta$-Ecdyson (Ecd $4 \mathrm{mg} / \mathrm{kg} \mathrm{KG;} \mathrm{Ecd} 10 \mathrm{mg} / \mathrm{kg} \mathrm{KG)}$ auf die Tibialänge (in Millimeter) nach dreimonatigem Futterversuch an weiblichen ovx S.D.-Ratten im Vergleich zur Kontrollgruppe mit ovx S.D.-Ratten unter sf Futter. 


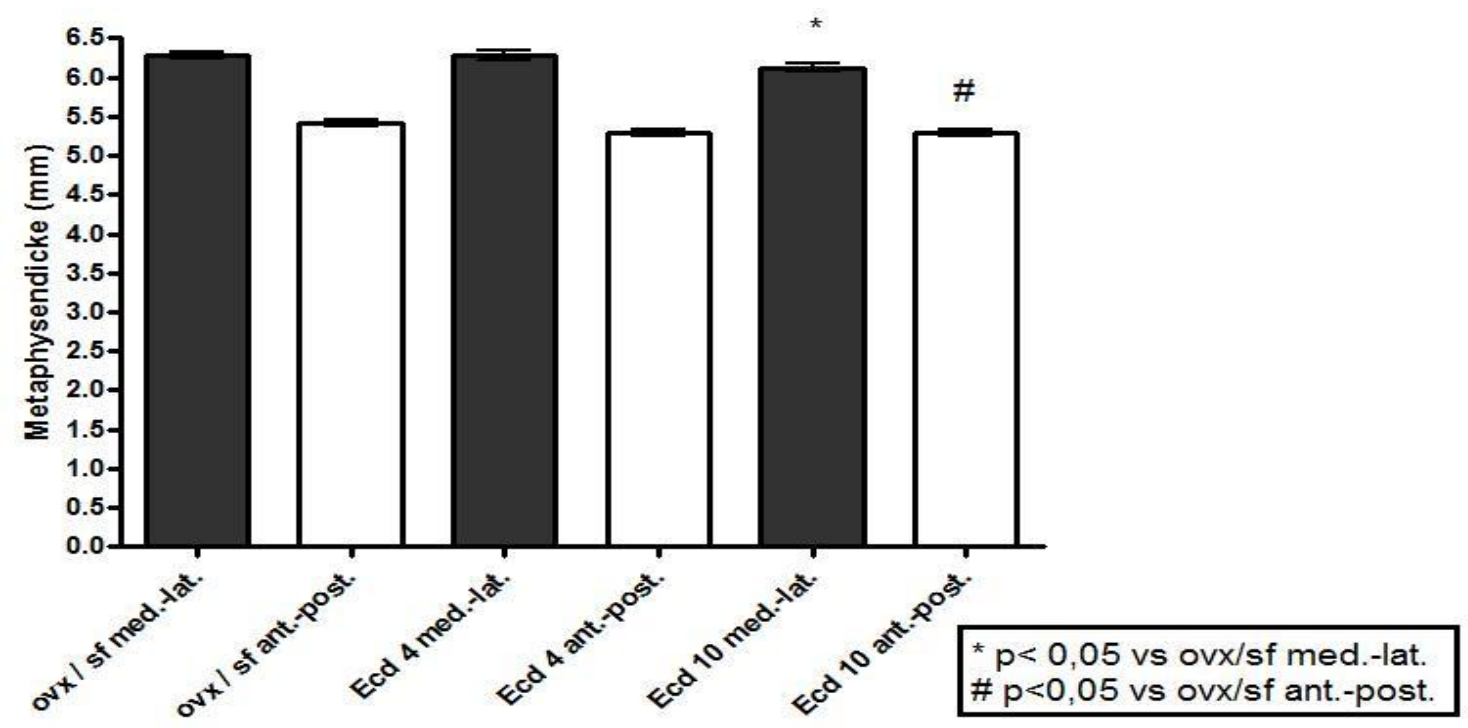

Abb.32: Der Effekt von $\beta$-Ecdyson (Ecd $4 \mathrm{mg} / \mathrm{kg} \mathrm{KG;} \mathrm{Ecd} 10 \mathrm{mg} / \mathrm{kg} \mathrm{KG}$ ) auf die Metaphysendicke in medio-lateraler (grau) und anterior-posteriorer (weiß) Messung (in Millimeter) nach dreimonatigem Futterversuch an weiblichen ovx S.D.-Ratten im Vergleich zur ovx Kontrollgruppe unter sf Futter.

\section{III.5) Effekt von $\beta$-Ecdyson auf die diaphysäre und metaphysäre Kortikalisdicke}

\section{III.5.1) Diaphysäre und metaphysäre Kortikalisdicke der männlichen S.D.- Ratten}

Die Dicke der tibialen Kortikalis wurde jeweils in der Diaphyse und in der Metaphyse an zwei gegenüberliegenden Lokalisationen gemessen (Abb.6). Die Ergebnisse der beiden Messungen pro Tibiabereich wurden anschließend in je einer graphischen Darstellung zusammengefasst (Abb.33, Abb.34).

Bei den männlichen S.D.-Ratten ergaben die Messungen der Kortikalisdicke in den beiden Kontrollgruppen eine tendenziell dickere Kortikalis bei den orx im Vergleich zu den intakten Tieren. Mit der angewandten Statistik war dieser Dickeunterschied jedoch nur bei der Metaphyse mit einer Mittelwertdifferenz von $(35,8 \pm 17,8) \mu \mathrm{m}$ als signifikant nachweisbar (Abb.34). Die Ergebnisse für die Diaphyse hingegen waren unter den statistischen Vorgaben nicht signifikant. 
Die Wirkung von $\beta$-Ecdyson im Bereich der Diaphyse erwies sich als senkend auf die Kortikalisdicke. Dieser reduzierende Effekt war signifikant für die $\beta$-Ecdyson-Konzentration von $11 \mathrm{mg} / \mathrm{kg} \mathrm{KG}$ und von $67 \mathrm{mg} / \mathrm{kg} \mathrm{KG}$ im Vergleich zur orx Kontrollgruppe (Abb.33). In absoluten Werten bedeutete dies eine Mittelwertdifferenz von $(49,0 \pm 19,3) \mu \mathrm{m}$ bei der Dosis von $11 \mathrm{mg} / \mathrm{kg} \mathrm{KG}$ und von $(79,4 \pm 19,8) \mu \mathrm{m}$ bei der Dosis von $67 \mathrm{mg} / \mathrm{kg} \mathrm{KG}$.

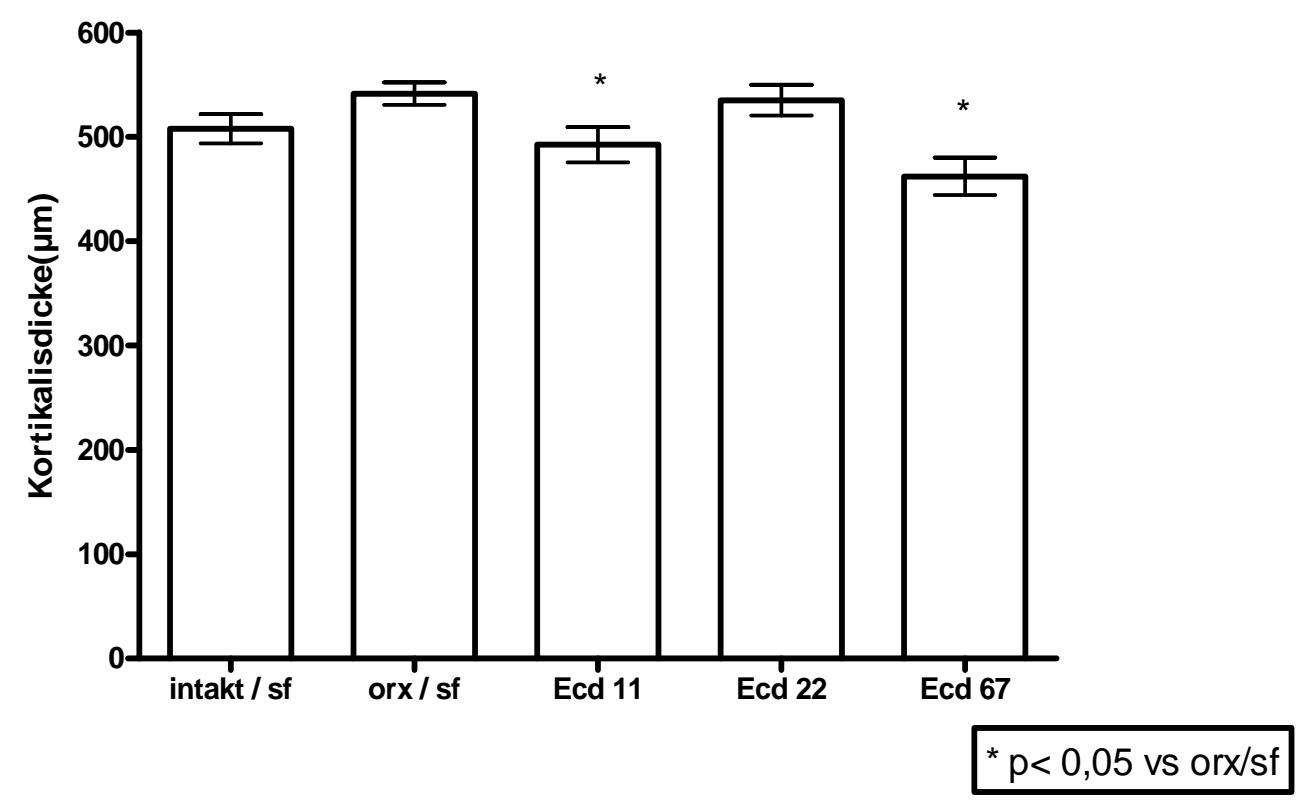

Abb.33: Der Effekt von $\beta$-Ecdyson (Ecd $11 \mathrm{mg} / \mathrm{kg} \mathrm{KG;} \mathrm{Ecd} 22 \mathrm{mg} / \mathrm{kg} \mathrm{KG;} \mathrm{Ecd}$ $67 \mathrm{mg} / \mathrm{kg} \mathrm{KG}$ ) auf die diaphysäre Kortikalisdicke (in Mikrometer) der Tibia nach dreimonatigem Futterversuch an männlichen orx S.D.-Ratten im Vergleich zur intakten bzw. orx Kontrollgruppe unter sf Futter.

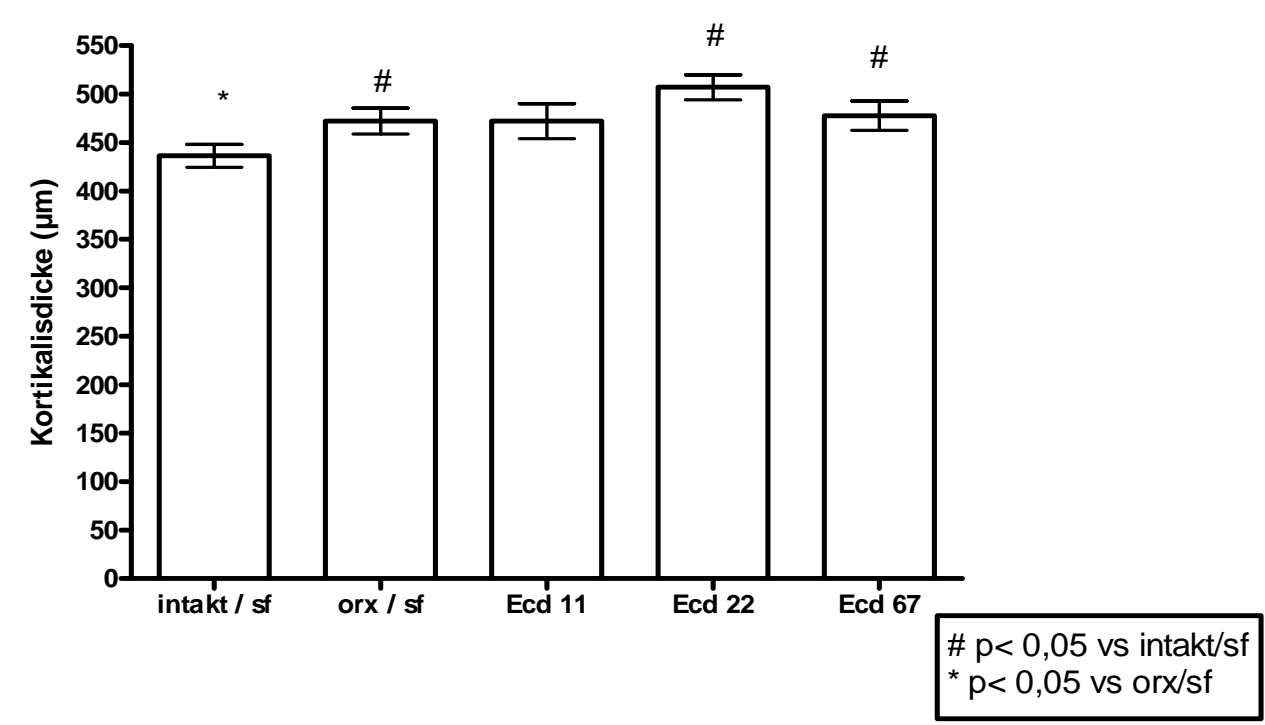

Abb.34: Der Effekt von $\beta$-Ecdyson (Ecd 11 mg/kg KG; Ecd 22 mg/kg KG; Ecd $67 \mathrm{mg} / \mathrm{kg} \mathrm{KG}$ ) auf die metaphysäre Kortikalisdicke (in Mikrometer) der Tibia nach dreimonatigem Futterversuch an männlichen orx S.D.-Ratten im Vergleich zur intakten bzw. orx Kontrollgruppe unter sf Futter. 
In Bezug auf die metaphysäre Kortikalis konnte mit dem verwendeten statistischen Verfahren bei den männlichen orx S.D.-Ratten kein signifikanter Dickeunterschied zwischen den mit $\beta$ Ecdyson behandelten Tieren und der orx Kontrollgruppe mit sojafreiem Futter nachgewiesen werden. Allerdings steigerte $\beta$-Ecdyson bei den orx Tieren in der Dosis von $22 \mathrm{mg} / \mathrm{kg} \mathrm{KG}$ und von $67 \mathrm{mg} / \mathrm{kg} \mathrm{KG}$ die metaphysäre Kortikalisdicke signifikant im Vergleich zur intakten Kontrollgruppe (Abb.23). Der Unterschied zwischen den Mittelwerten betrug bei der Gruppe mit $22 \mathrm{mg} \beta$-Ecdyson $/ \mathrm{kg} \mathrm{KG} \bar{x} \pm s=(70,7 \pm 17,5) \mu \mathrm{m}$ und bei jener mit $67 \mathrm{mg} \beta$ Ecdyson $/ \operatorname{kg~KG} \bar{x} \pm s=(41,4 \pm 19,1) \mu \mathrm{m}$.

Der Vergleich der Kortikalisdicke im Bereich der Metaphyse mit jener in der Diaphyse zeigte, dass die metaphysäre Kortikalis bei den beiden Kontrollgruppen signifikant dünner war als die der Diaphyse. Bei den Tieren, die $\beta$-Ecdyson-haltiges Futter erhielten, war dieser Dickeunterschied mit der angewandten statistischen Methode nicht mehr als signifikant nachzuweisen (Abb.35).

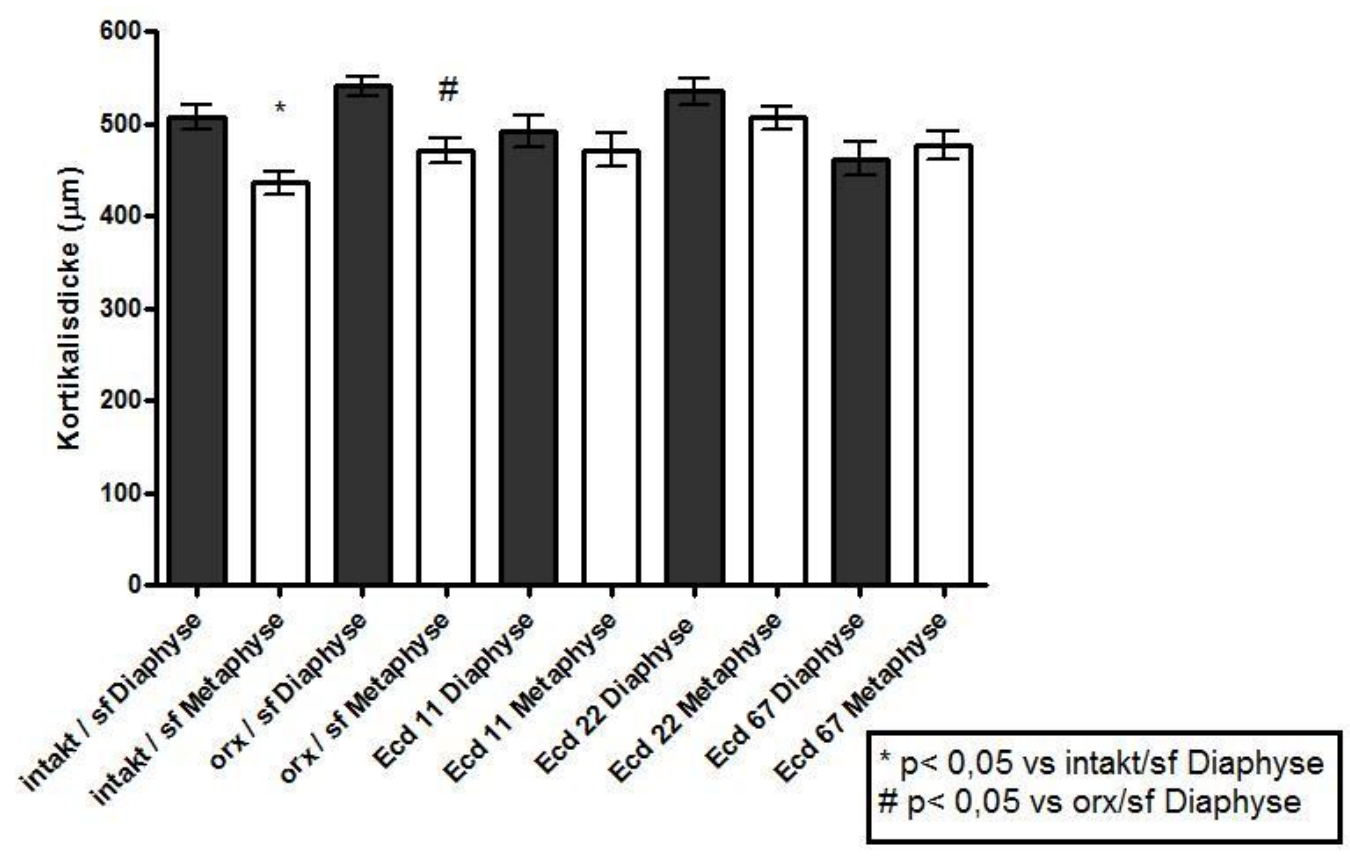

Abb.35: Der Effekt von $\beta$-Ecdyson (Ecd $11 \mathrm{mg} / \mathrm{kg} \mathrm{KG;} \mathrm{Ecd} 22 \mathrm{mg} / \mathrm{kg} \mathrm{KG}$; Ecd 67 $\mathrm{mg} / \mathrm{kg} \mathrm{KG)}$ auf den Unterschied der tibialen Kortikalisdicke in Metaphyse und Diaphyse (in Mikrometer) nach dreimonatigem Futterversuch an orx S.D.-Ratten im Vergleich zur orx bzw. intakten Kontrollgruppe unter sf Futter. 


\section{III.5.2) Diaphysäre und metaphysäre Kortikalisdicke der weiblichen S.D.- Ratten}

Bei den weiblichen ovx S.D.-Ratten konnten mit der angewandten Statistik keine signifikanten Unterschiede bezüglich des Effekts von $\beta$-Ecdyson in einer Dosis von $4 \mathrm{mg} / \mathrm{kg}$ $\mathrm{KG}$ und von $10 \mathrm{mg} / \mathrm{kg} \mathrm{KG}$ auf die tibiale Kortikalis nachgewiesen werden (Abb.36). Der Vergleich zwischen der Kortikalisdicke in der Diaphyse mit jener in der Metaphyse zeigte, dass letztere in jeder der untersuchten Gruppen signifikant dünner war (Abb.36). Die im Folgenden errechneten Differenzen zwischen den Mittelwerten der diaphysären und metaphysären Kortikalisdicke der jeweiligen Gruppe sind in Tabelle 3 dargestellt.

Tabelle 3: Differenz der errechneten Mittelwerte der gemessenen Kortikalisdicke zwischen Diaphyse und Metaphyse der Tibia bei ovx S.D.-Ratten nach dreimonatigem Futterversuch mit $\beta$-Ecdyson im Vergleich zur ovx Kontrollgruppe unter sf Futter

\begin{tabular}{|l|c|}
\hline & Mittelwertdifferenz (Diaphyse-Metaphyse) in Mikrometer \\
\hline OVX / sf & $\bar{x} \pm s=(88,7 \pm 22,6) \mu \mathrm{m}$ \\
\hline B-Ecdyson 4 $\mathbf{~ m g / k g ~ K G}$ & $\bar{x} \pm s=(83,5 \pm 19,6) \mu \mathrm{m}$ \\
\hline B-Ecdyson $10 \mathbf{~ m g / k g ~ K G}$ & $\bar{x} \pm s=(60,6 \pm 17,5) \mu \mathrm{m}$ \\
\hline
\end{tabular}

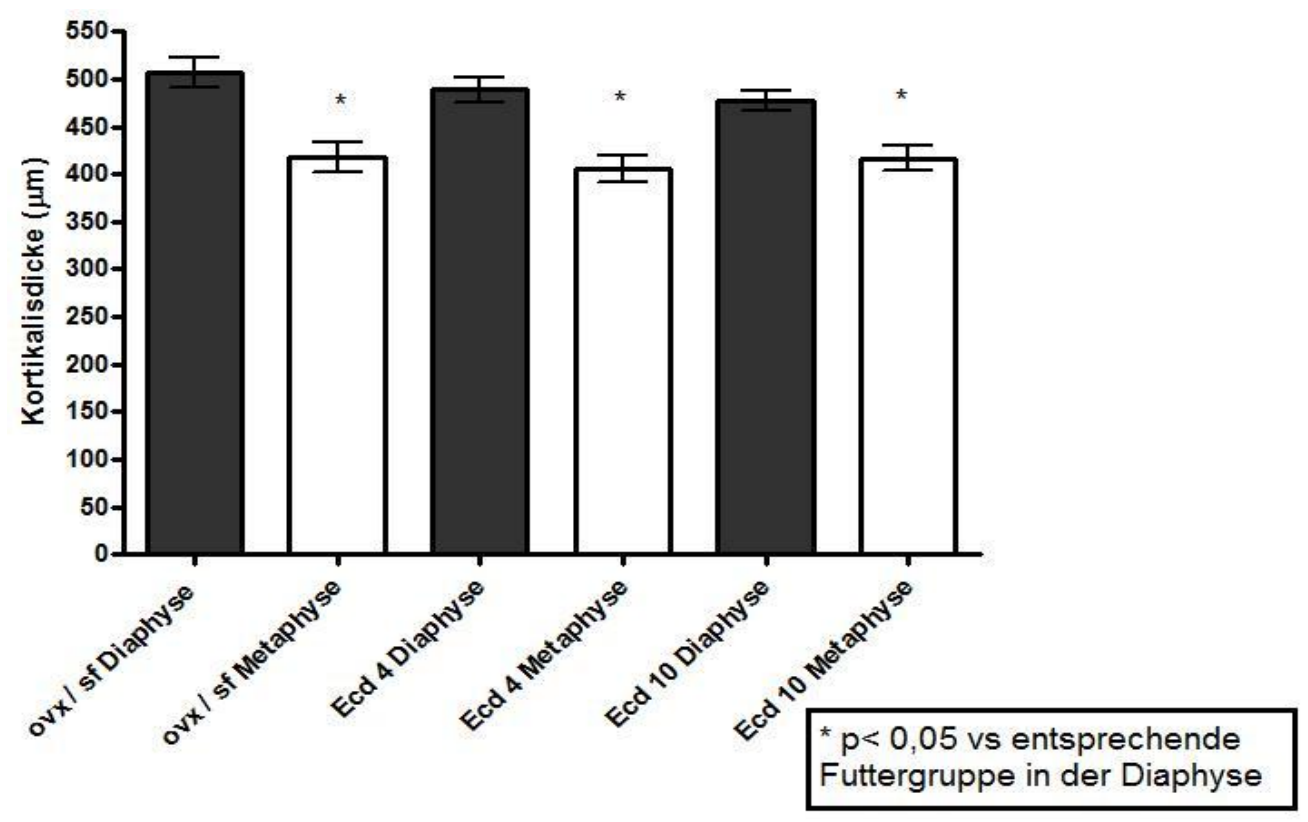

Abb.36: Der Effekt von $\beta$-Ecdyson (Ecd $4 \mathrm{mg} / \mathrm{kg} \mathrm{KG;} \mathrm{Ecd} 10 \mathrm{mg} / \mathrm{kg} \mathrm{KG)} \mathrm{auf} \mathrm{die} \mathrm{diaphysäre} \mathrm{(grau)}$ und metaphysäre (weiß) Kortikalisdicke, sowie auf den Unterschied der tibialen Kortikalisdicke in Metaphyse und Diaphyse (in Mikrometer) nach dreimonatigem Futterversuch an ovx S.D.-Ratten im Vergleich zur ovx Kontrollgruppe unter sf Futter. 


\section{III.6) Effekt von $\beta$-Ecdyson auf weitere mikroskopische Aspekte der tibialen Metaphyse von männlichen S.D.-Ratten}

\section{III.6.1) Trabekelfläche und prozentualer Trabekelanteil in der tibialen Metaphyse}

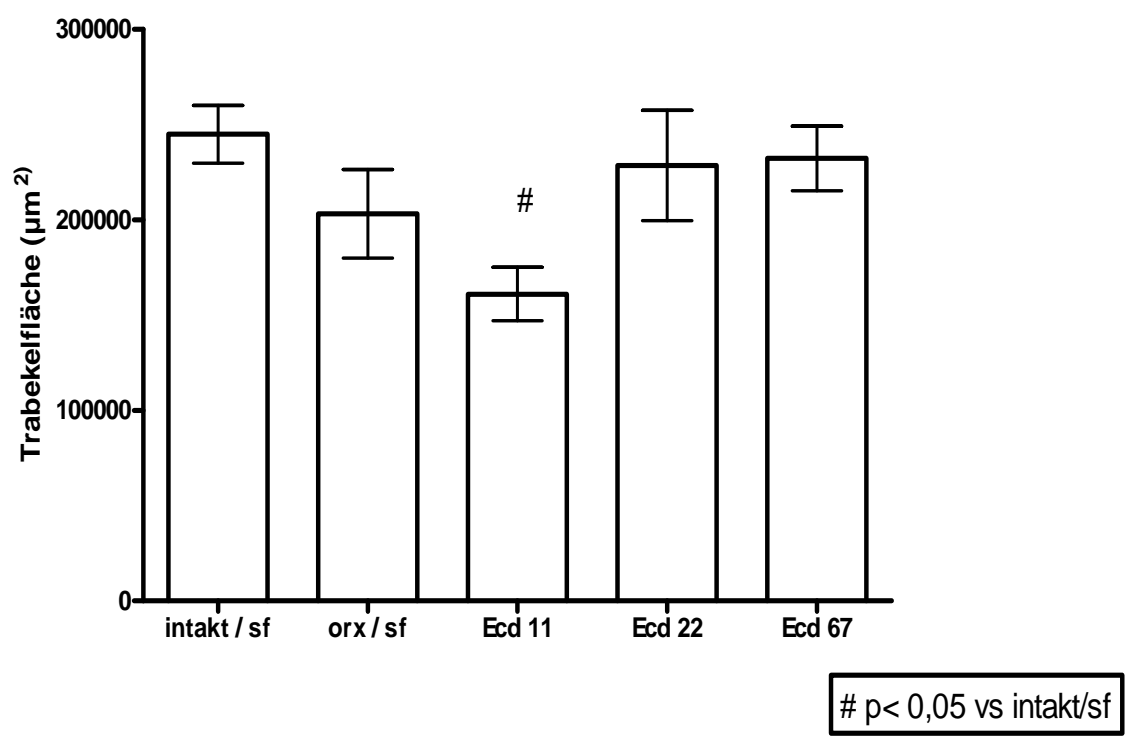

Abb.37: Der Effekt von $\beta$-Ecdyson (Ecd $11 \mathrm{mg} / \mathrm{kg} \mathrm{KG;} \mathrm{Ecd} 22 \mathrm{mg} / \mathrm{kg} \mathrm{KG;} \mathrm{Ecd} \mathrm{67mg/kg}$ KG) auf die Trabekelfläche (in Mikrometer ${ }^{2}$ ) in der tibialen Metaphyse im Bereich von einem Millimeter distal der proximalen Epiphysenfuge nach dreimonatigem Futterversuch an männlichen orx S.D.-Ratten im Vergleich zur intakten bzw. orx Kontrollgruppe unter sf Futter. Gemittelte Ergebniskombination aus Schwellenwertbildung am 8-Bit-Grauwertbild (D-Methode) sowie mit jener am Negativbild im roten Farbauszug (F-Methode).

Mittels histologischer Untersuchung eines metaphysären Tibiaausschnitts im Bereich von einem Millimeter distal der proximalen Epiphysenfuge (Abb.7a) konnte die Trabekelfläche in Mikrometer $^{2}$ für die jeweilige Futtergruppe bestimmt werden. Die Ergebnisse setzen sich aus der gemittelten Kombination zweier Auswertungsverfahren zusammen. Beide basieren auf Schwellenwertbestimmung im identischen Tibiaauschnitt. Während die D-Methode am 8-BitGrauwertbild durchgeführt wird, erfolgt die F-Methode im Negativbild im Farbauszug rot.

Bei den männlichen S.D.-Ratten konnten mit der verwendeten Statistik keine signifikanten trabekulären Flächenunterschiede zwischen der orx Kontrollgruppe und den mit $\beta$-Ecdyson substituierten Tieren nachgewiesen werden. Auch konnte mit der statistischen Methode kein signifikantes Ergebnis bezüglich eines Unterschieds zwischen der Trabekelfläche bei der intakten Kontrollgruppe im Vergleich zur orx Kontrollgruppe gezeigt werden. Es konnte lediglich eine signifikant geringere Trabekelfläche bei der Gruppe mit einer $\beta$-EcdysonAufnahme von $11 \mathrm{mg} / \mathrm{kg} \mathrm{KG}$ im statistischen Vergleich mit der intakten Kontrollgruppe unter 
sojafreiem Futter belegt werden. Der Flächenunterschied unter Verwendung der entsprechenden Mittelwerte betrug dabei $\bar{x} \pm s=(83920 \pm 20690) \mu \mathrm{m}^{2}$ (Abb.37). Bei den Tieren mit einer $\beta$-Ecdyson-Aufnahme von $22 \mathrm{mg} / \mathrm{kg} \mathrm{KG}$ und von $67 \mathrm{mg} / \mathrm{kg} \mathrm{KG}$ zeigten sich hingegen keine signifikanten trabekulären Flächenunterschiede im Vergleich mit der intakten Kontrollgruppe.

Im gleichen Metaphysenabschnitt, in dem die Trabekelfläche bestimmt wurde, erfolgte auch die Berechnung des prozentualen Anteils der dortigen Trabekel am Gesamtbild der benachbarten Strukturen, das heißt gelbem und rotem Knochenmark. Der prozentuale Trabekelanteil bei den männlichen Ratten der orx Kontrollgruppe mit sf Futter war mit $\bar{x} \pm s=(4,7 \pm 0,5) \%$ signifikant geringer als bei den Tieren der intakten Kontrollgruppe mit einem Trabekelanteil von $\bar{x} \pm s=(7,45 \pm 0,5) \%$. Durch den Vergleich der Ergebnisse der orx Kontrollgruppe mit denen der Tiere, die $\beta$-Ecdyson-haltiges Futter mit einer Dosis von 22 $\mathrm{mg} / \mathrm{kg} \mathrm{KG}$ oder $67 \mathrm{mg} / \mathrm{kg} \mathrm{KG}$ erhielten, war ein signfikanter Unterschied zwischen den Trabekelanteilen erkennbar (Abb.38). Während die orx Tiere mit sf Nahrung einen durchschnittlichen Trabekelanteil von $\bar{x} \pm s=(4,7 \pm 0,5) \%$ aufwiesen, beliefen sich die Mittelwerte bei der Gruppe mit einer $\beta$-Ecdysondosis von $22 \mathrm{mg} / \mathrm{kg} \mathrm{KG}$ auf $\bar{x} \pm s=(7,4 \pm$ $0,8) \%$ und bei jener mit $67 \mathrm{mg} / \mathrm{kg} \mathrm{KG}$ auf $\bar{x} \pm s=(7,04 \pm 0,5) \%$.

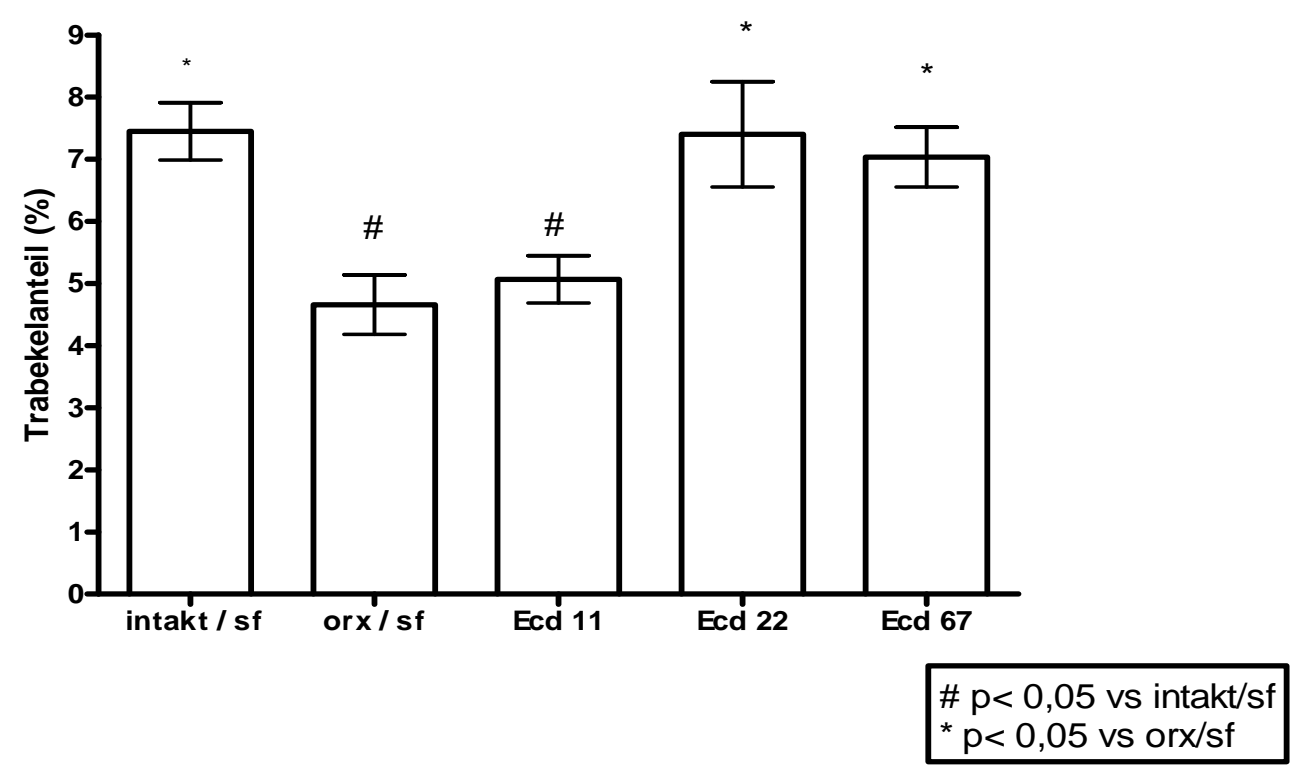

Abb.38: Der Effekt von $\beta$-Ecdyson (Ecd 11 mg/kg KG; Ecd 22 mg/kg KG; Ecd 67mg/kg KG) auf den prozentualen Trabekelanteil in der tibialen Metaphyse im Bereich von einem Millimeter distal der proximalen Epiphysenfuge nach dreimonatigem Futterversuch an männlichen orx S.D.-Ratten im Vergleich zur intakten bzw. orx Kontrollgruppe unter sf Futter. Gemittelte Ergebniskombination aus Schwellenwertbildung am 8-Bit-Grauwertbild (D-Methode) sowie mit jener am Negativbild im roten Farbauszug (F-Methode). 


\section{III.6.2) Fläche und prozentualer Anteil gelben Knochenmarks in der tibialen Metaphyse}

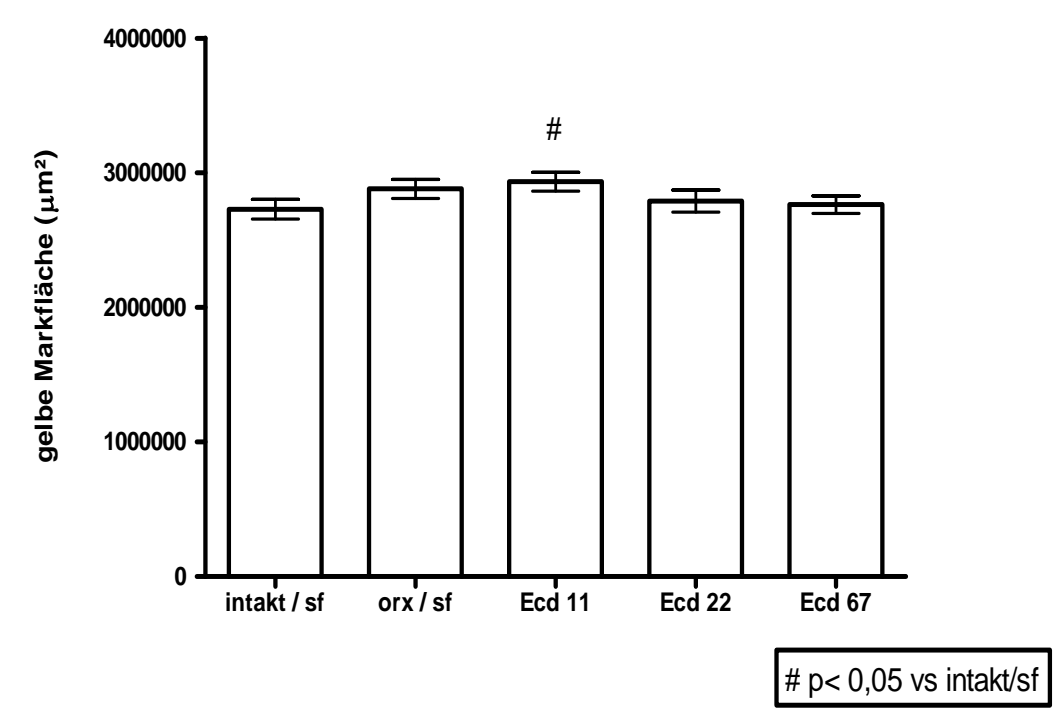

Abb.39: Der Effekt von $\beta$-Ecdyson (Ecd $11 \mathrm{mg} / \mathrm{kg} \mathrm{KG;} \mathrm{Ecd} 22 \mathrm{mg} / \mathrm{kg}$ $\mathrm{KG}$; Ecd $67 \mathrm{mg} / \mathrm{kg} \mathrm{KG}$ ) auf die Fläche gelben Knochenmarks (in Mikrometer $^{2}$ ) in der tibialen Metaphyse im Bereich von einem Millimeter distal der proximalen Epiphysenfuge nach dreimonatigem Futterversuch an männlichen orx S.D.-Ratten im Vergleich zur intakten bzw. orx Kontrollgruppe unter sf Futter. Gemittelte Ergebniskombination aus Schwellenwertbildung am 8-Bit-Grauwertbild (D-Methode) sowie mit jener am Negativbild im roten Farbauszug (F-Methode).

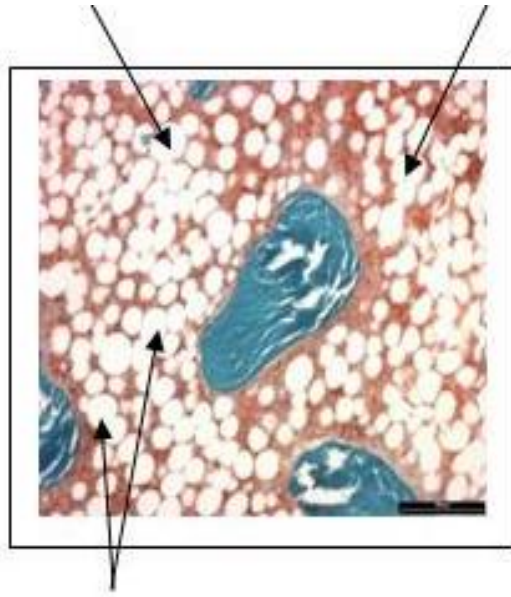

Abb.40: Foto eines histologischen Tibiapräparats (Nr.34-10; Ecd 11) im Bereich Metaphyse. Pfeile zeigen auf Elemente des gelben Knochenmarks

In der Metaphyse wurde die Fläche gelben Marks unter den statistischen Vorgaben im Allgemeinen nicht signifikant durch $\beta$-Ecdyson beeinflusst. Lediglich die $\beta$-Ecdyson-Dosis von $11 \mathrm{mg} / \mathrm{kg} \mathrm{KG}$ stellte sich als signifikant größer als jene der intakten Kontrolltiere unter sf Futter dar (Abb.39). Der Flächenunterschied betrug bei Betrachtung der Mittelwertdifferenz zwischen intakten Tieren und der Ecd 11-Gruppe $\bar{x} \pm s=(-316000 \pm 87900) \mu \mathrm{m}^{2}$. Tendenziell erwies sich die Fläche gelben Marks bei den orx Kontrollgruppen als am größten, die der intakten Kontrolltiere als am kleinsten. Dieser Unterschied zwischen den Kontrolltieren wurde jedoch nur durch die Schwellenwertbestimmung am 8-Bit-Grauwertbild (D-Methode) als signifikant nachgewiesen, das heißt die Schwellenwertbildung am Negativbild im Farbauszug rot (F-Methode) und die Kombination beider Methoden zeigten in dieser Hinsicht keinen statistisch signifikanten Unterschied. Die $\beta$-Ecdyson-substituierten Tiere lagen mit ihren Werten für die Fläche gelben Marks somit zwischen den beiden Kontrollgruppen. 


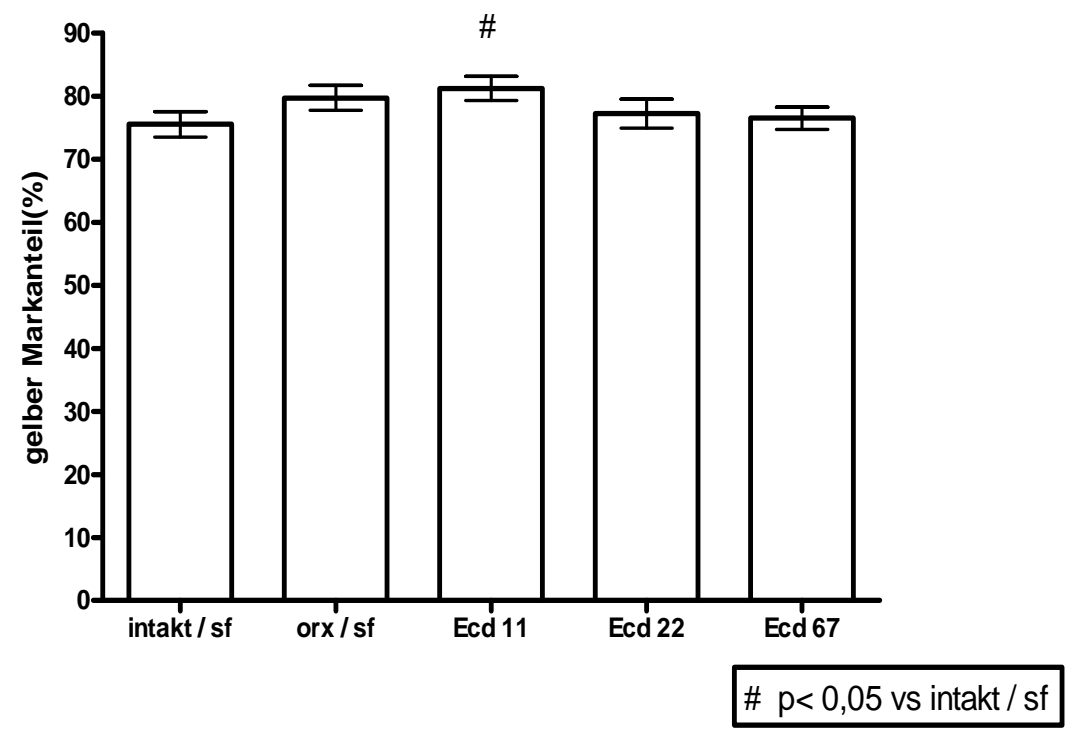

Abb.41: Der Effekt von $\beta$-Ecdyson (Ecd $11 \mathrm{mg} / \mathrm{kg} \mathrm{KG;} \mathrm{Ecd} 22 \mathrm{mg} / \mathrm{kg} \mathrm{KG;} \mathrm{Ecd}$ $67 \mathrm{mg} / \mathrm{kg} \mathrm{KG)} \mathrm{auf} \mathrm{den} \mathrm{prozentualen} \mathrm{Anteil} \mathrm{gelben} \mathrm{Knochenmarks} \mathrm{in} \mathrm{der} \mathrm{tibialen}$ Metaphyse im Bereich von einem Millimeter distal der proximalen Epiphysenfuge nach dreimonatigem Futterversuch an männlichen orx S.D.-Ratten im Vergleich zur intakten bzw. orx Kontrollgruppe unter sf Futter. Gemittelte Ergebniskombination aus Schwellenwertbildung am 8-Bit-Grauwertbild (D-Methode) sowie mit jener am Negativbild im roten Farbauszug (F-Methode).

Die Analyse des prozentualen Anteil gelben Knochenmarks an den umgebenen Strukturen im metaphysären Tibiabereich ergab im Großen und Ganzen keine signifikanten Ergebnisse. Die Ausnahme machte, wie schon bei der Flächenmessung, die Gruppe mit einer $\beta$-EcdysonDosis von $11 \mathrm{mg} / \mathrm{kg} \mathrm{KG.} \mathrm{Im} \mathrm{Vergleich} \mathrm{zur} \mathrm{intakten} \mathrm{Kontrollgruppe} \mathrm{wies} \mathrm{sie} \mathrm{einen} \mathrm{signifikant}$ höheren prozentualen Fettanteil auf. Der Unterschied zwischen den Anteilen unter Berücksichtigung der Mittelwerte betrug $\bar{x} \pm s=(-5.670 \pm 2.799)$ Prozentpunkte. Tendenziell erwies sich auch hier der prozentuale Anteil gelben Marks bei der orx Kontrollgruppe als am größten, die der intakten Kontrolltiere als am kleinsten. Dieser Unterschied zwischen den Kontrolltieren wurde jedoch wiederum nur durch die D-Methode als signifikant nachgewiesen, das heißt die F-Methode und die Kombination beider Methoden zeigten in dieser Hinsicht keinen statistisch signifikanten Unterschied. Die $\beta$-Ecdyson-substituierten Tiere lagen mit ihren Messergebnissen bezüglich des Anteils gelben Marks somit zwischen den beiden Kontrollgruppen. Ausgenommen blieben davon die mit $11 \mathrm{mg} / \mathrm{kg} \mathrm{KG} \beta$-Ecdyson substituierten Tiere, welche bei dieser Messung die größten Anteile gelben Marks aufwiesen. (Abb. 41) 


\section{III.6.3) Fläche und prozentualer Anteil roten Knochenmarks in der tibialen Metaphyse}

Die Analyse der Spongiosa im metaphysären Bereich erbrachte für die Fläche und für den prozentualen Anteil roten Knochenmarks bei den männlichen Gruppen keine signifikanten Ergebnisse. Demnach konnte mit der angewandten Statistik kein signifikanter Effekt von $\beta$ Ecdyson auf das rote Knochenmark bei orx S.D.-Ratten im Vergleich zur intakten und zur orx Kontrollgruppe unter sf Futter nachgewiesen werden (Abb.42; Abb.43). Die Betrachtung der nicht signifikanten Messergebnisse zeigte lediglich, dass die Fläche und der Anteil roten Marks bei den orx Kontrolltieren kleiner ausfiel, als bei der intakten Kontrolle. Weiterhin waren die Fläche und der Anteil bei den $\beta$-Ecdysonkonzentrationen von $11 \mathrm{mg} / \mathrm{kg} \mathrm{KG}$ und von $22 \mathrm{mg} / \mathrm{kg} \mathrm{KG} \mathrm{kleiner} \mathrm{als} \mathrm{die} \mathrm{der} \mathrm{beiden} \mathrm{Kontrollgruppen,} \mathrm{während} \mathrm{jene} \mathrm{bei} \mathrm{der} \mathrm{Dosis} \mathrm{von}$ $67 \mathrm{mg} / \mathrm{kg} \mathrm{KG}$ größere Werte aufwiesen.

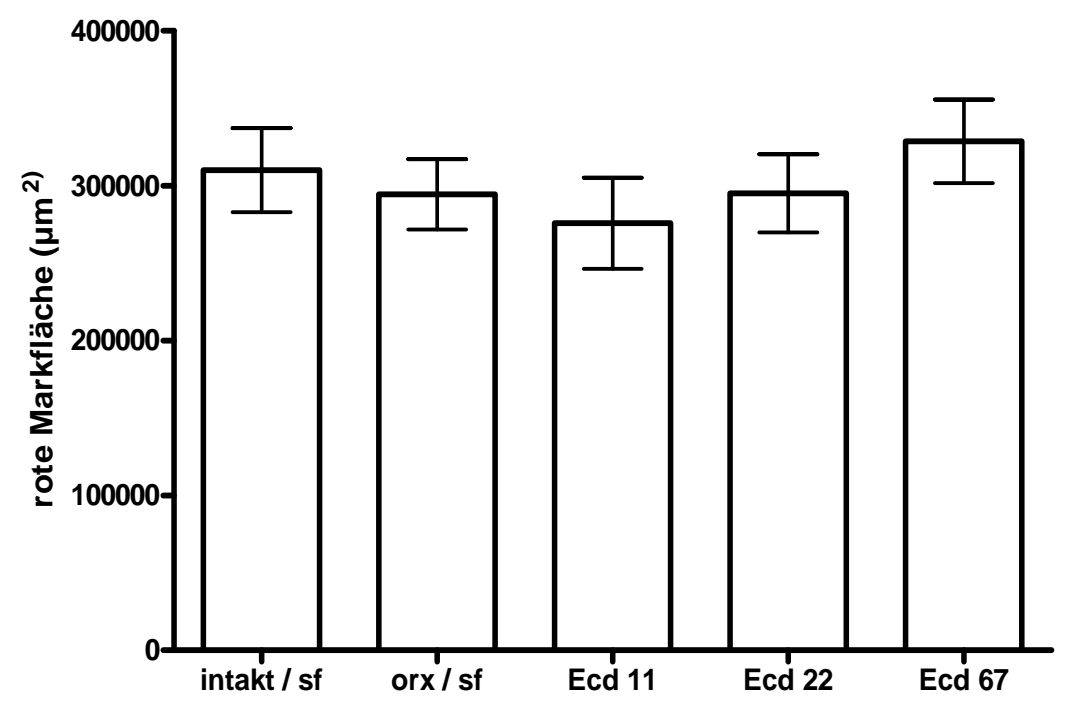

Abb.42: Der Effekt von $\beta$-Ecdyson (Ecd $11 \mathrm{mg} / \mathrm{kg} \mathrm{KG;} \mathrm{Ecd} 22 \mathrm{mg} / \mathrm{kg} \mathrm{KG;} \mathrm{Ecd}$ $67 \mathrm{mg} / \mathrm{kg} \mathrm{KG}$ ) auf die Fläche roten Knochenmarks (in Mikrometer ${ }^{2}$ ) in der tibialen Metaphyse im Bereich von einem Millimeter distal der proximalen Epiphysenfuge nach dreimonatigem Futterversuch an männlichen orx S.D.-Ratten im Vergleich zur intakten bzw. orx Kontrollgruppe unter sf Futter. Gemittelte Ergebniskombination aus Schwellenwertbildung am 8-Bit-Grauwertbild (D-Methode) sowie mit jener am Negativbild im roten Farbauszug (F-Methode). 


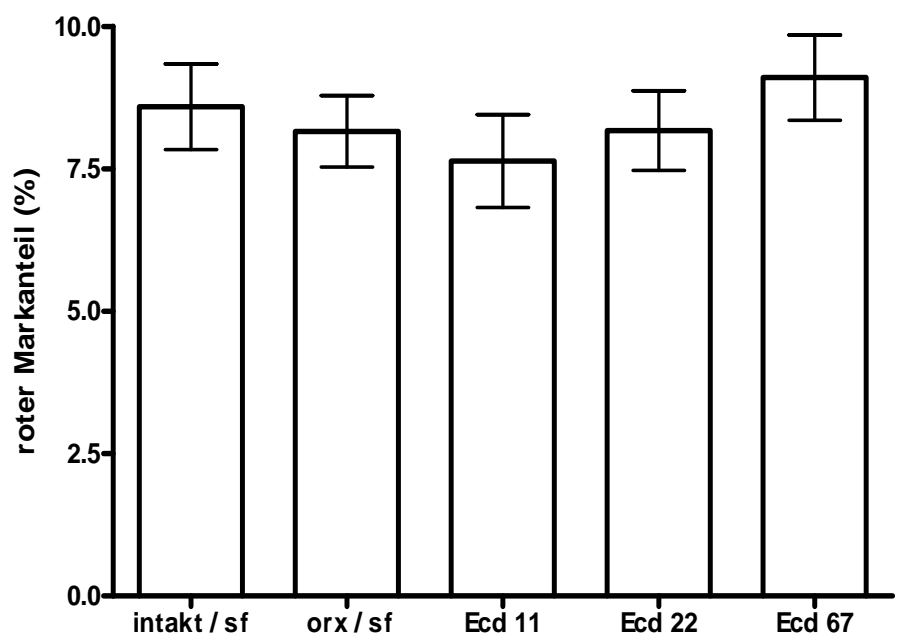

Abb.43: Der Effekt von $\beta$-Ecdyson (Ecd $11 \mathrm{mg} / \mathrm{kg} \mathrm{KG;} \mathrm{Ecd} 22 \mathrm{mg} / \mathrm{kg} \mathrm{KG;} \mathrm{Ecd}$ $67 \mathrm{mg} / \mathrm{kg} \mathrm{KG})$ auf den prozentualen Anteil roten Knochenmarks in der tibialen Metaphyse im Bereich von einem Millimeter distal der proximalen Epiphysenfuge nach dreimonatigem Futterversuch an männlichen orx S.D.-Ratten im Vergleich zur intakten bzw. orx Kontrollgruppe unter sf Futter. Gemittelte Ergebniskombination aus Schwellenwertbildung am 8-Bit-Grauwertbild (D-Methode) sowie mit jener am Negativbild im roten Farbauszug (F-Methode).

\section{II.7) Effekt von $\beta$-Ecdyson auf weitere mikroskopische Aspekte der tibialen Metaphyse von weiblichen S.D.-Ratten}

\section{III.7.1) Trabekelfläche und prozentualer Trabekelanteil in der tibialen Metaphyse}

Die histologische Analyse der metaphysären Spongiosa im Bereich von einem Millimeter distal der proximalen Epiphysenfuge bei den weiblichen ovx S.D.-Ratten ergab mit der verwendeten Statistik und einer $\beta$-Ecdyson-Dosis von $4 \mathrm{mg} / \mathrm{kg} \mathrm{KG}$ und von $10 \mathrm{mg} / \mathrm{kg} \mathrm{KG}$ keine signifikanten Ergebnisse bezüglich eines Effekts von $\beta$-Ecdyson auf die Trabekelfläche (Abb.44).

Auch der prozentuale Trabekelanteil bei den ovx Weibchen wurde mit der verwendeten Statistik durch die $\beta$-Ecdyson-Aufnahme nicht signifikant beeinflusst (Abb.45) 


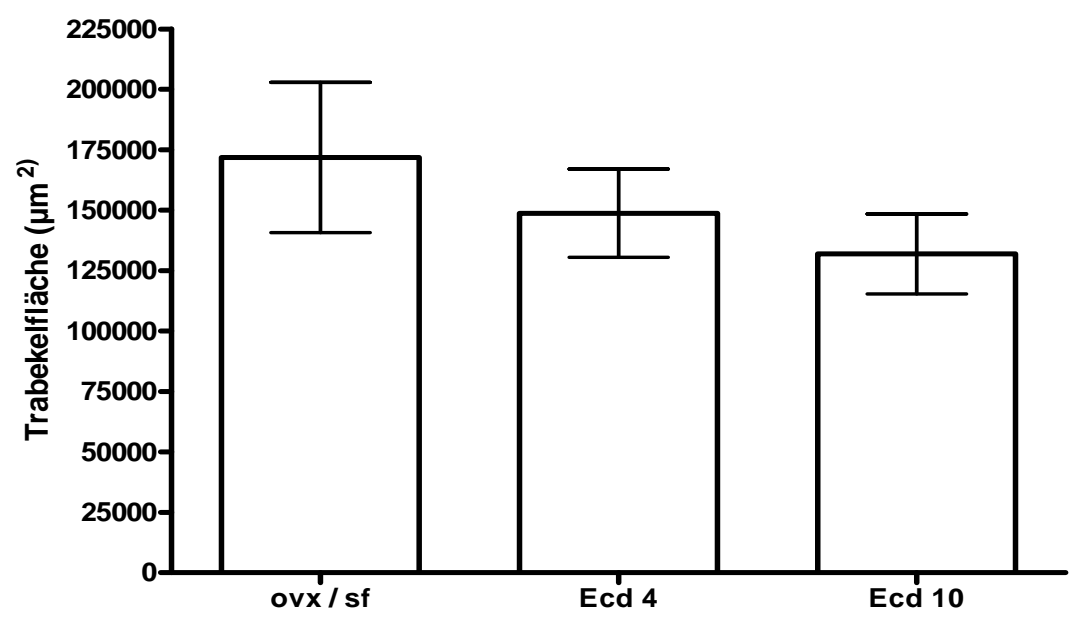

Abb.44: Der Effekt von $\beta$-Ecdyson (Ecd 4 mg/kg KG; Ecd $10 \mathrm{mg} / \mathrm{kg} \mathrm{KG)} \mathrm{auf} \mathrm{die}$ Trabekelfläche (in Mikrometer ${ }^{2}$ ) in der tibialen Metaphyse im Bereich von einem Millimeter distal der proximalen Epiphysenfuge nach dreimonatigem Futterversuch an weiblichen ovx S.D.-Ratten im Vergleich zur ovx Kontrollgruppe unter sf Futter. Gemittelte Ergebniskombination aus Schwellenwertbildung am 8-Bit-Grauwertbild (D-Methode) sowie mit jener am Negativbild im roten Farbauszug (F-Methode).

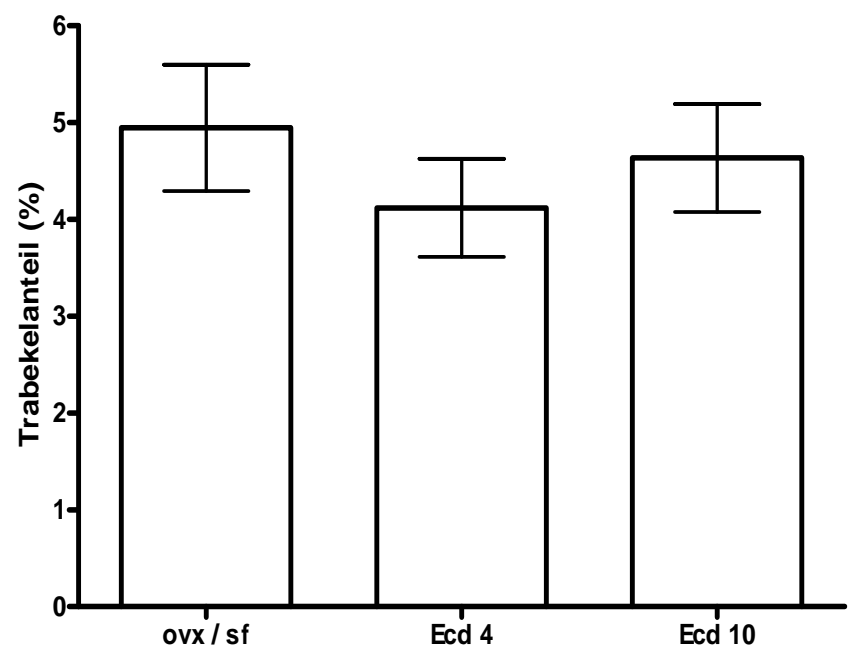

Abb.45: Der Effekt von $\beta$-Ecdyson (Ecd 4 mg/kg KG; Ecd $10 \mathrm{mg} / \mathrm{kg} \mathrm{KG)} \mathrm{auf} \mathrm{den}$ prozentualen Trabekelanteil in der tibialen Metaphyse im Bereich von einem Millimeter distal der proximalen Epiphysenfuge nach dreimonatigem Futterversuch an weiblichen ovx S.D.-Ratten im Vergleich zur ovx Kontrollgruppe unter sf Futter. Gemittelte Ergebniskombination aus Schwellenwertbildung am 8-Bit-Grauwertbild (D-Methode) sowie mit jener am Negativbild im roten Farbauszug (F-Methode). 


\section{III.7.2) Fläche und prozentualer Anteil gelben Knochenmarks in der tibialen Metaphyse}

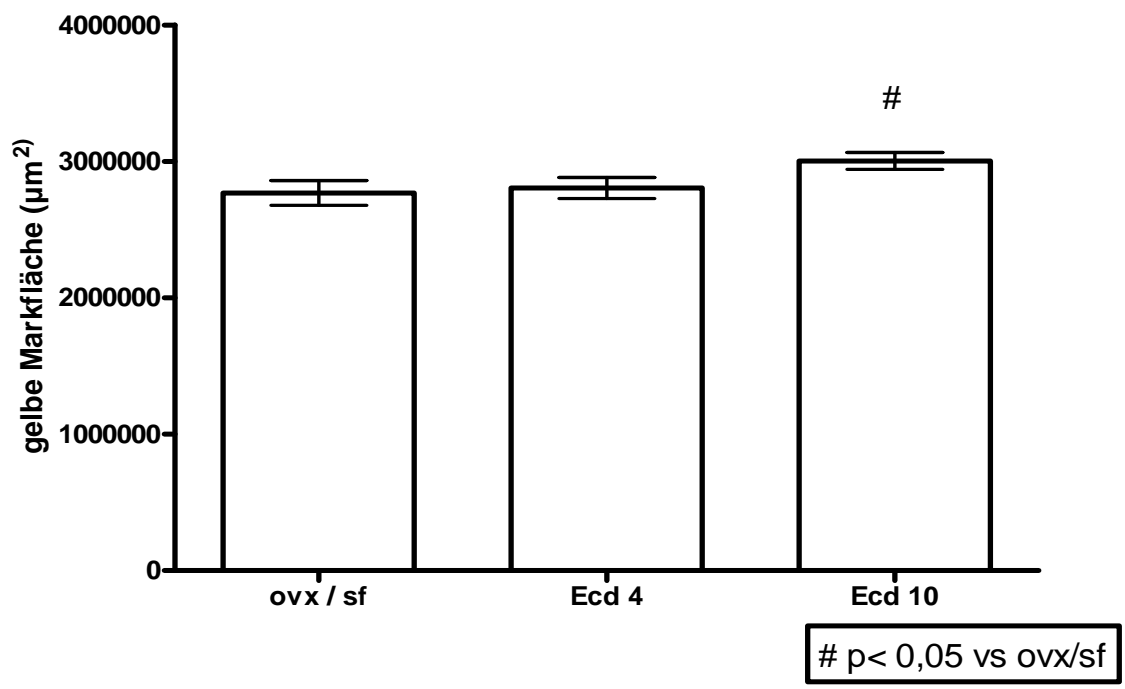

Abb.46: Der Effekt von $\beta$-Ecdyson (Ecd $4 \mathrm{mg} / \mathrm{kg} \mathrm{KG;} \mathrm{Ecd} \mathrm{10mg/kg} \mathrm{KG)} \mathrm{auf} \mathrm{die} \mathrm{Fläche}$ gelben Knochenmarks (in Mikrometer ${ }^{2}$ ) in der tibialen Metaphyse im Bereich von einem Millimeter distal der proximalen Epiphysenfuge nach dreimonatigem Futterversuch an weiblichen ovx S.D.-Ratten im Vergleich zur ovx Kontrollgruppe unter sf Futter. Gemittelte Ergebniskombination aus Schwellenwertbildung am 8-Bit-Grauwertbild (D-Methode) sowie mit jener am Negativbild im roten Farbauszug (F-Methode).

Bei den weiblichen ovx Tieren erwies sich die Fläche des gelben Knochenmarks in der Metaphyse bei den ovx Kontrolltieren im Vergleich zu den $\beta$-Ecdyson-substituierten Tieren als am kleinsten. Der Vergleich mit den Tieren, die Ecdyson in einer Dosis von $4 \mathrm{mg} / \mathrm{kg}$ KG erhielten, zeigte trotz größerer Flächen keinen signifikanten Unterschied, wohingegen die Dosis von 10 mg/kg KG die gelbe Markfläche signifikant erhöhte. Der Unterschied zwischen den Kontrolltieren und der Gruppe mit $10 \mathrm{mg} / \mathrm{kg}$ KG $\beta$-Ecdyson umfasste eine Mittelwertdifferenz von $\bar{x} \pm s=(-234600 \pm 115900) \mu \mathrm{m}^{2}($ Abb.46). 


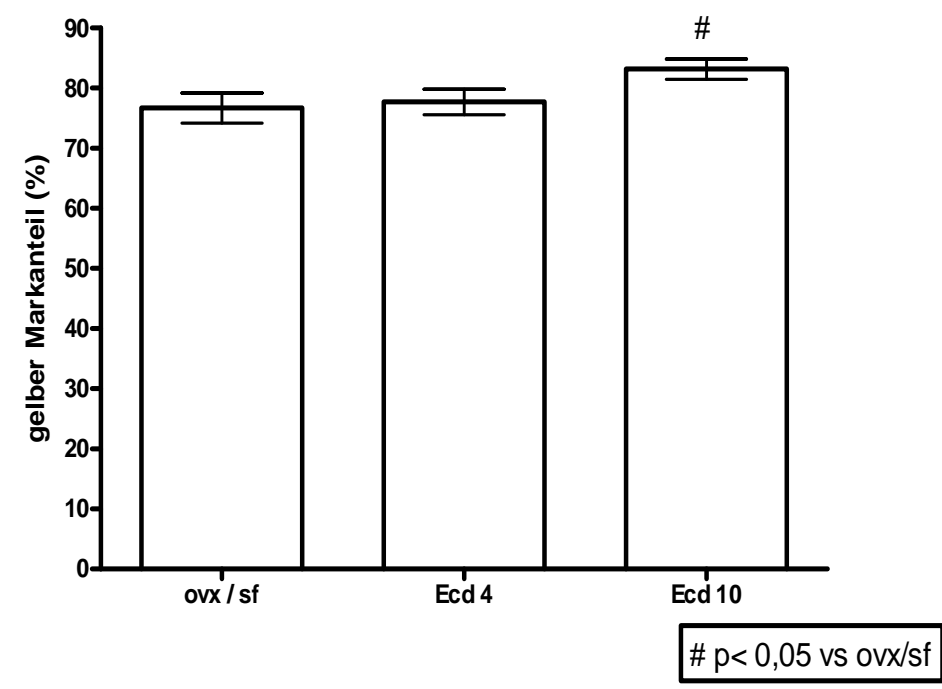

Abb.47: Der Effekt von $\beta$-Ecdyson (Ecd $4 \mathrm{mg} / \mathrm{kg} \mathrm{KG;} \mathrm{Ecd} 10 \mathrm{mg} / \mathrm{kg} \mathrm{KG}$ ) auf den prozentualen Anteil gelben Knochenmarks in der tibialen Metaphyse im Bereich von einem Millimeter distal der proximalen Epiphysenfuge nach dreimonatigem Futterversuch an weiblichen ovx S.D.-Ratten im Vergleich zur ovx Kontrollgruppe unter sf Futter. Gemittelte Ergebniskombination aus Schwellenwertbildung am 8-Bit-Grauwertbild (DMethode) sowie mit jener am Negativbild im roten Farbauszug (F-Methode).

Die Untersuchung des prozentualen Anteils gelben Marks an den umgebenen Strukturen in der Metaphyse, sprich rotem Knochenmark und Trabekeln, ergab bei den weiblichen S.D-Ratten signifikant höhere Anteile bei jenen, die $10 \mathrm{mg} / \mathrm{kg} \mathrm{KG} \beta$-Ecdyson erhielten im Vergleich zur Kontrollgruppe mit sf Futter. Letztere zeigte von den drei untersuchten Gruppen weiblicher Ratten mit durchschnittlich $\bar{x} \pm s=(76.66 \pm 2.512) \%$ den geringsten Anteil an gelbem Knochenmark. Die Mittelwertdifferenzen zu den mit $\beta$-Ecdyson-haltigem Futter ernährten Tieren betrug bei der Dosis von $4 \mathrm{mg} / \mathrm{kg}$ KG $\bar{x} \pm s=(-1.016 \pm 3.289)$ Prozentpunkte und bei $10 \mathrm{mg} / \mathrm{kg} \mathrm{KG} \bar{x} \pm s=(-6.498 \pm 3.209)$ Prozentpunkte (Abb.47). 


\section{III.7.3) Fläche und prozentualer Anteil roten Knochenmarks in der tibialen Metaphyse}

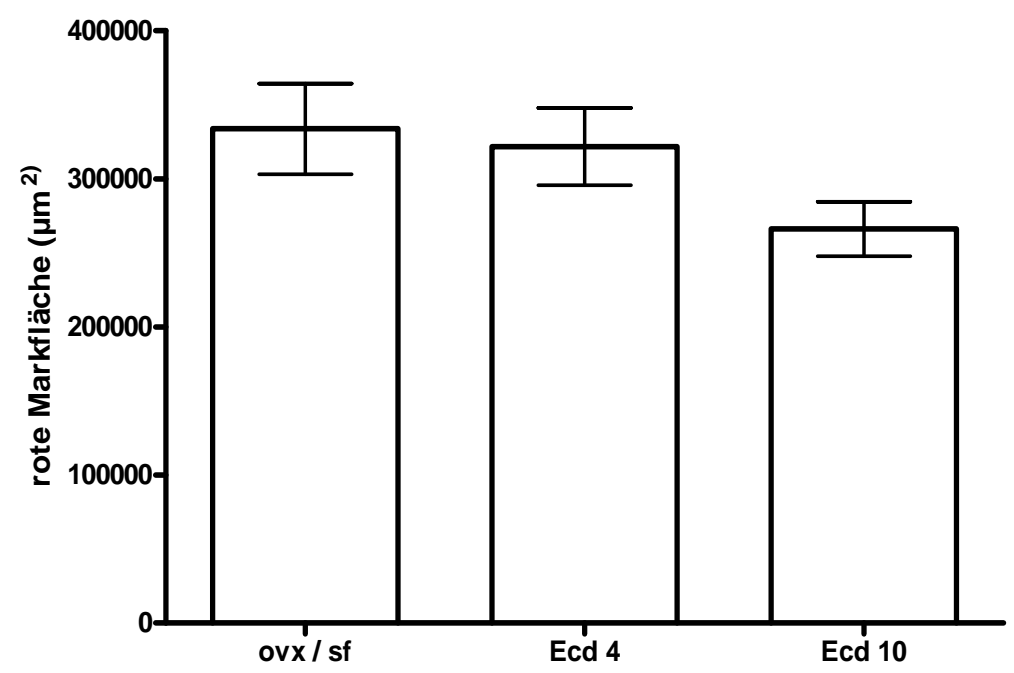

Abb.48: Der Effekt von $\beta$-Ecdyson (Ecd $4 \mathrm{mg} / \mathrm{kg} \mathrm{KG;} \mathrm{Ecd} \mathrm{10mg/kg} \mathrm{KG)} \mathrm{auf} \mathrm{die} \mathrm{Fläche}$ roten Knochenmarks (in Mikrometer ${ }^{2}$ ) in der tibialen Metaphyse im Bereich von einem Millimeter distal der proximalen Epiphysenfuge nach dreimonatigem Futterversuch an weiblichen ovx S.D.-Ratten im Vergleich zur ovx Kontrollgruppe unter sf Futter. Gemittelte Ergebniskombination aus Schwellenwertbildung am 8-Bit-Grauwertbild (D-Methode) sowie mit jener am Negativbild im roten Farbauszug (F-Methode).

Auch bei den weiblichen ovx S.D.-Ratten konnte mit der angewandten Statistik kein signifikanter Effekt von $\beta$-Ecdyson auf die Fläche und auf den prozentualen Anteil roten Marks in der tibialen Metaphyse im Vergleich zur Kontrollgruppe nachgewiesen werden. Ohne dass der Unterschied zwischen den einzelnen Gruppen signifikant war, erwies sich die Fläche roten Knochenmarks bei den ovx Kontrolltieren mit durchschnittlich $\bar{x} \pm s=(333800$ $\pm 30600) \mu \mathrm{m}^{2}$ als am größten, während sie bei den Tieren mit einer $\beta$-Ecdyson-Dosis von 4 $\mathrm{mg} / \mathrm{kg} \mathrm{KG}$ eine Größe von $\bar{x} \pm s=(321800 \pm 26120) \mu \mathrm{m}^{2}$ und bei $10 \mathrm{mg} / \mathrm{kg} \mathrm{KG}$ von $\bar{x} \pm s=$ $(266200 \pm 18290) \mu \mathrm{m}^{2}$ aufwies (Abb.48). Der prozentuale Anteil war bei den ovx Kontrolltieren mit durchschnittlich $\bar{x} \pm s=(9.24 \pm 0.85) \%$ ebenfalls am größten. Bei der $\beta$ Ecdyson-Dosis von $4 \mathrm{mg} / \mathrm{kg} \mathrm{KG}$ betrug er $\bar{x} \pm s=(8.91 \pm 0.72) \%$ und bei $10 \mathrm{mg} / \mathrm{kg} \mathrm{KG}$ $\bar{x} \pm s=(7.37 \pm 0.51) \%($ Abb.49). 


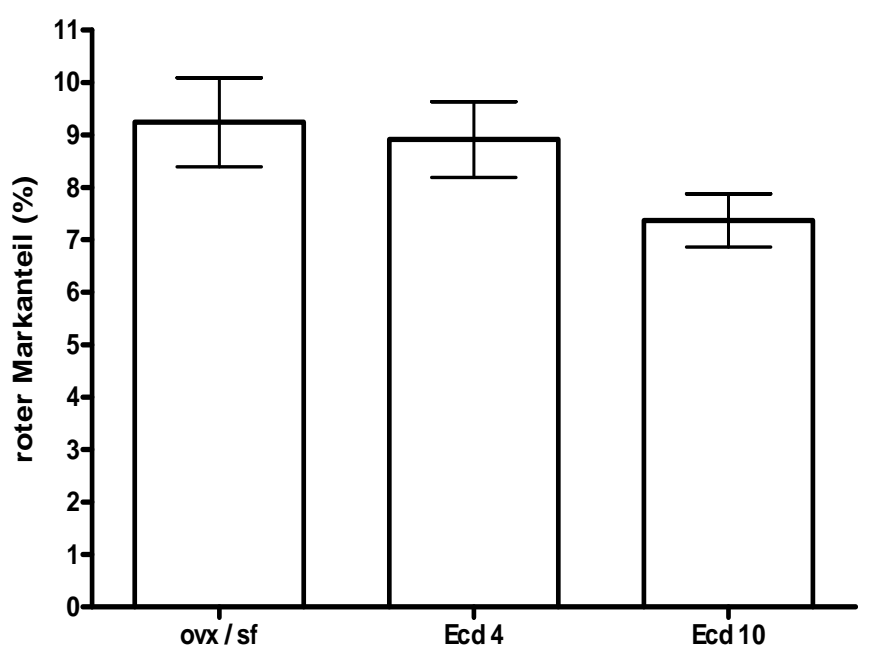

Abb.49: Der Effekt von $\beta$-Ecdyson (Ecd $4 \mathrm{mg} / \mathrm{kg} \mathrm{KG;} \mathrm{Ecd} 10 \mathrm{mg} / \mathrm{kg} \mathrm{KG}$ ) auf den prozentualen Anteil roten Knochenmarks in der tibialen Metaphyse im Bereich von einem Millimeter distal der proximalen Epiphysenfuge nach dreimonatigem Futterversuch an weiblichen ovx S.D.-Ratten im Vergleich zur ovx Kontrollgruppe unter sf Futter. Gemittelte Ergebniskombination aus Schwellenwertbildung am 8-Bit-Grauwertbild (DMethode) sowie mit jener am Negativbild im roten Farbauszug (F-Methode).

\section{III.8) Effekt von $\beta$-Ecdyson auf weitere mikroskopische Aspekte der tibialen Epiphyse von männlichen S.D.-Ratten}

\section{III.8.1) Trabekelfläche und prozentualer Trabekelanteil in der tibialen Epiphyse}

Durch histologische Untersuchung zweier epiphysärer Tibiaausschnitte direkt angrenzend an die proximale Epiphysenfuge (Abb.8a; Abb.50) konnte die Trabekelfläche in Mikrometer ${ }^{2}$ für die jeweilige Futtergruppe bestimmt werden. Es wurde für diese Auswertung nur noch die F-Methode, also die Schwellenwertbestimmung am Negativbild im roten Farbauszug, angewendet.

Die Analyse der Trabekelfläche in der Epiphyse brachte bei den männlichen S.D-Ratten keine signifikanten Ergebnisse hervor. Es konnte somit kein Effekt von $\beta$-Ecdyson in den angewendeten Konzentrationen auf die Trabekelfläche der orx Tiere im Vergleich zu den beiden Kontrollgruppen unter sf Futter nachgewiesen werden (Abb.51). 


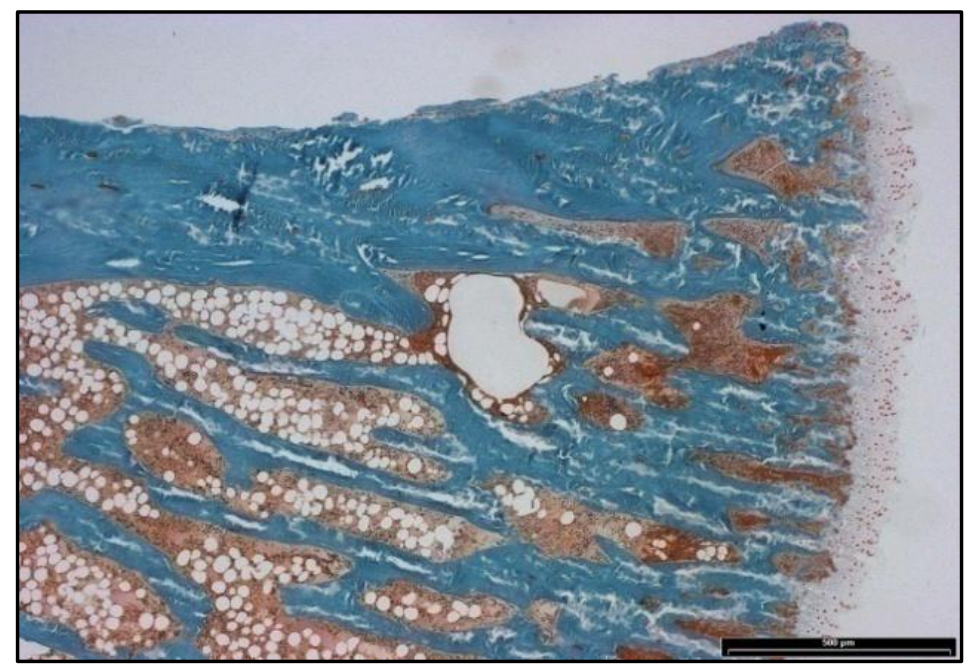

Abb.50: Foto eines histologischen Tibiapräparats (Nr.20-5; intakt) im Bereich der Epiphyse. Messung der Fläche / des prozentualen Anteils der Trabekel, sowie des roten und gelben Knochenmarks in einem medialen und einem lateralen Epiphysenbereich direkt angrenzend an die proximale Epiphysenfuge

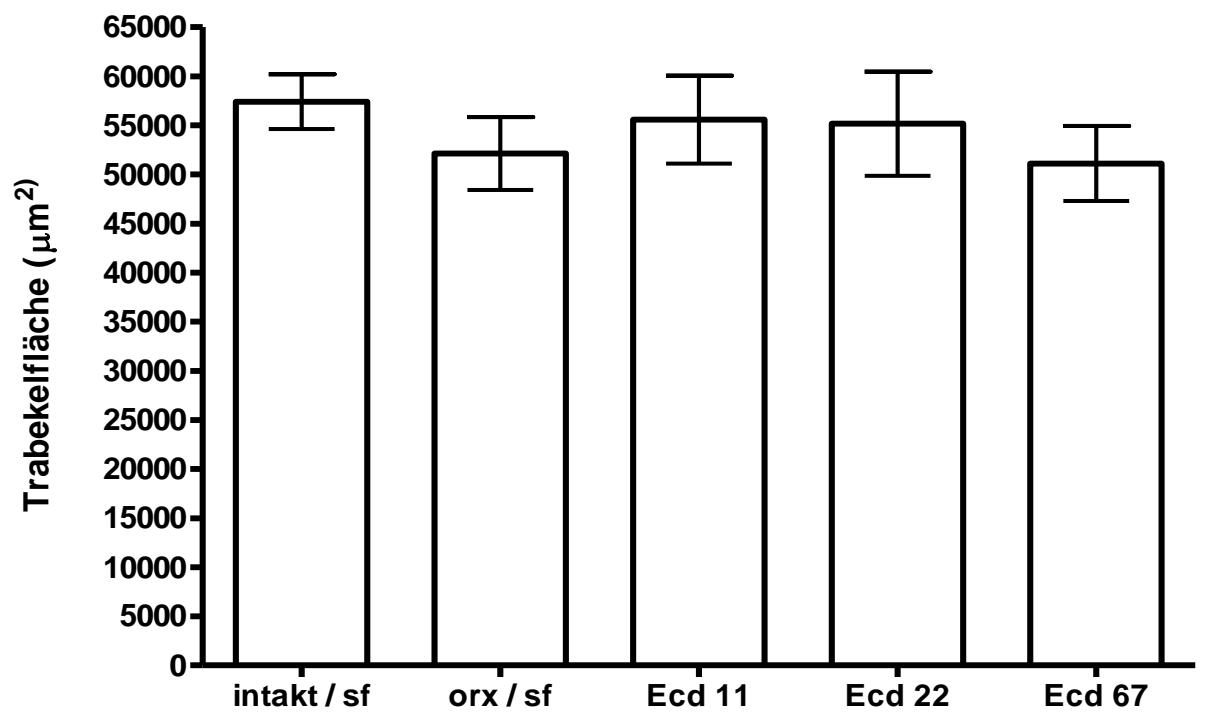

Abb.51: Der Effekt von $\beta$-Ecdyson (Ecd $11 \mathrm{mg} / \mathrm{kg} \mathrm{KG;} \mathrm{Ecd} 22 \mathrm{mg} / \mathrm{kg} \mathrm{KG}$; Ecd $67 \mathrm{mg} / \mathrm{kg} \mathrm{KG)}$ ) auf die Trabekelfläche (in Mikrometer ${ }^{2}$ ) in der tibialen Epiphyse angrenzend an die proximale Epiphysenfuge nach dreimonatigem Futterversuch an männlichen orx S.D.-Ratten im Vergleich zur intakten bzw. orx Kontrollgruppe unter sf Futter. Ergebnisse aus Einzelanwendung der Schwellenwertbestimmung am Negativbild im roten Farbauszug (F-Methode). 
Im gleichen epiphysären Bereich wie die Trabekelfläche wurde auch der prozentuale Anteil der dortigen Trabekel am Gesamtbild der benachbarten Strukturen, das heißt gelbem und rotem Knochenmark, bestimmt.

Der steigernde Effekt von $\beta$-Ecdyson auf den trabekulären Prozentanteil im Vergleich zur orx Kontrollgruppe war mit der angewandten Statistik nur für eine Dosis von $11 \mathrm{mg} / \mathrm{kg} \mathrm{KG}$ als signifikant nachweisbar. Die anderen Konzentrationen erhöhten den Trabekelanteil ohne dabei eine statistische Signifikanz zu erreichen (Abb.52).

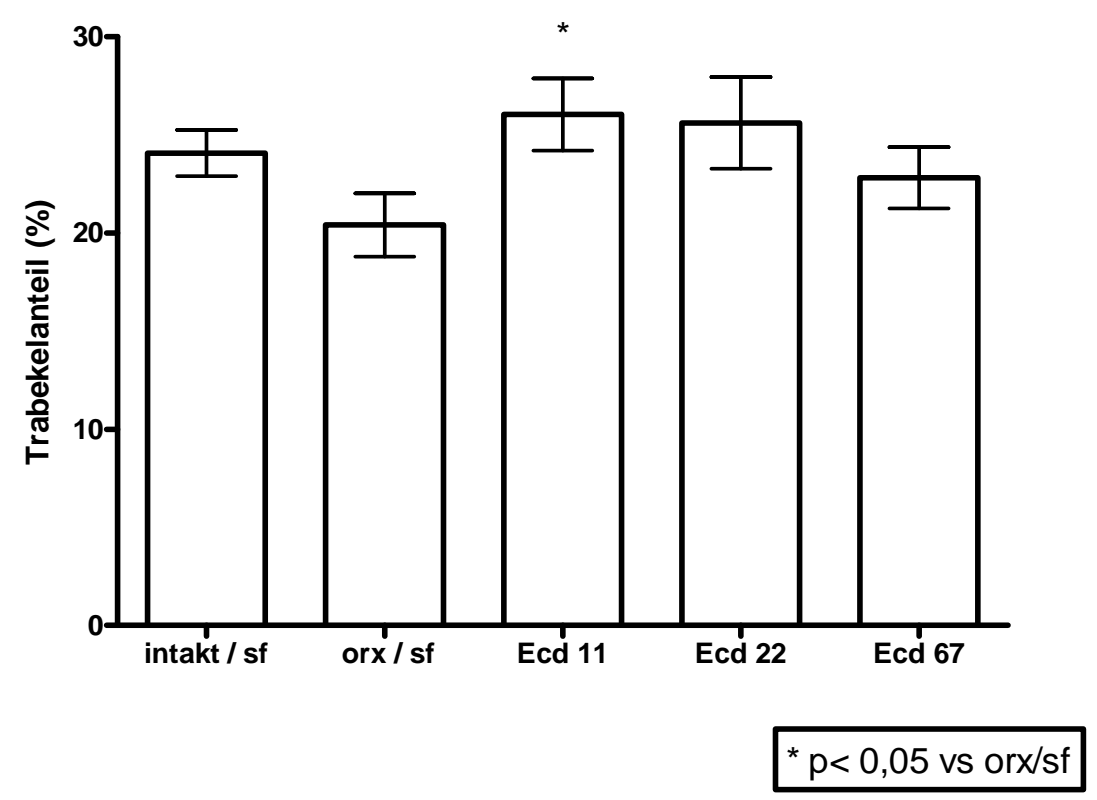

Abb.52: Der Effekt von $\beta$-Ecdyson (Ecd 11 mg/kg KG; Ecd 22 mg/kg KG; Ecd 67mg/kg KG) auf den prozentualen Trabekelanteil in der tibialen Epiphyse angrenzend an die proximale Epiphysenfuge nach dreimonatigem Futterversuch an männlichen orx S.D.Ratten im Vergleich zur intakten bzw. orx Kontrollgruppe unter sf Futter. Ergebnisse aus Einzelanwendung der Schwellenwertbestimmung am Negativbild im roten Farbauszug (FMethode).

Der Vergleich der erhaltenen Messergebnisse für den prozentualen Trabekelanteil in Metaphyse und Epiphyse wies einen starken signifikanten Unterschied auf. So konnte in allen Gruppen ein höherer Trabekelanteil in der Epiphyse im Vergleich zur Metaphyse nachgewiesen werden (Abb.53). Die Differenzen zwischen den ermittelten Mittelwerten sind in Tabelle 4 aufgeführt und zeigen, dass die Unterschiede gruppen-unabhängig in einem Bereich von etwa 15 bis 20 Prozentpunkten liegen. 


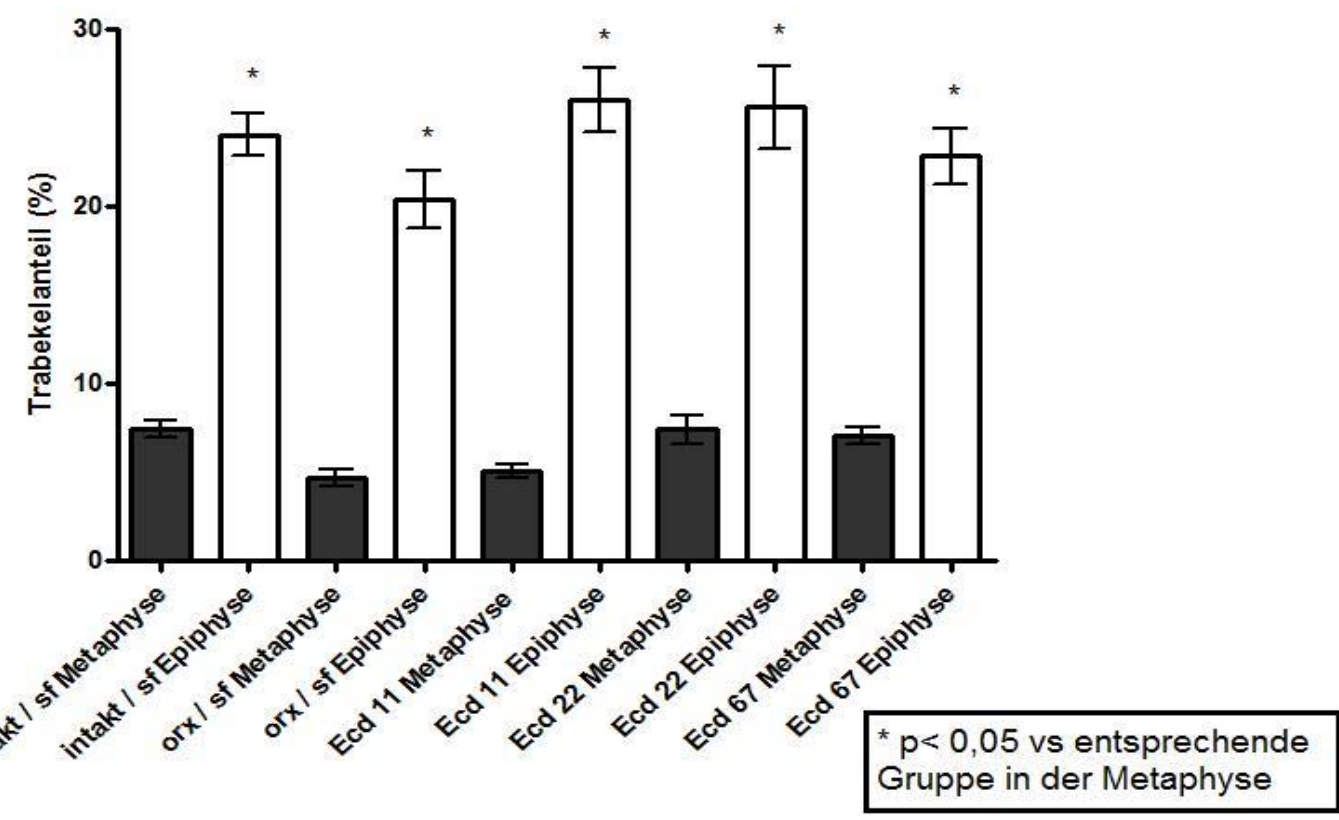

Abb.53: Vergleich und Gegenüberstellung der Messergebnisse für den Parameter des prozentualen Trabekelanteils in Metaphyse (grau) und Epiphyse (weiß) für alle Gruppen mit männlichen S.D.-Ratten.

Tabelle 4: Mittelwertdifferenzen und Standardabweichungen für den Parameter des prozentualen Trabekelanteils zwischen Metaphyse und Epiphyse bei männlichen S.D.-Ratten

\begin{tabular}{|l|l|l|l|l|l|}
\hline $\begin{array}{l}\text { Trabekelanteil } \\
(\%)\end{array}$ & Intakt /sf & ORX / sf & Ecd 11 & Ecd 22 & Ecd 67 \\
\hline $\begin{array}{l}\text { Metaphyse } \\
\text { minus } \\
\text { Epiphyse }\end{array}$ & $-16,62 \pm 1,39$ & $-15,75 \pm 1,39$ & $-20,97 \pm 1,68$ & $-18,21 \pm 2,14$ & $-15,8 \pm 1,65$ \\
\hline
\end{tabular}

\section{III.8.2) Fläche und prozentualer Anteil gelben Knochenmarks in der tibialen Epiphyse}

Die Analyse der Fläche und des prozentualen Anteils gelben Marks in der Epiphyse erfolgte ebenfalls nur unter Verwendung der F-Methode, d.h. mittels Schwellenwertbildung am Negativbild im roten Farbauszug. In der Epiphyse konnte mit der angewandten Statistik, abgesehen von einer Ausnahme, kein signifikanter Einfluss von $\beta$-Ecdyson auf die Fläche gelben Marks nachgewiesen werden. Bei der Ausnahme handelte es sich um die $\beta$-EcdysonDosis von $67 \mathrm{mg} / \mathrm{kg} \mathrm{KG}$, nach deren Aufnahme die orx Tiere im Vergleich zu den intakten Kontrolltieren unter sf Futter eine signifikant größere Fläche gelben Marks aufwiesen (Abb.54). Der Flächenunterschied betrug bei Betrachtung der Mittelwertdifferenz zwischen intakten Tieren und der Ecd 67-Gruppe $\bar{x} \pm s=(-18070 \pm 6795) \mu \mathrm{m}^{2}$. 
Tendenziell präsentierten sich die Flächen der intakten Tiere als am kleinsten, die der mit $\beta$ Ecdyson substituierten Tiere am größten ohne dass dabei eine Signifikanz der Unterschiede nachgewiesen werden konnte.

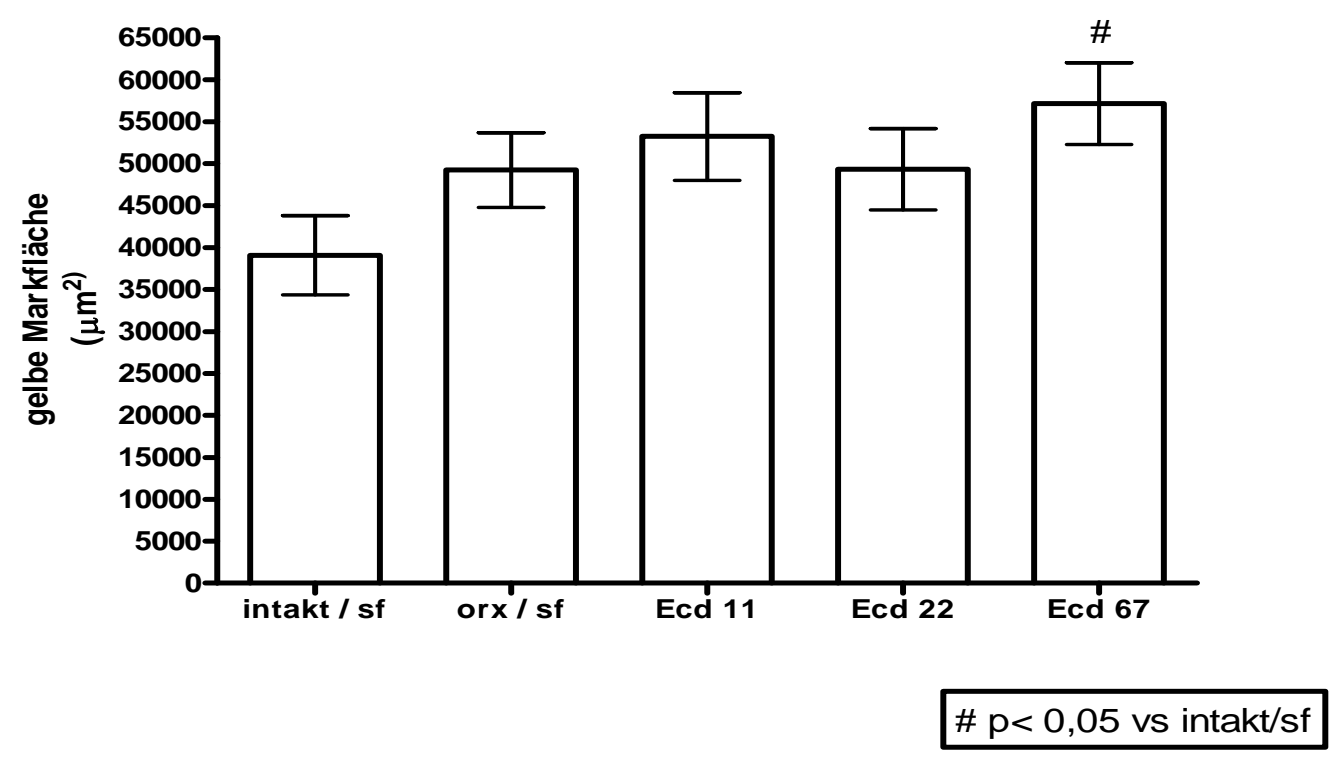

Abb.54: Der Effekt von $\beta$-Ecdyson (Ecd $11 \mathrm{mg} / \mathrm{kg} \mathrm{KG;} \mathrm{Ecd} 22 \mathrm{mg} / \mathrm{kg} \mathrm{KG;} \mathrm{Ecd} \mathrm{67mg/kg}$ KG) auf die Fläche gelben Knochenmarks (in Mikrometer ${ }^{2}$ ) in der tibialen Epiphyse angrenzend an die proximalen Epiphysenfuge nach dreimonatigem Futterversuch an männlichen orx S.D.-Ratten im Vergleich zur intakten bzw. orx Kontrollgruppe unter sf Futter. Ergebnisse aus Einzelanwendung der Schwellenwertbestimmung am Negativbild im roten Farbauszug (F-Methode).

Die Ergebnisse der Messung des prozentualen Anteils gelben Marks ergaben keine signifikanten Unterschiede zwischen den beiden Kontrollgruppen. Jedoch konnten signifikante Unterschiede zwischen der intakten Kontrollgruppe und den mit einer $\beta$-EcdysonDosis von $11 \mathrm{mg} / \mathrm{kg} \mathrm{KG}$ und von $67 \mathrm{mg} / \mathrm{kg}$ KG behandelten Tieren aufgezeigt werden. Letztere wiesen diesbezüglich höhere Prozentanteile auf. Die Mittelwertdifferenzen betrugen bei $11 \mathrm{mg} / \mathrm{kg} \mathrm{KG} \beta$-Ecdyson $\bar{x} \pm s=(-5.937 \pm 2.969)$ Prozentpunkte und bei $67 \mathrm{mg} / \mathrm{kg} \mathrm{KG}$ $\bar{x} \pm s=(-7.577 \pm 2.849)$ Prozentpunkte (Abb.55). 


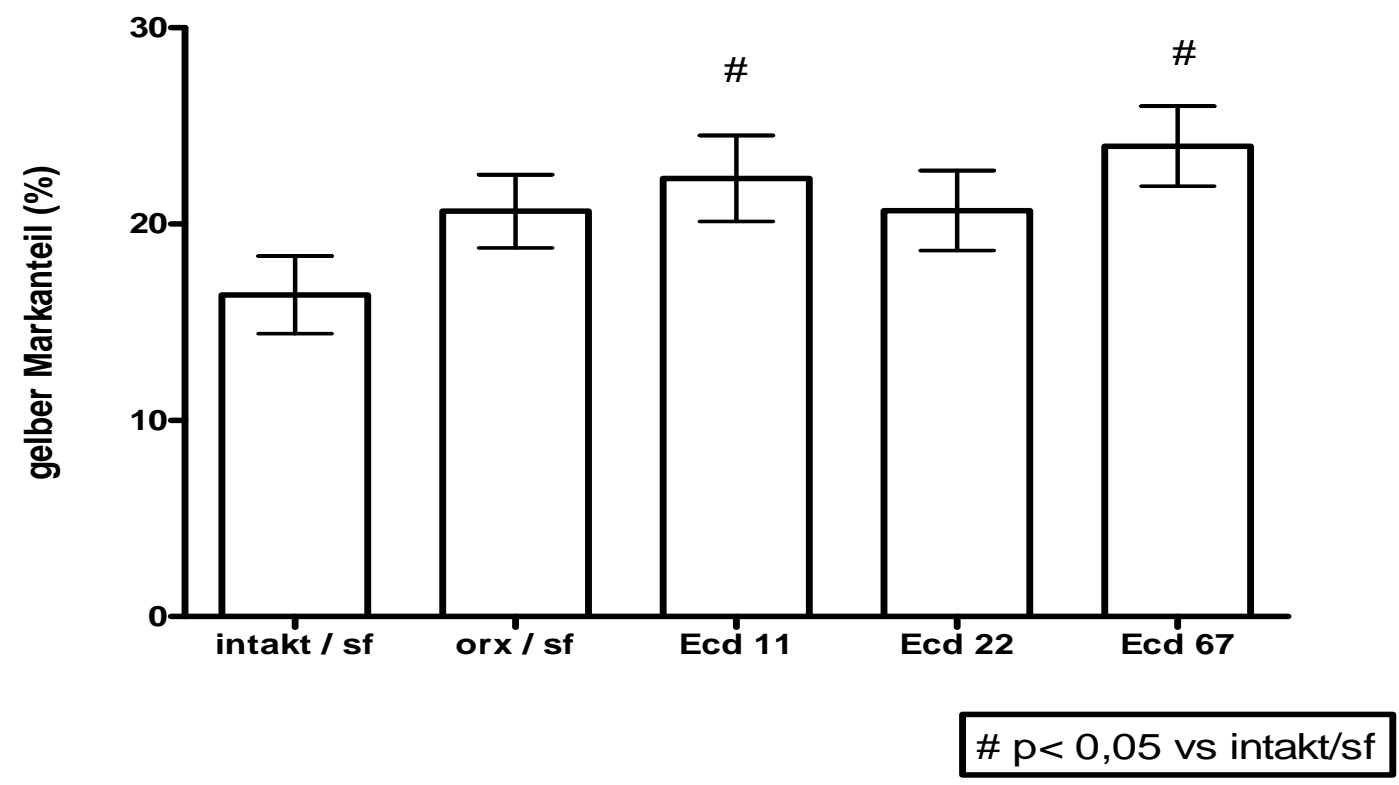

Abb.55: Der Effekt von $\beta$-Ecdyson (Ecd $11 \mathrm{mg} / \mathrm{kg} \mathrm{KG;} \mathrm{Ecd} 22 \mathrm{mg} / \mathrm{kg} \mathrm{KG;} \mathrm{Ecd} \mathrm{67mg/kg} \mathrm{KG)} \mathrm{auf}$ den prozentualen Anteil gelben Knochenmarks in der tibialen Epiphyse angrenzend an die proximalen Epiphysenfuge nach dreimonatigem Futterversuch an männlichen orx S.D.-Ratten im Vergleich zur intakten bzw. orx Kontrollgruppe unter sf Futter. Ergebnisse aus Einzelanwendung der Schwellenwertbestimmung am Negativbild im roten Farbauszug (F-Methode).

Im Anschluss an die Auswertung des prozentualen Anteils gelben Marks in tibialer Metaphyse und Epiphyse wurden die erhaltenen Messergebnisse einander gegenüber gestellt und statistisch verglichen. Dieser Vergleich wies einen statistisch siginifikanten Unterschied zwischen den Markanteilen an den beiden unterschiedlichen Tibialokalisationen nach. So war der Anteil gelben Marks in der Metaphyse in jeder der untersuchten Gruppen signifikant höher als in der Epiphyse (Abb.56). Die Unterschiede in Form der Mittelwertdifferenzen sind in Tabelle 5 aufgeführt und demonstrieren, dass die Unterschiede Gruppen-unabhängig in einem Bereich von etwa 52 bis 60 Prozentpunkten liegen.

Tabelle 5: Mittelwertdifferenzen und Standardabweichungen für den Parameter des prozentualen Anteils gelben Knochenmarks zwischen Metaphyse und Epiphyse

\begin{tabular}{|l|l|l|l|l|l|}
\hline $\begin{array}{l}\text { Anteil gelben } \\
\text { Knochenmarks } \\
(\%)\end{array}$ & Intakt /sf & ORX / sf & Ecd 11 & Ecd 22 & Ecd 67 \\
\hline $\begin{array}{l}\text { Metaphyse } \\
\text { minus } \\
\text { Epiphyse }\end{array}$ & $59.19 \pm 2.83$ & $59.10 \pm 2.88$ & $58.93 \pm 2.91$ & $56.59 \pm 3.29$ & $52.56 \pm 2.73$ \\
\hline
\end{tabular}




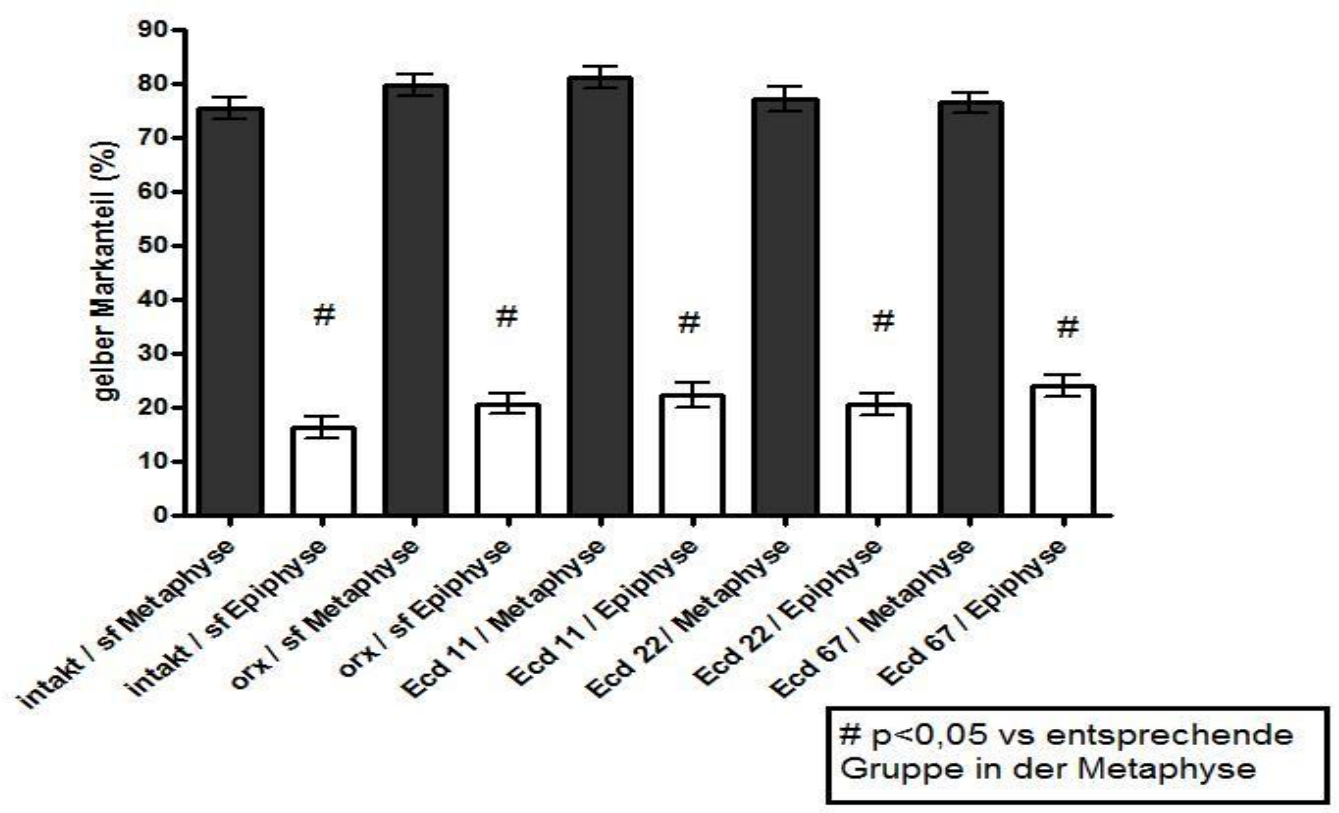

Abb.56: Vergleich und Gegenüberstellung der Messergebnisse für den Parameter des prozentualen Anteils gelben Marks in Metaphyse (grau) und Epiphyse (weiß) für alle Gruppen mit männlichen S.D.-Ratten.

\section{III.8.3) Fläche und prozentualer Anteil roten Knochenmarks in der tibialen Epiphyse}

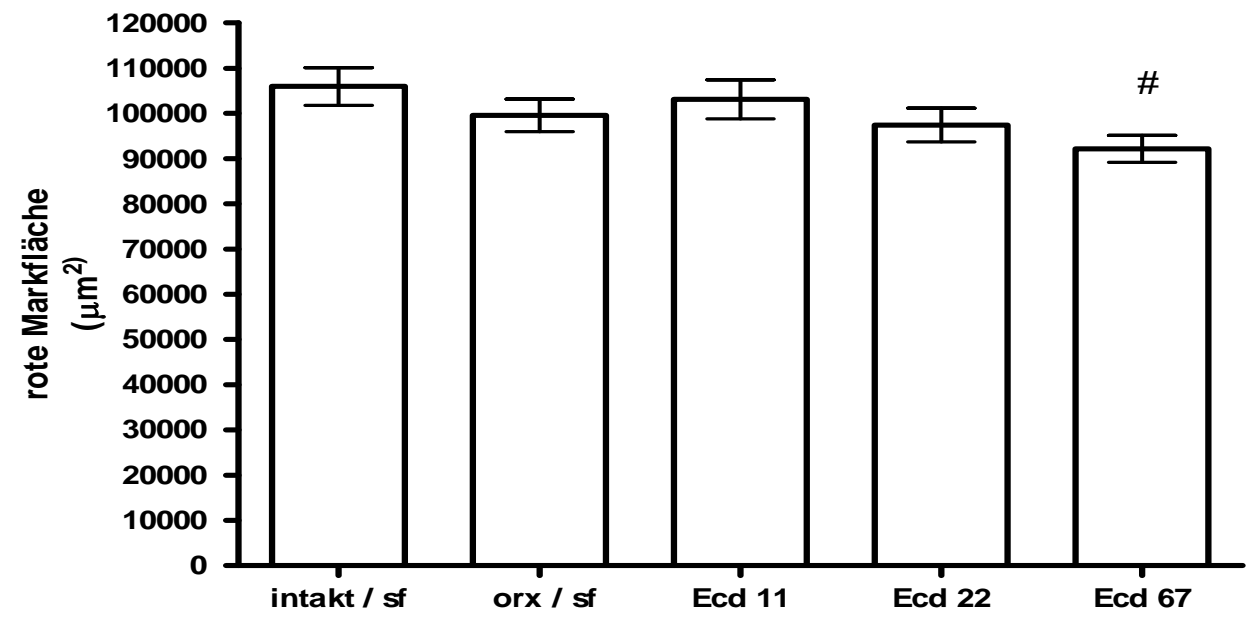

$\# p<0,05$ vs intakt/sf

Abb.57: Der Effekt von $\beta$-Ecdyson (Ecd $11 \mathrm{mg} / \mathrm{kg} \mathrm{KG;} \mathrm{Ecd} 22 \mathrm{mg} / \mathrm{kg} \mathrm{KG;} \mathrm{Ecd} \mathrm{67mg/kg} \mathrm{KG)}$ auf die Fläche roten Knochenmarks (in Mikrometer ${ }^{2}$ ) in der tibialen Epiphyse angrenzend an die proximalen Epiphysenfuge nach dreimonatigem Futterversuch an männlichen orx S.D.Ratten im Vergleich zur intakten bzw. orx Kontrollgruppe unter sf Futter. Ergebnisse aus Einzelanwendung der Schwellenwertbestimmung am Negativbild im roten Farbauszug (FMethode). 
Die Auswertung der Fläche und des prozentualen Anteils roten Knochenmarks in der tibialen Epiphyse erfolgte ebenfalls ausschließlich unter Verwendung der F-Methode also die Schwellenwertbestimmung am Negativbild im roten Farbauszug, angewendet. Bei den männlichen S.D.-Ratten erbrachte die Analyse des epiphysären Bereichs mit der angewandten Statistik, mit einer Ausnahme, keinen signifikanten Nachweis bezüglich eines Effekts von $\beta$ Ecdyson auf die Fläche und auf den Anteil roten Marks. Die Ausnahme machte dabei die $\beta$ Ecdyson-Konzentration von $67 \mathrm{mg} / \mathrm{kg} \mathrm{KG}$ im Vergleich zur Gruppe mit den intakten Tieren. Die mit $\beta$-Ecdyson substituierten Tiere wiesen im Vergleich zu den intakten Tieren sowohl eine signifikant kleinere Fläche, als auch einen geringeren prozentualen Anteil roten Marks auf (Abb.57; Abb.58). Der Flächenunterschied betrug bei Betrachtung der Mittelwertdifferenz zwischen intakten Tieren und der Ecd 67-Gruppe $\bar{x} \pm s=(13810 \pm 5255) \mu \mathrm{m}^{2}$. Tendenziell präsentierten sich die Flächen der intakten Tiere als am größten, jene der mit $\beta$-Ecdyson substituierten Tiere als am kleinsten, ohne dass dabei eine Signifikanz der Unterschiede nachgewiesen werden konnte. Die Differenz der prozentualen Anteile bei den beiden Gruppen betrug $\bar{x} \pm s=(5.79 \pm 2.20)$ Prozentpunkte. Auch bei diesem Messparameter war die Prozentanteil bei den intakten Tieren höher als bei den mit $\beta$-Ecdyson-haltigem Futter ernährten S.D.-Ratten. Auch konnte hier dabei jedoch kein signifikanter Unterschied nachgewiesen werden.

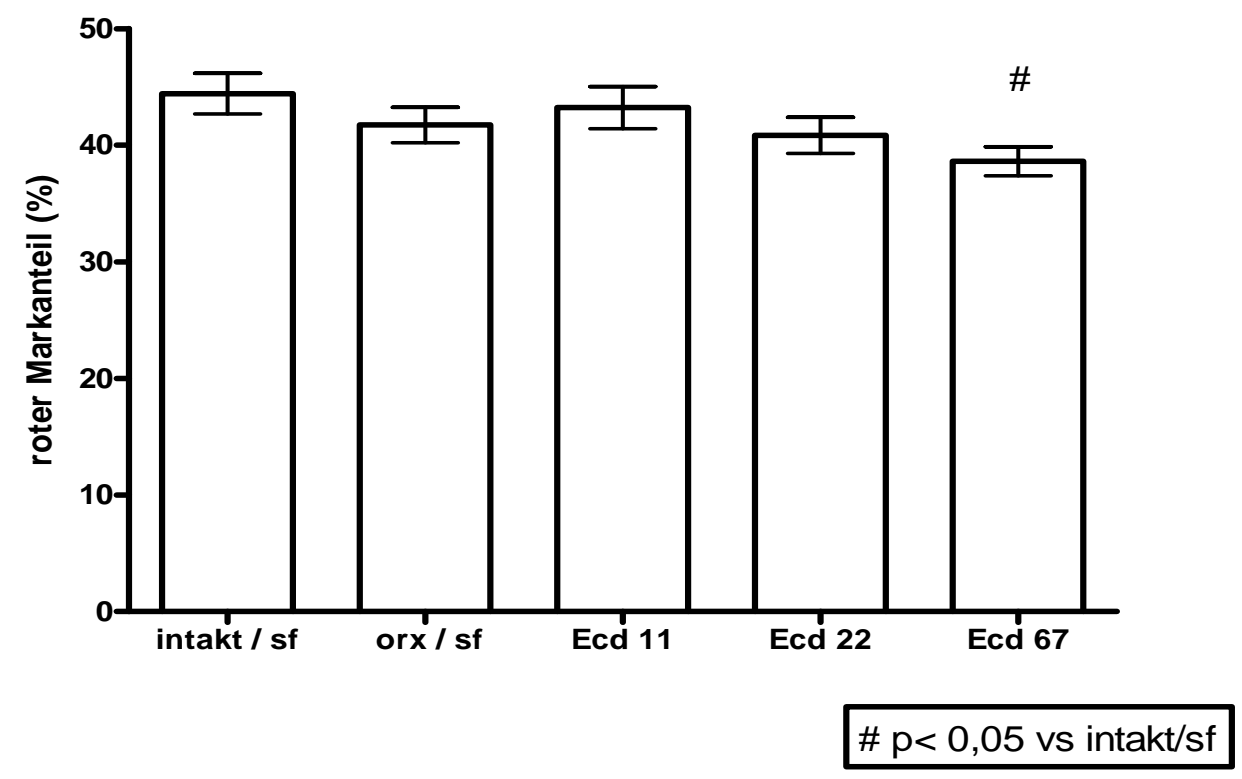

Abb.58: Der Effekt von $\beta$-Ecdyson (Ecd $11 \mathrm{mg} / \mathrm{kg} \mathrm{KG;} \mathrm{Ecd} 22 \mathrm{mg} / \mathrm{kg} \mathrm{KG;} \mathrm{Ecd} \mathrm{67mg/kg}$ KG) auf den prozentualen Anteil roten Knochenmarks in der tibialen Epiphyse angrenzend an die proximalen Epiphysenfuge nach dreimonatigem Futterversuch an männlichen orx S.D.-Ratten im Vergleich zur intakten bzw. orx Kontrollgruppe unter sf Futter. Ergebnisse aus Einzelanwendung der Schwellenwertbestimmung am Negativbild im roten Farbauszug (F-Methode). 
Wie zuvor schon bei den Ergebnissen für den prozentualen Trabekelanteil und jenem des gelben Marks, wurden auch die metaphysären und epiphysären Messergebnisse für den prozentualen Anteil roten Knochenmarks im Anschluss an die Auswertung einander gegenüber gestellt und statistisch verglichen. Dieser Vergleich wies einen statistisch siginifikanten Unterschied zwischen den roten Markanteilen an den beiden unterschiedlichen Tibialokalisationen nach. Der Anteil roten Marks stellte sich in der Metaphyse in jeder der untersuchten Gruppen signifikant geringer dar als in der Epiphyse (Abb.59). Die Unterschiede in Form der jeweiligen Mittelwertdifferenzen sind in Tabelle 6 aufgeführt und legen dar, dass die Unterschiede gruppen-unabhängig in einem Bereich von etwa 29 bis 35 Prozentpunkten liegen.

Tabelle 6: Mittelwertdifferenzen und Standardabweichungen für den Parameter des prozentualen Anteils roten Knochenmarks zwischen Metaphyse und Epiphyse

\begin{tabular}{|l|l|l|l|l|l|}
\hline $\begin{array}{l}\text { Anteil roten } \\
\text { Knochenmarks } \\
(\%)\end{array}$ & Intakt /sf & ORX / sf & Ecd 11 & Ecd 22 & Ecd 67 \\
\hline $\begin{array}{l}\text { Metaphyse } \\
\text { minus } \\
\text { Epiphyse }\end{array}$ & $-35.84 \pm 1.91$ & $-33.59 \pm 1.45$ & $-35.60 \pm 1.85$ & $-32.68 \pm 1.52$ & $-29.53 \pm 1.48$ \\
\hline
\end{tabular}

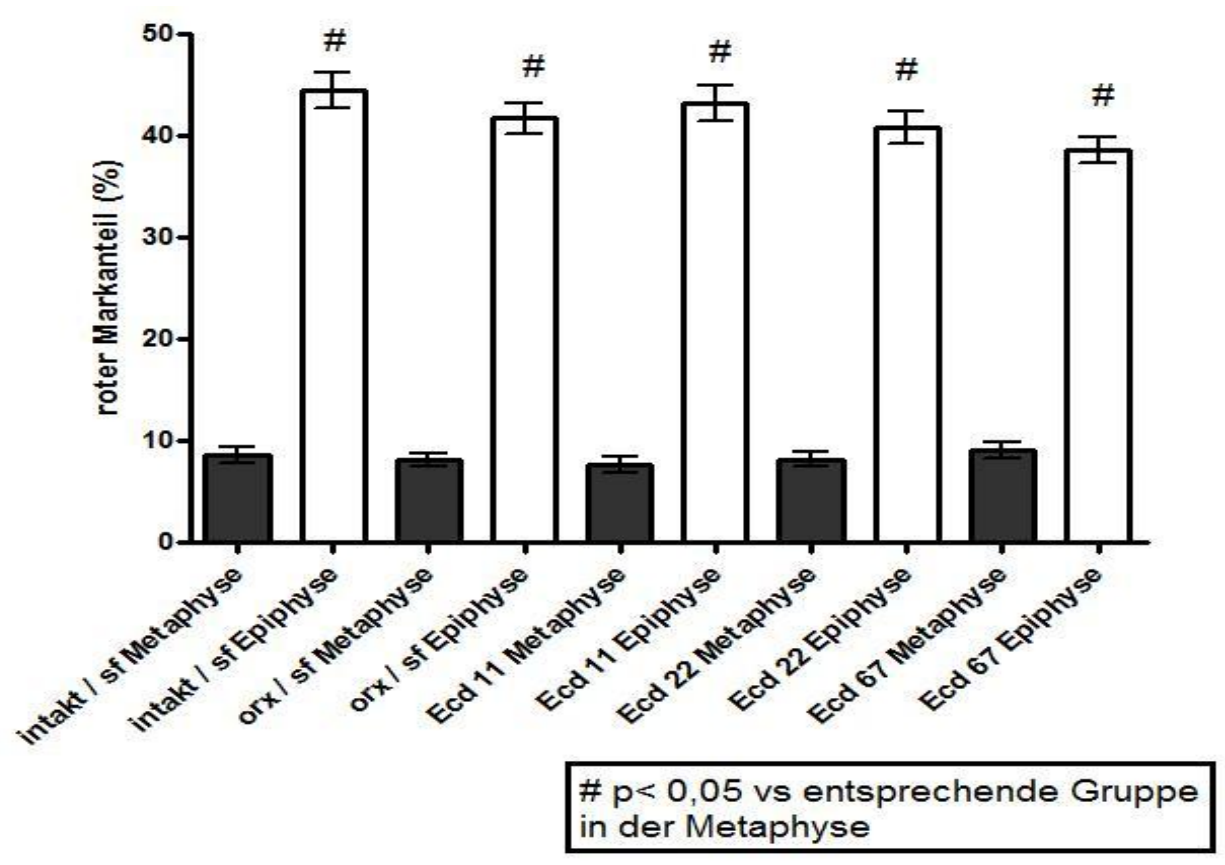

Abb.59: Vergleich und Gegenüberstellung der Messergebnisse für den Parameter des prozentualen Anteils roten Knochenmarks in Metaphyse (grau) und Epiphyse (weiß) für alle Gruppen mit männlichen S.D.-Ratten. 
III.9) Effekt von $\beta$-Ecdyson auf weitere mikroskopische Aspekte der tibialen Epiphyse von weiblichen S.D.-Ratten

III.9.1) Trabekelfläche und prozentualer Trabekelanteil in der tibialen Epiphyse

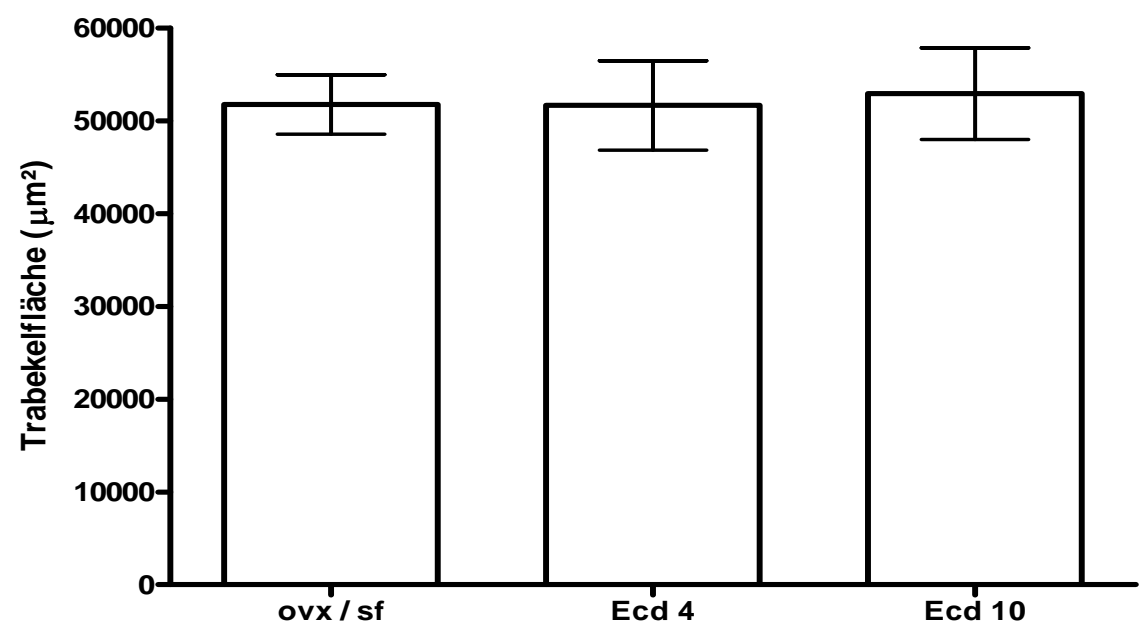

Abb.60: Der Effekt von $\beta$-Ecdyson (Ecd $4 \mathrm{mg} / \mathrm{kg} \mathrm{KG;} \mathrm{Ecd} 10 \mathrm{mg} / \mathrm{kg} \mathrm{KG)} \mathrm{auf} \mathrm{die}$ Trabekelfläche (in Mikrometer ${ }^{2}$ ) in der tibialen Epiphyse angrenzend an die proximale Epiphysenfuge nach dreimonatigem Futterversuch an weiblichen ovx S.D.-Ratten im Vergleich zur ovx Kontrollgruppe unter sf Futter. Ergebnisse aus Einzelanwendung der Schwellenwertbestimmung am Negativbild im roten Farbauszug (F-Methode).

Bei den weiblichen S.D.-Ratten ergab die Bestimmung der Trabekelfläche in der Epiphyse, unter alleiniger Anwendung der F-Methode, das heißt Schwellenwertbildung am Negativbild im roten Farbauszug, kein signifikantes Ergebnis bezüglich eines Effekts von $\beta$-Ecdyson in den verwendeten Konzentrationen von $4 \mathrm{mg} / \mathrm{kg} \mathrm{KG}$ und $10 \mathrm{mg} / \mathrm{kg} \mathrm{KG}$ bei ovx Ratten (Abb.60).

Des Weiteren konnte auch durch die Messung des prozentualen Trabekelanteils in der tibialen Epiphyse weiblicher ovx S.D.-Ratten kein signifikantes Ergebnis bezüglich eines Effekts von $\beta$-Ecdyson in der Dosis von $4 \mathrm{mg} / \mathrm{kg} \mathrm{KG} \mathrm{bzw.} \mathrm{von} 10 \mathrm{mg} / \mathrm{kg} \mathrm{KG}$ nachgewiesen werden (Abb.61). 


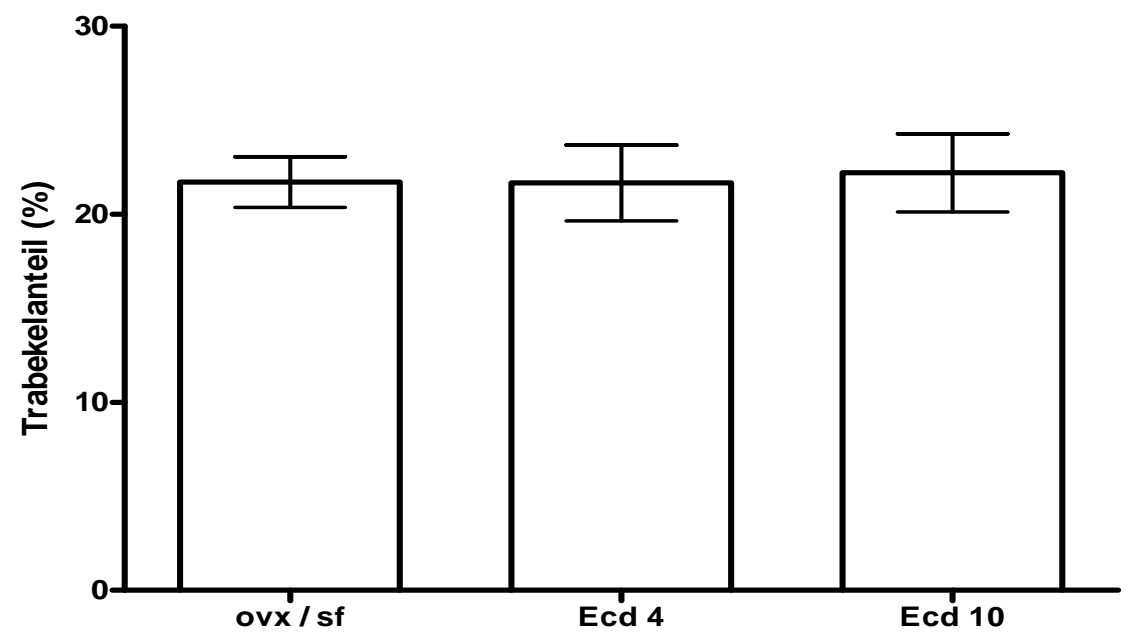

Abb.61: Der Effekt von $\beta$-Ecdyson (Ecd $4 \mathrm{mg} / \mathrm{kg} \mathrm{KG;} \mathrm{Ecd} 10 \mathrm{mg} / \mathrm{kg} \mathrm{KG)} \mathrm{auf}$ den prozentualen Trabekelanteil in der tibialen Epiphyse angrenzend an die proximale Epiphysenfuge nach dreimonatigem Futterversuch an weiblichen ovx S.D.-Ratten im Vergleich zur ovx Kontrollgruppe unter sf Futter. Ergebnisse aus Einzelanwendung der Schwellenwertbestimmung am Negativbild im roten Farbauszug (F-Methode).

\section{III.9.2) Fläche und prozentualer Anteil gelben Knochenmarks in der tibialen Epiphyse}

Bei den weiblichen ovx S.D.-Ratten übte $\beta$-Ecdyson in der applizierten Dosis mit der angewandten Statistik keinen signifikanten Effekt auf die Fläche und auf den prozentualen Anteil gelben Marks in der tibialen Epiphyse aus (Abb.62; Abb.63).

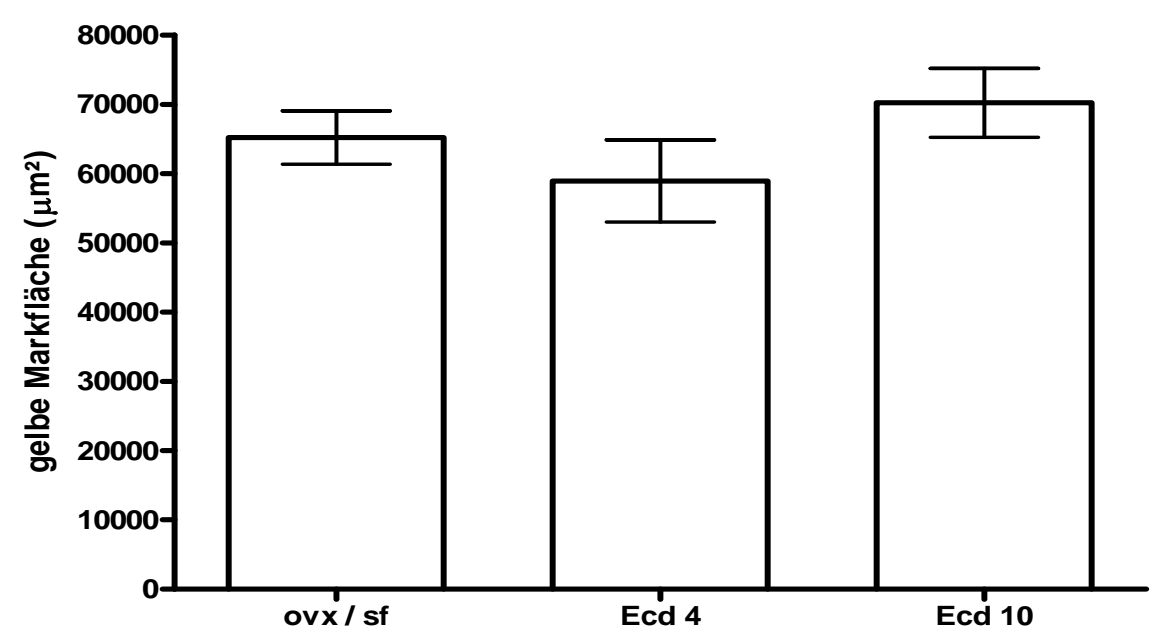

Abb.62: Der Effekt von $\beta$-Ecdyson (Ecd $4 \mathrm{mg} / \mathrm{kg} \mathrm{KG;} \mathrm{Ecd} \mathrm{10mg/kg} \mathrm{KG)} \mathrm{auf} \mathrm{die} \mathrm{Fläche}$ gelben Knochenmarks (in Mikrometer ${ }^{2}$ ) in der tibialen Epiphyse angrenzend an die proximale Epiphysenfuge nach dreimonatigem Futterversuch an weiblichen ovx S.D.-Ratten im Vergleich zur ovx Kontrollgruppe unter sf Futter. Ergebnisse aus Einzelanwendung der Schwellenwertbestimmung am Negativbild im roten Farbauszug (F-Methode). 


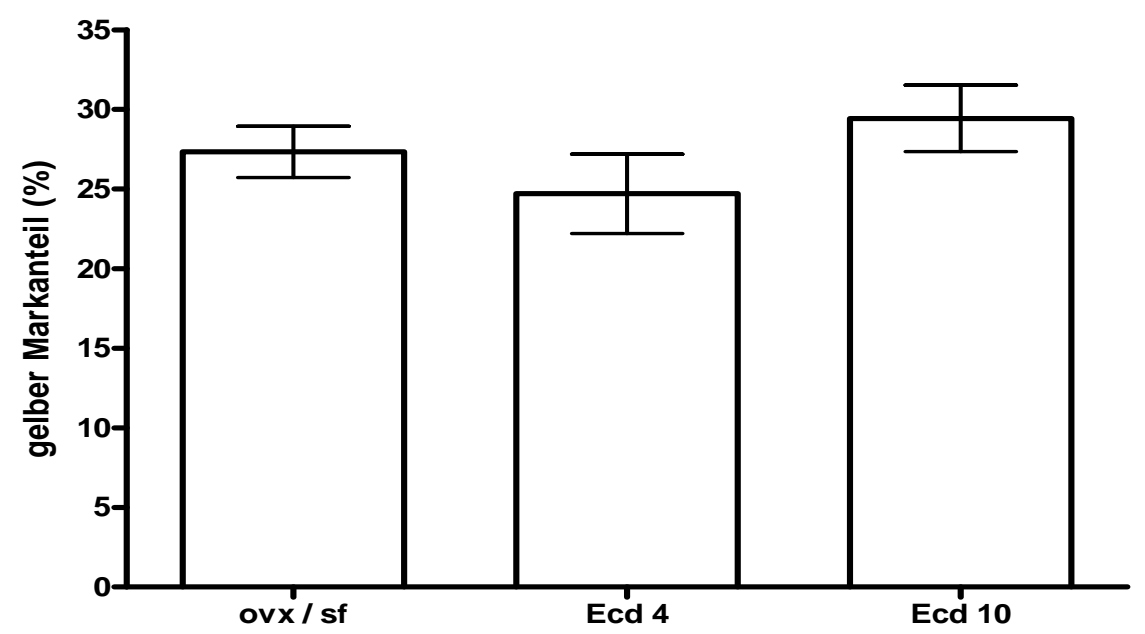

Abb.63: Der Effekt von $\beta$-Ecdyson (Ecd $4 \mathrm{mg} / \mathrm{kg} \mathrm{KG;} \mathrm{Ecd} \mathrm{10mg/kg} \mathrm{KG)} \mathrm{auf} \mathrm{den}$ prozentualen Anteil gelben Knochenmarks in der tibialen Epiphyse angrenzend an die proximale Epiphysenfuge nach dreimonatigem Futterversuch an weiblichen ovx S.D.Ratten im Vergleich zur ovx Kontrollgruppe unter sf Futter. Ergebnisse aus Einzelanwendung der Schwellenwertbestimmung am Negativbild im roten Farbauszug (F-Methode).

\section{III.9.3) Fläche und prozentualer Anteil roten Knochenmarks in der tibialen} Epiphyse

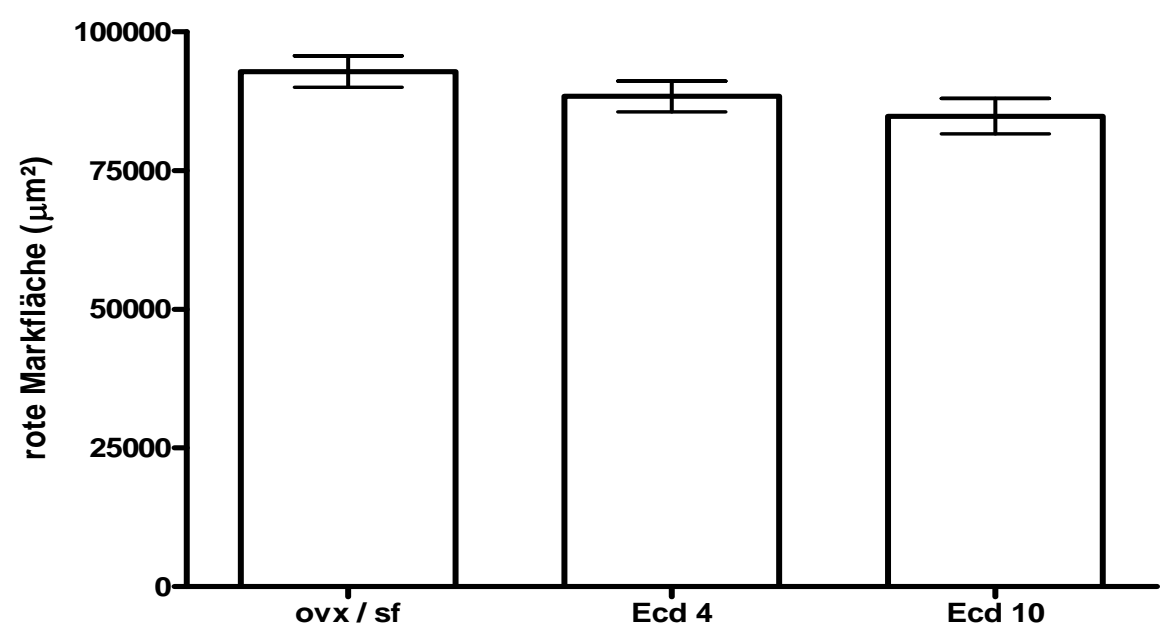

Abb.64: Der Effekt von $\beta$-Ecdyson (Ecd $4 \mathrm{mg} / \mathrm{kg} \mathrm{KG;} \mathrm{Ecd} \mathrm{10mg/kg} \mathrm{KG)} \mathrm{auf} \mathrm{die}$ Fläche roten Knochenmarks (in Mikrometer ${ }^{2}$ ) in der tibialen Epiphyse angrenzend an die proximale Epiphysenfuge nach dreimonatigem Futterversuch an weiblichen ovx S.D.-Ratten im Vergleich zur ovx Kontrollgruppe unter sf Futter. Ergebnisse aus Einzelanwendung der Schwellenwertbestimmung am Negativbild im roten Farbauszug (F-Methode). 
Bei den weiblichen ovx S.D.-Ratten konnte mit der angewandten Statistik kein signifikanter

Effekt von $\beta$-Ecdyson in den Konzentrationen von $4 \mathrm{mg} / \mathrm{kg} \mathrm{Kg}$ und von $10 \mathrm{mg} / \mathrm{kg} \mathrm{KG}$ auf die Fläche und auf den prozentualen Anteil roten Marks in der tibialen Epiphyse nachgewiesen werden (Abb.64; Abb.65).

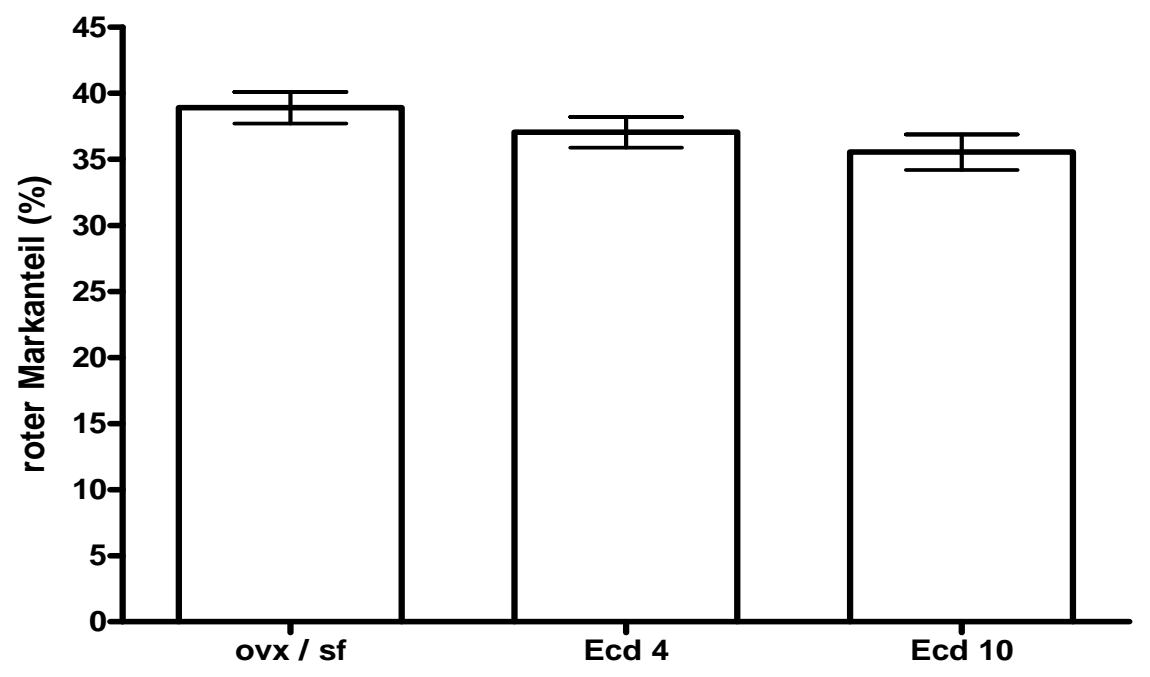

Abb.65: Der Effekt von $\beta$-Ecdyson (Ecd 4 mg/kg KG; Ecd $10 \mathrm{mg} / \mathrm{kg} \mathrm{KG)} \mathrm{auf}$ den prozentualen Anteil roten Knochenmarks in der tibialen Epiphyse angrenzend an die proximale Epiphysenfuge nach dreimonatigem Futterversuch an weiblichen ovx S.D.-Ratten im Vergleich zur ovx Kontrollgruppe unter sf Futter. Ergebnisse aus Einzelanwendung der Schwellenwertbestimmung am Negativbild im roten Farbauszug (F-Methode). 


\section{$\underline{\text { IV.) Diskussion }}$}

Die Osteoporose ist eine systemische Skeletterkrankung, die aufgrund eines erhöhten Frakturrisikos mit einer nicht zu unterschätzenden Morbidität assoziiert ist. In Verbindung mit dem demographischen Wandel zu einer zunehmend alternden Gesellschaft, steigt gegenwärtig auch die Häufigkeit des Auftretens dieser Erkrankung und dementsprechend auch von damit assoziierten Komplikationen. Unter diesem Gesichtspunkt geraten die derzeit bestehenden Therapieoptionen, sowie deren Nebenwirkungsprofil aktuell ins Blickfeld des Interesses, um sie bezüglich ihrer Anwendbarkeit und den damit verbundenen Kosten für das Gesundheitssystem zu überprüfen und kritisch zu hinterfragen. In dieser Hinsicht fallen dabei vor allem die derzeit, im Vergleich zur weiblichen Osteoporose, noch eingeschränkten Therapiemöglichkeiten dieser Erkrankung beim Mann auf. Im Hinblick auf eine für beide Geschlechter typische, altersbedingte Abnahme der Knochenmasse sowie auf den zusätzlich verstärkten Knochenverlust bei sinkendem Geschlechtshormonspiegel, stellt insbesondere die Entwicklung von prophylaktischen Therapieansätzen, als Ergänzung der bereits empfohlenen Maßnahmen, ein erstrebenswertes Ziel dar.

\section{IV.1) Studienziel}

Durch Hinweise in der aktuellen Literatur auf die Beobachtung, dass $\beta$-Ecdyson auf zellulärem Niveau einen stimulierenden Effekt auf die in vitro Differenzierung von Mesenchymzellen zu Osteoblasten bei Mäusen (Gao L et al. 2008) und auf die Proliferation von Osteoblasten-ähnlichen Zellen bei Ratten (Gao XY et al. 2000) ausübt, wird die Vermutung nahe gelegt, dass es möglicherweise auch in vivo auf Organebene eine knochenprotektive Wirkung zeigen könnte. Diese Hypothese wird durch eine weitere Studie bestärkt, in der sich $\beta$-Ecdyson heilungsfördernd auf Knochenfrakturen erwies (Syrov et al. 1986). Die Problematik bezüglich der beiden letztgenannten Studien liegt in der Tatsache, dass sie nicht in englischer Sprache oder lediglich in Abstractform verfügbar und somit schwer zu bewerten sind. Sowohl die interessante Beobachtung einer Wirkung auf zellulärer Knochenebene, als auch die diesbezüglich kritische bestehende Studienlage, motivieren zur Konstruktion einer eigenen entsprechenden Untersuchung. In diesem Sinne besteht das Ziel der vorliegenden Studie in der Analyse eines potenziellen knochenprotektiven Effekts von $\beta$ Ecdyson auf die Tibia von S.D.-Ratten gegenüber einem Knochenverlust nach Gonadektomie. Die dreimonatige Applikation der Testsubstanz erfolgte hierfür über das Futter. Ein möglicher Effekt wurde mit Hilfe der histologischen Analyse der proximalen Tibiastruktur evaluiert. Zur Beurteilung ihrer Anwendbarkeit im Hinblick auf die Fragestellung wurden des Weiteren 
zwei der angewandten morphometrischen, Computer-assistierten Fotoanalyseverfahren in einem vorangestellten Abschnitt der Arbeit miteinander verglichen und beurteilt.

\section{IV.2) Vergleich zweier Computer-assistierter Fotoanalyseverfahren im Hinblick auf die Untersuchung von Trabekel- und Knochenmarkstruktur in der tibialen Metaphyse}

Neben der Analyse und Bewertung der erhaltenen Ergebnisse bezüglich eines Knocheneffekts von $\beta$-Ecdyson, sollte zunächst die kritische Beurteilung und Auseinandersetzung mit der angewandten Methodik folgen, um deren mögliche Grenzen in der Auswertung aufzuzeigen und in der Bewertung berücksichtigen zu können. Mit dem Hintergrund etwaige methodische Einschränkungen bezüglich der zwei angewandten histomorphometrischen, Computerassistierten Auswertungsverfahren bei der metaphysären Trabekel- und Knochenmarksanalyse feststellen zu können, wurden die erhaltenen Messwerte nach deren eigentlicher statischer Auswertung zusätzlich innerhalb der verwendeten Methode gegenüber gestellt und statistisch miteinander verglichen. Bei den beiden im Folgenden $\mathrm{zu}$ vergleichenden Fotoanalyseverfahren handelt es sich zum einen um die Schwellenwertbestimmung am 8-BitGrauwertbild (D-Methode), zum anderen um die Schwellenwertbildung am Negativbild im roten Farbauszug (F-Methode).

Der Vergleich zwischen den erhaltenden Messwerten für die metaphysären Trabekelflächen mittels Schwellenwertbestimmung am 8-Bit-Grauwertbild bzw. Negativbild im roten Farbauszug zeigte bei den männlichen Tieren keinen signifikanten Unterschied zwischen den beiden Verfahren (Abb.9). Dabei fiel interessanterweise auf, dass die beiden männlichen Kontrollgruppen nahezu keine Unterschiede aufwiesen, während bei den männlichen $\beta$ Ecdyson-Tieren die D-Methode tendenziell leicht größere, aber nicht signifikante, Messergebnisse ermittelte als die F-Methode.

Die Gegenüberstellung der Messwerte für den prozentualen Trabekelanteil wiesen ebenfalls keine signifikanten Unterschiede zwischen den beiden Methoden auf (Abb.10). Diese beiden Vergleiche zeigen somit keine signifikanten Unterschiede zwischen den ermittelten Werten und lassen darauf schließen, dass die F- und die D-Methode gleichwertig geeignet sind, um trabekuläre Parameter, wie Fläche und prozentualem Anteil, in der proximalen Tibiametaphyse zu bestimmen.

Bei den weiblichen Tieren zeigten die beiden Verfahren ebenfalls keine signifikanten Unterschiede in den trabekulären Messungen bei der ovx Kontrollgruppe und einer 
$\beta$-Ecdyson-Dosis von 4mg/kg KG (Abb.15; Abb.16). Die Ausnahme bildete jedoch die Gruppe mit einer Konzentration von 10mg/kg KG. Bei jener fielen die Ergebnisse in der FMethode, das heißt der Schwellenwertbildung am Negativbild im roten Farbauszug, signifikant geringer aus als in der D-Methode mit Schwellenwertbestimmung am 8-BitGrauwertbild. Da es sich bei dem letztgenannten signifikanten Unterschied zwischen den Auswertungsmethoden im Bereich der Trabekelanalyse scheinbar um einen Einzelfall innerhalb der vorliegenden Studie handelt, lässt sich dieser möglicherweise vernachlässigen.

Die entsprechende vergleichende Analyse der angewandten Methoden erbrachte bei den Parametern der beiden Knochenmarkstypen allerdings deutlich gegenteilige Ergebnisse. So konnten bei dem analysierenden Methodenvergleich signifikante Unterschiede zwischen den erhaltenen Werten für das rote und gelbe Knochenmark durch die beiden unterschiedlichen Methoden festgestellt werden. Diese Differenzen waren bei beiden Geschlechtern gleichermaßen zu beobachten. Die Verwendung der D-Methode ergab für das gelbe Knochenmark stets eine signifikant geringere Fläche (Abb.11, Abb.17), sowie geringeren Prozentanteil (Abb.12, Abb.18) als die vergleichbare Auswertung mittels F-Methode. Bei dem jeweils anderen Knochenmarkstypen, hier also dem roten Knochenmark, fielen die entsprechenden Messergebnisse dann kompensatorisch und jeweils gegenläufig zum anderen aus. Dies bedeutet also, dass die D-Methode für das rote Knochenmark stets eine signifikant größere Fläche (Abb.13, Abb.19), sowie höheren Prozentanteil (Abb.14, Abb.20) als die FMethode ermittelte. Die überraschenderweise signifikant unterschiedlichen Messergebnisse für das gelbe und rote Knochenmark durch Anwendung zweier Methoden legen nahe, dass diese mit einer kritischen Haltung bewertet werden sollten. Die Hintergründe bezüglich der Unterschiede bleiben zunächst fraglich und sollten vor zukünftigen Anwendungen gegebenenfalls analysiert und geklärt werden. Bei Anwendung der F-Methode fiel lediglich auf, dass es im Rahmen der Schwellenwertverteilung schwierig war, Artefakte innerhalb des Präparats, wie beispielsweise Luftbläschen, von den Anteilen des gelben Fettmarks zu trennen, da es für das Grafikprogramm scheinbar problematisch war, beides voneinander zu unterscheiden. $\mathrm{Ob}$ dies nun einen möglichen oder entscheidenden Beitrag zu den beschriebenen Auswertungsdifferenzen geleistet hat, bleibt jedoch offen. Die Frage nach Vorund Nachteilen der einzelnen Methoden bleibt somit vorerst unbeantwortet. Möglicherweise konnten etwaige methodische Fehler jedoch auch durch die Kombination beider Methoden in der metaphysären Auswertung kompensatorisch kleiner gehalten werden als in der Einzelanwendung. 
Der Methodenvergleich konnte zusammenfassend somit deutlich machen, dass beide Verfahren gleichwertig gut in der histologischen Auswertung des trabekulären Knochens bezüglich Prozentanteil und Fläche in der proximalen Tibiametaphyse angewendet werden können. Die Analyse des Knochenmarks jedoch wies signifikante Unterschiede in den Messergebnissen der einzelnen Methoden auf, sodass dies für die folgende Ergebnisinterpretation und Bewertung berücksichtigt werden sollte. $\mathrm{Ob}$ der Methodenvergleich auf mögliche methodische Schwachpunkte hinweist, sollte vor zukünftiger Anwendung gegebenenfalls geklärt bzw. möglicherweise durch geeignete Verfahren, wie beispielsweise der MRT, ergänzt werden. Für die histologische Analyse bezüglich eines Effekts von $\beta$-Ecdyson auf Trabekel und Knochenmark in der Metaphyse wurden Schwellenwerte sowohl am 8-Bit-Grauwertbild (D-Methode), als auch am Negativbild im roten Farbauszug (F-Methode) gebildet. Die erhaltenen Ergebnisse wurden anschließend gemittelt. Die zwei morphometrischen Verfahren wurden in der Metaphyse kombiniert verwendet, da sie für die Trabekelanalyse eine vergleichbare Eignung aufwiesen, sich in Bezug auf die Knochenmarkuntersuchung jedoch möglicherweise ergänzen bzw. Methodenfehler aufgrund eines größeren Stichprobenumfangs möglichst gering halten können.

\section{IV.3) Futteraufnahme und Körpergewichtsverlauf im Rahmen der Futterstudie mit $\beta$-Ecdyson}

Den intakten und gonadektomierten Kontrollgruppen wurde über den gesamten Versuchszeitraum sojafreies phytoöstrogenarmes Standardfutter ad libitum angeboten. Der Ausschluss von sojahaltigen Proteinbestandteilen basiert auf dem Hintergrund, dass die in Soja enthaltenen Isoflavone einen potentiellen altersabhängigen Einfluss auf den Knochenstoffwechsel und somit auf die Analyse des $\beta$-Ecdyson-Effekts ausüben könnten. Eine frühere Analyse von sojahaltigem Standardfutter konnte immerhin einen Isoflavongehalt von $5,6 \mathrm{mg} / \mathrm{kg}$ zeigen, der sich aus Genistein und Daidzein zusammensetzte (Seidlová-Wuttke et al. 2008a). Das $\beta$-Ecdyson-haltige Futter für die anderen Versuchsgruppen war ebenfalls phytoöstrogenarm und unterschied sich von jenem der Kontrollgruppen lediglich durch entsprechende Zusätze an Testsubstanz.

\section{IV.3.1) Futteraufnahme und Körpergewicht der männlichen S.D.-Ratten}

Die wöchentliche Kontrolle des Futterverbrauchs zeigte bei den männlichen Tieren initial einen allgemeinen Peak in der zweiten Woche nach ORX, der zeitlich mit sehr kalten 
Außentemperaturen von bis zu minus $10^{\circ} \mathrm{C}$ zusammen fiel (Abb.21). Hierbei lässt sich eine diskrete Auswirkung der kalten Witterung auf die Tierstallklimatisierung nicht vollkommen ausschließen. Nach einer post-orx Adaptionsphase von vier Wochen, pendelte sich der Futterkonsum allerdings auf ein relativ stabiles Niveau ein. Die geringste Futteraufnahme und demnach auch Körpergewichtszunahme fand bei den orx Kontrolltieren über den gesamten Versuchszeitraum statt. Vergleichbare Beobachtungen nach ORX fanden sich auch in anderen Studien (Erben et al. 2000, Borst und Conover 2006). Die intakten und die mit $\beta$-Ecdyson substituierten Tiere hingegen fraßen zwar vergleichbare Mengen (Abb.22), allerdings nahmen die intakten Tiere dabei signifikant mehr an Körpergewicht zu, während die $\beta$-Ecdyson-Tiere keinen Unterschied zu den orx Kontrolltieren aufwiesen (Abb.26). Diese Ergebnisse zeigen interessanterweise eine Abweichung zu dem in der Literatur beschriebenen Effekt, dass Ecdysteroide bei beispielsweise Nutztieren eine Gewichtszunahme-fördernde Wirkung bei gleichzeitig niedrigem Futterverbrauch ausüben können (Báthori et al. 2008). Vermutlich liegt das Ausbleiben eines vergleichbaren Effekts an der zuvor erfolgten ORX, da diese typischerweise eine senkende Wirkung auf Futterkonsum und Gewichtszunahme ausübt, welche in diesem Fall offensichtlich durch eine Ecdysteroidsubstitution nicht $\mathrm{zu}$ kompensieren war. Allerdings bewerteten Lafont und Dinan im Rahmen eines Reviews (2003) den von Báthori et al. (2008) beschriebenen Ecdysteroideffekt auf Körpergewicht und Futterverbrauch auch eher kritisch. Dabei bemängelten sie die Tatsache, dass einige der Daten auf Analysen basierten, die sich lediglich auf bestimmte Wachstumsphasen, ein einzelnes Geschlecht, zu geringe Testsubstanzdosen oder eine inadäquate statistische Methodik beschränkten. $\mathrm{Ob} \beta$-Ecdyson dabei möglicherweise durch einen charakteristischen Eigengeschmack oder anderweitig noch einen Effekt auf den Futterkonsum ausübt, bleibt zunächst jedoch fraglich.

\section{IV.3.2) Futteraufnahme und Körpergewicht der weiblichen S.D.-Ratten}

Bei den weiblichen Tieren zeigten sich keine Unterschiede hinsichtlich Futteraufnahme (Abb.24) und Körpergewicht (Abb.28) zwischen den Kontrolltieren und jenen mit $\beta$-EcdysonApplikation. Vor dem Einpendeln auf ein konstantes Futterkonsumniveau, zeigten die weiblichen Tiere ebenfalls einen initialen Peak parallel zu den kalten Außentemperaturen (Abb.23). Außerdem wirkte sich im Verlauf wahrscheinlich auch ein kurzfristiger Käfigpositionswechsel steigernd auf den Futterverbrauch aus, der sich nach Korrektur wieder auf ein nahezu konstantes Niveau einstellte. 
Die Weibchen nahmen ebenfalls über den gesamten Untersuchungszeitraum gleichmäßig zu, was für eine ausgewogene Verstoffwechselung der aufgenommen Nahrung spricht.

Im Ganzen betrachtet spielt die Berücksichtigung des Körpergewichts für die folgende Analyse etwaiger Knochenveränderungen aus zwei Gründen eine wichtige Rolle. Zum einen stellt das Körpergewicht einen mechanischen Belastungsfaktor und somit gemeinsam mit der Wirkung von Muskelkraft einen funktionellen Anpassungsreiz auf den Knochen dar (Taes et al. 2009), zum anderen sind Körperbau und Körperfett zwei Parameter, die eng mit Hormonhaushalt und Knochenstoffwechsel verknüpft sind (Rosen und Klibanski 2009, Reid 2008). Dies zeigt sich beispielsweise in der Beobachtung, dass ein erhöhter Body Mass Index tendenziell eher einen protektiven Faktor gegen Osteoporose-assoziierte Frakturen darstellt, während ein niedriges Körpergewicht das Risiko für Spontanfrakturen erhöhen kann (Rosen und Klibanski 2009, Reid 2009).

\section{IV.4) Die Tibia der gonadektomierten Ratte als Osteoporosemodell}

Die gonadektomierte Ratte hat sich im Laufe der vergangenen Jahre als tierexperimentelles Modell der Osteoporose bewährt. Neben vorteilhaften Aspekten bezüglich der unkomplizierten Haltung und des überschaubaren Lebenszyklus, überzeugen vor allem die mittlerweile gut untersuchten Knochenstukturen und die entsprechenden Veränderungen nach OVX bzw. ORX (Lelovas et al. 2008). Da dieser Gonadektomie-bedingte Geschlechtshormonmangel mit einer unausgewogenen Steigerung der Resorption und Neubildung von Knochenmaterial im Rahmen des Remodeling und folglich mit einem Knochenverlust einhergehen (Schot und Schuurs 1990), wird die Übertragung auf die damit vergleichbare Knochensituation der postmenopausalen Frau (Turner et al. 2001) bzw. des osteoporotischen Mannes (Vanderschueren et al. 2004) gerechtfertigt. In der vorliegenden Studie konnte bei den männlichen orx S.D.-Ratten anhand einer signifikanten Abnahme des metaphysären prozentualen Trabekelanteils im Vergleich zur intakten Kontrollgruppe ein entsprechender, experimentell induzierter Knochenverlust abgeleitet werden (Abb.38). Bei den weiblichen Tieren lässt sich aufgrund einer fehlenden intakten Kontrollgruppe keine entsprechende Aussage treffen. Allerdings lässt sich ein Gonadektomie-induzierter Knochenverlust aufgrund der langjährigen Erfahrung als tierexperimentelles Osteoporosemodell nahezu voraussetzen. 


\section{IV.5) Effekt von $\beta$-Ecdyson auf makroskopische Aspekte der Tibia}

Basierend auf der für Ratten besonderen Eigenschaft einer nahezu lebenslang unverknöcherten Epiphysenfuge, das heißt etwa acht Monate bei männlichen und zehn Monate bei weiblichen S.D.-Ratten (Martin EA et al. 2003), war für die vorliegende Studie neben der mikroskopischen Untersuchung auch die makroskopische Vermessung des Tibiaknochens von Interesse, um mögliche $\beta$-Ecdyson-Effekte auf dessen Länge und Durchmesser als Ausdruck des Knochenmodelings zu evaluieren.

\section{IV.5.1) Auswirkungen auf Tibialänge und Tibiakopfdurchmesser der männlichen S.D.-Ratten}

Das Längenwachstum von langen Röhrenknochen, wie der Tibia, hat seinen Ursprung in der Wachstumszone bzw. Epiphysenfuge und erfolgt über den Mechanismus der endochondralen Ossifikation (Martin EA et al. 2003). In der vorliegenden Studie konnte die Vermessung der männlichen Tibiae einen signifikanten Längenunterschied zwischen den Kontrolltieren und den unter $\beta$-Ecdyson-haltiger Ernährung festgestellt werden (Abb.29). So waren die Knochen ab einer $\beta$-Ecdyson-Dosis von $22 \mathrm{mg} / \mathrm{kg}$ KG kürzer als jene der beiden Kontrollgruppen. Unter Berücksichtigung einer möglichen methodischen Einschränkung bezüglich der Messgenauigkeit mittels Schieblehre und der Dimension des Längenunterschieds im Millimeterbereich, lässt sich bei den Männchen somit ein schwacher hemmender Einfluss von $\beta$-Ecdyson auf das tibiale Längenwachstum durch endochondrale Ossifikation feststellen.

Der Knochenumfang und somit das Dickenwachstum der Tibia wird über den Mechanismus der perichondralen Ossifikation geprägt (Martin EA et al. 2003). In der vorliegenden Studie konnten zwischen den einzelnen Gruppen männlicher S.D.-Ratten keine Unterschiede bezüglich der Parameter des metaphysären Tibiakopfdurchmessers festgestellt werden (Abb.30). B-Ecdyson scheint hier in den angewandten Dosen also keinen Einfluss auf das perichondrale Knochenwachstum zu nehmen.

\section{IV.5.2) Auswirkungen auf Tibialänge und Tibiakopfdurchmesser der weiblichen S.D.-Ratten}

Bei den weiblichen Tieren konnte kein Einfluss auf die Tibialänge beobachtet werden (Abb.31). Dies beruht möglicherweise auf der Höhe der applizierten $\beta$-Ecdyson-Dosen, da die Effekt-ausübende Dosis bei den Männchen mit 22mg/kg KG mehr als doppelt so groß war wie die bei den Weibchen applizierte Höchstdosis von 10mg/kg KG. 
Allerdings konnte bei den weiblichen Tieren wiederum bei $10 \mathrm{mg} / \mathrm{kg}$ KG ein signifikant geringerer Tibiakopfdurchmesser in medio-lateraler und anterior-posteriorer Messung beobachtet werden (Abb.32). Da es sich hier lediglich um einen vereinzelten Wert handelt, sollte ein möglicher Effekt auf den weiblichen Tibiakopfdurchmesser kritisch betrachtet werden und gegebenenfalls mit einem größeren Stichprobenumfang in Folgestudien genauer untersucht werden.

\section{IV.6) Effekt von $\beta$-Ecdyson auf mikroskopische Aspekte der Tibia}

Die mikroskopische Untersuchung des Knochens zur Beurteilung von etwaigen osteoporotischen Veränderungen ist derzeit eher ein Privileg des experimentellen Bereichs, da sie für eine angewandte klinische Diagnostik einen relativ invasiven Charakter aufweist bzw. dabei gegen ebenso geeignete, nicht-invasive Methoden wie DXA oder pQCT konkurriert (Banse et al. 2002). Im experimentellen Bereich können die genannten Methoden allerdings eine sinnvolle gegenseitige Ergänzung darstellen, da sie den zweidimensionalen, verhältnismäßig kleinen Knochenausschnitt im histologischen Präparat durch Integration in ein größeres Gesamtbild besser beurteilen lassen. Ein wesentlicher Vorteil der Histologie und Histomorphometrie des Knochens besteht dabei in der Möglichkeit, neben der Analyse von Knochenzellen auch einzelne Strukturelemente, wie rotes und gelbes Knochenmark, sowie die einzelnen Trabekel, voneinander abgrenzen und individuell beurteilen zu können (Turner et al. 2001). Die histologische Untersuchung des Knochens ermöglicht somit über die Beurteilung der Mikroarchitektur eine gewisse Einschätzung von Knochenbrüchigkeit und Frakturrisiko, da diese für die Qualität und Belastbarkeit des Knochens eine entscheidende Rolle spielt (Dalle Carbonare et al. 2005). Im Rahmen der vorliegenden Studie wurden diese Vorteile für die Analyse des Effekts von $\beta$-Ecdyson auf den Knochen genutzt und die einzelnen Knochenelemente mikroskopisch vermessen, ausgewertet und in das von Interaktion geprägte Gesamtbild gestellt. Dabei muss jedoch im Rahmen der Ergebnisbewertung die Tatsache berücksichtigt werden, dass die erhaltenen Resultate stets nur für den ausgewerteten Bereich gelten können und somit ein Nachteil der Histologie unter anderem in der Beschränkung des analysierten Gewebeausschnitts besteht (Turner et al. 2001).

\section{IV.6.1) Auswirkungen auf die diaphysäre und metaphysäre Kortikalisdicke}

Die Kortikalis der Tibia bildet aus Lamellenknochen die äußere Hülle des Röhrenknochens und ist eine wichtige Komponente für Stabilität und Festigkeit des Knochens. Somit stellt die Kortikalisdicke einen wichtigen zu untersuchenden Parameter für die Beurteilung eines 
Substanzeffekts in der Osteoporoseprophylaxe und Therapie dar (Danielsen et al. 1993). Die Gestalt und Dicke der Kortikalis wird geprägt aus dem Verhältnis von periostalem Appositionswachstum und endokortikaler Resorption bzw. Wachstum (Seeman 2008). Je weiter sich die Markhöhle durch endokortikales Remodeling ausdehnt, desto größer wird der Abstand zwischen Kortikalis und Neutralnullachse des Knochens. Durch diese kortikale Verlagerung lässt sich aufgrund von Materialeinsparung in der Kortikalisdicke ein leichterer, aber dennoch fester Knochen aufbauen (Chavassieux et al. 2007). Dies ist eine der Grundlagen dafür, dass Männer durch ihre größeren, weiteren und somit stärkeren Knochen auch ein niedrigeres spontanes Frakturrisiko bei Osteoporose aufweisen als Frauen, obwohl sich die absolute kortikale Dicke zwischen den Geschlechtern nicht oder nur kaum unterscheidet (Seeman 2003). Abhängig von der Knochenlokalisation und der dortigen mechanischen Belastung weist die Kortikalis außerdem eine unterschiedliche Dicke auf, sodass in der vorliegenden Studie jeweils zweimal zehn Messungen im Metaphysen-, sowie im Diaphysenbereich durchgeführt wurden. Aus den dabei erhaltenen Werten wurden anschließend Mittelwerte gebildet.

\section{IV.6.1.1) Auswirkungen auf die Kortikalisdicke männlicher S.D.-Ratten}

Die Messungen im Diaphysenbereich der männlichen Tiere ergaben zunächst einmal keinen signifikanten Dickeunterschied zwischen den beiden Kontrollgruppen (Abb.33). Diese Beobachtung bestätigt offensichtlich die frühere Feststellung, dass es durch Gonadektomieinduzierten Geschlechtshormonmangel kaum oder erst im späten Verlauf zu einem kortikalen Knochenverlust im Diaphysenbereich kommt. Dies wurde beispielsweise in Studien dargelegt, die eine kortikale Veränderung nach OVX erst nach 90-120 Tagen feststellen konnten (Jee und Yao 2001). Dabei wird vermutet, dass dies auf einer zunächst ausgeglichenen Bilanz zwischen endokortikaler Resorption und periostaler Apposition basiert (Jee und Yao 2001). Außerdem konnte in weiteren Studien beobachtet werden, dass die kortikale Fläche bei intakten S.D.-Ratten erst im Alter von etwa 12 bis 15 Monaten ihr Maximum erreicht und dass ein anschließender altersbedingter Kortikalisverlust langsamer von statten geht als ein Trabekulärer (Ke et al. 2001). Diese altersabhängigen Eigenschaften der Kortikalis von S.D.-Ratten, sowie die erst spät auftretenden Veränderungen nach Gonadektomie lassen vermuten, dass die Versuchsdauer der vorliegenden Studie nicht ausreichte, um einen Kortikalisverlust bei den Kontrolltieren beobachten zu können. Ein in dieser Hinsicht eventuell zu kritisierender Schwachpunkt der Studie besteht möglicherweise 
darin, dass keine Referenz-Kontroll-Gruppe zum Zeitpunkt des Studienbeginns als Vergleichsmöglichkeit mit der ursprünglichen Kortikalisdicke eingerichtet wurde.

Während zwischen den Kontrollgruppen somit kein signifikanter Unterschied bestand, zeigte hingegen die Applikation von $\beta$-Ecdyson in niedrigster und höchster Dosis im Vergleich zur orx Kontrolle einen senkenden Effekt auf die diaphysäre Kortikalisdicke der männlichen S.D.-Ratten (Abb.33). Das bedeutet, dass die Kortikalis hier nach $\beta$-Ecdysonaufnahme mit der physiologischen Dicke der intakten Tiere vergleichbar war, die in dieser Studie tendenziell, aber nicht signifikant dünner war als die der orx Kontrolle. Dabei lässt sich nur vermuten, dass das Prinzip einer vorteilhaften Kombination aus Materialeinsparung und erhöhter Stabilität durch abstandserhöhende Verlagerung der Kortikalis weg von der Neutralnullachse des Knochens umgesetzt wurde (Chavassieux et al. 2007). Warum die mittlere Dosis keinen entsprechenden Effekt zeigen konnte, bleibt vorerst fraglich. Eine mögliche Ursache dafür jedoch könnte der methodische Hintergrund sein, dass vereinzelt Werte aufgrund morphologischer Auffälligkeiten bezüglich der Präparatschnitte nicht in der statistischen Auswertung berücksichtigt werden konnten und sich der Stichprobenumfang somit entsprechend verkleinerte. So konnten beispielsweise einige der Präparate gar nicht ausgewertet werden oder andere aufgrund einer abweichenden Schnittebene bei der statistischen Auswertung und Interpretation nicht berücksichtigt werden.

Die Kortikalis im Metaphysenbereich zeigte sich nach ORX signifikant dicker als jene der intakten Kontrollgruppe (Abb.34). Bei einem Blick auf die Messergebnisse bezüglich des metaphysären Trabekelanteils der Kontrolltiere zeigte sich, dass dort, wo der Trabekelanteil der intakten Tiere größer ist als jener der orx Kontrolle, auch die metaphysäre Kortikalis dünner ausgeprägt ist (Abb.38). Umgekehrt zeigte sich eine dickere Kortikalis bei den orx Kontrolltieren dort, wo der Trabekelanteil im Vergleich zu den intakten Tieren kleiner ist. Die Beobachtung beschränkte sich auf den Metaphysenbereich, da dieser eine Prädilektionsstelle für einen erhöhten Knochenumsatz nach Gonadektomie darstellt (Zhang et al. 2007). Diese Ergebniskonstellation lässt eine gewisse funktionelle Anpassungsreaktion der Kortikalis auf den schon früh nach Gonadektomie verringerten Trabekelanteil und damit auch auf die veränderten mechanischen Belastungsreize vermuten. Da der kortikale Knochen als äußere Knochenhülle auch als ein besonderer Angriffsort mechanischer Kräfte gilt, könnte dort durch veränderte Trabekelstruktur ein entsprechender Reiz für das adaptierende Remodeling ausgeübt worden sein (Westerlind et al. 1997). 
Im Hinblick auf diesen hypothetischen Aspekt ist weiterhin von Interesse, dass bei Männern lebenslang ein im Vergleich $\mathrm{zu}$ Frauen ausgeprägteres, kontinuierliches periostales Appositionswachstum im Extremitätenskelett aufrecht erhalten wird (Riggs et al. 2002). Dieses Appositionswachstum ist außerdem Lokalisations-abhängig, was somit als ein möglicher Grund für einen ausschließlich metaphysären und nicht diaphysären KortikalisEffekt spricht (Seeman et al. 2006). Gegen die Vermutung eines ebensolchen Anpassungsmechanismus spricht jedoch ein Großteil der Studien bezüglich eines kortikalen Effekts der ORX bei männlichen Ratten, da jene vielmehr die Tendenz zu einer im späteren Verlauf ausdünnenden Kortikalis aufweisen (Vanderschueren et al. 2004). Letzteres beruht dabei auf dem Mechanismus eines erhöhten kortikalen Remodelings mit verstärkter endokortikaler Resorption und damit assoziierter Ausdehnung der Markhöhle bei gleichzeitig verringerter periostaler Apposition (Ke et al. 2001).

Eine mögliche Begründung für die Beobachtung, dass es in der vorliegenden Studie zu einer dickeren Kortikalis bei der orx Kontrolle gekommen ist, liegt möglicherweise zum einen daran, dass bei Studienende noch eine ausgeglichene Remodelingbilanz vorlag und zeitlich noch kein kortikaler Knochenverlust aufgetreten ist. Zum anderen könnte jedoch ein methodischer Schwachpunkt vorgelegen haben, der auf einer leicht verschieden hohen Präparatschnittebene oder jedoch auf dem größentechnisch eingeschränkten Gewebeausschnitts beruht. In dieser Hinsicht wäre somit gegebenenfalls eine vergleichende Zusammenschau mit den Ergebnissen der pQCT-Messung von Interesse

Bei den männlichen Tieren, die $\beta$-Ecdyson über das Futter erhielten, zeigte die metaphysäre Kortikalis in mittlerer und höchster Dosis ebenfalls eine signifikant größere Dicke als jene der intakten Tiere, wohingegen kein Unterschied zu den orx Tieren vorlag (Abb.34).

Ein genereller Gruppenvergleich der Kortikalisdicke zwischen Metaphyse und Diaphyse der männlichen Tiere konnte zeigen, dass auch hier ein physiologisch zu erwartender Dickeunterschied in Abhängigkeit von der Lokalisation vorliegt (Abb.35). Interessanterweise wurde dieser kortikale Dickeunterschied zwischen Metaphyse und Diaphyse durch die Aufnahme von $\beta$-Ecdyson durch alle drei angewandten Konzentrationen aufgehoben, sodass bei den $\beta$-Ecdyson-behandelten Tieren kein signifikanter Lokalisations-abhängiger Unterschied der Kortikalisdicke mehr nachgewiesen werden konnte. Diese Beobachtung lässt vermuten, dass die Anwendung von $\beta$-Ecdyson unterschiedlich starke Effekte auf die einzelnen Kortikalisabschnitte der männlichen Rattentibia ausübt. Hierfür spricht auch die 
Beobachtung, dass sich eine $\beta$-Ecdyson-Applikation in der Diaphyse eher senkend im Vergleich zur orx Kontrolle und in der Metaphyse steigernd im Vergleich zur intakten Kontrolle auf die Kortikalisdicke auswirkt.

Insgesamt betrachtet ist die Analyse der Kortikalisdicke tendenziell schwierig und nicht ganz eindeutig zu bewerten, da sich die vorhandenen zu beobachtenden Effekte von ORX und $\beta$ Ecdyson-Applikation auf die Kortikalisdicke sehr vielgestaltig darstellten. Somit wären Folgestudien, auch bezüglich der Aufklärung des ecdysteroidalen Wirkmechanismus am Knochen von Säugern, sowie eine ergänzende Zusammenschau mit den pQCT-Ergebnissen, von besonderem Interesse.

\section{IV.6.1.2) Auswirkungen auf die Kortikalisdicke weiblicher S.D.-Ratten}

Bei den weiblichen Tieren konnte nach $\beta$-Ecdyson-Applikation hingegen kein signifikanter Unterschied zur Kortikalisdicke der ovx Kontrollgruppe festgestellt werden (Abb.36). Dabei lässt sich als entscheidender Grund vermuten, dass die angewandten $\beta$-EcdysonKonzentrationen, im Vergleich zu jenen der männlichen Tiere, zu niedrig für einen kortikalen Effekt waren. Durch die fehlende intakte Kontrolle bei den Weibchen lässt sich diesbezüglich auch keine Aussage zu einem etwaigen kortikalen Unterschied nach Gonadektomie treffen.

Bei den weiblichen S.D.-Ratten konnte der Dickeunterschied zwischen metaphysärer und diaphysärer Kortikalis hingegen durch Applikation von $\beta$-Ecdyson in den jeweiligen Dosen allerdings nicht aufgehoben bzw. ausgeglichen werden (Abb.36).

\section{IV.6.2) Auswirkungen auf das Trabekelsystem in der proximalen Tibia}

Das Trabekelsystem eines gesunden intakten Knochens besteht aus einem schwammartigen Netzwerk von miteinander verbundenen Knochenbälkchen. Mit zunehmendem Alter bzw. Abnahme der verfügbaren Geschlechtshormone, zum Beispiel nach der Menopause, verändert sich die Trabekelstruktur in mehr oder weniger charakteristischer Weise. So lässt sich der damit assoziierte Knochenverlust bei Frauen durch einen tendenziellen trabekulären Konnektivitätsverlust charakterisieren, während sich bei Männern vielmehr eine Trabekelausdünnung bei erhaltener Konnektivität beschreiben lässt (Venken et al. 2008). Histologische Knochenanalysen beziehen sich meist auf die tibiale Metaphyse im Bereich von einem Millimeter distal der Epiphysenfuge (Lelovas et al. 2008), da dort das Trabekelsystem bzw. die sekundäre Spongiosa schwerpunktmäßig lokalisiert ist, die mechanische Belastung als Einflussfaktor relativ gering ist (Turner 1999), es sich dabei um einen zentralen Ort des Knochenstoffwechsels mit überwiegender Remodelingaktivität handelt (Lelovas et al. 2008) 
und sich somit besonders reagibel auf gegebenenfalls applizierte Substanzen zeigt (Zhang et al. 2007). Obwohl einige Studien der Analyse im Epiphysenbereich mit Hinweis auf die dort vorliegende primäre Spongiosa und der Nähe zur Epiphysenfuge mit überwiegender Modelingaktivität (Lelovas et al. 2008) kritisch gegenüber stehen, argumentieren andere für eine epiphysäre Untersuchung auf Effekte von applizierten Substanzen, da dies ebenfalls eine Knochenlokalisation mit erhöhtem Knochenstoffwechsel darstelle (Westerlind et al. 1997). Im Rahmen der vorliegenden Studie wurden sowohl die proximale Metaphyse, als auch die proximale Epiphyse ausschnittsweise hinsichtlich Trabekelfläche und prozentualem Trabekelanteil auf einen möglichen Effekt von $\beta$-Ecdyson hin analysiert.

\section{IV.6.2.1) Auswirkungen auf das Trabekelsystem männlicher S.D.-Ratten}

Die histologische Untersuchung der proximalen Tibiametaphyse bezüglich der Trabekelfläche ergab bei den männlichen S.D.-Ratten weder einen signifikanten Unterschied zwischen den beiden Kontrollgruppen noch zwischen den Kontrollgruppen und den mit $\beta$-Ecdysonsubstituierten Tieren (Abb.37). Lediglich die geringste $\beta$-Ecdyson-Konzentration resultierte in einer signifikant niedrigeren Trabekelfläche im Vergleich zu den intakten Kontrolltieren. Der prozentuale Trabekelanteil im proximalen Metaphysenbereich hingegen zeigte einen signifikanten Unterschied zwischen den intakten und den orx Kontrolltieren (Abb.38). Die Applikation von $\beta$-Ecdyson in der mittleren und der höchsten Dosis erreichte außerdem einen Anstieg des prozentualen Trabekelanteils auf nahezu das Niveau der intakten Tiere, sodass bei den behandelten Ratten ein signifikanter Unterschied zur orx Kontrollgruppe vorlag. Die niedrigste $\beta$-Ecdyson-Dosis schien für diesen Effekt nicht ausreichend hoch gewesen zu sein, da diese Tiere, wie die orx Kontrolle, einen signifikanten Unterschied der Prozentanteile im Vergleich zu den intakten Ratten zeigten. Die Beobachtung, dass sich die $\beta$-Ecdyson-Gabe über das Futter steigernd auf den Trabekelanteil in der proximalen Tibiametaphyse orx Ratten auswirkt, stellt einen Hinweis auf eine gewisse osteoprotektive Wirkung dieses Ecdysteroids dar. Unter Hinzunahme der Studie von Gao L et al. (2008) lässt sich vermuten, dass diesem Effekt auf den metaphysären Knochen möglicherweise, zumindest anteilig, eine geförderte Differenzierung von mesenchymalen Stammzellen in Richtung osteoblastärer Zelllinie zugrunde liegt. Auch ein proliferativer Effekt auf die Osteoblastenvorläufer wäre diesbezüglich denkbar (Gao XY et al. 2000). Des Weiteren kann der stimulierende Effekt auf den Knochenaufbau bzw. Knochenerhaltung auch mit dem Skelettmuskelsystem verbunden sein. Ein gedanklicher Hintergrund für diese Hypothese stellt die bekannte und oft beschriebene anabole, den Muskelaufbau fördernde Wirkung des $\beta$-Ecdysons dar, die schon des Öfteren zum Vergleich mit jener des Testosteron herangezogen wurde (Lafont und Dinan 
2009, Báthori et al. 2008). So vermuteten Vandenput et al. in einer 2002 veröffentlichten Studie, dass die stimulierende Wirkung von Testosteron auf den Knochen unter anderem auch mit der erhöhten mechanischen Belastung durch eine Steigerung der Muskelmasse assoziiert sein könnte. Damit bezogen sie sich auf eine ihrer Vorgängerstudien, in welcher gezeigt werden konnte, dass etwa 50\% der knochenprotektiven Eigenschaften von Testosteron auf dessen fördernden Effekt bezüglich einer Zunahme der fettfreien Körpermasse basieren (Vanderschueren et al. 2000). Eine vergleichbare Überlegung wäre somit anteilig auch für eine Erklärung des knochenprotektiven Effekts von $\beta$-Ecdyson denkbar. Ein genaues Verständnis für den Ansatzpunkt der knochenprotektiven Wirkung des $\beta$-Ecdysons bleibt jedoch vermutlich bis zur Aufklärung des Wirkmechanismus im Säugetierorganismus, inklusive des Menschen, noch ungeklärt.

Die Tendenz, dass die niedrigste $\beta$-Ecdyson-Konzentration keine, die beiden höheren jedoch eine signifikante steigernde Wirkung auf den prozentualen Trabekelanteil der Metaphyse aufweisen, könnte außerdem auf eine mögliche Dosisabhängigkeit des knochenprotektiven Effekts hinweisen.

Die Histologie der Epiphyse zeigte bei den männlichen S.D.-Ratten keinen signifikanten Unterschied bezüglich der Trabekelfläche zwischen der orx Kontrollgruppe und den intakten Tieren (Abb.51). Dieses Ergebnis bestätigt die in vielen Studien häufige Beobachtung, dass die proximale Tibiaepiphyse trotz erhöhter Remodelingrate nicht oder nur kaum vom Knochenverlust nach Gonadektomie betroffen ist (Westerlind et al. 1997). Einer der Gründe hierfür ist die Feststellung, dass bei der Ratte in unmittelbarer Nähe zur Epiphysenfuge der Modelingprozess überwiegt, wobei jedoch das Remodeling der entscheidenden Mechanismus für den Gonadektomie-induzierten Knochenverlust darstellt (Lelovas et al. 2008). Außerdem ist möglicherweise auch die Lokalisations-bedingte höhere mechanische Belastung und das damit ausgeglichene Gleichgewicht zwischen Knochenresorption und Bildung eine Ursache für den fehlenden bzw. weniger deutlichen trabekulären Knochenverlust (Baldock et al. 1999). So konnte dementsprechend auch kein statistisch signifikanter Unterschied bezüglich der epiphysären Trabekelflächen zwischen den Kontrollgruppen und den mit $\beta$-Ecdyson behandelten Tieren detektiert werden. Die Analyse sowie das Fehlen eines $\beta$-Ecdyson-Effekts in der Epiphyse zeigen somit aber auch, dass zum Zeitpunkt des Studienendes wohl keine signifikante Auswirkung auf das Modeling mehr vorlag.

Der Messparameter des epiphysären prozentualen Trabekelanteils zeigte ebenfalls keinen Unterschied zwischen den beiden männlichen Kontrollgruppen (Abb.52). Allerdings konnte 
bei den Tieren mit der niedrigsten $\beta$-Ecdysondosis ein signifikanter Effekt bezüglich eines erhöhten Trabekelanteils beobachtet werden. Warum diese Steigerung bei den höheren Konzentrationen mit der angewandten Statistik als nicht signifikant ausfiel, bleibt vorerst fraglich.

Ein Vergleich der gemessenen Werte hinsichtlich des prozentualen Trabekelanteils zwischen Metaphyse und Epiphyse zeigte, dass letztere Lokalisation einen deutlich höheren Knochenanteil an den benachbarten Strukturen, wie rotem und gelbem Knochenmark, aufweist (Abb.53). Dabei konnten Differenzen von etwa 15 bis 20 Prozentpunkten festgestellt werden (Tabelle 4). Diese Beobachtung spiegelt die physiologische Abnahme des Knochenanteils mit zunehmendem Abstand zur Epiphysenfuge als Ursprungsort des Knochenlängenwachstums wider (Martin RB und Zissimos 1991). Je weiter distal vom Gelenk des Röhrenknochens man den Trabekelanteil betrachtet, desto geringer wird dieser bis zum völligen Fehlen in der Diaphyse.

\section{IV.6.2.2) Auswirkungen auf das Trabekelsystem weiblicher S.D.-Ratten}

Bei den weiblichen Tieren konnten bei der histologischen Auswertung der proximalen Tibiametaphyse keine Unterschiede zwischen den ovx Kontrolltieren und den mit $\beta$-Ecdyson substituierten Tieren bezüglich Trabekelfläche (Abb.44) und prozentualem Trabekelanteil (Abb.45) festgestellt werden. Wie schon zuvor vermutet, könnte der fehlende Anhalt für einen $\beta$-Ecdyson-Effekt auf den trabekulären Knochen aus den vergleichsweise geringen Konzentrationen an aufgenommenen $\beta$-Ecdyson bei den weiblichen S.D.-Ratten resultieren.

Bei den weiblichen S.D.-Ratten konnten bei der histologischen Auswertung der proximalen Epiphyse, wie schon bei der Metaphyse, mit und gegebenenfalls wegen der angewandten Substanzdosis ebenfalls keine Unterschiede zwischen den ovx Kontrolltieren und den mit $\beta$ Ecdyson substituierten Tieren bezüglich Trabekelfläche (Abb.60) und prozentualem Trabekelanteil (Abb.61) festgestellt werden.

\section{IV.6.3) Auswirkungen auf das gelbe Knochenmark in der proximalen Tibia}

Das gelbe Knochenmark füllt physiologischerweise gemeinsam mit dem roten Knochenmark die maschenartigen Zwischenräume im Trabekelsystem aus (Rosen und Klibanski 2009). Die Bezeichnung gelbes Knochenmark bezieht sich auf den Hintergrund, dass es aus Fettzellen besteht, die naturgemäß einen gelblichen Farbton aufweisen (Abb.40). Das Vorkommen der beiden Knochenmarktypen, sowie deren Verhältnis zueinander, zeigen eine altersabhängige Ausprägung. Bei Neugeborenen und im Kindesalter beispielsweise dominiert das rote 
blutbildende Knochenmark gegenüber den nur spärlich vorhandenen Adipozyten des gelben Marks (Gimble et al. 1996). Untersuchungen zum Thema Knochenveränderungen bei zunehmendem Lebensalter konnten hingegen zeigen, dass es während des Alterungsprozesses typischerweise zu einer Verstärkung des gelben Knochenmarkanteils durch Erhöhung der Adipozytenzahl auf Kosten der Knochenneubildung kommt (Gimble et al. 2006). Die verstärkte Adipogenese im Vergleich zur reduzierten Knochenneubildung zeigte sich dabei besonders deutlich bei osteoporotischen Patienten (Justesen et al. 2001). Syed et al. (2008) konnten diesbezüglich zeigen, dass der altersassoziierte Wandel der Knochenmarkstruktur bei postmenopausalen osteoporotischen Frauen zumindest anteilig auf dem vorliegenden Östrogenmangel beruht. Aufgrund des gemeinsamen Ursprungs von Osteoblasten und Adipozyten in der mesenchymalen Stammzelle, wird derzeit von einem Ungleichgewicht zwischen den beiden eingeschlagenen Differenzierungswegen zu jeweils dem einen bzw. dem anderen Zelltypen vermutet (Duque 2008). Nach neuestem Kenntnisstand wird für diesen Prozess unter anderem auch die lipotoxische Wirkung von Zytokinen und Fettsäuren verantwortlich gemacht, die durch die Adipozyten selbst freigesetzt werden (Duque 2008). So kann die wachsende Zahl an Fettzellen das zelluläre Milieu von beispielsweise Osteoblasten, Osteoklasten sowie rotem Knochenmarkzellen innerhalb der Knochenmarkhöhle auf parakrinem Wege mit beeinflussen und regulieren (Rosen et al. 2009). Auf Organebene können die Adipozyten somit über die Sekretion zellaktiver Substanzen einen nicht zu unterschätzenden Effekt auf das Knochenremodeling ausüben.

Die Knochenlokalisation betreffend zeigen sich der Rückgang des hämatopoetischen roten Knochenmarks und die progressive Ausbreitung des gelben Knochenmarks am Beispiel des Röhrenknochens initial in der Diaphyse und schreiten anschließend in proximaler Richtung auf die Metaphyse zu (Vahlensieck und Schmidt 2000). In der Epiphyse ist dieser Umwandlungsprozess schon früh nach der Verknöcherung zu beobachten. Schätzungen zufolge werden vermutlich etwa 50\% der menschlichen Markhöhle durch das Fettmark ausgefüllt (Gimble et al. 1996). Durch die charakteristischen Veränderungen des Verteilungsmusters von rotem und gelbem Knochenmark während des Alterungsprozesses, sowie im Rahmen von osteoporotischen Knochenveränderungen, lassen sich dementsprechend histologische Untersuchungen als Parameter zur Bewertung der vorherrschenden Knochenveränderungen nach Gonadektomie bzw. Substanzapplikation im Tiermodell anwenden. 


\section{IV.6.3.1) Auswirkungen auf das gelbe Knochenmark männlicher S.D.-Ratten}

Im Rahmen der vorliegenden Studie zeigte die histologische Analyse hinsichtlich Fläche (Abb.39) und prozentualem Anteil (Abb.41) gelben Knochenmarks im Metaphysenbereich keinen statistisch signifikanten Unterschied zwischen der intakten und der orx Kontrollgruppe der männlichen S.D.-Ratten. Nach Applikation von $\beta$-Ecdyson zeigten sich, mit einer Ausnahme, keine signifikanten Unterschiede im Vergleich $\mathrm{zu}$ den beiden Kontrollen. Lediglich die niedrigste Dosis von $11 \mathrm{mg} / \mathrm{kg}$ KG erhöhte die Fläche und den prozentualen Anteil gelben Marks im Vergleich zu den intakten Kontrolltieren signifikant. Die im ersten Abschnitt der vorliegenden Arbeit untersuchten Differenzen in den Ergebnissen zwischen den beiden angewandten Methoden im Bereich der Knochenmarksanalyse sollten bei der Interpretation jedoch berücksichtigt werden. Dabei ist fraglich, ob die Kombination beider Methoden methodische Fehler möglichst klein hält oder jedoch etwaige Effekte tendenziell eher verschleiert. In dieser Hinsicht ist zum Beispiel von Interesse, dass die D-Methode im Gegensatz zur F-Methode den erwarteten und durch Studien vorbeschriebenen Unterschied zwischen der intakten und der orx Kontrollgruppe signifikant belegen konnte. Dieser besteht darin, dass es nach Gonadektomie typischerweise zu einer Steigerung des Anteils bzw. der Fläche gelben Knochenmarks in der Metaphyse kommt (Sharp et al. 2000). Tendenziell, jedoch nicht statistisch signifikant, ließ sich allerdings auch durch die kombinierte Methodik eine Erhöhung von Fläche und Anteil gelben Marks in der proximalen Tibiametaphyse nach ORX beobachten. Nach Applikation von $\beta$-Ecdyson in der mittleren und höchsten Dosis wurden diese beiden Parameter im Vergleich zur orx Kontrolle, wieder ohne Signifikanz, gesenkt. Im Vergleich zur intakten Kontrollgruppe blieben die Messwerte jedoch erhöht, sodass eine $\beta$-Ecdyson-Applikation in der angewandten Dosis die ORX-assoziierte Erhöhung folglich nicht vollständig kompensieren konnte.

Die histologische Untersuchung der proximalen Tibiaepiphyse ergab bezüglich der gelben Knochenmarkfläche zunächst einmal keinen signifikanten Unterschied zwischen den beiden Kontrollgruppen (Abb.54). Auch hier zeigten die orx Tiere eine größere Fläche ohne dabei ein signifikantes Niveau zu erreichen. Durch die Gabe der höchsten $\beta$-Ecdysondosis von $67 \mathrm{mg} / \mathrm{kg}$ KG wurden die Fläche und der prozentuale Anteil (Abb.55) im Vergleich zur intakten Kontrolle signifikant gesteigert. Bei der Messung des prozentualen Anteils zeigte sich außerdem auch schon bei einer Dosis von $11 \mathrm{mg} / \mathrm{kg}$ KG eine signifikante Erhöhung im Vergleich zu den intakten Tieren. Aufgrund der lediglich vereinzelt messbaren Unterschiede bezüglich des gelben Knochenmarks zwischen Tieren mit $\beta$-Ecdyson-Substitution bzw. mit 
sojafreiem Futter ist ein eindeutiger Nachweis eines ecdysteroidalen Effekts im Rahmen dieser Studie nicht abzuleiten. Tendenziell lässt sich jedoch beobachten, dass in der Epiphyse, im Gegensatz zur Metaphyse, der Anteil und die Fläche gelben Marks durch $\beta$-Ecdyson im Vergleich zu den bereits erhöhten Werten der orx Tiere scheinbar noch erhöht werden. Möglicherweise beruhen diese Beobachtungen jedoch auch auf der Tatsache, dass im epiphysären Bereich lediglich die F-Methode angewandt wurde, welche in der metaphysären Analyse stets signifikant höhere Messwerte ergab als die D-Methode. Dies bedeutet, dass die Kombination beider Methoden möglicherweise einen etwaigen methodischen Fehler kompensatorisch kleiner gehalten hat. Somit sollte die Bewertung der Ergebnisse bezüglich des gelben Knochenmarks eher kritisch erfolgen.

Ein Vergleich der gemessenen Werte hinsichtlich des prozentualen Anteils gelben Marks zwischen Metaphyse und Epiphyse zeigte, dass epiphysär ein wesentlich geringerer Prozentsatz vorlag (Abb.56). Dabei konnten Differenzen von etwa 52 bis 60 Prozentpunkten festgestellt werden (Tabelle 5). Die Messwerte zeigen somit, dass dort, wo epiphysär der Trabekelanteil höher ist, der Fettmarkanteil niedriger ist und umgekehrt im metaphysären Bereich. Diese Beobachtung findet Bestätigung in einigen Studien, die eine Erhöhung des Fettmarkanteils auf Kosten von jenem des Knochens in Verbindung mit Alterungsprozessen und Osteoporose feststellen konnten (Justesen et al. 2001, Duque 2008). Die genauen Hintergründe für die morphologische Umgestaltung des Knochenmarkverteilungsmusters sind bisweilen umstritten. Unter Berücksichtigung der aktuellen Studienlage wird derzeit vermutet, dass es sich dabei vor allem um eine Gleichgewichtsverschiebung der Differenzierung von mesenchymalen Stammzellen zu Adipozyten auf Kosten der Osteoblasten handelt (Duque 2008, Nuttall und Gimble 2000). Ein entscheidender Transkriptionsfaktor für den Differenzierungsweg zum Adipozyten stellt PPAR $\gamma$ dar (Rosen et al. 2009), dessen Wirkung auf Adipozyten und Osteoblasten durch PPAR $\gamma$-Modulatoren unabhängig beeinflusst werden kann (Lecka-Czernik und Suva 2006). So wirkt PPARy2 der Differenzierung von Osteoblasten und somit der Knochenbildung entgegen (Lecka-Czernik und Suva 2006). Des Weiteren scheint er ebenfalls in gewisser Weise Einfluss auf die Knochenresorption nehmen zu können. Durch Sekretion von proinflammatorischen Zytokinen und Fettsäuren können die Adipozyten somit selbst über Einflussnahme auf die zelluläre Umgebung die Adipogenese auf Kosten von Knochenzellen und hämatopoetischem Mark forcieren. Weitgehend verlassen wurde mittlerweile die Hypothese, dass das gelbe Mark hauptsächlich die Funktion der Lückenfüllung nach dem vorrausgegangenen Knochenverlust übernimmt (Gimble et al. 1996). Des Weiteren gibt es jedoch auch von anderen Studiengruppen die Vermutung, dass 
der Knochenumsatz bei Östrogenmangel in Bereichen mit rotem Knochenmark höher ist als in jenen mit gelbem Fettmark ( $\mathrm{Li}$ et al.1996), sodass hier in der vorliegenden Studie bei fehlender Vergleichsmöglichkeit zum Zeitpunkt Null zu Studienbeginn auch die örtlichen Grundvoraussetzungen des ursprünglichen Verteilungsmusters zumindest anteilig mit in ursächliche Erwägung einbezogen werden sollten. Die Vielfalt der unterschiedlichen Argumente macht bereits deutlich, dass es sich beim Verhältnis von gelbem Knochenmark zu den anderen Strukturen innerhalb der Markhöhle, sowie dessen Beitrag an der Knochenphysiologie und am Prozess der osteoporotischen Veränderungen, um ein komplexes Interaktionsmuster handelt, deren genaue Zusammenhänge noch zu untersuchen sind.

\section{IV.6.3.2) Auswirkungen auf das gelbe Knochenmark weiblicher S.D.-Ratten}

Bei den weiblichen S.D.-Ratten bewirkte $\beta$-Ecdyson in der mikroskopischen Auswertung der proximalen Tibiametaphyse in der höchsten Dosis von $10 \mathrm{mg} / \mathrm{kg} \mathrm{KG}$ eine signifikante Steigerung der Fläche (Abb.46) und des prozentualen Anteils (Abb.47) gelben Knochenmarks im Vergleich zu der ovx Kontrollgruppe. Beim Vergleich mit den entsprechenden Messergebnissen der männlichen Tiere ergibt sich eine Parallele in der Hinsicht, dass die ähnliche $\beta$-Ecdyson-Dosis von $11 \mathrm{mg} / \mathrm{kg} \quad \mathrm{KG}$ zunächst eine Steigerung der gelben Knochenmarkparameter im Vergleich zur intakten Kontrollgruppe bewirkte, während die höheren Konzentrationen einen senkenden Einfluss darauf ausübten. Ob es zu einer ähnlichen Effektkonstellation mit steigender Dosis auch bei den Weibchen kommen würde oder ob es sich lediglich um einen methodischen Fehler in der Auswertung handelt, bleibt im Rahmen dieser Studie fraglich.

Bei den weiblichen S.D.-Ratten bewirkte die Applikation von $\beta$-Ecdyson in den Konzentrationen von 4 bzw. $10 \mathrm{mg} / \mathrm{kg}$ KG keinen signifikanten Effekt auf die Fläche (Abb.62) und den prozentualen Anteil (Abb.63) gelben Knochenmarks in der proximalen Tibiaepiphyse. Vermutlich spielt auch bei diesem Messparameter erneut die Dosis-WirkungsBeziehung eine entscheidende Rolle.

\section{IV.6.4) Auswirkungen auf das rote Knochenmark in der proximalen Tibia}

Das rote Knochenmark ist der Ursprungsort der Hämatopoese. Es setzt sich neben einem Grundgerüst retikuloendothelialer Zellen aus der Vielfalt an Blutzellen und deren Vorläufern zusammen. Die Bezeichnung rotes Knochenmark basiert auf dessen scheinbar rötlichem Farbton, der durch die Anwesenheit von Erythrozyten und deren Vorläuferzellen erzeugt wird. Wie im Abschnitt über das gelbe Knochenmark beschrieben, weist das rote 
Knochenmark ein altersabhängiges Verteilungsmuster innerhalb des Knochens und des Skelettsystems auf. Mit zunehmendem Alter wird es fortschreitend durch gelbes, hämatopoetisch inaktives Knochenmark verdrängt und beschränkt sich beim Erwachsenen auf vereinzelte Lokalisationen wie proximale Metaphysen der Röhrenknochen, Wirbelsäule sowie platte Knochen wie Becken, Brustbein, Rippen und Skapula (Vahlensieck und Schmidt 2000). Aktuelle Studien konnten außerdem zeigen, dass osteoporotische Veränderungen des Knochens nach OVX von S.D.-Ratten neben einer Erhöhung des Volumens an gelbem Fettmark auch mit einer Reduktion von jenem des roten Knochenmarks einhergehen (Lei et al. 2009). Die Ursachen und Hintergründe für diese Gonadektomie-assoziierte gegenläufige Veränderung des Verteilungsmusters der beiden Knochenmarktypen bleiben vorerst noch zu klären. Allerdings wird derzeit davon ausgegangen, dass die Lipotoxizität durch die von Adipozyten freigesetzten Substanzen, wie Zytokine und Fettsäuren, neben den Effekten auf Osteoblasten, auch einen entsprechenden Einfluss auf das rote, blutbildende Knochenmark ausüben könnte (Rosen et al. 2009, Gimble et al. 2006, Lei et al. 2009).

\section{IV.6.4.1) Auswirkungen auf das rote Knochenmark männlicher S.D.-Ratten}

Im Rahmen der vorliegenden Studie erbrachte die histologische Auswertung der proximalen Tibiametaphyse bei den männlichen S.D.-Ratten keinen signifikanten Effekt zwischen den Flächen (Abb.42) und prozentualen Anteilen (Abb.43) roten Knochenmarks zwischen den einzelnen Versuchsgruppen. Die Anwendung von $\beta$-Ecdyson zeigte also keine Auswirkungen auf das blutbildende Knochenmark. Tendenziell, jedoch ohne Signifikanz, konnte lediglich beobachtet werden, dass das rote Mark nach ORX in Fläche und Anteil abnahm und dass durch die Aufnahme von $\beta$-Ecdyson in Dosis-abhängiger Weise diese Messparameter wieder angehoben wurde.

Die histologische Untersuchung der proximalen Tibiaepiphyse ergab hinsichtlich der Fläche (Abb.57) und dem Prozentanteil (Abb.58) roten Knochenmarks keinen signifikanten Unterschied zwischen der intakten und der orx Kontrollgruppe. Die orx Tiere zeigten dabei, wie im metaphysären Bereich, eine geringere Fläche sowie Anteil, ohne dabei ein signifikantes Niveau $\mathrm{zu}$ erreichen. Eine $\beta$-Ecdysongabe in den beiden niedrigsten Substanzzusätzen ergaben keine signifikanten Veränderungen des roten Knochenmarks. Durch die Gabe der höchsten $\beta$-Ecdysondosis von $67 \mathrm{mg} / \mathrm{kg} \mathrm{KG}$ wurden die Fläche und der prozentuale Anteil im Vergleich zur intakten Kontrolle jedoch signifikant gesenkt. Dieser hier scheinbar senkende Effekt von $\beta$-Ecdyson auf das blutbildende rote Knochenmark steht zu gewissen Teilen im Gegensatz zu der Beobachtung von Syrov et al. (1997), dass Ecdysteroide 
eine steigernde Wirkung auf die Erythrozytenzahl zumindest im Blut innehaben. Mit dem Hintergrund, dass die metaphysäre Auswertung in der F-Methode stets signifikant niedrigere Ergebnisse bezüglich des roten Knochenmarks ergab als die D-Methode (Abb.13 / 14), lässt sich die epiphysäre Auswertung unter ausschließlicher Verwendung der F-Methode allerdings auch nur unter Vorbehalt betrachten.

Ein Vergleich der Messergebnisse hinsichtlich des prozentualen Anteils roten Knochenmarks zwischen Metaphyse und Epiphyse zeigte, dass epiphysär ein wesentlich höherer Prozentsatz vorlag (Abb.59). Dabei konnten Mittelwertdifferenzen von etwa 29 bis 35 Prozentpunkten errechnet werden (Tabelle 6). Diese Ergebnisse bezüglich des unterschiedlichen lokalen Verteilungsmusters des roten Knochenmarks konnten mittels bildgebender Techniken, wie der MRT, auch in anderen Studien bestätigt werden. Dort wurde gezeigt, dass der altersbedingte Wandel von rotem hämatopoetisch aktivem Knochenmark zum in dieser Hinsicht inaktiven gelben Fettmark in der Diaphyse von Röhrenknochen beginnt und von dort aus nach proximal fortschreitet (Vahlensieck und Schmidt 2000). Somit ist der Unterschied zwischen dem geringeren roten Markanteil in der proximalen Metaphyse im Vergleich zum entsprechend höheren in der proximalen Epiphyse mehr oder minder physiologisch.

\section{IV.6.4.2) Auswirkungen auf das rote Knochenmark weiblicher S.D.-Ratten}

Auch bei den weiblichen Tieren konnte kein Unterschied der Fläche (Abb.48) und des Prozentanteils (Abb.49) roten Knochenmarks zwischen den $\beta$-Ecdyson-substituierten Ratten und der ovx Kontrollgruppe festgestellt werden. Allerdings zeigte die Tendenz im Gegensatz $\mathrm{zu}$ den männlichen Tieren eine statistisch nicht signifikante Abnahme der beiden Messparameter mit Zunahme der $\beta$-Ecdysondosis.

Des Weiteren konnte in der Epiphyse der weiblichen S.D.-Ratten in der vorliegenden Studie kein signifikanter Unterschied zwischen der ovx Kontrollgruppe unter sf Futter und den Tieren mit einer $\beta$-Ecdyson-Substitution bezüglich der Messparameter für rotes Knochenmark festgestellt werden. Dies bedeutet, dass die Applikation von $\beta$-Ecdyson in den Konzentrationen von 4 bzw. $10 \mathrm{mg} / \mathrm{kg}$ KG keinen signifikanten Effekt auf die Fläche (Abb.64) und den prozentualen Anteil (Abb.65) roten Knochenmarks in der proximalen Tibiaepiphyse bewirken konnte. Ohne Erreichen eines signifikanten Niveaus konnte lediglich die Tendenz zu einer Abnahme roten Knochenmarks mit steigender $\beta$-Ecdyson-Dosis beobachtet werden. 


\section{IV.7) Kritische Auseinandersetzung mit der angewandten Methodik}

Neben der im ersten Abschnitt der vorliegenden Arbeit durchgeführten Analyse und Bewertung zweier angewandter Computer-assistierter histomorphometrischer Fotoanalyseverfahren, sollte abschließend eine kritische Beurteilung und Auseinandersetzung mit der zusätzlich angewandten Methodik erfolgen.

Zunächst einmal fällt dabei das Augenmerk auf mögliche Einschränkungen in der Anwendbarkeit der gonadektomierten Ratte als Tiermodell für die postmenopausale sowie senile Osteoporose. Bis zum heutigen Stand der guten Etablierung und den oben beschriebenen Vorteilen wurden diesbezüglich wiederholt gewisse Kritikpunkte in Erwägung gezogen. Zum einen gilt es als umstritten, dass es bei Ratten erst spät zum Epiphysenfugenschluss kommt und somit ein kontinuierliches Längenwachstum, sowie damit assoziierte Knochenveränderungen, möglicherweise einen Störfaktor der eigentlichen Knochenanalyse darstellen könnten (Lelovas 2008). Allerdings relativierten andere Studien und Reviews diese Befürchtungen, indem sie postulierten, dass dieser Wachstumseffekt nicht zu überbewerten sei (Vanderschueren et al. 2004) und in dieser Hinsicht kein entscheidender Unterschied zwischen der Anwendung von jungen oder alten Ratten als osteoporotisches Tiermodell vorläge (Zhang et al. 2007).

Des Weiteren wird im Rahmen der Beurteilung der Ratte als Osteoporosemodell teilweise kritisch angemerkt, dass sich ein intrakortikales Remodeling aufgrund des bei Ratten fehlenden Havers-Kanal-Systems nicht ausreichend beurteilen lasse (Vanderschueren et al. 2004). Diese anatomische Besonderheit stellt einen Unterschied $\mathrm{zu}$ den menschlichen Knochenverhältnissen dar und sollte bei der Interpretation der kortikalen Messergebnisse gegebenenfalls eine gewisse Berücksichtigung finden.

Nicht zuletzt wurde im Rahmen einer Studie gezeigt, dass selbst die individuelle Untergruppe der Rattenspezies eine gewisse Rolle für die Beurteilung von möglichen Knochenveränderungen spielt (Danielsen et al. 1993). Im Rahmen der vorliegenden Studie wurden allerdings S.D.-Ratten verwendet, deren Skelettsystem und Reagibilität des Knochens auf Gonadektomie durch eine Vielzahl an Studien bekannt und gut belegt sind. Unter Berücksichtigung der möglichen Vor- und Nachteile stellt die Ratte insgesamt jedoch zu Recht ein gut etabliertes Tiermodell der Osteoporose dar, dass die entsprechenden Veränderungen im Rahmen dieser Skeletterkrankung repräsentieren kann (Lelovas 2008, Turner et al. 2001, Jee und Yao 2001). 


\section{V.) Zusammenfassung:}

Die Osteoporose stellt eine Skeletterkrankung mit erhöhtem Frakturrisiko dar, von der neben postmenopausalen Frauen auch Männer im fortgeschrittenen Lebensalter betroffen sein können. Zusätzlich zu einigen prophylaktischen Empfehlungen, existieren derzeit verschiedene Therapieoptionen für diese an Komplikationsmöglichkeiten reiche Knochenerkrankung. Allerdings weisen die Behandlungsmöglichkeiten der Osteoporose neben einem umfangreichen Nebenwirkungsspektrum zum Teil auch fehlende Anwendungserfahrungen bei männlichen Osteoporosepatienten auf. Bei der Suche nach alternativen Behandlungsmöglichkeiten mit möglichst geringen Nebenwirkungen und Anwendbarkeit bei beiden Geschlechtern, bietet sich die genauere Untersuchung von Knocheneffekten sogenannter Ecdysteroide an. Diese bei Arthropoden als Steroidhormone fungierenden Substanzen bzw. deren Hauptvertreter $\beta$-Ecdyson konnten in einigen wenigen Studien bereits förderliche Effekte auf knochenbildende Osteoblasten als Beispiel für eine Skelettwirkung zeigen. Durch den zusätzlichen Vorteil einer geringen akuten Toxizität und wenig ausgeprägter Nebenwirkungen, setzte sich die vorliegende Studie somit das Ziel einer Analyse möglicher knochenprotektiver Eigenschaften des $\beta$-Ecdysons gegenüber einem Gonadektomie-induzierten Knochenverlust bei männlichen und weiblichen S.D.-Ratten. Zu diesem Zweck erfolgte eine dreimonatige per os Substanzapplikation über das Futter. Nach makroskopischer Vermessung der unbehandelten Knochen unmittelbar nach Versuchsende, wurden diese für die lichtmikroskopische Untersuchung eingebettet, geschnitten sowie mittels Goldner-Färbung zu histologischen Präparaten aufgearbeitet. Für die histologische Untersuchung mittels computergestützter Fotoanalyse wurde die proximale Tibiametaphyse gewählt, da diese als Tiermodell der Osteoporose und Zielorgan von Effektstudien durch langjährige Erfahrung anerkannt und etabliert ist. Ergänzend dazu erfolgte eine entsprechende vergleichende Untersuchung im proximalen Epiphysenbereich. Die makroskopische Vermessung der Tibialänge zeigte einen schwachen Hemmeffekt von $\beta$-Ecdyson ab der mittleren Applikationsdosis auf das Längenwachstum der männlichen Tiere, während ein entsprechender Effekt bei den Weibchen ausblieb. Der metaphysäre Tibiakopfdurchmesser bei den Männchen wurde durch $\beta$-Ecdyson-Applikation nicht signifikant beeinflusst, während dieser bei den Weibchen mit der höchsten Dosis schwach signifikant geringer war als bei den Kontrolltieren. Mit Hilfe der histologischen Analyse der proximalen Tibia konnten anschließend die lokalisations-abhängigen Effekte von $\beta$-Ecdyson auf die einzelnen Strukturelemente des Knochens gezeigt werden. Die kortikalen Veränderungen erwiesen sich als vielgestaltig. Diaphysär wurde durch Orchidektomie über die dreimonatige Versuchsdauer 
kein kortikaler Knochenverlust induziert, jedoch bewirkte $\beta$-Ecdyson eine Abnahme der Kortikalisdicke im Vergleich zur orx Kontrolle, sodass diese etwa jener der intakten Tiere entsprach. Im Metaphysenbereich hingegen wirkte $\beta$-Ecdyson in mittlerer und höchster Dosis steigernd auf die Kortikalisdicke, sodass diese signifikant größere Messergebnisse aufwies als die intakten Tiere. Bei den weiblichen Tieren blieben entsprechende Effekte wiederum aus. In der Trabekelanalyse wiesen die metaphysären Trabekelflächen der Männchen keine signifikanten Unterschiede zwischen den einzelnen Gruppen auf, während die prozentualen Trabekelanteile nach $\beta$-Ecdyson-Applikation in mittlerer und höchster Dosis auf ein nahezu intaktes Niveau gesteigert wurden. Diese Beobachtung deutet auf eine vermutlich Dosisabhängige, knochenprotektive Wirkung des $\beta$-Ecdysons gegenüber Gonadektomieinduziertem Knochenverlust hin. Bei den Weibchen blieb ein entsprechender Effekt vermutlich aus Gründen zu geringer Substanzdosen aus. In der Epiphyse konnten bei beiden Geschlechtern weder durch Gonadektomie noch, mit nur einer Ausnahme, durch $\beta$-EcdysonApplikation signifikante Veränderungen von Trabekelfläche und prozentualem Trabekelanteil beobachtet werden. Dies Ergebnis steht im Einklang mit einem Großteil der derzeit verfügbaren Studien, welche die proximale Tibiaepiphyse aufgrund ihrer Nähe zur Epiphysenfuge und dort überwiegender Modelingaktivität als nicht oder nur kaum von Gonadektomie-induziertem Knochenverlust betroffen sehen. Zusammenfassend lässt sich durch die histologische Analyse der proximalen Tibiametaphyse anhand einer Zunahme des prozentualen Trabekelanteils ein gewisser knochenprotektiver Effekt von $\beta$-Ecdyson in mittlerer und höchster Dosis gegenüber Gonadektomie-induziertem Knochenverlust feststellen. Ein entsprechender Effekt fehlte jedoch in der weniger reagiblen und von überwiegender Modelingaktivität geprägten Tibiaepiphyse. Bei den weiblichen Tieren waren die applizierten $\beta$-Ecdyson-Dosen für den überwiegenden Teil der Knochenmessparameter vermutlich zu niedrig für eine Induktion möglicher Effekte und Veränderungen. Die Analyse des roten Knochenmarks zeigte bei beiden Geschlechtern keine signifikanten Effekte von $\beta$ Ecdyson auf Fläche und Prozentanteil in der Epiphyse und Metaphyse. Beim gelben Knochenmark zeigte sich diaphysär eine isolierte Erhöhung von Anteil und Fläche bei den Männchen in einer Dosis von $11 \mathrm{mg} / \mathrm{kg} \mathrm{KG}$ und bei den Weibchen von $10 \mathrm{mg} / \mathrm{kg} \mathrm{KG}$. In der Epiphyse erhöhten sich die Parameter im Vergleich zu den intakten männlichen Tieren auch für die höchste Dosis, während sie bei den Weibchen unverändert blieben. Die Ergebnisse für das gelbe Mark erwiesen sich somit je nach Lokalisation und Dosis als vielgestaltig. Aufgrund der lediglich vereinzelt messbaren Unterschiede zwischen Tieren mit $\beta$-EcdysonSubstitution bzw. mit sojafreiem Futter ist ein ecdysteroidaler Effekt auf das gelbe Mark, auch 
aufgrund der Differenzen zwischen den Methoden, im Rahmen dieser Studie nicht eindeutig abzuleiten. Der abschließende Methodenvergleich konnte durch fehlende signifikante Unterschiede zwischen den Messergebnissen zeigen, dass die Schwellenwertbildung am 8Bit-Grauwertbild und jene am Negativbild im roten Farbauszug gleichwertig geeignet sind, um trabekuläre Parameter wie Fläche und prozentualen Anteil in der proximalen Tibiametaphyse zu bestimmen. Für die Knochenmarksanalyse jedoch wiesen signifikante Unterschiede in den Messergebnissen der einzelnen Methoden auf mögliche methodische Schwachpunkte hin und sollten bisweilen kritisch betrachtet werden. 


\section{VI.) Anhang}

\section{VI.1) Methodischer Anhang}

$\underline{\text { Zusammensetzung des Futters der Firma ssniff } ® \text { Spezialdiäten, Soest: }}$

\section{Phytoöstrogenarmes Futter:}

\section{1354-000 ssniff R-Z, 10mm Pellets}

$\begin{array}{ll}\text { Rohprotein: } & 21,70 \% \\ \text { Rohfett : } & 4,30 \% \\ \text { Rohfaser } & 4,20 \% \\ \text { Rohasche } & 6,10 \% \\ \text { Calcium } & 1,00 \% \\ \text { Phosphor } & 0,70 \% \\ \text { Natrium } & 0,19 \%\end{array}$

Zusatzstoffe: Vitamin A 15.000 ( IE, IU)

Vitamin D3 1.000 ( IE, IU)

Vitamin E $100(\mathrm{mg})$

Vitamin C (mg)

Kupfer / Kupfer-(II)-Sulfat-Pentahydrat $5 \mathrm{mg}$

Dieses Mischfutter enthält genetisch veränderte Mais-, Kartoffelprotein- und Zuckerrübenschnitzelprodukte.

\section{Testsubstanzhaltiges Futter:}

Zusätzlich $\beta$-Ecdyson in folgenden Konzentrationen: + 0,2 mg/kg $\beta$-Ecdyson

$$
\begin{aligned}
& +0,5 \mathrm{mg} / \mathrm{kg} \beta \text {-Ecdyson } \\
& +1,0 \mathrm{mg} / \mathrm{kg} \beta \text {-Ecdyson } \\
& +3,0 \mathrm{mg} / \mathrm{kg} \beta \text {-Ecdyson }
\end{aligned}
$$




\section{Zusammensetzung und Bestandteile des Technovit@ 9100 NEU der Firma}

Heraeus Kulzer (Quelle: Technovit@ 9100 NEU Produkt-Prospekt):

1000ml Technovit® 9100 Basis (stab.): Monomer aus polymerisationsfähigen

Kohlenstoffketten / Methylmethacrylat

8 g Härter 1: Dibenzoylperoxid / Dicyclohexylphthalat 1:1

120 g PMMA-Pulver: Polymethylmethacrylat

\section{0 ml Härter 2}

\section{5 ml Polymerisationsregler}

\section{$\underline{\text { Rezepte für die Herstellung der benötigten Lösungen: }}$}

- Präinfiltration: $200 \mathrm{ml}$ Basis $+1 \mathrm{~g}$ Härter 1

- Infiltration: $250 \mathrm{ml}$ Basis + 20g PMMA-Pulver + $2 \mathrm{~g}$ Härter 1

- Stammlösung A: $500 \mathrm{ml}$ Basis + 80g PMMA-Pulver + 4g Härter 1

- Stammlösung B: $50 \mathrm{ml}$ Basis $+4 \mathrm{ml}$ Härter $2+2 \mathrm{ml}$ Polymerisationsregler

* $\rightarrow$ vor Gebrauch müssen die gekühlten Stammlösungen A+B im Verhältnis 9:1 gemischt werden und direkt im Anschluss über die einzubettenden Präparate in die entsprechende Einbettform gegossen werden. Anschließend mittels Exsikkator eingeschlossene Luft entfernen und dann luftdicht verschlossen im Kühlschrank 2-3 Tage aushärten lassen 
VI.2) Abbildungsverzeichnis / Tabellenverzeichnis

\begin{tabular}{|c|c|}
\hline$\underline{\text { Abbildung }}$ & $\underline{\text { Seite }}$ \\
\hline Abb.1: & 21 \\
\hline Abb.2: & 29 \\
\hline Abb.3: & 30 \\
\hline Abb.4: & 32 \\
\hline Abb.5: & 32 \\
\hline Abb.6a: & 33 \\
\hline Abb.6b: & 33 \\
\hline Abb.6c: & 33 \\
\hline Abb.6d: & 33 \\
\hline Abb.7a: & 34 \\
\hline Abb.7b: & 34 \\
\hline Abb.7c: & 35 \\
\hline Abb.7d: & 35 \\
\hline Abb.8a: & 35 \\
\hline Abb.8b: & 35 \\
\hline Abb.8c: & 36 \\
\hline Abb.8d: & 36 \\
\hline Abb.9 & 37 \\
\hline Abb.10: & 38 \\
\hline Abb.11: & 39 \\
\hline Abb.12: & 40 \\
\hline Abb.13: & 41 \\
\hline Abb.14: & 42 \\
\hline Abb.15: & 43 \\
\hline Abb.16: & 44 \\
\hline Abb.17: & 45 \\
\hline Abb.18: & 46 \\
\hline Abb.19: & 47 \\
\hline Abb.20: & 48 \\
\hline
\end{tabular}

\begin{tabular}{|c|c|}
\hline Abbildung & Seite \\
\hline Abb.21: & 49 \\
\hline Abb.22: & 50 \\
\hline Abb.23: & 51 \\
\hline Abb.24: & 51 \\
\hline Abb.25: & 52 \\
\hline Abb.26: & 53 \\
\hline Abb.27: & 54 \\
\hline Abb.28: & 54 \\
\hline Abb.29: & 55 \\
\hline Abb.30: & 56 \\
\hline Abb.31: & 56 \\
\hline Abb.32: & 57 \\
\hline Abb.33: & 58 \\
\hline Abb.34: & 58 \\
\hline Abb.35: & 59 \\
\hline Abb.36: & 60 \\
\hline Abb.37: & 61 \\
\hline Abb.38: & 62 \\
\hline Abb.39: & 63 \\
\hline Abb.40: & 63 \\
\hline Abb.41: & 64 \\
\hline Abb.42: & 65 \\
\hline Abb.43: & 66 \\
\hline Abb.44: & 67 \\
\hline Abb.45: & 67 \\
\hline Abb.46: & 68 \\
\hline Abb.47: & 69 \\
\hline Abb.48: & 70 \\
\hline Abb.49 & 71 \\
\hline
\end{tabular}

\begin{tabular}{|ll|}
\hline Abbildung & Seite \\
\hline Abb.50: & 72 \\
Abb.51: & 72 \\
Abb.52: & 73 \\
Abb.53: & 74 \\
Abb.54: & 75 \\
Abb.55: & 76 \\
Abb.56: & 77 \\
Abb.57: & 77 \\
Abb.58: & 78 \\
Abb.59: & 79 \\
Abb.60: & 80 \\
Abb.61: & 81 \\
Abb.62: & 81 \\
Abb.63: & 82 \\
Abb.64: & 82 \\
Abb.65: & 83 \\
\hline
\end{tabular}

\begin{tabular}{|lc|}
\hline$\underline{\text { Tabelle }}$ & $\underline{\text { Seite }}$ \\
\hline Tabelle 1: & 24 \\
Tabelle 2: & 28 \\
Tabelle 3: & 60 \\
Tabelle 4: & 74 \\
Tabelle 5: & 76 \\
Tabelle 6: & 79 \\
\hline
\end{tabular}




\section{VII.) Literaturverzeichnis}

Audran M, Chappard D, Legrand E, Libouban H, Baslé MF (2001): Bone Microarchitecture and Bone Fragility in Men: DXA and Histomorphometry in Humans and in the Orchidectomized Rat Model Calcif Tissue Int 69, 214-217

Baldock PAJ, Need AG, Moore RJ, Durbridge TC, Morris HA (1999): Discordance Between Bone Turnover and Bone Loss: Effects of Aging and Ovariectomy in the Rat $J$ Bone Miner Res 14, 1142-1448

Banse X, Devogelaer JP, Grynpas M (2002): Patient-specific Microarchitecture of Vertebral Cancellous Bone: A Peripheral Quantitative Computed Tomographic and Histological Study Bone $\underline{30}$, 829-835

Bassil N, Alkaade S, Morley JE (2009): The benefits and risks of testosterone replacement therapy: a review Ther Clin Risk Manag 5, 427-448

Báthori M, Pongrácz Z (2005): Phytoecdysteroids- From Isolation to Their Effects on Humans Curr Med Chem $\underline{12}$, 153-172

Báthori M, Kálmán A, Argay G, Kalász H (2000): The Analysis and Chrystallographic Characterization of 20-Hydroxyecdysone Curr Med Chem , 1305-1312.

Báthori M, Tóth N, Hunyadi A, Márki A, Zádor E (2008): Phytoecdysteroids and Anabolic-Androgenic Steroids-Structure and Effects on Humans Curr Med Chem 15, 75-91

Borst SE, Conover CF (2006): Orchiectomized Fischer 344 male rat models body composition in hypogonadal state Life Sci $\underline{79}$, 411-415

Callewaert F, Venken K, Ophoff J, De Gendt K, Torcasio A, Van Lenthe H, Van Oosterwyck H, Boonen S, Bouillon R, Verhoeven G, Vanderschueren D (2009): Differential regulation of bone and body composition in male mice with combined inactivation of androgen and estrogen receptor $\alpha$ FASEB J $\underline{23}, 232-240$

Chavassieux P, Seeman E, Delmas PD (2007): Insights into Material and Structural Basis of Bone Fragility from Diseases Associated with Fractures: How Determinants of the Biomechanical Properties of Bone Are Compromised by Disease Endocr Rev 28, 151-164

Consensus Development Conference (1991): Consensus Development Conference: Prophylaxis and Treatment of Osteoporosis Osteoporosis Int 1, 114-117

Dalle Carbonare L, Valenti MT, Bertoldo F, Zanatta M, Zenari S, Realdi G, Lo Cascio V, Giannini S (2005): Bone microarchitecture evaluated by histomorphometry Micron 36, 609-616

Danielsen CC, Mosekilde L, Svenstrup B (1993): Cortical Bone Mass, Composition, and Mechanical Properties in Female Rats in Relation to Age, Long-Term Ovariectomy, and Estrogen Substitution Calcif Tissue Int 52, 26-33

Delmas PD (1997): Hormone Replacement Therapy in the Prevention and Treatment of Osteoporosis. Osteoporos Int 7 Suppl 1, S3-S7

Detmar M, Dumas M, Bonté F, Meybeck A, Orfanos CE (1994): Effects of ecdysterone on the differentiation of normal human keratinocytes in vitro Eur J Dermatol 4, 558-569 
Dinan L (1995): A strategy for the identification of ecdyteroid receptor agonists and antagonists from plants Eur J Entomol 92, 271-283

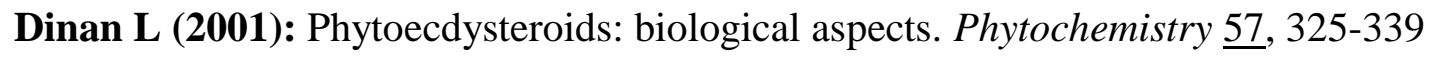

Dinan L, Lafont $\mathbf{R}$ (2006): Effects and applications of arthropod steroid hormones (ecdysteroids) in mammals $J$ Endocrinol 191, 1-8

Dinan L, Harmatha J, Volodin V, Lafont R: Phytoecdysteroids: Diversity, Biosynthesis and Distribution; in: Ecdysone: Structures and Functions; Smagghe Guy; Springer Science + Business Media B.V., Ghent 2009, 3-45

Duque G (2008): Bone and fat connection in aging bone Curr Opin Rheumatol 20, 429-434

Erben RG, Eberle J, Stahr K, Goldberg M (2000): Androgen Deficiency Induces High Turnover Osteopenia in Aged Male Rats: A Sequential Histomorphometric Study J Bone Miner Res 15, 1085-1098

Gao L, Cai G, Shi X (2008): Beta-ecdysterone induces osteogenic differentiation in mouse mesenchymal stem cells and relieves osteoporosis Biol Pharm Bull 31, 2245-2249

Gao XY, Wang DW, Li FM (2000): Determination of ecdysterone in Achyranthes bidentata $\mathrm{BL}$ and its activity promoting proliferation of osteoblast-like cells Yao Xue Xue Bao = Acta Pharmaceutica Sinica $\underline{35}$, 868-870

Gennari L, Merlotti D, Martini G, Gonnelli S, Franci B, Campagna S, Lucani B, Dal Canto N, Valenti R, Gennari C, Nuti R (2003): Longitudinal Association between Sex Hormone Levels, Bone Loss, and Bone Turnover in Elderly Men J Clin Endocrinol Metab $\underline{88}$, 5327-5333.

Gennari L, Nuti R, Bilezikian JP (2004): Aromatase Activity and Bone Homeostasis in Men J Clin Endocrinol Metab 89, 5898-5907

Gimble JM, Robinson CE, Wu X, Kelly KA (1996): The Function of Adipocytes in the Bone Marrow Stroma: An Update Bone 19 421-428

Gimble JM, Zvonic S, Floyd ZE, Kassem M, Nuttall ME (2006): Playing With Bone and Fat $J$ Cell Biochem $\underline{\text { 98, }}$ 251-266

Hampshire F, Horn DHS (1966): Structure of Crustecdysone, a Crustacean Moulting Hormone Chem Commun 2, 37-38

Horn DHS: Historical Introduction; in: Ecdysone- From chemistry to Mode of Action; Koolman J; Georg Thieme Verlag, Stuttgart 1989, 8-19.

Jee WSS, Yao W (2001): Overview: animal models of osteopenia and osteoporosis J Musculoskelet Neuronal Interact 1 , 193-207

Justesen J, Stenderup K, Ebbesen EN, Mosekilde L, Steiniche T, Kassem M (2001): Adipocyte tissue volume in bone marrow is increased with aging and in patients with osteoporosis Biogerontology 2 , 165-171

Juul A (2001): The effects of oestrogens on linear bone growth Hum Reprod Update 7, 303-313 
Kalu DN (1991): The ovariectomized rat model of postmenopausal bone loss Bone Miner 15, 175-192

Kanis JA, Burlet N, Cooper C, Delmas PD, Reginster JY, Borgstrom F, Rizzoli R (2008): European guidance for the diagnosis and management of osteoporosis in postmenopausal women Osteoporos Int $\underline{19}, 399-428$

Karlson P (1996): On the hormonal control of insect metamorphosis. A historical review Int J Dev Biol 40, 93-96

Kawai M, Rosen CJ (2009): Marrow Fat and Bone: New Insights from Mice and Humans Clinic Rev Bone Miner Metab ㄱ, 216-223

Ke HZ, Crawford DT, Qi H, Chidsey-Frink KL, Simmons HA, Li M, Jee WSS, Thompson DD (2001): Long-term effects of aging and orchidectomy on bone and body composition in rapidly growing male rats $J$ Musculoskelet Neuronal Interact $\underline{1}, 215-224$

Khosla S, Shreyasee A, Orwoll E (2008): Osteoporosis in Men Endocr Rev 29, 441-464

Kizelsztein P, Govorko D, Komarnytsky S, Evans A, Wang Z, Cefalu W, Raskin I (2009): 20-Hydroxyecdysone decreases weight and hyperglycemia in a diet-induced obesity mice model Am J Physiol Endocrinol Metab 296, 433-439

Konovalova NP, Mitrokhin YI, Volkova LM, Sidorenko LI, Todorov IN (2002): Ecdysterone Modulates Antitumor Activity of Cytostatics and Biosynthesis of Macromolecules in Tumor-Bearing Mice Biol Bull 29, 530-536

Koudela K, Tenora J, Bajer J, Mathová Á, Sláma K (1995) Stimulation of growth and development in Japanese quails after oral administration of ecdysteroid-containing diet Eur J Entomol 92, 349-354

Lafont R, Horn DHS: Phytoecdysteroids: Structures and Occurrence; in: Ecdysone - From Chemistry to Mode of Action; Koolman J; Georg Thieme Verlag, Stuttgart 1989, 39-64

Lafont R, Dinan L (2003): Practical uses for ecdysteroids in mammals including humans: an update $J$ Insect $S c i \underline{3}, 1-30$

Lafont R, Dinan L: Innovative and Future Applications for Ecdysteroids; in: Ecdysone: Structures and Functions; Smagghe Guy; Springer Science + Business Media B.V., Ghent 2009, 551-578

Le Bizec B, Antignac JP, Monteau F, Andre F (2002): Ecdysteroids: one potential new anabolic family in breeding animals Anal Chim Acta $\underline{473}$, 89-97

Lecka-Czernik B, Suva LJ (2006) Resolving the Two "Bony" Faces of PPAR $\gamma$ PPAR Res 2006, 1-9.

Lei Z, Xiaoying Z, Xingguo L (2009): Ovariectomy-associated changes in bone mineral density and bone marrow haematopoiesis in rats Int J Exp Pathol 90, 512-519

Lelovas PP, Xanthos TT, Thoma SE, Lyritis GP, Dontas IA (2008): The Labatory Rat as an Animal Model for Osteoporosis Research Comp Med $\underline{58}$, 424-430

Li M, Shen Y, Qi H, Wronski TJ (1996): Comparative Study of Skeletal Responnse to Estrogen Depletion at Red and Yellow Marrow Sites in Rats Anat Rec 245, 472-480 
Lupien PJ, Hinse C, Chaudhary KD (1969) Ecdysone as a hypocholesterolemic agent Arch Int Physiol Biochim ㄱ, 206-212

Manolagas, SC (2000): Birth and Death of Bone Cells: Basic Regulatory Mechanisms and Implications for the Pathogenesis and Treatment of Osteoporosis Endocr Rev 21, 115-137

Martin EA, Ritman El, Turner RT (2003): Time course of epiphyseal growth plate fusion in rat tibiae Bone $\underline{32}, 261-267$

Martin RB, Zissimos SL (1991): Relationships Between Marrow Fat and Bone Turnover in Ovariectomized and Intact Rats Bone $\underline{12}$, 123-131

Martin TJ, Seeman E (2007): New mechanisms and targets in the treatment of bone fragility Clin Sci (Lond) 112, 77-91

Moerman EJ, Teng K, Lipschitz DA, Lecka-Czernik B (2004): Aging activates adipogenic and suppresses osteogenic programs in mesenchymal marrow stroma/stem cells: the role of PPAR $\gamma$ - 2 transcription factor and TGF- $\beta$ /BMP signaling pathways. Aging Cell $\underline{3}$, 379-389

Nuttall ME, Gimble JM (2000): Is There a Therapeutic Opportunity to Either Prevent or Treat Osteopenic Disorders by Inhibiting Marrow Adipogenesis? Bone 27, 177-184

Ogawa S, Nishimoto N, Matsuda H: Pharmacology of Ecdysones in Vertebrates; in: Invertebrate endocrinology and hormonal heterophylly; Burdette WJ; Springer-Verlag, New York Inc 1974, 341-344

Ohlsson C, Vandenput L (2009): The role of estrogens for male bone health Eur J Endocrinol 160, 883-889

Oro AE, McKeown M, Evans RM (1990): Relationship between the product of the Drosophila ultraspiracle locus and the retinoid X receptor Nature $\underline{347}$, 298-301

Pfeilschifter J, Köditz R, Pfohl M, Schatz H (2002): Changes in Proinflammatory Cytokine Activity after Menopause Endocr Rev 23, 90-119

Pietschmann P, Rauner M, Sipos W, Kerschan-Schindl K (2009): Osteoporosis: an agerelated and gender-specific disease--a mini-review Gerontology $\underline{55}$, 3-12

Prabhu VKK, Nayar KK (1974): Crustecdysone is Without Estrogenic or Antiestrogenic Activity in the Rat Experientia 30, 821

Raisz LC (1999): Physiology and Pathophysiology of Bone Remodeling Clin Chem $\underline{45}, 1353-1358$

Reid IR (2008): Relationships between fat and bone Osteoporos Int 19, 595-606

Reid IR (2009): Adipose Tissue and Bone Clin Rev Bone Miner Metab , 207-209

Reim NS, Breig B, Stahr K, Eberle J, Hoeflich A, Wolf E, Erben RG (2008): Cortical Bone Loss in androgen-Deficient Aged Male Rats Is Mainly Caused by Increased Endocortical Bone Remodeling J Bone Miner Res 23, 694-704

Riede UN, Olah AJ, Goebel HH, Mohr W, Peter HH, Höpker WW, Gerlach UV, Werner M: Lokomotorisches System; in: Allgemeine und spezielle Pathologie; Werner M, Schaefer HE, Riede UN; Georg Thieme Verlag, Stuttgart 2004, 20, 1115-1176 
Riggs BL, Khosla S, Melton LJ (1998): A Unitary Model for Involutional Osteoporosis: Estrogen Deficiency Causes Both Type I and Type II Osteoporosis in Postmenopausal Women and Contributes to Bone Loss in Aging Men J Bone Miner Res $\underline{13}$, 763-773

Riggs BL, Khosla S, Melton LJ (2002): Sex Steroids and the Construction and Conservation of the Adult Skeleton Endocr Rev 23, 279-302

Rosen CJ, Klibanski A (2009) Bone, Fat, and Body Composition: Evolving Concepts in the Pathogenesis of Osteoporosis Am J Med 122, 409-414

Rosen CJ, Ackert-Bicknell C, Rodriguez JP, Pino AM (2009): Marrow Fat and the Bone Microenvironment: Developmental, Functional, and Pathological Implications Crit Rev Eukaryot Gene Expr 19, 109-124

Saatov Z, Agzamkhodzhaeva DA, Syrov VN (1999): Distribution of Phytoecdsteroids in plants of Uzbekistan and the possibility of using drugs based on them in neurological practice Chem Nat Comp $\underline{35}$, 186-191

Schot LPC, Schuurs AHWM (1990): Pathophysiology of bone loss in castrated animals J Steroid Biochem Mol Biol $\underline{37}$, 461-465

Seeman E (2002): Pathogenesis of bone fragility in women and men Lancet $\underline{359}$, 1841-1850

Seeman E (2003): Invited Review: Pathogenesis of osteoporosis J Appl Physiol 95, 2142-2151

Seeman E (2004): Estrogen, Androgen, and the Pathogenesis of Bone Fragility in Women and Men Curr Osteoporos Rep 2, 90-96

Seeman E (2008): Bone quality: the material and structural basis of bone strength $J$ Bone Miner Metab 26, 1-8

Seeman E, Bianchi G, Khosla S, Kanis JA, Orwoll E (2006) Bone fragility in men - where are we? Osteoporos Int $\underline{17}, 1577-1583$

Seidlová-Wuttke D, Jarry H, Jäger Y, Wuttke W (2008a): Bone development in female rats maintained with soy-free ir soy-containing food as determined by computer-assisted tomography and serum bone markers J Bone Miner Metab 26, 321-327

Seidlová-Wuttke D, Prelle K, Fritzemeier KH, Wuttke W (2008b): Effects of estrogen receptor alpha- and beta-selective substances in the metaphysis of the tibia and on serum parameters of bone and fat tissue metabolism of ovariectomized rats Bone $\underline{43}, 849-855$

Sharp JC, Copps JC, Liu Q, Ryner LN, Sebastian LA, Zeng GQ, Smith S, Niere JO, Tomanek B, Sato M (2000): Analysis of Ovariectomy and Estrogen Effects on Body Composition in Rats by X-Ray and Magnetic Resonance Imagin Techniques $J$ Bone Miner Res $\underline{15}, 138-146$

Sláma K, Lafont R (1995): Insect hormones - ecdysteroids: their presence and actions in vertebrates Eur J Entomol 92, 355-377

Stürmer EK, Sehmisch S, Tezval M, Tezval H, Rack T, Boekhoff J, Wuttke W, Herrmann TRW, Seidlova-Wuttke D, Stürmer KM (2009): Effect of testosterone, raloxifene and estrogen replacement on the microstructure and biomechanics of metaphyseal osteoporotic bones in orchiectomized male rats World J Urol 27, 547-555 
Syed FA, Oursler MJ, Hefferanm TE, Peterson JM, Riggs BL, Khosla S (2008): Effects of estrogen therapy on bone marrow adipocytes in postmenopausal osteoporotic women Osteoporos Int $\underline{19}, 1323-1330$

Syrov VN (2000): Comparative experimental investigation of the anabolic activity of phytoecdysteroids and steranabols Pharm Chem J $\underline{34}$, 193-197

Syrov VN, Matveev SB, Kurmukov AG, Islambekov US (1986): Effect of ecdysterone and nerobol on the healing of experimental bone fractures Med Zh $U z b \underline{3}$, 67-69 (in Russisch)

Syrov VN, Nasyrova SS, Khushbaktova ZA (1997): The results of experimental study of phytoecdysteroids as erythropoiesis stimulators in laboratory animals Eksp Klin Farmakol $\underline{60}$, $41-44$

Taes YEC, Papauw B, Vanbillemont G, Bogaert V, De Bacquer D, Zmierczak H, Goemaere S, Kaufman JM (2009): Fat Mass Is Negatively Associated with Cortical Bone Size in Young Healthy Male Siblings J Clin Endocrinol Metab 94, 2325-2331

Thompson MJ, Lusby R: Methods for the Structural Analysis of Ecdysteroids; in: Ecdysone-From Chemistry to Mode of Action; Koolman J; Georg Thieme Verlag, Stuttgart 1989, 65-73

Turner RT (1999): Mechanical signaling in the development of postmenopausal osteoporosis Lupus $\underline{8}, 388-392$

Turner RT, Maran A, Lotinum S, Hefferan T, Evans GL, Zhang M, Sibonga JD (2001): Animal Models for Osteoporosis Rev Endocr Metab Disord 2, 117-127

Vahlensieck M, Schmidt HM (2000): Normales Knochenmark und seine Variationen in der MRT Radiologe $\underline{40}, 688-693$

Vandenput L, Boonen S, Van Herck E, Swinnen JV, Bouillon R, Vanderschueren D (2002): Evidence From the Aged Orchidectomized Male Rat Model That 17 $\beta$-Estradiol Is a More Effective Bone-Sparing and Anabolic Agent than 5 $\alpha$-Dihydrotestosterone J Bone Miner Res 17, 2080-2086

Vanderschueren D, Van Herck E, De Coster R, Bouillon R (1996): Aromatization of Androgens is Important for Skeletal Maintenance of Aged Male Rats Calcif Tissue Int $\underline{59}, 179-183$

Vanderschueren D, Vandenput L, Boonen S, Van Herck E, Swinnen JV, Bouillon R (2000): An Aged Rat Model of Partial Androgen Deficiency: Prevention of Both Loss of Bone and Lean Body Mass by Low-Dose Androgen Replacement Endocrinology 141, 16421647

Vanderschueren D, Vandenput L, Boonen S, Lindberg MK, Bouillon R, Ohlsson C (2004): Androgens and Bone Endocr Rev 25, 389-425

Venken K, Callewaert F, Boonen S, Vanderschueren D (2008): Sex hormones, their receptors and bone health Osteoporos Int $\underline{19}, 1517-1525$

Westerlind KC, Wronski TJ, Ritman EL, Luo ZP, An KN, Bell NH, Turner RT (1997): Estrogen regulates the rate of bone turnover but bone balance in ovariectomized rats is modulated by prevailing mechanical strain Proc Natl Acad Sci USA 94, 4199-4204 
WHO Study Group (1994): Assessment of fracture risk and application to screening for postmenopausal osteoporosis; WHO Geneva: s.n., 1-136, WHO Technical Report Series No.843

Wronski TJ, Lowry PL, Walsh CC, Ignaszewski LA (1985): Skeletal Alterations in Ovariectomized Rats Calcif Tissue Int 37, 324-328

Wronski TJ, Walsh CC, Ignaszewski LA (1986): Histologic Evidence for Osteopenia and Increased Bone Turnover in Ovariectomized Rats Bone 7, 119-123

Wronski TJ, Dann LM, Scott KS, Cintrón M (1989): Long-Term Effects of Ovariectomy and Aging on the Rat Skeleton Calcif Tissue Int 45, 360-366

Yamaura M, Nakamura T, Hijioka A, Narusawa K, Ohnishi H, Ohta T, Hosoda K (1996): Local bone turnover in the Metaphysis of the Proximal Tibia and the Lumbar Vertebra During the Early Periods After Ovariectomy in Rats Calcif Tissue Int $\underline{58}$, 52-59

Yao TP, Forman BM, Jlang Z, Cherbas L, Chen JD, McKeown M, Cherbas P, Evans RM (1993): Functional ecdysone receptor is the product of EcR and Ultraspiracle genes Nature 366, 476-479

Yoshida T, Otaka T, Uchiyama M, Ogawa S (1971): Effect of Ecdysterone on hyperglycemia in experimental animals Biochem Pharmacol 20, 3263-3268

Zhang Y, Lai WP, Leung PC, Wu CF, Wong MS (2007): Short- to mid-term effects of ovariectomy on bone turnover, bone mass and bone strength in rats Biol Pharm Bull $\underline{30}$, 898-903 


\section{Danksagung}

Zuallererst möchte ich meinen ganz herzlichen Dank Herrn Prof. Dr. W. Wuttke für die Bereitstellung des Themas, sowie für die freundliche und hilfreiche Betreuung meiner Arbeit aussprechen.

Ein großer Dank gebührt auch Frau Dr. D. Seidlová-Wuttke für ihre engagierte und tatkräftige Unterstützung zu jedem Zeitpunkt der Arbeit.

Herzlichen Dank auch an Frau Heidi Brüggemann-Meyer für die freundliche Hilfe bei der Erstellung der Knochenpräparate.

Vielen Dank auch an Sabine Lüdemann für die stets freundliche Beantwortung aller möglichen Zwischenfragen und Hilfe in organisatorischen Dingen 